Cochrane Database of Systematic Reviews

\title{
Virtual reality for stroke rehabilitation (Review)
}

Laver KE, Lange B, George S, Deutsch JE, Saposnik G, Crotty M

Laver KE, Lange B, George S, Deutsch JE, Saposnik G, Crotty M.

Virtual reality for stroke rehabilitation.

Cochrane Database of Systematic Reviews 2017, Issue 11. Art. No.: CD008349.

DOI: 10.1002/14651858.CD008349.pub4.

www.cochranelibrary.com 
TABLE OF CONTENTS

HEADER

ABSTRACT

PLAIN LANGUAGE SUMMARY

SUMMARY OF FINDINGS

BACKGROUND

OBJECTIVES

METHODS

RESULTS

Figure 1.

Figure 2.

Figure 3.

DISCUSSION

AUTHORS' CONCLUSIONS

ACKNOWLEDGEMENTS

REFERENCES

CHARACTERISTICS OF STUDIES

DATA AND ANALYSES

Analysis 1.1. Comparison 1 Virtual reality versus conventional therapy: effect on upper limb function post intervention, Outcome 1 Upper limb function post intervention (composite measure).

Analysis 1.2. Comparison 1 Virtual reality versus conventional therapy: effect on upper limb function post intervention, Outcome 2 Upper limb function post intervention (Fugl Meyer).

Analysis 1.3. Comparison 1 Virtual reality versus conventional therapy: effect on upper limb function post intervention, Outcome 3 Hand function post intervention (grip strength).

Analysis 1.4. Comparison 1 Virtual reality versus conventional therapy: effect on upper limb function post intervention, Outcome 4 Upper limb function post intervention: amount of use (subjective).

Analysis 1.5. Comparison 1 Virtual reality versus conventional therapy: effect on upper limb function post intervention, Outcome 5 Upper limb function at short term follow-up (up to 3 months).

Analysis 2.1. Comparison 2 Virtual reality versus conventional therapy: upper limb function: subgroup analyses, Outcome 1 Dose of intervention.

Analysis 2.2. Comparison 2 Virtual reality versus conventional therapy: upper limb function: subgroup analyses, Outcome 2 Time since onset of stroke.

Analysis 2.3. Comparison 2 Virtual reality versus conventional therapy: upper limb function: subgroup analyses, Outcome 3 Specialised or gaming.

Analysis 2.4. Comparison 2 Virtual reality versus conventional therapy: upper limb function: subgroup analyses, Outcome 4 Severity of impairment.

Analysis 3.1. Comparison 3 Additional virtual reality intervention: effect on upper limb function post intervention, Outcome 1 Upper limb function (composite measure).

Analysis 4.1. Comparison 4 Additional virtual reality intervention: effect on upper limb function post intervention: subgroup analyses, Outcome 1 Dose of intervention.

Analysis 4.2. Comparison 4 Additional virtual reality intervention: effect on upper limb function post intervention: subgroup analyses, Outcome 2 Time since onset of stroke.

Analysis 4.3. Comparison 4 Additional virtual reality intervention: effect on upper limb function post intervention: subgroup analyses, Outcome 3 Specialised or gaming.

Analysis 5.1. Comparison 5 Virtual reality versus conventional therapy: effect on lower limb activity post intervention, Outcome 1 Gait speed.

Analysis 5.2. Comparison 5 Virtual reality versus conventional therapy: effect on lower limb activity post intervention, Outcome 2 Timed Up and Go Test.

Analysis 5.3. Comparison 5 Virtual reality versus conventional therapy: effect on lower limb activity post intervention, Outcome 3 Balance.

Analysis 6.1. Comparison 6 Virtual reality versus conventional therapy: effect on lower limb activity post intervention: subgroup analyses, Outcome 1 Dose of intervention: effect on gait speed.

Analysis 7.1. Comparison 7 Additional virtual reality intervention: effect on lower limb activity post intervention, Outcome 1 Gait speed. 
Analysis 7.2. Comparison 7 Additional virtual reality intervention: effect on lower limb activity post intervention, Outcome 2 Functional mobility (Timed Up and Go).

Analysis 7.3. Comparison 7 Additional virtual reality intervention: effect on lower limb activity post intervention, Outcome 3 Balance.

Analysis 8.1. Comparison 8 Additional virtual reality intervention: effect on global motor function post intervention, Outcome 1 Global motor function.

Analysis 9.1. Comparison 9 Virtual reality versus conventional therapy: effect on activity limitation, Outcome 1 ADL outcome. . 142

Analysis 10.1. Comparison 10 Additional virtual reality intervention: effect on activity limitation, Outcome 1 ADL outcome. .... 142

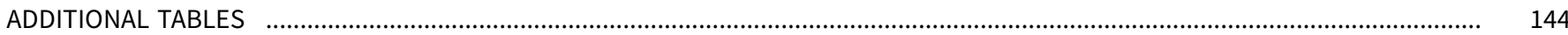

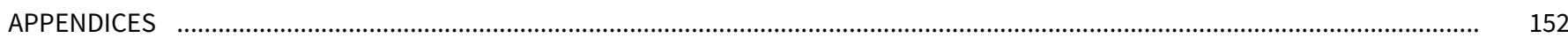

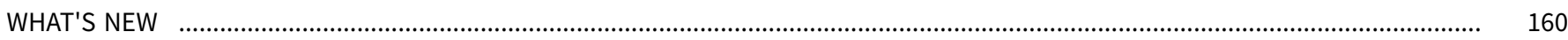

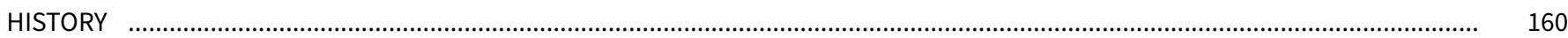

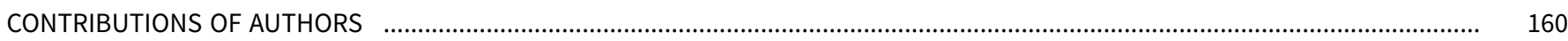

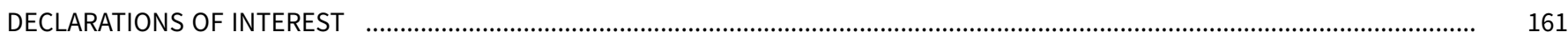

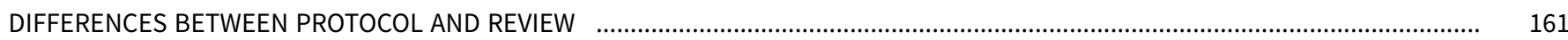

INDEX TERMS 
[Intervention Review]

\section{Virtual reality for stroke rehabilitation}

Kate E Laver ${ }^{1}$, Belinda Lange ${ }^{2}$, Stacey George ${ }^{1}$, Judith E Deutsch ${ }^{3}$, Gustavo Saposnik ${ }^{4}$, Maria Crotty ${ }^{1}$

1Department of Rehabilitation, Aged and Extended Care, Flinders University, Adelaide, Australia. ${ }^{2}$ School of Health Sciences, Discipline of Physiotherapy, Flinders University, Adelaide, Australia. ${ }^{3}$ Department of Rehabilitation and Movement Science, Rutgers University, Newark, New Jersey, USA. ${ }^{4}$ Department of Medicine (Neurology), St Michael's Hospital, University of Toronto, Toronto, Canada

Contact address: Kate E Laver, Department of Rehabilitation, Aged and Extended Care, Flinders University, Level 1, C Block, Repatriation General Hospital, Daws Road, Daw Park, Adelaide, South Australia, 5041, Australia. kate.laver@flinders.edu.au.

Editorial group: Cochrane Stroke Group.

Publication status and date: Edited (no change to conclusions), published in Issue 1, 2018.

Citation: Laver KE, Lange B, George S, Deutsch JE, Saposnik G, Crotty M. Virtual reality for stroke rehabilitation. Cochrane Database of Systematic Reviews 2017, Issue 11. Art. No.: CD008349. DOI: 10.1002/14651858.CD008349.pub4.

Copyright @ 2018 The Cochrane Collaboration. Published by John Wiley \& Sons, Ltd.

\section{A B S T R A C T}

\section{Background}

Virtual reality and interactive video gaming have emerged as recent treatment approaches in stroke rehabilitation with commercial gaming consoles in particular, being rapidly adopted in clinical settings. This is an update of a Cochrane Review published first in 2011 and then again in 2015.

\section{Objectives}

Primary objective: to determine the efficacy of virtual reality compared with an alternative intervention or no intervention on upper limb function and activity.

Secondary objectives: to determine the efficacy of virtual reality compared with an alternative intervention or no intervention on: gait and balance, global motor function, cognitive function, activity limitation, participation restriction, quality of life, and adverse events.

\section{Search methods}

We searched the Cochrane Stroke Group Trials Register (April 2017), CENTRAL, MEDLINE, Embase, and seven additional databases. We also searched trials registries and reference lists.

\section{Selection criteria}

Randomised and quasi-randomised trials of virtual reality ("an advanced form of human-computer interface that allows the user to 'interact' with and become 'immersed' in a computer-generated environment in a naturalistic fashion") in adults after stroke. The primary outcome of interest was upper limb function and activity. Secondary outcomes included gait and balance and global motor function.

\section{Data collection and analysis}

Two review authors independently selected trials based on pre-defined inclusion criteria, extracted data, and assessed risk of bias. A third review author moderated disagreements when required. The review authors contacted investigators to obtain missing information.

\section{Main results}

We included 72 trials that involved 2470 participants. This review includes 35 new studies in addition to the studies included in the previous version of this review. Study sample sizes were generally small and interventions varied in terms of both the goals of treatment and the virtual reality devices used. The risk of bias present in many studies was unclear due to poor reporting. Thus, while there are a large number of randomised controlled trials, the evidence remains mostly low quality when rated using the GRADE system. Control groups usually received no intervention or therapy based on a standard-care approach. Primary outcome: results were not statistically significant for 
upper limb function (standardised mean difference (SMD) 0.07, 95\% confidence intervals (CI) -0.05 to 0.20, 22 studies, 1038 participants, low-quality evidence) when comparing virtual reality to conventional therapy. However, when virtual reality was used in addition to usual care (providing a higher dose of therapy for those in the intervention group) there was a statistically significant difference between groups (SMD 0.49, 0.21 to $0.77,10$ studies, 210 participants, low-quality evidence). Secondary outcomes: when compared to conventional therapy approaches there were no statistically significant effects for gait speed or balance. Results were statistically significant for the activities of daily living (ADL) outcome (SMD $0.25,95 \% \mathrm{Cl} 0.06$ to $0.43,10$ studies, 466 participants, moderate-quality evidence); however, we were unable to pool results for cognitive function, participation restriction, or quality of life. Twenty-three studies reported that they monitored for adverse events; across these studies there were few adverse events and those reported were relatively mild.

\section{Authors' conclusions}

We found evidence that the use of virtual reality and interactive video gaming was not more beneficial than conventional therapy approaches in improving upper limb function. Virtual reality may be beneficial in improving upper limb function and activities of daily living function when used as an adjunct to usual care (to increase overall therapy time). There was insufficient evidence to reach conclusions about the effect of virtual reality and interactive video gaming on gait speed, balance, participation, or quality of life. This review found that time since onset of stroke, severity of impairment, and the type of device (commercial or customised) were not strong influencers of outcome. There was a trend suggesting that higher dose (more than 15 hours of total intervention) was preferable as were customised virtual reality programs; however, these findings were not statistically significant.

\section{PLAIN LANGUAGE SUMMARY}

\section{Virtual reality for stroke rehabilitation}

\section{Review question}

We wanted to compare the effects of virtual reality versus an alternative treatment or no treatment on recovery after stroke using arm function and other outcomes such as walking speed and independence in managing daily activities after stroke.

\section{Background}

Many people after having a stroke have difficulty moving, thinking, and sensing. This often results in problems with everyday activities such as writing, walking, and driving. Virtual reality and interactive video gaming are types of therapy being provided to people after having a stroke. The therapy involves using computer-based programs designed to simulate real life objects and events. Virtual reality and interactive video gaming may have some advantages over traditional therapy approaches as they can give people an opportunity to practise everyday activities that are not or cannot be practised within the hospital environment. Furthermore, there are several features of virtual reality programs that might mean that patients spend more time in therapy: for example, the activity might be more motivating.

\section{Study characteristics}

We identified 72 studies involving 2470 people after stroke. A wide range of virtual reality programs were used, with most aimed to improve either arm function or walking ability. The evidence is current to April 2017.

\section{Key results}

Twenty-two trials tested whether the use of virtual reality compared with conventional therapy resulted in an improved ability to use one's arm and found that the use of virtual reality did not result in better function (low-quality evidence). When virtual reality was used in addition to usual care or rehabilitation to increase the amount of time the person spent in therapy there were improvements in the functioning of the arm (low-quality evidence). Six trials tested whether the use of virtual reality compared with conventional therapy resulted in improved walking speed. There was no evidence that virtual reality was more effective in this case (low-quality evidence). Ten trials found that there was some evidence that virtual reality resulted in a slightly better ability to manage everyday activities such as showering and dressing (moderate-quality evidence). However, these positive effects were found soon after the end of the treatment and it is not clear whether the effects are long lasting. Results should be interpreted with caution as, while there are a large number of studies, the studies are generally small and not of high quality. A small number of people using virtual reality reported pain, headaches, or dizziness. No serious adverse events were reported.

\section{Quality of the evidence}

The quality of the evidence was generally of low or moderate quality. The quality of the evidence for each outcome was limited due to small numbers of study participants, inconsistent results across studies, and poor reporting of study details. 


\begin{tabular}{|c|c|c|c|c|c|c|}
\hline \multicolumn{7}{|c|}{$\begin{array}{l}\text { S U M M A R Y O F F I N D I N G S } \\
\text { Summary of findings for the main comparison. Virtual reality compared to conventional therapy for stroke rehabilitation }\end{array}$} \\
\hline \multicolumn{7}{|c|}{ Virtual reality compared to conventional therapy for stroke rehabilitation } \\
\hline \multicolumn{7}{|c|}{$\begin{array}{l}\text { Patient or population: people receiving stroke rehabilitation } \\
\text { Settings: hospital, clinic or home } \\
\text { Intervention: virtual reality } \\
\text { Comparison: conventional therapy }\end{array}$} \\
\hline \multirow[t]{3}{*}{ Outcomes } & \multicolumn{2}{|c|}{ Illustrative comparative risks* $(95 \% \mathrm{CI})$} & \multirow{3}{*}{$\begin{array}{l}\text { Relative effect } \\
(95 \% \mathrm{Cl})\end{array}$} & \multirow{3}{*}{$\begin{array}{l}\text { No of partici- } \\
\text { pants } \\
\text { (studies) }\end{array}$} & \multirow{3}{*}{$\begin{array}{l}\text { Quality of the } \\
\text { evidence } \\
\text { (GRADE) }\end{array}$} & \multirow[t]{3}{*}{ Comments } \\
\hline & Assumed risk & Corresponding risk & & & & \\
\hline & Control & Virtual reality & & & & \\
\hline $\begin{array}{l}\text { Upper limb } \\
\text { function }\end{array}$ & $\begin{array}{l}\text { Same dose of } \\
\text { conventional } \\
\text { therapy }\end{array}$ & $\begin{array}{l}\text { The mean upper limb function in the } \\
\text { intervention groups was } \\
\mathbf{0 . 0 7} \text { standard deviations higher } \\
\text { (-0.05 to } 0.20 \text { higher) }\end{array}$ & & $\begin{array}{l}1038 \\
\text { (22 studies) }\end{array}$ & $\begin{array}{l}\oplus \oplus \Theta \odot \\
\text { low }^{1,2,3}\end{array}$ & $\begin{array}{l}\text { No statistically significant dif- } \\
\text { ference between groups }\end{array}$ \\
\hline Quality of life & $\begin{array}{l}\text { Same dose of } \\
\text { conventional } \\
\text { therapy }\end{array}$ & $\begin{array}{l}\text { No significant benefit found on total } \\
\text { score of the SF- } 36\end{array}$ & & $\begin{array}{l}300 \\
\text { (3 studies) }\end{array}$ & $\begin{array}{l}\oplus \oplus \Theta \odot \\
\text { low } 1,2,4\end{array}$ & $\begin{array}{l}\text { Studies could not be pooled. } \\
\text { None of the } 3 \text { studies found sig- } \\
\text { nificant differences between } \\
\text { groups in total score. } 2 \text { studies } \\
\text { reported significant differences } \\
\text { in domains of the SF } 36\end{array}$ \\
\hline Gait speed & $\begin{array}{l}\text { Same dose of } \\
\text { conventional } \\
\text { therapy }\end{array}$ & $\begin{array}{l}\text { The mean gait speed in the interven- } \\
\text { tion groups was } \\
\mathbf{0 . 0 9} \text { metres per second faster } \\
\text { ( } 0.04 \text { lower to } 0.22 \text { higher) }\end{array}$ & & $\begin{array}{l}139 \\
\text { (6 studies) }\end{array}$ & $\begin{array}{l}\oplus \oplus \odot \Theta \\
\text { low }^{1,3,4}\end{array}$ & $\begin{array}{l}\text { No statistically significant dif- } \\
\text { ference between groups }\end{array}$ \\
\hline ADL outcome & $\begin{array}{l}\text { Same dose of } \\
\text { conventional } \\
\text { therapy }\end{array}$ & $\begin{array}{l}\text { The mean } A D L \text { outcome in the inter- } \\
\text { vention groups was } \\
\mathbf{0 . 2 5} \text { standard deviations higher } \\
\text { ( } 0.06 \text { to } 0.43 \text { higher) }\end{array}$ & & $\begin{array}{l}466 \\
\text { (10 studies) }\end{array}$ & $\begin{array}{l}\oplus \oplus \oplus \ominus \\
\text { moderate }^{1}\end{array}$ & $\begin{array}{l}\text { Small effect in favour of those } \\
\text { receiving virtual reality inter- } \\
\text { vention }\end{array}$ \\
\hline
\end{tabular}

ADL: activities of daily living; $\mathrm{Cl}$ : confidence interval

GRADE Working Group grades of evidence

High quality: we are very confident that the true effect lies close to that of the estimate of the effect 
Moderate quality: we are moderately confident in the effect estimate; the true effect is likely to be close to the estimate of effect, but there is a possibility that it is substantially different

Low quality: our confidence in the effect estimate is limited; the true effect may be substantially different from the estimate of the effect

Very low quality: we have very little confidence in the effect estimate; the true effect is likely to be substantially different from the estimate of effect

${ }^{1}$ Risk of bias was unclear in a number of studies.

2Downgraded by 1 due to inconsistency in findings across studies.

3Surrogate outcome.

${ }^{4}$ Small total population size $(<400)$.

\section{Summary of findings 2 . Virtual reality plus usual care compared with usual care alone}

\section{Virtual reality intervention compared with usual care (thus provided as additional therapy) for stroke rehabilitation}

Patient or population: people receiving stroke rehabilitation

Settings: hospital, clinic or home

Intervention: virtual reality provided in addition to usual care

Comparison: usual care

\begin{tabular}{|c|c|c|c|c|c|c|}
\hline \multirow[t]{3}{*}{ Outcomes } & \multicolumn{2}{|c|}{ Illustrative comparative risks* $(95 \% \mathrm{CI})$} & \multirow{3}{*}{$\begin{array}{l}\text { Relative effect } \\
(95 \% \mathrm{Cl})\end{array}$} & \multirow{3}{*}{$\begin{array}{l}\text { No of partici- } \\
\text { pants } \\
\text { (studies) }\end{array}$} & \multirow{3}{*}{$\begin{array}{l}\text { Quality of the } \\
\text { evidence } \\
\text { (GRADE) }\end{array}$} & \multirow[t]{3}{*}{ Comments } \\
\hline & Assumed risk & Corresponding risk & & & & \\
\hline & Control & $\begin{array}{l}\text { Virtual reality (provided in addition to } \\
\text { usual care) }\end{array}$ & & & & \\
\hline $\begin{array}{l}\text { Upper limb } \\
\text { function }\end{array}$ & Usual care & $\begin{array}{l}\text { The SMD in the intervention groups was } \\
\mathbf{0 . 4 9} \text { standard deviations higher ( } 0.21 \text { to } \\
0.77 \text { ) }\end{array}$ & - & $\begin{array}{l}210 \\
\text { (10 studies) }\end{array}$ & $\begin{array}{l}\oplus \oplus \odot \odot \\
\text { low }^{1,3,4}\end{array}$ & $\begin{array}{l}\text { Moderate effect in favour of } \\
\text { providing virtual reality inter- } \\
\text { vention in addition to usual } \\
\text { care }\end{array}$ \\
\hline $\begin{array}{l}\text { Quality of life } \\
\text { - not measured } \\
\text { in any of the } \\
\text { studies }\end{array}$ & - & - & - & - & - & Not measured in the studies \\
\hline Gait speed & Usual care & $\begin{array}{l}\text { The mean difference in the intervention } \\
\text { groups was }\end{array}$ & - & $\begin{array}{l}57 \\
\text { (3 studies) }\end{array}$ & $\begin{array}{l}\oplus \oplus \ominus \ominus \\
\text { low }^{1,3,4}\end{array}$ & $\begin{array}{l}\text { No statistically significant dif- } \\
\text { ference between groups }\end{array}$ \\
\hline
\end{tabular}


0.08 metres per second faster $(-0.05$ to

$0.21)$

\begin{tabular}{|c|c|c|c|c|c|c|}
\hline $\begin{array}{l}\text { Global motor } \\
\text { function }\end{array}$ & Usual care & $\begin{array}{l}\text { The SMD in the intervention groups was } \\
\mathbf{0 . 0 1} \text { standard deviations higher }(-0.60 \\
\text { to } 0.61)\end{array}$ & - & $\begin{array}{l}43 \\
\text { (3 studies) }\end{array}$ & $\begin{array}{l}\oplus \oplus \ominus \ominus \\
\text { low } 1,3,4\end{array}$ & $\begin{array}{l}\text { No statistically significant dif- } \\
\text { ference between groups }\end{array}$ \\
\hline ADL outcome & Usual care & $\begin{array}{l}\text { The SMD in the intervention groups was } \\
\mathbf{0 . 4 4} \text { standard deviations higher }(0.11 \text { to } \\
0.76)\end{array}$ & - & $\begin{array}{l}153 \\
\text { (8 studies) }\end{array}$ & $\begin{array}{l}\oplus \oplus \ominus \ominus \\
\text { low } 1,3,4\end{array}$ & $\begin{array}{l}\text { Small to moderate effect in } \\
\text { favour of virtual reality inter- } \\
\text { vention }\end{array}$ \\
\hline
\end{tabular}

${ }^{\star}$ The basis for the assumed risk (e.g. the median control group risk across studies) is provided in footnotes. The corresponding risk (and its $95 \%$ confidence interval) is based on the assumed risk in the comparison group and the relative effect of the intervention (and its $95 \% \mathrm{Cl}$ ).

ADL: activities of daily living; Cl: confidence interval; MD: mean difference; RR: risk ratio; SMD: standardised mean difference

GRADE Working Group grades of evidence

High quality: we are very confident that the true effect lies close to that of the estimate of the effect

Moderate quality: we are moderately confident in the effect estimate; the true effect is likely to be close to the estimate of effect, but there is a possibility that it is substantially different

Low quality: our confidence in the effect estimate is limited; the true effect may be substantially different from the estimate of the effect

Very low quality: we have very little confidence in the effect estimate; the true effect is likely to be substantially different from the estimate of effect

${ }^{1}$ Risk of bias was unclear in a number of studies.

2Downgraded by 1 due to inconsistency in findings across studies.

3Surrogate outcome.

${ }^{4}$ Small total population size $(<400)$. 


\section{B A C K G R O U N D}

\section{Description of the condition}

Stroke is one of the leading causes of death and disability and has been described as a worldwide epidemic (Feigin 2014; Go 2014). The effects of a stroke may include sensory, motor, and cognitive impairment as well as a reduced ability to perform self care and participate in social and community activities (Miller 2010). While most recovery is thought to be made in the first few weeks after stroke, patients may make improvements on functional tasks many months after having a stroke (Teasell 2014). Many stroke survivors report long-term disability and reduced quality of life (Patel 2006; Sturm 2004).

\section{Description of the intervention}

Repetitive task training has been shown to be effective in some aspects of rehabilitation, such as improving walking distance and speed and improving upper limb function (French 2016; Veerbeek 2014). Virtual reality is a relatively recent approach that may enable simulated practice of functional tasks at a higher dosage than traditional therapies (Demain 2013; Fung 2012; Kwakkel 2004; Merians 2002). Virtual reality has been defined as the "use of interactive simulations created with computer hardware and software to present users with opportunities to engage in environments that appear and feel similar to real-world objects and events" (Weiss 2006).

Virtual reality has previously been used in a variety of vocational training settings, such as flight simulation training for pilots (Lintern 1990) and procedural training for surgeons (Larsen 2009). Within health care, the intervention has been used to treat phobias, post-traumatic stress disorder, and body image disorders (Jiandani 2014; Raghav 2016). Although its research in rehabilitation is becoming more prevalent as technology becomes more accessible and affordable, the use of virtual reality is not yet routinely used in clinical rehabilitation settings. However, gaming consoles are ubiquitous and so researchers and clinicians have turned to low-cost commercial gaming systems as an alternative way of delivering virtual reality (Levac 2015). These systems, which were originally designed for recreation, are being adapted by clinicians for therapeutic purposes. In addition, interactive video games are specifically being designed for rehabilitation (Lange 2010; Lange 2012).

In virtual rehabilitation, virtual environments and objects provide the user with visual feedback, which may be presented though a head-mounted device, projection system, or flat screen. Feedback may also be provided through the senses, for example, hearing, touch, movement, balance, and smell (Weiss 2006). The user interacts with the environment by a variety of mechanisms. These may be simple devices, such as a mouse or joystick, or more complex systems using cameras, sensors, or haptic (touch) feedback devices (Weiss 2006). Thus, depending on the intervention, the user's level of physical activity may range from relatively inactive (for example, sitting at a computer using a joystick), to highly active (for example, challenging, full-body movements). Virtual reality relies on computer hardware and software that mediates the interaction between the user and the virtual environment (Gaggioli 2009).
Key concepts related to virtual reality are immersion and presence. Immersion refers to the extent to which the user perceives that they are in the virtual environment rather than the real world and is related to the design of the software and hardware (Gaggioli 2009; Weiss 2006). Virtual environments can range in their degree of immersion of the user. Systems that include projection onto a concave surface, head-mounted display, or video capture in which the user is represented within the virtual environment are generally described as immersive, whereas a single screen projection or desktop display are considered low immersion.

Presence is the subjective experience of the user and is dependent on the characteristics of the virtual reality system, the virtual task, and the characteristics of the user. People are considered present when they report the feeling of being in the virtual world (Schuemie 2001).

\section{How the intervention might work}

Virtual reality may be advantageous as it offers several features, such as goal-oriented tasks and repetition, shown to be important in neurological rehabilitation (Langhorne 2011; Veerbeek 2014). Animal research has shown that training in enriched environments results in better problem solving and performance of functional tasks than training in basic environments (Risedal 2002). Virtual reality may have the potential to provide an enriched environment in which people with stroke can problem solve and master new skills. Virtual tasks have been described as more interesting and enjoyable by children and adults, thereby encouraging higher numbers of repetitions (Lewis 2012).

Evidence of neuroplasticity as a result of training in virtual reality is modest; however, neuroimaging findings are guiding the development of virtual reality. Two studies have shown that functional improvements after virtual reality training were paralleled with a lateralisation of neural activation from the contralesional sensorimotor activation prior to training, to an ipsilesional representation after training (Jang 2005; You 2005). Tunik and colleagues have shown that when individuals post stroke were presented with discordant feedback, they activated the primary motor region (M1) to a greater extent than when feedback was not discordant (Tunik 2013). Notably, when discordant feedback corresponded to the affected and moving hand, the contralateral M1 region was recruited (Bagce 2012; Tunik 2013). Conversely, by having participants move the unaffected hand with virtual mirror feedback, the ipsilateral (affected) M1 region was recruited (despite the affected hand remaining static) (Saleh 2014). Their findings suggest that tailoring manipulation of the visual feedback in virtual reality to the needs of the patient may serve as a tool for rehabilitation.

One major advantage of virtual reality programs, which has been underutilised to date, is that they allow clinicians to be able to trial tasks that are unsafe to practise in the real world, such as crossing the street. In addition, some programs are designed to be used without supervision, also meaning that increased dosage of therapy can be provided without increased staffing levels.

\section{Why it is important to do this review}

As using technology becomes an integral part of daily living, virtual reality is likely to become even more widely used in clinical rehabilitation settings (Bohil 2011; Burridge 2010). It is important to 
evaluate the efficacy of virtual reality in order to guide future design and use. Furthermore, therapeutic interventions that increase the dose of task-specific training without increasing staffing will be sought after.

There are now a number of systematic reviews examining the efficacy of virtual reality for stroke rehabilitation (Crosbie 2007; Darekar 2015; Lohse 2014; Moreira 2013; Saposnik 2011) and, more specifically, commercial gaming devices for upper limb stroke rehabilitation (Thomson 2014). Our initial review published in 2011 identified 19 studies and a number of ongoing studies. Our update published in 2015 resulted in the inclusion of more studies bringing the total to 37 studies. The area is rapidly expanding and therefore an update of our review was warranted.

\section{O B J E C T IVES}

\section{Primary objective}

To determine the efficacy of virtual reality compared with an alternative intervention or no intervention on upper limb function and activity.

\section{Secondary objectives}

To determine the efficacy of virtual reality compared with an alternative intervention or no intervention on gait and balance, global motor function, cognitive function, activity limitation, participation restriction, quality of life, and adverse events.

\section{MET HOD S}

\section{Criteria for considering studies for this review}

\section{Types of studies}

We planned to include randomised controlled trials (RCTs) and quasi-randomised (e.g. allocation by birth date) controlled trials (QRCTs). We included one QRCT and the remaining studies were RCTs. Where the QRCT was included in a meta-analysis we carried out a sensitivity analysis restricting analysis to truly randomised studies. We looked for studies that compared virtual reality with either an alternative intervention or no intervention. We did not include studies that compared two different types of virtual reality without an alternative group. We included trials that evaluated any intensity and duration of virtual reality that exceeded a single treatment session.

\section{Types of participants}

The study participants had a diagnosis of stroke, defined by the World Health Organization as "a syndrome of rapidly developing symptoms and signs of focal, and at times global, loss of cerebral function lasting more than 24 hours or leading to death with no apparent cause other than that of vascular origin" (WHO 1989), diagnosed by imaging or neurological examination. We included people who were 18 years and older with all types of stroke, all levels of severity, and at all stages post stroke, including those people with subarachnoid haemorrhage. We excluded studies of participants with mixed aetiology (for example, participants with acquired brain injury) unless data were available relating to the people with stroke only.

\section{Types of interventions}

We included studies using virtual reality interventions that met the following definition: "an advanced form of human-computer interface that allows the user to 'interact' with and become 'immersed' in a computer-generated environment in a naturalistic fashion" (Schultheis 2001).

We included studies using any form of non-immersive or immersive virtual reality, and studies that used commercially available gaming consoles.

The comparison group received either an alternative intervention or no intervention. Given the broad range of alternative interventions, we considered these to include any activity designed to be therapeutic at the impairment, activity, or participation level that did not include the use of virtual reality.

\section{Types of outcome measures}

\section{Primary outcomes}

As one of the most common applications of virtual reality in stroke rehabilitation is upper limb rehabilitation, we selected the following primary outcome.

1. Upper limb function and activity:

a. arm function and activity: including assessments such as the Fugl Meyer, Motor Assessment Scale (upper limb), Action Research Arm Test, Wolf Motor Function Test, Box and Block Test, Jebsen Taylor Hand Function Test

b. hand function: grip strength

\section{Secondary outcomes}

1. Gait and balance:

a. lower limb activity: including assessments such as walking distance, walking speed, Community Walk Test, functional ambulation, Timed Up and Go Test;

b. balance and postural control: including assessments such as the Berg Balance Scale and forward reach test.

2. Global motor function: including assessments such as the Motor Assessment Scale.

3. Cognitive function: including assessments such as Trail Making Test, Useful Field of View Test.

4. Activity limitation: addressing activities of daily living and including assessments such as the Functional Independence Measure (FIM), Barthel Index, on-road driving test.

5. Participation restriction and quality of life: including assessments such as the SF36, EQ5D, Stroke Impact Scale or other patient-reported outcome measure.

6. Adverse events: including motion sickness, pain, injury, falls and death.

We included the primary outcome (upper limb function) and gait, global motor function, and quality of life in Summary of findings for the main comparison.

\section{Search methods for identification of studies}

See the 'Specialised register' section in the Cochrane Stroke Group module. We searched for relevant trials in all languages and arranged translation of trial reports published in languages other than English. 


\section{Electronic searches}

The searches for studies in our previous reviews were conducted in March 2010 and November 2013. The search for this update was completed in May 2016 and then updated again in April 2017. Cochrane Stroke's Managing Editor searched the Group's Trials Register in April 2017 using the intervention codes 'computer-aided therapy' and 'virtual reality therapy'.

In addition, we searched the following electronic bibliographic databases: the Cochrane Central Register of Controlled Trials (CENTRAL; 2017, Issue 3, searched 1 April 2017) (Appendix 1); MEDLINE Ovid (1950 to April Week 1, 2017) (Appendix 2); Embase (1980 to Week 13, 2017) (Appendix 3); Ovid AMED (1985 to April 2017) (Appendix 4); CINAHL Ebsco (1982 to April Week 1, 2017) (Appendix 5); Ovid PsycINFO (1840 to April Week 1, 2017) (Appendix 6); PsycBITE (Psychological Database for Brain Impairment Treatment Efficacy, www.psycbite.com/) (to 1 April 2017) and OTseeker (www.otseeker.com/) (to 1 April 2017). We also searched the engineering databases COMPENDEX (1970 to 1 April 2017) for studies from a non-medical background.

The Cochrane Stroke Group Information Specialist developed our search strategies for MEDLINE (Ovid) and we adapted them for other databases with the assistance of an experienced medical librarian.

\section{Searching other resources}

In order to identify further published, unpublished and ongoing trials, we:

1. searched the following ongoing trials registers: Current Controlled Trials (www.isrctn.com), National Institute of Health Clinical Trials Database (www.clinicaltrials.gov) and Stroke Trials Registry (www.strokecenter.org/trials/) to 1 June 2016;

2. used the Cited Reference Search within Science Citation Index (SCI) and Social Science Citation Index (SSCI) to track relevant references for all included studies;

3. scanned the reference lists of all included studies;

4. searched Dissertation Abstracts via Proquest (1 June 2016);

5. scanned the abstracts of non-English language studies if they were available in English;

6. searched the IEEE (Institute of Electrical and Electronic Engineers) electronic library (to 1 April 2017).

For the previous version of this review we carried out the following searches; however, we did not repeat these searches for this update.

1. We handsearched the proceedings of the International Workshop on Virtual Rehabilitation (2003 to 2005), Virtual Rehabilitation Conference (2007 to 2009), International Conference Series on Disability, Virtual Reality and Associated Technologies (2000 to 2008) and Cybertherapy (2003 to 2007).

2. We contacted 12 manufacturers of virtual reality equipment to ask for details of trials. We contacted the following manufacturers by telephone, email or postal mail: Nintendo, Sony, GestureTek, NeuroVR, Hocoma, Motek, Virtual Realities, Haptic Master, Microsoft Xbox, Essential Reality, SensAble, Novint and Cyberglove. Three of the manufacturers responded (Nintendo, Motek, and Novint); however, they were unable to provide details of studies eligible for inclusion in the review.

\section{Data collection and analysis}

\section{Selection of studies}

One review author $(\mathrm{KL})$ performed the searches. Two of the authors ( $\mathrm{KL}$ and $\mathrm{BL}$ ) independently reviewed the titles and abstracts identified from the database searches to assess whether they met the pre-defined inclusion criteria. The review authors obtained potentially relevant articles in full text and $\mathrm{KL}$ contacted study authors when more information was required. $\mathrm{KL}$ and $\mathrm{BL}$ then independently reviewed full-text articles and correspondence with investigators to determine studies to be included in the review. JD made the final decision on studies that $\mathrm{KL}$ and $\mathrm{BL}$ disagreed on. We documented the reasons for the exclusion of studies. Where studies published in non-English languages appeared relevant, we sought the full text of the study. In these cases, we arranged for someone fluent in the non-English language to review the paper to ascertain whether the study met the inclusion criteria.

\section{Data extraction and management}

Two review authors ( $\mathrm{KL}$ and SG, JD, GS or MC) independently extracted data using a pre-designed data extraction form for each selected study. Data extracted included citation details, trial setting, inclusion and exclusion criteria, study population, participant flow, intervention details, outcome measures and results, and methodological quality. We resolved disagreements by discussion or by referral to a third review author (BL) as necessary. The review authors contacted study authors by email to request any missing information necessary for the review.

\section{Assessment of risk of bias in included studies}

Two review authors (KL and SG, JD, GS or MC) used Cochrane's 'Risk of bias' tool to independently assess the methodological quality of the included studies (Appendix 7; Higgins 2011a). The tool covers the domains of sequence generation, allocation concealment, blinding of outcome assessors, incomplete outcome data and selective reporting. We classified items as 'low risk', 'high risk' or 'unclear risk' of bias. We omitted the domain that assesses the blinding of participants as we were of the opinion that this domain related to the nature of the intervention and not study quality. We contacted the authors of the included studies for more information where insufficient information was published to assess the risk of bias. We resolved disagreements with help from a third review author (BL).

We employed GRADE to interpret findings (Guyatt 2008) and used GRADEpro GDT to create 'Summary of findings' tables (GRADEpro GDT 2015). The tables provide outcome-specific information concerning the overall quality of evidence from studies included in the comparisons, the magnitude of effect of the intervention, and the sum of available data on the outcomes considered. When using GRADE, we downgraded the evidence from 'high quality' by one level for serious (or by two for very serious) study limitations (risk of bias), indirectness of evidence, serious inconsistency, imprecision of effect estimates, or potential publication bias.

\section{Measures of treatment effect}

Two review authors ( $\mathrm{KL}$ and SG, JD, GS or MC) independently classified outcome measures in terms of the domain assessed (upper limb function, hand function, lower limb and gait activity, balance and postural control, global motor function, cognitive function, activity limitation, participation restriction, and quality 
of life). When a study presented more than one outcome measure for the same domain, we included the measure most frequently used across studies in the analysis. We planned to calculate risk ratios (RR) with $95 \%$ confidence intervals (Cls) for any dichotomous outcomes, if recorded. We calculated mean differences (MD) or standardised mean differences (SMD) for continuous outcomes as appropriate.

\section{Unit of analysis issues}

The unit of randomisation in these trials was the individual participant. We did not include any cluster-randomised controlled trials. Seven of the studies were three-armed trials. We used the approach of splitting the 'shared' group into two or more groups with smaller sample size and including two (reasonably independent) comparisons (as described in part 16.5.4 of the Cochrane Handbook for Systematic Reviews of Interventions: Higgins 2011b). Lam 2006 compared virtual reality with an alternative intervention and no intervention. We used data in the analyses according to the comparison (i.e. we used the data comparing the virtual reality arm with the alternative intervention arm in one meta-analysis and the data comparing virtual reality with no intervention in another meta-analysis). Coupar 2012 compared a usual-care group with a group that received additional 'low intensity' virtual reality intervention and a group that received additional 'high intensity' virtual reality intervention. We split the control group data enabling comparison of high intensity with usual care and low intensity with usual care. da Silva Cameirao 2011 compared a virtual reality intervention using a specialised program with a control group who either received gaming or conventional occupational therapy. Data were only provided for intervention (virtual reality) versus control (Wii or conventional therapy) and so were included in the meta-analysis in this manner. Byl 2013 compared conventional therapy with unilateral and bilateral virtual reality intervention. We used the data from both intervention groups and split the control group. Zucconi 2012 compared a virtual reality intervention with feedback on performance with a virtual reality intervention without feedback and conventional therapy. We were only able to obtain data from the virtual reality with feedback on performance group versus the control group and so this is what was used in the analysis. A study published by Fan 2014 randomised people to an interactive video gaming group, a conventional occupational therapy group, and a recreational board game group; we were unable to obtain data from this study in a form suitable for meta-analysis so provided a descriptive summary. Finally, Kong 2014 randomised participants to interactive video gaming, conventional therapy or usual care. We used data comparing the gaming, conventional therapy, and usual care in separate analyses.

\section{Dealing with missing data}

We contacted study authors to obtain any missing data and converted available data when possible (e.g. we converted gait speed reported as metres per minute to metres per second (Jaffe 2004)). We used the actual denominator of the participants contributing the data.

\section{Assessment of heterogeneity}

We pooled results to present an overall estimate of the treatment effect using a fixed-effect model in the primary analysis. We assessed heterogeneity by visual inspection of the forest plot. We quantified inconsistency amongst studies using the $\mathrm{I}^{2}$ statistic
(Higgins 2003), where we considered levels greater than 50\% as substantial heterogeneity. We used a random-effects model as part of a sensitivity analysis in the presence of heterogeneity (Deeks 2011).

\section{Assessment of reporting biases}

Our search of clinical trials registers assisted in reducing publication bias. We also investigated selective outcome reporting through the comparison of the methods section of papers with the results reported and contacting study authors to check whether additional outcomes had been collected. We inspected funnel plots for each of the analyses; however, interpretation was limited due to the small sample sizes.

\section{Data synthesis}

Where there were acceptable levels of heterogeneity, we pooled results. We used the fixed-effect model with $95 \% \mathrm{Cl}$ using Review Manager 5 (RevMan 5) (RevMan 2014). We used a random-effects model as part of a sensitivity analysis. Where meta-analysis was not appropriate due to unacceptable heterogeneity, we have presented a narrative summary of study results. We pooled outcomes measured with different instruments using the SMD.

\section{Subgroup analysis and investigation of heterogeneity}

We attempted to perform subgroup analyses to determine whether outcomes varied according to age, severity of stroke, time since onset of stroke, dose of intervention (total hours of intervention) and type of intervention (highly specialised program designed for rehabilitation versus commercial gaming console). However, not all of these analyses were possible due to the homogeneity of trial participants. We were able to undertake subgroup analysis in some cases for:

1. dosage of intervention (for upper limb function we compared less than 15 hours' intervention with more than 15 hours' intervention and for lower limb function we compared less than 10 hours' intervention with more than 10 hours' intervention). We selected the doses of 10 and 15 hours based on examining the included studies and their characteristics and choosing a threshold that appeared to separate the studies approximately in half (to enable comparisons of higher- and lower-dose treatments);

2. time since onset of stroke (less than or more than six months);

3. type of intervention (specialised program or commercial gaming console);

4. severity of impairment (upper limb).

\section{Sensitivity analysis}

We performed sensitivity analyses to determine whether there was a difference in using a fixed-effect model versus a randomeffects model. We conducted sensitivity analyses where possible to explore the effects of the methodological quality of the included studies on overall effect.

\section{RES U L T S}

\section{Description of studies}

See Characteristics of included studies; Characteristics of excluded studies. 


\section{Results of the search}

We identified 168 studies from searching the Cochrane Stroke Group Trials Register and 11,664 references from the database searches totaling 11,832 references to studies. A search of the trials registries elicited a further 108 potentially relevant studies. From the 11,940 titles and abstracts retrieved, we sought 422 of the articles in full text for further review. We grouped articles reporting the same study. We removed articles that did not meet the inclusion criteria, such as studies that used interventions that were not considered virtual reality and non-randomised controlled trials. We included a total of 72 studies. We have provided details on 34 excluded studies in the Characteristics of excluded studies table, which were closest to, but did not meet the inclusion criteria (Figure 1). We identified 14 studies awaiting classification, and 22 ongoing studies (Characteristics of ongoing studies). 


\section{Figure 1. Study flow diagram}

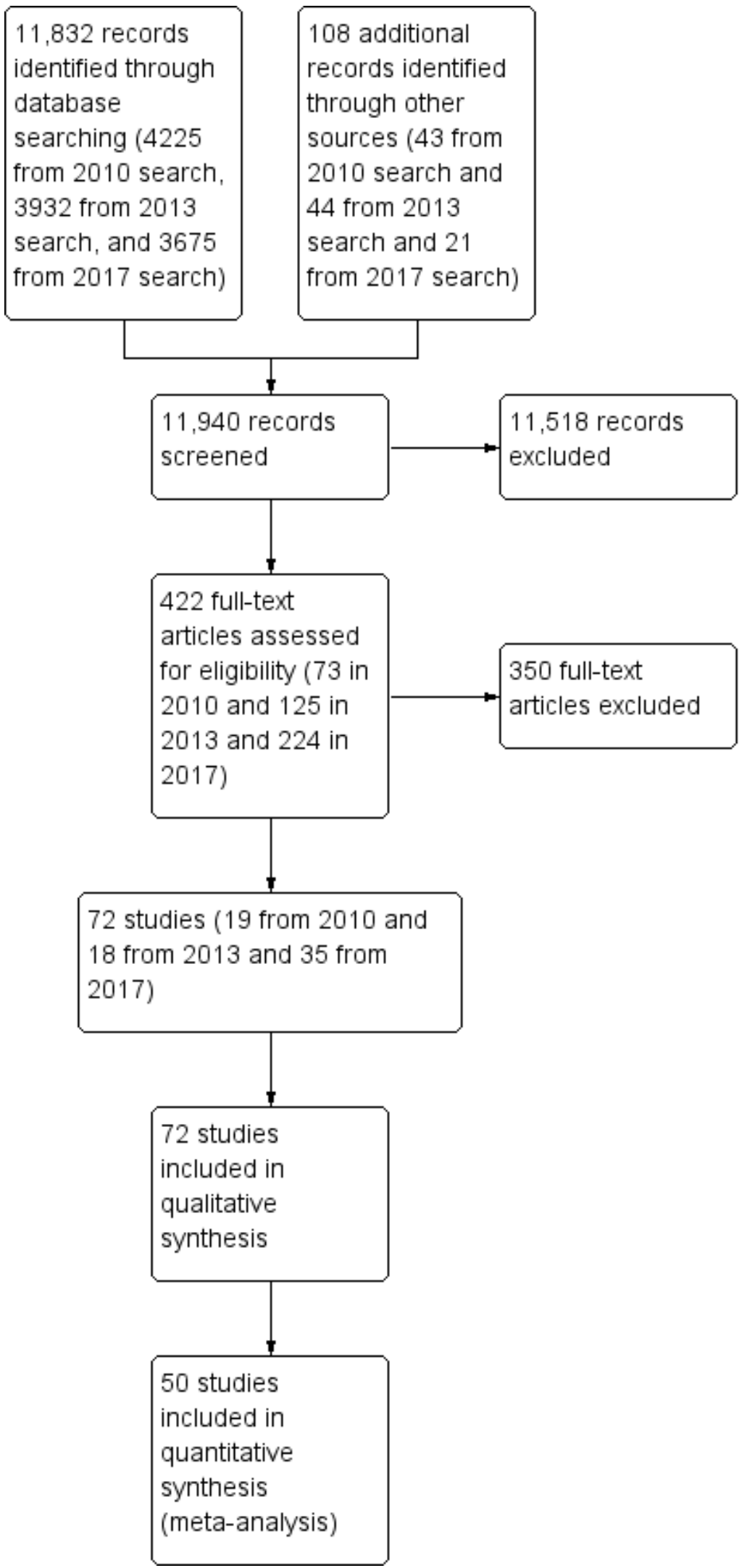




\section{Included studies}

We identified 72 RCTs with a total of 2470 participants, which met the inclusion criteria. Of the 72 included studies, we included 19 (with 565 participants) in the original version of this review, 18 new studies (with 454 participants) in the 2015 update, and 35 new studies (with 1451 participants) in this updated review.

\section{Sample characteristics}

All trials took place between 2004 and 2016. All but two were published in English (Galvao 2015; Xiang 2014). Over half (41; 57\%) of the studies involved sample sizes of fewer than 25 participants and only 10 studies involved more than 50 participants (Adie 2017; Akinwuntan 2005; Kiper 2011; Klamroth-Marganska 2014; Ko 2015; Kong 2014; Lam 2006; Linder 2015; Prange 2015; Saposnik 2016). A total of 2470 participants post stroke were included in the trials.

All studies, except for Ucar 2014, reported that they included both men and women. Although not always clearly reported, it appears that participants in the included studies were relatively young, with all studies reporting mean ages of 46 to 75 years.

Thirteen trials recruited participants within three months of stroke (Akinwuntan 2005; Coupar 2012; da Silva Cameirao 2011; Kwon 2012; Kong 2014; Low 2012; Mao 2015; Morone 2014; Piron 2007; Prange 2015; Saposnik 2010; Saposnik 2016; Xiang 2014); two trials recruited within six months of stroke (Adie 2017; Ko 2015); two trials recruited within 12 months (Kiper 2011; Yavuzer 2008); three trials recruited people more than two to three months post stroke (Levin 2012; McNulty 2015; Reinkensmeyer 2012); 31 trials recruited participants more than six months post stroke (Byl 2013; Crosbie 2008; da Silva Ribeiro 2015; Fan 2014; Givon 2016; Housman 2009; Hung 2014; Jaffe 2004; Jang 2005; Jung 2012; Kim 2009; Kim 2012a; Klamroth-Marganska 2014; Lee 2013; Lee 2014a; Lee 2015a; Lee 2015b; Llorens 2015; Manlapaz 2010; Mirelman 2008; Nara 2015; Piron 2010; Sin 2013; Sucar 2009; Subramanian 2013; Thielbar 2014; Yang 2008; Ucar 2014; Yang 2011; You 2005; Zucconi 2012). Time since onset of stroke was not reported in the inclusion criteria for the remaining studies. The average recruitment time since stroke for each study is reported in the Characteristics of included studies table.

Several trials excluded people who were deemed medically unstable, though how this was determined was often unclear. Ten trials specified that people with a history of epilepsy or seizures would be excluded (Akinwuntan 2005; Fan 2014; Givon 2016; Kim 2012a; Mazer 2005; Saposnik 2010; Saposnik 2016; Sin 2013; Ucar 2014; Yin 2014). Most studies reported that people with significant cognitive impairment would be excluded; however, this criterion was often poorly defined. Several studies listed the presence of aphasia, apraxia, and visual impairment as exclusion criteria. One study excluded people with computer-related phobias (Lam 2006). Studies involving upper limb training included participants with a range of function including those with severe functional impairment (Byl 2013; Coupar 2012; da Silva Cameirao 2011; Kiper 2011; Klamroth-Marganska 2014; Levin 2012; Linder 2015; McNulty 2015; Reinkensmeyer 2012; Shin 2014; Sin 2013). All studies except Bower 2015 involving lower limb and gait training only involved participants that were able to walk independently.

\section{Interventions}

\section{Intervention approaches}

Five intervention approaches were used: activity retraining; upper limb training; lower limb, balance and gait training; global motor function training; and cognitive/perceptual training. Four trials involved activity retraining; Akinwuntan 2005 and Mazer 2005 examined automobile driving retraining; Jannink 2008 examined scooter driving retraining; and Lam 2006 tested retraining skills in using public transport. Thirty-five trials involved upper limb training (Adie 2017; Byl 2013; Coupar 2012; Crosbie 2008; da Silva Cameirao 2011; Fan 2014; Galvao 2015; Housman 2009; Kim 2012a; Kiper 2011; Klamroth-Marganska 2014; Kong 2014; Lee 2015b; Levin 2012; Linder 2015; Manlapaz 2010; Matsuo 2013; McNulty 2015; Prange 2015; Piron 2007; Piron 2009; Piron 2010; Reinkensmeyer 2012; Saposnik 2010; Saposnik 2016; Shin 2014; Shin 2015; Sin 2013; Standen 2011; Subramanian 2013; Sucar 2009; Thielbar 2014; Yavuzer 2008; Yin 2014; Zucconi 2012). Twenty-three trials involved lower limb, balance and gait training (Barcala 2013; Bower 2015; Chow 2013; Han 2013; Hung 2014; Jaffe 2004; Jung 2012; Kim 2009; Ko 2015; Lee 2013; Lee 2014a; Lee 2015a; Llorens 2015; Mao 2015; Mirelman 2008; Morone 2014; Nara 2015; Rajaratnam 2013; Song 2015; Ucar 2014; Xiang 2014; Yang 2008; Yang 2011). Ten trials used virtual reality to improve global motor function (Cho 2012; da Silva Ribeiro 2015; Givon 2016; Jang 2005; Kim 2009; Kim 2011a; Kim 2011b; Kwon 2012; Low 2012; You 2005) and one trial used a visualperceptual retraining approach (Kang 2009).

Twenty-two (31\%) of the studies used commercially available gaming consoles: one study used the Playstation EyeToy (Yavuzer 2008), 15 studies used the Nintendo Wii (Barcala 2013; da Silva Ribeiro 2015; Fan 2014; Galvao 2015; Hung 2014; Kim 2012a; Kong 2014; Lee 2015a; Manlapaz 2010; Matsuo 2013; McNulty 2015; Morone 2014; Rajaratnam 2013; Saposnik 2010; Saposnik 2016) and four studies used the Microsoft Kinect (Chow 2013; Rajaratnam 2013; Sin 2013; Song 2015). Two studies used a mix of gaming consoles (Bower 2015; Givon 2016). Eight studies used GestureTek IREX, which is commercially available but more difficult to obtain and more expensive than off-the-shelf consoles (Cho 2012; Han 2013; Jang 2005; Kim 2009; Kim 2011a; Kim 2011b; Kwon 2012; You 2005). One study used the Armeo (Coupar 2012), one used the CAREN system (Subramanian 2013) and one used the Lokomat (Ucar 2014), which are also available for rehabilitation facilities to purchase. The remaining studies used customised virtual reality programs. The number of studies using commercially available gaming consoles increased from six in the previous version of this review to 22 in this update.

\section{Setting}

The majority of interventions were delivered in either an outpatient or inpatient setting, although five of the studies delivered the intervention in the participant's own home (Adie 2017; Linder 2015; McNulty 2015; Piron 2009; Standen 2011). Two of these studies used a telerehabilitation approach to deliver the intervention (Linder 2015; Piron 2009).

\section{Amount of therapy provided}

The total dose of therapy provided varied between studies. Fourteen studies provided less than five hours of total therapy (Barcala 2013; Bower 2015; Han 2013; Jannink 2008; Kim 2012a; Low 2012; Matsuo 2013; Morone 2014; Nara 2015; Shin 2014; Ucar 2014; Yang 2008; Yang 2011). Twenty-five studies provided between 
six and 10 hours of therapy (Crosbie 2008; Fan 2014; Jaffe 2004; Jung 2012; Kang 2009; Kim 2009; Kim 2011a; Kim 2011b; Ko 2015; Kwon 2012; Lam 2006; Lee 2013; Lee 2014a; Lee 2015a; Lee 2015b; Levin 2012; Manlapaz 2010; Mao 2015; Prange 2015; Saposnik 2010; Saposnik 2016; Sin 2013; Subramanian 2013; Xiang 2014; Yavuzer 2008). A further 26 studies provided between 11 and 20 hours of therapy (Akinwuntan 2005; Byl 2013; Cho 2012; Chow 2013; da Silva Cameirao 2011; da Silva Ribeiro 2015; Galvao 2015; Hung 2014; Jang 2005; Kiper 2011; Kong 2014; Klamroth-Marganska 2014; Llorens 2015; Mazer 2005; McNulty 2015; Mirelman 2008; Piron 2009; Piron 2010; Rajaratnam 2013; Shin 2015; Song 2015; Sucar 2009; Thielbar 2014; Yin 2014; You 2005; Zucconi 2012) and seven studies provided more than 21 hours of therapy (Adie 2017; Givon 2016; Housman 2009; Linder 2015; Piron 2007; Reinkensmeyer 2012; Standen 2011; ). The remaining study, Coupar 2012, had three arms; one of the arms received lower intensity therapy (four hours total) and another received higher intensity therapy (10 hours total).

\section{Comparison interventions}

Most of the trials compared virtual reality intervention with a comparable alternative intervention. The alternative intervention was often described as therapy using a conventional approach. One study allocated participants to either actively participating in the virtual reality intervention or watching others participate in the virtual reality intervention (Yavuzer 2008). Other studies of note compared virtual reality with recreational therapy (Saposnik 2016) and constraint-induced movement therapy (McNulty 2015). Eighteen of the studies examined the effect of virtual reality when used alone (the control group received no intervention) or as an adjunct (the control group received usual care or rehabilitation) and thus there was a discrepancy in the dose of therapy received between the intervention and control groups (Barcala 2013; Bower 2015; Cho 2012; Jang 2005; Kim 2011a; Kim 2012a; Kong 2014; Kwon 2012; Lee 2013; Lee 2014a; Low 2012; Matsuo 2013; Mazer 2005; Shin 2014; Sin 2013; Standen 2011; Ucar 2014; You 2005). There were seven three-armed trials with two comparison interventions (Byl 2013; Coupar 2012; da Silva Cameirao 2011; Fan 2014; Kong 2014; Lam 2006; Zucconi 2012).

\section{Outcomes}

As a result of the diverse intervention approaches, a wide range of outcome measures were used. Outcome measures for each of the predefined outcome categories are shown in Table 1. Due to the heterogeneity of outcome measures, we were unable to include all of them in the analyses. With regard to timing of outcome measurements, one study waited until five weeks after the end of the intervention to collect outcome measures (Jannink 2008). All remaining studies measured outcomes soon after the intervention was completed. For studies including further follow-up, the time interval until follow-up was generally at or less than three months (Coupar 2012; Crosbie 2008; da Silva Cameirao 2011; Fan 2014; Givon 2016; Hung 2014; Jaffe 2004; Kong 2014; Levin 2012; Matsuo 2013; Mirelman 2008; Morone 2014; Piron 2009; Reinkensmeyer 2012; Saposnik 2010; Saposnik 2016; Subramanian 2013; Thielbar 2014; Yang 2008; Yin 2014). Only five studies involved longer-term follow-up: four at six months (Adie 2017; Housman 2009; KlamrothMarganska 2014; McNulty 2015) and one at both six months and five years (Akinwuntan 2005).

Twenty-four studies reported on the presence or absence of adverse events (Adie 2017; Bower 2015; Byl 2013; Coupar 2012; Crosbie 2008; Givon 2016; Housman 2009; Hung 2014; Jaffe 2004; Kiper 2011; Klamroth-Marganska 2014; Levin 2012; Llorens 2015; McNulty 2015; Piron 2007; Piron 2010; Reinkensmeyer 2012; Saposnik 2010; Saposnik 2016; Shin 2015; Subramanian 2013; Sucar 2009; Yavuzer 2008; Yin 2014).

\section{Excluded studies}

We have provided details of 34 studies that we excluded. We listed studies as excluded if they were obtained in full text and required lengthy discussion between authors to confirm exclusion (Characteristics of excluded studies). Common reasons for exclusion were: studies compared different forms of virtual reality or the interaction between the virtual environment and the user was not genuine (for example, the person walked on a treadmill while viewing a virtual environment but there was no interaction between the user and environment and changes in speed of walking in the user did not impact on movement in the virtual world).

\section{Risk of bias in included studies}

Refer to Figure 2 and Figure 3. 
Figure 2. Methodological quality summary: review authors' judgements about each methodological quality item for each included study

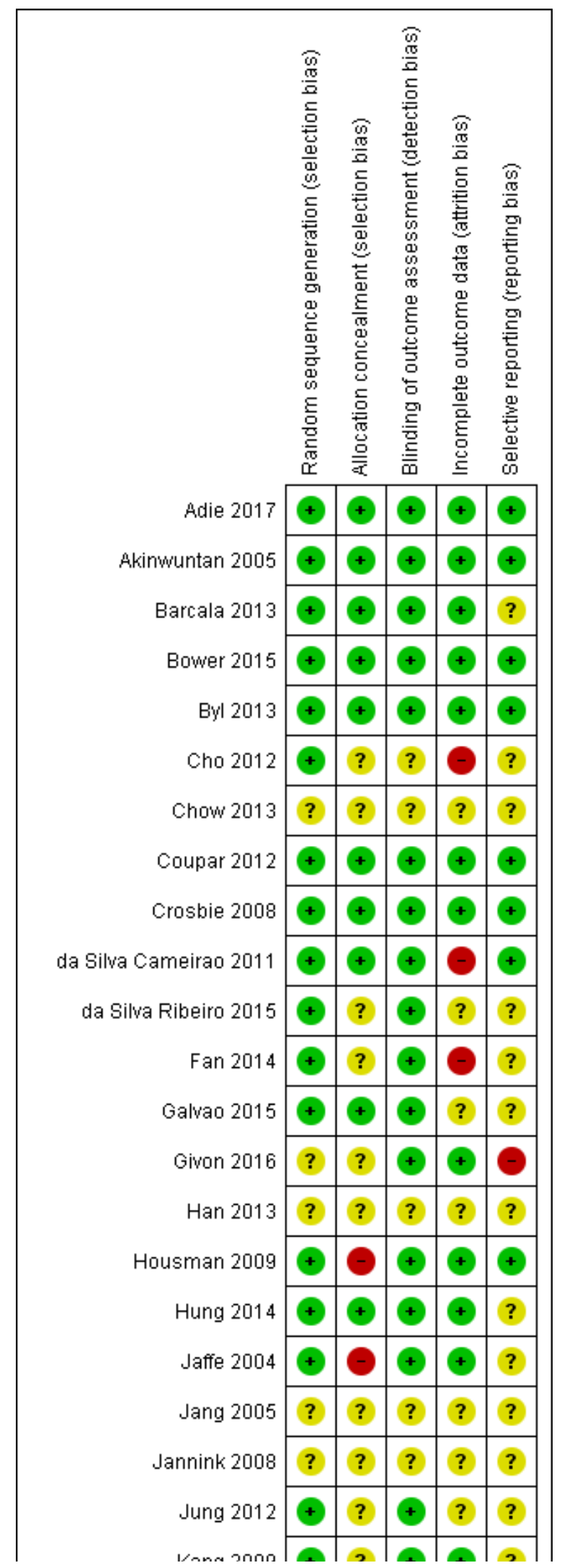


Figure 2. (Continued)

\begin{tabular}{|c|c|c|c|c|c|}
\hline \multirow[b]{2}{*}{ Kang 2009} & \multicolumn{2}{|c|}{10} & ๆ & : & : \\
\hline & $\odot$ & $?$ & + & + & $?$ \\
\hline Kim 2009 & $\odot$ & $\odot$ & + & + & + \\
\hline Kim 2011a & $?$ & $?$ & - & + & + \\
\hline Kim 2011b & ? & $?$ & + & + & + \\
\hline Kim 2012a & $?$ & $?$ & ? & ? & ? \\
\hline Kiper 2011 & $\odot$ & $\oplus$ & + & + & + \\
\hline Klamroth-Marganska 2014 & + & 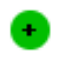 & + & + & + \\
\hline Ko 2015 & $?$ & $?$ & $?$ & $?$ & $?$ \\
\hline Kong 2014 & + & $\odot$ & + & + & $\oplus$ \\
\hline Kwon 2012 & $?$ & ? & $\odot$ & ? & ? \\
\hline Lam 2006 & + & $\odot$ & $\odot$ & + & + \\
\hline Lee 2013 & $\odot$ & $?$ & $?$ & - & $?$ \\
\hline Lee $2014 \mathrm{a}$ & 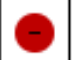 & - & + & + & $?$ \\
\hline Lee $2015 a$ & $?$ & $?$ & $?$ & $?$ & $?$ \\
\hline Lee $2015 b$ & $?$ & $?$ & $?$ & $?$ & $?$ \\
\hline Levin 2012 & 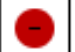 & + & + & + & $\oplus$ \\
\hline Linder 2015 & $\odot$ & $\odot$ & + & + & - \\
\hline Llorens 2015 & + & $?$ & + & + & $?$ \\
\hline Low 2012 & $?$ & $?$ & $?$ & $?$ & $?$ \\
\hline Manlapaz 2010 & $?$ & $\odot$ & + & $\odot$ & $?$ \\
\hline Mao 2015 & $\odot$ & $\odot$ & $?$ & $?$ & + \\
\hline Matsuo 2013 & $?$ & $?$ & $?$ & $?$ & $?$ \\
\hline Mazer 2005 & + & $\odot$ & + & 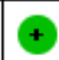 & 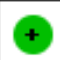 \\
\hline McNulty 2015 & + & $\odot$ & + & + & $?$ \\
\hline Mirelman 2008 & + & $\oplus$ & + & + & $\oplus$ \\
\hline Morone 2014 & + & $?$ & + & 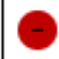 & $?$ \\
\hline Nara 2015 & $?$ & ? & ? & $\Theta$ & $?$ \\
\hline Piron 2007 & + & $\oplus$ & + & - & $\oplus$ \\
\hline Piron 2009 & + & $\oplus$ & + & + & $\oplus$ \\
\hline Piron 2010 & $\odot$ & $\oplus$ & + & + & + \\
\hline & 31 & a & a & a & \\
\hline
\end{tabular}


Figure 2. (Continued)

\begin{tabular}{|c|c|c|c|c|c|}
\hline טוטיונווז & - & 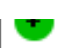 & $*$ & 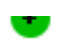 & 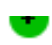 \\
\hline Prange 2015 & $?$ & 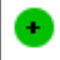 & + & + & + \\
\hline Rajaratnam 2013 & $\odot$ & ? & + & ? & ? \\
\hline Reinkensmeyer 2012 & $\odot$ & $?$ & + & ? & ? \\
\hline Saposnik 2010 & + & $?$ & + & $\odot$ & + \\
\hline Saposnik 2016 & + & + & + & + & + \\
\hline Shin 2014 & $\odot$ & + & + & + & + \\
\hline Shin 2015 & $\oplus$ & $?$ & + & 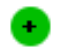 & $?$ \\
\hline $\operatorname{Sin} 2013$ & + & $?$ & + & $?$ & $?$ \\
\hline Song 2015 & $?$ & $?$ & $?$ & $?$ & $?$ \\
\hline Standen 2011 & + & + & + & - & + \\
\hline Subramanian 2013 & + & + & + & + & + \\
\hline Sucar 2009 & $\Theta$ & $?$ & $\odot$ & + & + \\
\hline Thielbar 2014 & - & + & + & + & ? \\
\hline Ucar 2014 & $?$ & $?$ & $\Theta$ & $?$ & ? \\
\hline Xiang 2014 & $?$ & $?$ & $\Theta$ & $?$ & ? \\
\hline Yang 2008 & $\odot$ & $?$ & + & $?$ & ? \\
\hline Yang 2011 & $?$ & $?$ & + & $?$ & $?$ \\
\hline Yavuzer 2008 & + & + & + & $\odot$ & ? \\
\hline Yin 2014 & $?$ & $?$ & $\odot$ & + & $?$ \\
\hline You 2005 & $?$ & $?$ & + & $?$ & $?$ \\
\hline Zucconi 2012 & + & + & + & $\odot$ & + \\
\hline
\end{tabular}


Figure 3. Methodological quality graph: review authors' judgements about each methodological quality item presented as percentages across all included studies

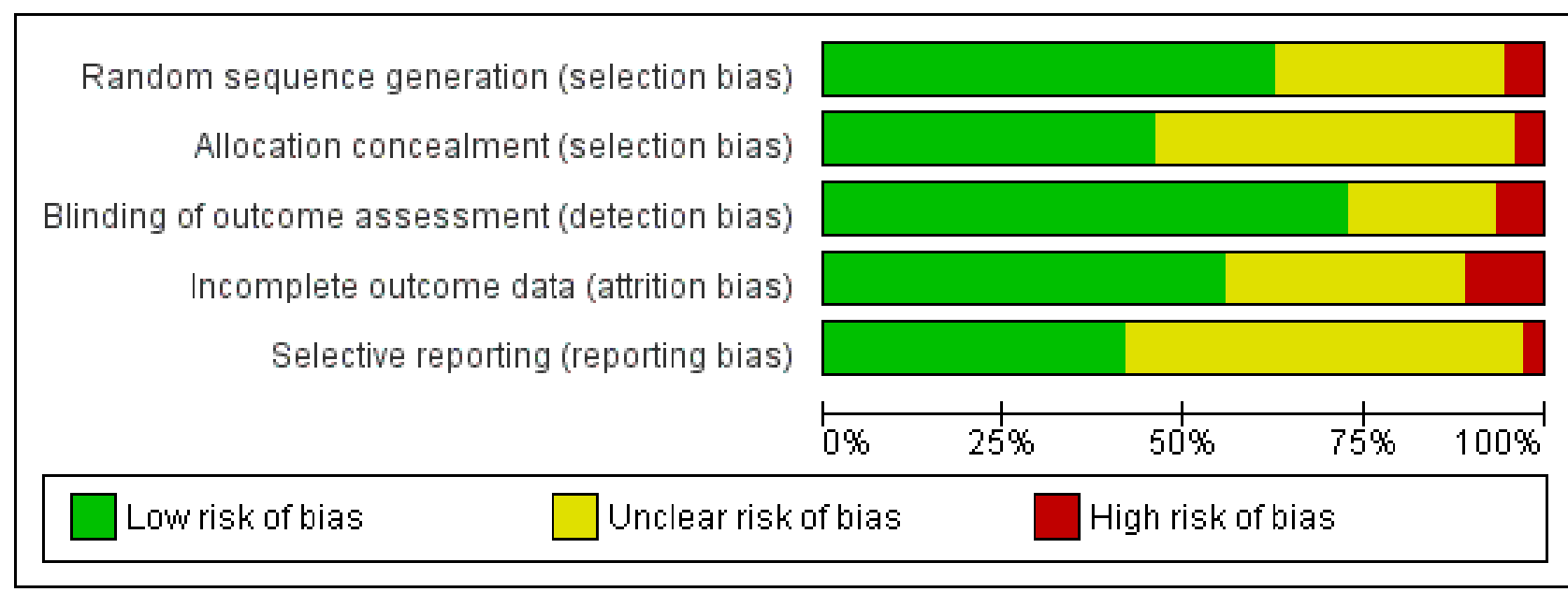

Not all included studies followed the CONSORT guidelines (Schulz 2010), in which case we contacted the corresponding authors for clarification of study methodology. If we did not obtain a response from a corresponding author we recorded the 'Risk of bias' criterion as 'unclear'.

\section{Allocation}

We assessed random sequence generation as being adequate in $63 \%$ of trials. Allocation concealment was reported as adequate in $46 \%$ of trials.

\section{Blinding}

Seventy-two per cent of studies reported blinding of the outcome assessor. No trials were able to blind participants or personnel.

\section{Incomplete outcome data}

We deemed $56 \%$ of studies to be at low risk of bias in relation to incomplete outcome data. Dropouts from studies appeared generally balanced across groups.

\section{Selective reporting}

We judged that $43 \%$ of studies were free of selective reporting by comparing published results with trials register entries or protocol papers or through correspondence with study authors. It was unclear whether selective reporting was present in most other studies.

\section{Effects of interventions}

See: Summary of findings for the main comparison Virtual reality compared to conventional therapy for stroke rehabilitation; Summary of findings $\mathbf{2}$ Virtual reality plus usual care compared with usual care alone

\section{Primary outcome: upper limb function and activity}

We present results for upper limb function and activity.

\section{Virtual reality versus conventional therapy: effect on upper limb function post intervention}

Results are presented for upper limb function and activity and hand function. All outcomes were taken within days of the end of the intervention program.

\section{Comparison 1.1: Upper limb function and activity}

Twenty-two studies presented outcomes for upper limb function and activity in a form suitable for inclusion in the metaanalysis (1038 participants) (Adie 2017; Byl 2013; Crosbie 2008; da Silva Cameirao 2011; da Silva Ribeiro 2015; Galvao 2015; Givon 2016; Housman 2009; Kiper 2011; Kong 2014; Levin 2012; Piron 2007; Piron 2009; Piron 2010; Prange 2015; Reinkensmeyer 2012; Saposnik 2010; Saposnik 2016; Subramanian 2013; Sucar 2009; Thielbar 2014; Zucconi 2012). The impact of virtual reality on upper limb function was not significant: standardised mean difference (SMD) $0.07,95 \%$ confidence interval $(\mathrm{Cl})-0.05$ to 0.20 , low-quality evidence (Analysis 1.1). Statistical heterogeneity was moderate ( 12 $=43 \%)$.

We were unable to obtain data in a suitable format for pooling for three studies (Fan 2014; McNulty 2015; Shin 2015). Fan 2014 reported that there were no significant differences between groups on outcomes on the Jebsen Taylor Hand Function Test; McNulty 2015 reported no significant differences between virtual reality and constraint-induced movement therapy on the Wolf Motor Function Test; and Shin 2015 reported no significant differences between groups on the Fugl Meyer Assessment.

\section{Sensitivity analysis for comparison 1.1}

Excluding those studies judged to be unclear or at high risk of bias in one or more categories left 10 studies (Adie 2017; Byl 2013; Crosbie 2008; Kiper 2011; Kong 2014; Piron 2009; Piron 2010; Saposnik 2016; Subramanian 2013; Zucconi 2012). The result was similar (SMD $-0.02,95 \% \mathrm{Cl}-0.17$ to 0.13$)$; however, statistical heterogeneity was lower $(12=7 \%)$. We conducted a sensitivity analysis involving use of a random-effects model. The difference was minor: SMD 0.17 (95\% $\mathrm{Cl}-0.01$ to 0.35 )

Comparison 1.2: Upper limb function (Fugl Meyer Upper Extremity Scale) 
Sixteen of the trials (with 599 participants) used the Fugl Meyer Upper Extremity (UE) Scale as an outcome measure (Byl 2013; da Silva Cameirao 2011; da Silva Ribeiro 2015; Galvao 2015; Housman 2009; Kiper 2011; Kong 2014; Levin 2012; Piron 2007; Piron 2009; Piron 2010; Prange 2015; Reinkensmeyer 2012; Subramanian 2013; Sucar 2009; Zucconi 2012). The impact of virtual reality as measured by the Fugl Meyer UE Scale showed a small significant effect: mean difference (MD) 2.85, 95\% Cl 1.06 to 4.65 (Analysis 1.2).

\section{Sensitivity analysis for comparison 1.2}

When including only the seven trials deemed to be at low risk of bias in all categories in the analysis, the effect of virtual reality compared to conventional therapy on the Fugl Meyer was not significant (MD 2.01, 95\% Cl -0.46 to 4.47) (Byl 2013; Kiper 2011; Kong 2014; Piron 2009; Piron 2010; Subramanian 2013; Zucconi 2012).

\section{Comparison 1.3: Hand function}

Six trials measured the effect of virtual reality versus alternative therapy on grip strength (266 participants) (Givon 2016; Housman 2009; Reinkensmeyer 2012; Saposnik 2010; Saposnik 2016; Thielbar 2014). The impact of virtual reality compared to conventional therapy was not significant: SMD $-0.02,95 \% \mathrm{Cl}-0.27$ to 0.22 (Analysis 1.3). Statistical heterogeneity was moderate $\left(I^{2}=44 \%\right)$.

\section{Comparison 1.4: Amount of use of upper limb (self-reported)}

We pooled five studies (with 161 participants) to examine the effect on amount of use (self-reported component of the Motor Activity Log) (Galvao 2015; Housman 2009; Levin 2012; Reinkensmeyer 2012; Subramanian 2013). There was no statistically significant difference between the groups receiving virtual reality and conventional therapy (SMD $-0.11,95 \% \mathrm{Cl}-0.42$ to 0.21 ). Data from a further two studies could not be pooled; these studies both reported that there were greater improvements in the intervention group than the control group on the 'amount of use' scale (Jang 2005; Standen 2011). One study, which could not be included in the analysis due to unavailability of data in a suitable format for pooling, found no significant differences in outcome between virtual reality and constraint-induced movement therapy (McNulty 2015).

\section{Comparison 1.5: Upper limb function follow-up}

We pooled nine studies that reported follow-up assessments of arm function taken between two weeks and three months after the end of intervention (Crosbie 2008; da Silva Cameirao 2011; Givon 2016; Kong 2014; Levin 2012; Piron 2009; Reinkensmeyer 2012; Saposnik 2016; Thielbar 2014). The difference between performance of the virtual reality and conventional therapy groups at this later followup point was not significant (SMD $0.11,95 \% \mathrm{Cl}-0.10$ to 0.32 ). A further three studies measured outcomes six months after the end of intervention. Housman 2009 reported that participants in the virtual reality group had improved significantly more on the Fugl Meyer UE Scale at the six-month follow-up assessment than participants in the alternative treatment group $(P=0.045)$. Participants in the virtual reality group improved by 3.6 points (standard deviation (SD) 3.9) whereas participants in the alternative treatment group improved by 1.5 points (SD 2.7). However, the trial found no other significant differences between groups at six months on the other outcome measures used (Rancho Functional Test, grip strength and Motor Activity Log). In contrast, Adie 2017 reported no significant differences between groups on the Action
Research Arm Test or Motor Activity Log at six-month follow-up and McNulty 2015 reported that at six months upper limb function was not significantly different between groups that had participated in Wii-based movement therapy and those participating in modified constraint-induced movement therapy.

\section{Upper limb function: subgroup analyses}

\section{Comparison 2.1: Dose of treatment}

We compared trials providing under 15 hours of intervention with trials providing 15 hours or more of intervention. Neither group had a statistically significant difference between virtual reality and alternative intervention. While trials providing less than 15 hours of intervention had a non-significant effect (SMD $-0.01,95 \% \mathrm{Cl}-0.20$ to 0.18 ), trials providing more than 15 hours of intervention showed a trend (although not statistically significant) in favour of the virtual reality intervention (SMD $0.13,95 \% \mathrm{Cl}-0.03$ to 0.29 ). The difference between groups was not statistically significant $\left(\mathrm{Chi}^{2}=1.26, \mathrm{df}=1\right.$, $P$ value $=0.26)($ Analysis 2.1)

\section{Comparison 2.2: Time since onset of stroke}

We classified trials based on whether their participants were recruited within six months of stroke or more than six months post stroke. The group recruited within six months of stroke did not demonstrate a significant effect (SMD $-0.06,95 \% \mathrm{Cl}-0.23$ to 0.11 ) nor did the group recruited after six months (SMD $0.19,95 \%$ $\mathrm{Cl}-0.02$ to 0.39 ) although there was a trend towards the virtual reality intervention. The difference between groups bordered on significant $\left(\mathrm{Chi}^{2}=3.36, \mathrm{df}=1, \mathrm{P}\right.$ value $\left.=0.07\right)($ Analysis 2.2) .

Comparison 2.3: Specialised virtual reality system or commercial gaming console

Studies utilising virtual reality programs specifically designed for rehabilitation settings demonstrated statistically significant benefits over alternative intervention (SMD $0.17,95 \% \mathrm{Cl} 0.00$ to 0.35). In contrast those involving off-the-shelf gaming programs were not found to be significant (SMD $-0.02,95 \% \mathrm{Cl}-0.20$ to 0.15 ) (Analysis 2.3). However, the test for subgroup differences did not indicate significance $(P$ value $=0.12)$.

\section{Comparison 2.4: Severity of upper limb impairment}

We compared outcomes for people with mild to moderate upper limb impairment and people with moderate to severe impairment. The group with mild to moderate impairment showed a nonsignificant effect (SMD $0.10,95 \% \mathrm{Cl}-0.06$ to 0.25 ) as did the group with moderate to severe impairment (SMD $0.01,95 \% \mathrm{Cl}-0.22$ to 0.23) (Analysis 2.4).

We did not undertake other planned subgroup analyses due to similarities in these studies in regard to the age of participants and frequency of intervention sessions.

\section{Additional virtual reality intervention: effect on upper limb function post intervention}

We examined the effects of virtual reality intervention when it was compared with no intervention and used to augment standard care (i.e. people in the virtual reality intervention group received additional therapy time relative to the control group). 


\section{Comparison 3.1: Upper limb function}

Ten studies with a total of 210 participants presented outcomes for upper limb function (Cho 2012; Coupar 2012; Jang 2005; Kim 2011a; Kwon 2012; Manlapaz 2010; Shin 2014; Sin 2013; Standen 2011; Yavuzer 2008). There was a moderate significant effect that demonstrated that virtual reality intervention was more effective than no intervention: SMD $0.49,95 \% \mathrm{Cl} 0.21$ to 0.77 , low-quality evidence (Analysis 3.1). There was no statistical heterogeneity.

Two studies could not be included in the analysis due to our inability to obtain data in a suitable format for pooling (Low 2012; Yin 2014). Both studies reported that there were no significant differences between groups on Fugl Meyer score.

\section{Sensitivity analysis}

We excluded trials that we deemed to be at high risk of bias in one or more categories (Cho 2012; Kim 2011a; Standen 2011). The result was a slightly higher SMD than found in the original analysis (SMD $0.55,95 \% \mathrm{Cl} 0.20$ to 0.91 ).

\section{Additional virtual reality intervention: effect on upper limb function post intervention: subgroup analyses}

\section{Comparison 4.1: Dose of treatment}

We compared trials providing less than 15 hours of intervention with trials providing 15 hours or more of intervention. Pooling of seven trials with less than 15 hours of intervention had a significant effect on upper limb function (SMD $0.47,95 \% \mathrm{Cl} 0.14$ to 0.80 ) as did pooling of three trials providing more than 15 hours of intervention (SMD 0.54, 95\% $\mathrm{Cl} 0.00$ to 1.07). The difference between groups was not significant $\left(\mathrm{Chi}^{2}=0.04, \mathrm{df}=1, \mathrm{P}\right.$ value $=0.83$ ) (Analysis 4.1).

\section{Comparison 4.2: Time since onset of stroke}

We compared analysis of five trials recruiting participants within six months of stroke with four trials recruiting participants more than six months post stroke. Analysis of trials recruiting within six months did not reveal a significant effect (SMD $0.28,95 \% \mathrm{Cl}-0.12$ to 0.67) whereas those recruiting people in the chronic phase of stroke experienced statistically significant benefits (SMD 0.65, 95\% Cl 0.19 to 1.11). The difference between groups was not significant ( $P$ value $=0.23$ ) (Analysis 4.2).

\section{Comparison 4.3: Specialised virtual reality system or gaming console}

We compared three trials evaluating the efficacy of gaming console use with seven trials evaluating the efficacy of virtual reality systems specifically designed for rehabilitation. Both types of virtual reality programs were found to be effective (when the virtual reality was used as an adjunct to treatment) and the difference between groups was not significant $\left(\mathrm{Chi}^{2}=0.75, \mathrm{df}=1, \mathrm{P}\right.$ value $=$ 0.39) (Analysis 4.3).

\section{Secondary outcomes}

\section{Virtual reality versus conventional therapy: effect on gait and balance: post intervention}

Results are presented for gait speed. All outcomes are taken within days of the end of the intervention program and measured in metres per second. We were unable to include seven relevant studies; one of these studies, Barcala 2013, compared different doses of therapy, and six studies did not report data in a format that allowed pooling nor did the corresponding authors provide the data upon request (Hung 2014; Kim 2009; Morone 2014; Rajaratnam 2013; Ucar 2014; Yang 2011).

\section{Comparison 5.1: Gait speed}

Six studies provided data on gait speed (139 participants) (Givon 2016; Jaffe 2004; Llorens 2015; Mirelman 2008; Song 2015; Yang 2008). The effect of virtual reality on gait speed was not significant: MD $0.09,95 \% \mathrm{Cl}-0.04$ to 0.22 , low-quality evidence (Analysis 5.1). Low statistical heterogeneity was indicated $\left(I^{2}=10 \%\right)$. Jaffe 2004 examined the effect of virtual reality on comfortable walking speed and fast walking speed. We included the data relating to comfortable walking speed in the meta-analysis. The effect on fast walking speed was found to be significantly greater in the virtual reality intervention group than the comparative group. One study, which could not be included in the analysis due to inability to obtain data in a suitable format for pooling, found no significant differences between groups on walking speed (Morone 2014). A second study, which could also not be pooled, reported that use of the Lokomat was significantly better than conventional therapy on walking speed $(P=0.007)$.

\section{Comparison 5.2: Timed Up and Go test}

We pooled three studies (89 participants, Hung 2014; Jung 2012; Song 2015) reporting data for the Timed Up and Go (TUG) test. There was no significant difference between those in the virtual reality and conventional therapy groups (MD -1.76, 95\% $\mathrm{Cl}-4.67$ to 1.16$)$ and statistical heterogeneity was high $\left(\mathrm{I}^{2}=59 \%\right)$ (Analysis 5.2). One study could not be included in the analysis as standard deviations were not available (Ucar 2014). The study authors reported that those receiving therapy on the Lokomat had significantly better performance on the TUG test than those receiving conventional therapy $(P=0.035)$.

\section{Comparison 5.3: Balance}

Three studies with 72 participants examined the effect of virtual reality intervention compared to conventional therapy on balance (Hung 2014; Lee 2014a; Llorens 2015). The effect was not statistically significant (SMD $0.39,95 \% \mathrm{Cl}-0.09$ to 0.86 ) (Analysis 5.3); heterogeneity was low. We could not include two studies in the analyses because we were unable to obtain the data required: Han 2013 found no significant differences between groups, whereas Morone 2014 reported that Wii Fit training was more effective than conventional balance therapy in improving performance on the Berg Balance Scale.

\section{Gait and balance activity: subgroup analyses}

Subgroup analyses comparing those receiving less than 10 hours' intervention with those receiving more than 10 hours' intervention did not suggest that this was an influential factor on gait speed outcome (Analysis 6.1).

We did not undertake other planned subgroup analyses due to homogeneity with regard to the age of participants, severity of stroke, time since onset of stroke, frequency of intervention sessions, and type of virtual reality program.

\section{Gait and balance activity: follow-up}

Only three trials measured the longer-term effects (at three months) of virtual reality on gait speed. Hung 2014 and Mirelman 2008 both reported that initial benefits in the intervention group (relative to the control group) were still present at follow-up, while 
Givon 2016 reported that initial differences between groups were not maintained.

\section{Additional virtual reality intervention: effect on gait and balance post intervention}

\section{Comparison 7.1: Gait speed}

Pooling of three studies with 57 participants utilising virtual reality intervention as an adjunct to usual care did not identify statistically significant benefits (SMD $0.08,95 \% \mathrm{Cl}-0.05$ to 0.21 , low-quality evidence) (Bower 2015; Lee 2014a; Xiang 2014). There was no statistical heterogeneity (Analysis 7.1). Two studies could not be included in the analysis due to our inability to obtain data in a suitable format for pooling (Chow 2013; Low 2012). Both papers (presented as conference abstracts only) reported no significant differences between groups in gait speed following intervention.

\section{Comparison 7.2: Timed Up and Go Test}

Pooling of three studies with 93 participants identified a statistically significant difference between people after receiving additional intervention using virtual reality programs on the Timed Up and Go Test in contrast to those receiving usual care (MD -4.76, 95\% Cl -8.91 to -0.61$)$ although statistical heterogeneity was present $\left(I^{2}=50 \%\right)$ (Analysis 7.2) (Barcala 2013; Ko 2015; Lee 2014a).

\section{Comparison 7.3: Balance}

We pooled seven studies (with 173 participants) to examine the effect of providing virtual reality as an adjunct to usual care on balance (Barcala 2013; Bower 2015; Kim 2009; Ko 2015; Lee 2013; Lee 2014a; Xiang 2014). The effect was significant and the effect size was moderate (SMD $0.59,95 \% \mathrm{Cl} 0.28$ to $0.90, \mathrm{I}^{2}=32 \%$, Analysis 7.3). Two studies could not be included in the analysis due to our inability to obtain data in a suitable format for pooling (Chow 2013; Low 2012). Both papers (presented as conference abstracts only) reported no differences between groups in outcome.

\section{Global motor function}

Four studies reported outcomes for global motor function (using the Modified Motor Assessment scale). However, Kim 2009 compared virtual reality with an alternative intervention. We pooled three studies (with 43 participants) that examined the effect of virtual reality on global motor function when used in addition to usual care, thus increasing the therapy dose received by the intervention group (Bower 2015; Kim 2012a; You 2005). The effect on global motor function was not significant (SMD 0.01, 95\% Cl -0.60 to 0.61 , low-quality evidence) (Analysis 8.1).

\section{Cognitive function}

Insufficient trials included assessments of cognition to allow us to perform analysis for this outcome.

\section{Activity limitation}

Two studies reported outcomes of a driving evaluation. However, we were unable to pool results as Akinwuntan 2005 compared virtual reality intervention with an alternative intervention, and Mazer 2005 compared virtual reality intervention with no alternative intervention. Akinwuntan 2005 reported the results from the follow-up assessments, which were completed at six months and five years post intervention. Six months post intervention they found that participants in the virtual reality intervention group had improved significantly more in their onroad performance (measured by the Test Ride for Investigating Practical fitness to drive checklist) than participants in the alternative intervention group ( $P$ value $=0.005$ ). Furthermore, $73 \%$ of the virtual reality group compared with $42 \%$ of the group that participated in driving-related cognitive tasks were classified by driving assessors as 'fit to drive' at six months. At five years, there was no significant difference between the groups in regards to 'fitness to drive' or resumption of driving.

\section{Virtual reality versus conventional therapy: effect on activity limitation}

\section{Comparison 9.1: Activities of daily living (ADL) outcome}

We pooled 10 studies with 466 participants that examined the difference between virtual reality intervention and alternative intervention on ADL (Byl 2013; da Silva Cameirao 2011; Kang 2009; Kim 2011b; Kiper 2011; Kong 2014; Piron 2007; Piron 2010; Saposnik 2016; Zucconi 2012). There was a small, significant effect (SMD 0.25, $95 \% \mathrm{Cl} 0.06$ to 0.43 , moderate-quality evidence) and presence of statistical heterogeneity $(12=22 \%$ ) (Analysis 9.1). Two studies could not be included in the analysis due to our inability to obtain data in a suitable format for pooling (Han 2013; Morone 2014). Morone 2014 presented a graph indicating that those in the Nintendo Wii group had significantly better scores on the Barthel Index post intervention than those in the conventional therapy group, whereas Han 2013 reported no significant differences between groups.

\section{Sensitivity analysis}

We explored the effects of methodological quality on the overall effect by excluding studies deemed to be at unclear or high risk of bias in one or more categories from the analysis (da Silva Cameirao 2011; Kang 2009; Kim 2011b; Piron 2007). The results were similar but the effect size was smaller and no longer statistically significant (SMD 0.20, $95 \% \mathrm{Cl}-0.01$ to 0.40 ).

\section{Additional virtual reality intervention: effect on activity limitation}

\section{Comparison 10.1: ADL outcome}

Pooling of eight studies with 153 participants examined the effect of providing additional intervention using virtual reality on ADL outcome (Barcala 2013; Coupar 2012; Kim 2011a; Kim 2012a; Kwon 2012; Shin 2014; Standen 2011; Yavuzer 2008). The effect was statistically significant with a small to moderate effect size (SMD $0.44,95 \% \mathrm{Cl} 0.11$ to 0.76 ). There was no heterogeneity (Analysis 10.1). We conducted a sensitivity analysis based on risk of bias and only including the two studies deemed at low risk of bias in all categories. The result was still positive; however the confidence intervals were wide (SMD 0.92, $95 \% \mathrm{Cl} 0.04$ to 1.81 ).

We could not include three studies in the analysis due to our inability to obtain data in a suitable format for pooling (Chow 2013; Low 2012; Yin 2014); none of these studies reported a significant difference between groups on ADL outcome.

\section{Participation restriction and quality of life}

Heterogeneity between trials and outcome measures used meant that we did not perform any analysis for this outcome. 
Six studies compared a virtual reality intervention with an alternative intervention and measured changes using either components or the full version of the Stroke Impact Scale (Adie 2017; Fan 2014; Kong 2014; Linder 2015; Saposnik 2010; Saposnik 2016). None of the six studies found a significant difference between the intervention and control group in score on the Stroke Impact Scale.

Three studies compared a virtual reality intervention with an alternative intervention and used a health-related, quality-oflife measure. Adie 2017 reported that there was no difference between groups identified via the EQ5D tool. The other two studies reported differences between groups in some domains of the SF36; participants receiving conventional therapy in the study conducted by da Silva Ribeiro 2015 reported significantly higher scores on the physical-functioning domain, whereas Shin 2015 reported that those in the virtual reality group reported significantly better scores in terms of role limitations due to physical problems.

\section{Adverse events}

Twenty-three studies monitored and reported on adverse events. Nineteen studies reported no significant adverse events linked to study participation (Adie 2017; Byl 2013; Coupar 2012; Givon 2016; Housman 2009; Jaffe 2004; Kiper 2011; Levin 2012; Llorens 2015; McNulty 2015; Piron 2007; Piron 2010; Reinkensmeyer 2012; Saposnik 2010; Saposnik 2016; Shin 2015; Subramanian 2013; Yavuzer 2008; Yin 2014). Crosbie 2008 found that two people in the virtual reality group reported side effects of transient dizziness and headache, and Sucar 2009 found that three participants in the virtual reality group reported pain caused by the treatment in contrast to two participants in the conventional therapy group. Bower 2015 reported that several of the participants receiving the intervention had symptoms of pain and one participant reported dizziness; however, these were not thought to be related to the intervention, and Hung 2014 reported that three of the intervention group (out of 15) reported an increase in hypertonicity during treatment.

\section{DISCUSSION}

\section{Summary of main results}

This review included 72 trials with 2470 participants. The main results are presented in Summary of findings for the main comparison and Summary of findings 2.

\section{Upper limb function and activity}

Twenty-two studies with 1033 participants compared a virtual reality intervention with conventional therapy and measured effects on upper limb function. These trials used a variety of different commercially available games or specialised virtual reality programs, and all interventions were delivered in a hospital or clinic setting, with the exception of one of these trials that used a home-based telerehabilitation approach. More of the trials (13 studies) recruited participants more than six months after stroke, with remaining trials recruiting participants within the first six months of stroke.

Six trials compared a virtual reality intervention with conventional therapy and measured grip strength. Pooling of results indicated that there was no significant difference in the efficacy of the therapy approaches on upper limb function or grip strength.
We also examined the effect of a virtual reality intervention on upper limb function when the intervention was provided to augment the usual dose of therapy. Thus, the intervention group received more therapy time than the control group. Ten studies with 210 participants found a moderately significant effect in favour of the virtual reality intervention (low-quality evidence). Eight of these studies involved the use of commercially available virtual reality programs and one of the studies provided the intervention in the home setting.

The addition of a virtual reality intervention to usual care resulted in improvements in upper limb function. However, the virtual reality intervention was not a more effective approach than conventional interventions. This finding is in contrast with the previous versions of this review where meta-analysis revealed a small significant benefit associated with virtual reality intervention when compared with conventional therapy approaches (Laver 2011; Laver 2015). This review included more studies in which virtual reality was used as a way to increase the amount of therapy provided and thus provides more information about the effectiveness of virtual reality as a therapy to augment usual care.

Results of this review did not indicate the most effective time to utilise the intervention in recovery (i.e. whether it was more effective to use virtual reality in the earlier recovery phase or the chronic (more than six months) phase post stroke. It appeared that trials providing more than 15 hours of intervention resulted in greater benefits than those providing a smaller dose of virtual reality therapy. Comparison of the type of program (specialised system versus commercial gaming system) revealed no significant differences in effect although there was a trend suggesting that specialised systems may be more effective.

\section{Secondary outcomes}

Six trials with 139 participants measured gait speed and could be included in the analysis comparing virtual reality with alternative intervention. All six studies included people who were more than one year post stroke. There was insufficient evidence to draw conclusions on whether a virtual reality approach was more effective in improving gait speed than conventional therapy (lowquality evidence). We were also unable to reach conclusions about the effects of virtual reality (compared to conventional therapy) on a more functional measure of mobility; performance on the Timed Up and Go Test. Four trials examined effect of virtual reality on global motor function (with three of these studies using the same virtual reality program). The effect on global motor function was not significant. There was a small effect on ADL when virtual reality was used instead of conventional therapy and a moderate effect on ADL when virtual reality was used to increase the dose of therapy and provided in addition to usual care (moderate-quality evidence). We were unable to pool results for cognitive function, participation restriction, and quality of life studies. There were few adverse events reported across studies and those reported (transient dizziness, headache, pain) were relatively mild.

\section{Heterogeneity of included studies}

There was considerable clinical heterogeneity between the studies included in the review, particularly in regard to the variety of intervention approaches used to address a variety of different patient needs. Some of these interventions were very specific (for example, retraining participants to use the local public transport system) and therefore studies were not comparable in many 
circumstances. In addition, a wide variety of outcome measures were used; this also limited our ability to pool results. The use of meta-analysis in cases where such heterogeneity is present can be considered controversial (Deeks 2011); however, we felt that metaanalysis in this review was justified and we were careful only to pool studies that were relatively comparable in terms of participants, interventions, comparison, and outcome measures. Meta-analysis of the individual studies enabled us to explore the overall treatment effect of the intervention when compared with an alternative, more traditional intervention or no intervention. Our sensitivity analyses suggested that there were no notable differences between using random-effects and fixed-effect models.

\section{Overall completeness and applicability of evidence}

Although we included 72 studies, the sample sizes of the included studies were generally small. There are now studies recruiting participants in both the earlier phases post stroke as well as the chronic phase. People with cognitive impairment, or communication or visual deficits were often excluded, thereby raising questions about how applicable this intervention is to a wide range of stroke survivors. Furthermore, the average age of participants in the included studies was relatively low, therefore, information about use with older stroke survivors is limited.

Researchers involved in future studies should provide more detail in their reporting, ensuring that they clearly describe their eligibility criteria, consent rate and the adherence and satisfaction of participants with the intervention. These details will be of interest to clinicians who will need to weigh up the cost of the virtual reality program with the potential benefits and the number of clients who may benefit from use.

Furthermore, the applicability of the intervention to stroke survivors needs further research in terms of which type of approach is best suited to the individual person and how acceptable the technology may be to stroke survivors. There are a number of studies suggesting that virtual reality training is motivating and enjoyable with some studies finding the intervention to be more engaging than usual therapy exercises (McNulty 2015; Webster 2014; Wingham 2015). Although there is a perception that people undergoing rehabilitation programs will find the technology difficult to use, the research suggests that a number of studies report the technology as acceptable and easy to use (Nawaz 2015) .

In contrast to our previous reviews, in which most of the virtual reality programs were specifically designed for rehabilitation purposes, this review has found a rise in the number of studies evaluating commercial gaming programs designed for the general population; yet it remains difficult to examine the effects of gamebased interventions as the goals of therapy and methods vary.

We did not conduct subgroup analyses to compare the effects of immersive and non-immersive technologies as these types of analyses were not specified in our protocol or carried out in previous versions of this review. As the number of studies in the field expand it may be possible to determine more information about the types of virtual reality that are likely to be effective through this type of subgroup analysis.

Several trials reported on the presence or absence of adverse events. There were few events reported: the small number of events were mild and limited to dizziness, headache and pain.

\section{Quality of the evidence}

While we were able to include a relatively large number of studies in the review, sample sizes in the included studies were mostly small and larger, adequately powered studies are required to confirm initial findings. The risk of bias present in many studies was unclear due to poor reporting and lack of clarification from study authors. Approximately half of the studies reported adequate allocation concealment, and in five of the included studies assessors were not blind to allocation. Thus, while there are a large number of randomised controlled trials, the evidence remains 'moderate', 'low' or 'very low' quality when rated using the GRADE system.

\section{Potential biases in the review process}

Despite a comprehensive search strategy it is possible that we did not identify some studiesin the search process, for example, studies where there is no published abstract in English. Whilst in the previous version of this review we contacted manufacturers of virtual reality equipment and searched conference proceedings, we opted not to do so in this update, as this method was not previously effective in eliciting original studies. However, this does mean that unpublished data may not have been identified. Furthermore, although we contacted all corresponding authors of included studies and sent a follow-up email to those that did not respond, few authors responded. This resulted in the study methodology of many trials being unclear and resulted in us being unable to include some data in the analyses. The process of two review authors independently reviewing abstracts and extracting data (with a third review author to moderate disagreements) enabled us to minimise bias. The search date of this review was April 2017. As this field is rapidly expanding there are likely to be more studies now eligible for inclusion.

\section{Agreements and disagreements with other studies or reviews}

Previous systematic reviews have argued that virtual reality appears promising (Cheok 2015; Corbetta 2015; Crosbie 2007; Li 2016; Lohse 2014; Moreira 2013; Saposnik 2011). This review is generally consistent with these reviews; however, due to the more recent and comprehensive search strategy we were able to identify a greater number of studies and conduct subgroup analyses. The various reviews have drawn different conclusions about the efficacy of virtual reality: most of the differences are due to different inclusion and exclusion criteria. For example, in this review we excluded studies where the interaction between the study participant and the virtual environment were mediated by the therapist rather than directly by the participant, such as when speed of movement through a virtual environment was controlled by the therapist during treadmill training. Other reviews did not make this distinction and included these types of studies. We were also careful to conduct separate analyses based on the treatment of the control group and the type and dose of therapy received.

In the previous version of this review, the main analysis examining effect on upper limb function included 12 studies and 397 participants and found that virtual reality intervention was more effective than conventional therapy (Laver 2015). There have been many studies published in the last couple of years and this updated version of the review included 22 studies with 1033 participants. The analysis for effect on upper limb function was not significant; 
this finding is a major change in the direction of results with practical implications for clinicians.

\section{AUTHORS' CONCLUSIONS}

\section{Implications for practice}

We found that virtual reality therapy may not be more effective than conventional therapy but there is low-quality evidence that virtual reality may be utilised to improve outcomes in the absence of other therapy interventions after stroke. We also found that virtual reality appears to be a safe intervention that is effective at improving arm function and activities of daily living (ADL) function following stroke. A greater improvement was seen at a higher dose but the association was not statistically significant. Gains made appear to be clinically significant with analyses showing reasonable effect sizes (that is, a moderate effect on upper limb function (standardised mean difference (SMD) 0.50, low-quality evidence) and a small to moderate effect on ADL function (SMD 0.44), moderate-quality evidence). However, at present, there is significant heterogeneity between studies. For example, there are only two studies that have examined the use of a virtual reality driving simulation program and thus it is unclear how effective virtual reality may be for driver rehabilitation after stroke. In addition, as virtual reality interventions may vary greatly (from inexpensive commercial gaming consoles to expensive customised programs), it is unclear which characteristics of the intervention are most important. Our analyses did not provide clear direction as to which virtual reality programs are superior to others.

The lack of adverse events, including motion sickness, nausea, headache, or pain suggests that these factors should not be of great concern to clinicians; however, this may vary depending on the characteristics of the person, the virtual reality hardware and software, and the task. Clinicians who currently have access to virtual reality programs should be reassured that their use as part of a comprehensive rehabilitation program appears reasonable, taking into account the patient's goals, abilities, and preferences.

\section{Implications for research}

This updated version of the review revealed that 35 new randomised controlled trials (RCTs) were published over approximately two years. Despite the inclusion of some higherquality studies, the new RCTs mostly mirror those included in the previous review. Researchers in this field are strongly encouraged to conduct larger, adequately powered trials that can provide more definitive results.

Researchers and manufacturers designing new virtual reality programs for rehabilitation purposes should include the use of pilot studies assessing usability and validity as part of the development process. This is an important part of the development process and should be conducted with the intended users of the program.

Our review included only RCTs, resulting in the exclusion of observational studies that showed improvements in real-world tasks based on virtual reality training. It is evident that the field is still developing and many studies are at feasibility and proof-ofconcept levels. In addition, it is challenging to design a controlled trial comparing virtual reality to real-world correlates. This is in part because virtual reality systems allow us to train in ways that are not possible in the real world. Future research needs to carefully examine what we control for when comparing real-world with virtual reality-based interventions and overcome, when possible, the challenge of making groups equivalent.

Ideally, studies should use common outcome measures. However, this is likely to be difficult due to the range of virtual reality interventions. Studies should measure whether effects are long lasting with outcome assessment more than three months after the end of the intervention. Researchers should also examine the impact of virtual reality on the person's motivation to participate in rehabilitation, engagement in therapy, and level of enjoyment.

Many of the studies included in this review did not report the number of participants screened against eligibility criteria. Future research trials should report these data as they provide useful information regarding the proportion of stroke survivors for whom virtual reality intervention may be appropriate.

The majority of studies to date have evaluated interventions that were designed to address motor impairments. There are few studies that include cognitive rehabilitation or studies that aim to make improvements at the levels of activity or participation. There is also currently insufficient evidence from RCTs to tell whether activity training in a virtual environment translates to activity performance in the real world.

\section{ACKNOWLEDGEMENTS}

We thank Brenda Thomas for her help with the search strategies, and Hazel Fraser, Joshua Cheyne, Valentina Assi, Peter Langhorne, Maree Hackett, Rachel Stockley, and Tam Watson for their editorial review and recommendations.

We also thank Abiodun Akinwuntan, Jacqueline Crosbie, Sarah Housman and David Reikensmeyer, David Jaffe, Sung You, David Man, Barbara Mazer, Anat Mirelman, Andrea Turolla and Lamberto Piron, Gustavo Saposnik, Enrique Sucar, Penny Standen, Min Cheol Chang, Nancy Byl, Paul Vershure, Joon-Ho Shin, Carla Zucconi, Pawel Kiper, Sandeep Subramanian, Mindy Levin, Le Li, Jen-Wen Hung, Donald Manlapaz, Andreia Silva, Kelly Bower, Christoph Hollenstein, and Lisa Sheehy, who generously provided additional details and analyses from their trials to assist us with the review. 


\section{R E F E R E N C E S}

\section{References to studies included in this review}

\section{Adie 2017 \{published data only\}}

Adie K, Schofield C, Berrow M, Wingham J, Humfryes J, Pritchard C, et al. Does the use of Nintendo Wii Sports improve arm function? Trial of Wii in stroke: a randomized controlled trial and economic analysis. Clinical Rehabilitation 2017;31(2):173-85.

\section{Akinwuntan 2005 \{published data only\}}

Akinwuntan A, Devos H, Verheyden G, Baten G, Kiekens C, Feys $\mathrm{H}$, et al. Retraining moderately impaired stroke survivors in driving-related visual attention skills. Topics in Stroke Rehabilitation 2010;17(5):328-36.

* Akinwuntan AE, De Weerdt W, Feys H, Pauwels J, Baten G, Arno $P$, et al. Effect of simulator training on driving after stroke. Neurology 2005;65(6):843-50.

Devos H, Akinwuntan AE, Nieuwboer A, Ringoot I, Van Berghen $\mathrm{K}$, Tant $\mathrm{M}$, et al. Effect of simulator training on fitness to drive after stroke: a 5-year follow up of a randomised controlled trial. Neurorehabilitation and Neural Repair 2010;24(9):843-50

Devos H, Akinwuntan AE, Nieuwboer A, Tant M, Truijen S, De Wit $L$, et al. Comparison of the effect of two driving retraining programs on on-road performance after stroke. Neurorehabilitation and Neural Repair 2009;23(7):699-705.

\section{Barcala 2013 \{published data only\}}

Barcala L, Grecco LAC, Colella F, Lucareli PRG, Salgado ASI, Oliveira CS. Visual biofeedback balance training using Wii Fit after stroke: a randomized controlled trial. Journal of Physical Therapy Science 2013;25(8):1027-32.

\section{Bower 2015 \{published data only\}}

Bower K, Louie J, Landesrocha Y, Seedy P, Gorelik A, Bernhardt J. Clinical feasibility of interactive motion-controlled games for stroke rehabilitation. Journal of Neuroengineering and Rehabilitation 2015;12:63.

\section{Byl 2013 \{published data only\}}

Byl N, Abrams G, Pitsch E, Fedulow I, Kim H, Simkins M, et al. Chronic stroke survivors achieve comparable outcomes following virtual task specific repetitive training guided by a wearable robotic orthosis (UL-EXO7) and actual task specific repetitive training guided by a physical therapist. Journal of Hand Therapy 2013;26(4):343-51.

\section{Cho 2012 \{published data only\}}

Cho K, Yu J, Jung J. Effects of virtual reality based rehabilitation on upper extremity function and visual perception in stroke patients: a randomized control trial. Journal of Physical Therapy Science 2012;24:1205-8.

\section{Chow 2013 \{published data only\}}

Chow TK, Chan CM, Tong JMC. Effectiveness of virtual reality in balance training in stroke rehabilitation: a pilot study. Cerebrovascular Diseases 2013;36:17-8.
Coupar 2012 \{published data only\}

Coupar F. Exploring Upper Limb Interventions After Stroke [PhD thesis]. Glasgow, UK: University of Glasgow, 2012.

\section{Crosbie 2008 \{published data only\}}

Crosbie J. Virtual Reality in the Rehabilitation of the Upper Limb Following Stroke [PhD Thesis]. UK: University of Ulster, 2008.

* Crosbie J, Lennon S, McGoldrick M, McNeil M, McDonough S. Virtual reality in the rehabilitation of the arm after hemiplegic stroke: a randomized controlled pilot study. Clinical Rehabilitation 2012;26(9):798-806.

\section{da Silva Cameirao 2011 \{published and unpublished data\}}

da Silva Cameirao M, Badia S, Duarte E, Verschure P. Virtual reality based rehabilitation speeds up functional recovery of the upper extremities after stroke: a randomized controlled pilot study in the acute phase of stroke using the Rehabilitation Gaming System. Restorative Neurology and Neuroscience 2011;29(5):287-98

\section{da Silva Ribeiro 2015 \{published data only\}}

da Fonseca EP, da Silva Ribeiro N, Pinto EB. Therapeutic effect of virtual reality on post-stroke patients: randomized clinical trial. Journal of Stroke and Cerebrovascular Diseases 2017;26(1):94-100.

* da Silva Ribeiro NM, Ferraz DD, Pedreira E, Pinheiro I, da Silva Pinto AC, Neto MG, et al. Virtual rehabilitation via Nintendo Wii and conventional physical therapy effectively treat poststroke hemiparetic patients. Topics in Stroke Rehabilitation 2015;22(4):299-305.

\section{Fan 2014 \{published data only\}}

Fan SC, Su FC, Chen SS, Hou WH, Sun JS, Chen KH, et al. Improved intrinsic motivation and muscle activation patterns in reaching task using virtual reality training for stroke rehabilitation: a pilot randomized control trial. Journal of Medical and Biological Engineering 2014;34(4):399-407.

\section{Galvao 2015 \{published data only\}}

Galvao MLC, Gouvea PM, Ocamato GN, Silva AT, dos Reis LM, Kosour C, et al. Virtual reality effect on upper limb motor function paretic in post stroke. Revista Neurociencias 2015;23(4):493-8.

\section{Givon 2016 \{published data only\}}

Givon N, Zeilig G, Weingarden H, Rand D. Video-games used in a group setting is feasible and effective to improve indicators of physical activity in individuals with chronic stroke: a randomized controlled trial. Clinical Rehabilitation 2016;30(4):383-92.

\section{Han 2013 \{published data only\}}

Han JY. The effect of virtual reality program on stroke patients with impaired standing balance. PM \& R: the Journal of Injury, Function, and Rehabilitation 2013;5(9 Suppl 1):S237-8. 
Housman 2009 \{published data only\}

Housman SJ, Scott KM, Reikensmeyer DJ. A randomized controlled trial of gravity-supported, computer-enhanced arm exercise for individuals with severe hemiparesis. Neurorehabilitation and Neural Repair 2009;23(5):505-14.

Hung 2014 \{published and unpublished data\}

Hung JW, Chou CX, Hsieh YW, Wu WC, Yu MY, Chen PC, et al. Randomized comparison trial of balance training by using exergaming and conventional weight-shift therapy in patients with chronic stroke. Archives of Physical Medicine and Rehabilitation 2014;95(9):1629-37.

\section{Jaffe 2004 \{published data only\}}

Jaffe DL, Brown DA, Pierson-Carey CD, Buckley EL, Lew HL. Stepping over obstacles to improve walking in individuals with poststroke hemiplegia. Journal of Rehabilitation Research and Development 2004;41(3A):283-92.

\section{Jang 2005 \{published data only\}}

Jang SH, You SH, Hallett M, Cho YW, Park CM, Cho SH, et al. Cortical reorganization and associated functional motor recovery after virtual reality in patients with chronic stroke: an experimenter-blind preliminary study. Archives of Physical Medicine and Rehabilitation 2005;86:2218-23.

Jannink 2008 \{published data only\} Jannink MJA, Erren-Wolters CV, De Kort AC, Van der Kooij H. An electric scooter simulation program for training the driving skills of stroke patients with mobility problems: a pilot study. Cyberpsychology and Behavior 2008;11(6):751-4.

\section{Jung 2012 \{published data only\}}

Jung J, Yu J, Kang H. Effects of virtual reality treadmill training on balance and balance self-efficacy in stroke patients with a history of falling. Journal of Physical Therapy Science 2012;24(11):1133-6.

\section{Kang 2009 \{published data only\}}

Kang SH, Kim DK, Seo KM, Choi KN, Yoo JY, Sung SY, et al. A computerized visual perception rehabilitation programme with interactive computer interface using motion tracking technology - a randomized controlled, single-blinded, pilot clinical trial study. Clinical Rehabilitation 2009;23:434-44.

\section{Kim 2009 \{published data only\}}

Kim JH, Jang SH, Kim CS, Jung JH, You JH. Use of virtual reality to enhance balance and ambulation in chronic stroke: a double-blind, randomized controlled study. American Journal of Physical Medicine and Rehabilitation 2009;88:693-701.

\section{Kim 2011a \{published data only\}}

Kim BR, Chun MH, Kim LS, Park JY. Effect of virtual reality on cognition in stroke patients. Annals of Rehabilitation Medicine 2011;35:450-9.

\section{Kim 2011b \{published data only\}}

Kim YM, Chun MH, Yun GJ, Song YJ, Young HE. The effect of virtual reality training on unilateral spatial neglect in stroke patients. Annals of Rehabilitation Medicine 2011;35:309-15.

\section{Kim 2012a \{published data only\}}

Kim E, Kang J, Park J, Jung B. Clinical feasibility of interactive commercial Nintendo gaming for chronic stroke rehabilitation. Journal of Physical Therapy Science 2012;24(9):901-3.

\section{Kiper 2011 \{published and unpublished data\}}

Kiper P, Piron L, Turolla A, Stozek J, Tonin P. The effectiveness of reinforced feedback in virtual environment in the first 12 months after stroke. Neurologia i Neurochirurgia Polska 2011;45(5):436-44.

\section{Klamroth-Marganska 2014 \{published data only\}}

Klamroth-Marganska V, Blanco J, Campen K, Curt A, Dietz V, Ettlin T, et al. Three-dimensional, task-specific robot therapy of the arm after stroke: a multicentre, parallel-group randomised trial. Lancet Neurology 2014;13(2):159-66.

\section{Ko 2015 \{published data only\}}

Ko YJ, Ha HG, Bae YH, Lee WH. Effect of space balance 3D training using visual feedback on balance and mobility in acute stroke patients. Journal of Physical Therapy Science 2015;27(5):1593-6.

\section{Kong 2014 \{published data only\}}

Kong KH. Efficacy of a virtual reality commercial gaming device in upper limb recovery after stroke: a randomized, controlled study. Topics in Stroke Rehabilitation 2016;23(5):333-40.

* Kong KH. Efficacy of computer gaming in upper limb recovery after stroke: a randomized, controlled study. Cerebrovascular Diseases 2014;38:109.

Loh YJ. Effectiveness of Nintendo Wii gaming in facilitating upper limb recovery after stroke: a randomised, controlled study. 5th Singapore Health and Biomedical Congress 2014. 2014; Vol. 43 (Suppl), issue 9:S147.

\section{Kwon 2012 \{published data only\}}

Kwon J, Park M, Yoon I, Park S. Effects of virtual reality on upper extremity function and activities of daily living performance in acute stroke: a double-blind randomized clinical trial. Neurorehabilitation 2012;31(4):379-85.

\section{Lam 2006 \{published data only\}}

Lam YS, Man DWK, Tam SF, Weiss PL. Virtual reality training for stroke rehabilitation. Neurorehabilitation 2006;21:245-53.

\section{Lee 2013 \{published data only\}}

Lee SW, Shin DC, Song CH. The effects of visual feedback training on sitting balance ability and visual perception of patients with chronic stroke. Journal of Physical Therapy Science 2013;25(5):635-9.

\section{Lee 2014a \{published data only\}}

Lee CH, Kim Y, Lee BH. Augmented reality-based postural control training improves gait function in patients with stroke: randomized controlled trial. Hong Kong Physiotherapy Journal 2014;32(2):51-7. 


\section{Lee 2015a \{published data only\}}

Lee HY, Kim YL, Lee SM. Effects of virtual reality based training and task oriented training on balance performance in stroke patients. Journal of Physical Therapy Science 2015;27(6):1883-8.

\section{Lee 2015b \{published data only\}}

Lee S, Kim Y, Lee B. Effect of virtual reality-based bilateral upper extremity training on upper extremity function after stroke: a randomized controlled clinical trial. Occupational Therapy International 2016;23(4):357-68.

* Lee SH, Kim YM, Lee BH. Effects of virtual reality-based bilateral upper-extremity training on brain activity in post-stroke patients. Journal of Physical Therapy Science 2015;27(7):2285-7.

\section{Levin 2012 \{published data only\}}

Levin MF, Snir O, Liebermann DG, Weingarden H, Weiss PL. Virtual reality versus conventional treatment of reaching ability in chronic stroke: clinical feasibility study. Neurology and Therapy 2012;1(1):1-15.

\section{Linder 2015 \{published data only\}}

Linder SM, Rosenfeldt AB, Bay RC, Sahu K, Wolf SL, Alberts JL. Improving quality of life and depression after stroke through telerehabilitation. American Journal of Occupational Therapy 2015;69:1-10.

\section{Llorens 2015 \{published data only\}}

Llorens R, Gil-Gomez JA, Alcaniz M, Colomer C, Noe E. Improvement in balance using a virtual-reality based stepping exercise: a randomized controlled trial involving individuals with chronic stroke. Clinical Rehabilitation 2015;29(3):261-8.

\section{Low 2012 \{published data only\}}

Low AY, Ng YS, Chan Y, Tan DML, Bok CW, Fook Chong SMC, et al. Effect of virtual reality rehabilitation as an adjunct to conventional therapy in people with sub-acute stroke: a randomised controlled pilot trial. Proceedings of Singapore Healthcare 2012;21:S357.

\section{Manlapaz 2010 \{published and unpublished data\}}

Manlapaz D, Silverio A, Navarro JA, Regacho M, Ang M, Canaberal $C$, et al. Effectiveness of using Nintendo Wii in rehabilitation of chronic stroke patients with upper limb hemiparesis. Physiotherapy 2011;97:eS746-eS747.

* Manlapaz D, Silverio L, Navarro J, Ang M, Regacho M, Canaberal $\mathrm{K}$, et al. Effectiveness of using Nintendo Wii in rehabilitation of chronic stroke patients with upper limb hemiparesis. Hong Kong Physiotherapy Journal 2010;28:25.

\section{Mao 2015 \{published and unpublished data\}}

Mao Y, Chen P, Li L, Li L, Huang D. Changes of pelvis control with subacute stroke: a comparison of body-weight support treadmill training coupled virtual reality system and overground training. Technology and Health Care 2015;23:S355S364.
Matsuo 2013 \{published data only\}

Matsuo A, Takahara T, Hiraoka N, Hiyamizu M, Maeoka H, Okada Y. Effectiveness of interactive video gaming system in stroke rehabilitation. Cerebrovascular Diseases 2013;35(Suppl 3):779.

\section{Mazer 2005 \{published and unpublished data\}}

Mazer B, Gelinas I, Duquette J, Vanier M, Rainville C, Chilingaryan G. A randomized clinical trial to determine effectiveness of driving simulator retraining on the driving performance of clients with neurological impairment. British Journal of Occupational Therapy 2015;78(6):369-76.

* Mazer B, Gelinas I, Vanier M, Duquette J, Rainville C, Hanley J. Effectiveness of retraining using a driving simulator on the driving performance of clients with a neurological impairment. Neurorehabilitation and Neural Repair 2005;19:383.

\section{McNulty 2015 \{published data only\}}

* McNulty PA, Thompson-Butel AG, Faux S, Lin G, Katrak P, Harris LR, et al. The efficacy of Wii-based movement therapy for upper limb rehabilitation in the chronic poststroke period: a randomized controlled trial. International Journal of Stroke 2015;10:1253-60.

Trinh T, Scheuer SE, Thompson-Butel AG, Shiner CT, McNulty PA. Cardiovascular fitness is improved post-stroke with upper limb Wii-based movement therapy but not dose matched constraint therapy. Topics in Stroke Rehabilitation 2016;23(3):208-16.

Mirelman 2008 \{published and unpublished data\}

* Mirelman A, Bonato P, Deutsch JE. Effects of training with a robot-virtual reality system compared with a robot alone on the gait of individuals after stroke. Stroke 2008;40:169-74.

Mirelman A, Pattriti B, Bonato P, Deutsch J. Effects of virtual reality training on gait biomechanics of individuals post-stroke. Gait and Posture 2010;31(4):433-7.

\section{Morone 2014 \{published data only\}}

Morone G, Tramontano M, Iosa M, Shofany J, lemma A, Musicco $M$, et al. The efficacy of balance training with video game-based therapy in subacute stroke patients: a randomized controlled trial. BioMed Research International 2014;DOI: 10.1155/2014/580861:1-6.

\section{Nara 2015 \{published data only\}}

Nara K, Yuhyun P, Byoung-Hee L. Effects of community-based virtual reality treadmill training on balance ability in patients with chronic stroke. Journal of Physical Therapy Science 2015;27(3):655-8.

\section{Piron 2007 \{published data only\}}

Piron L, Tombolini P, Turolla A, Zucconi C, Agostini M, Dam M, et al. Reinforced feedback in virtual environment facilitates the arm motor recovery in patients after a recent stroke. International Workshop of Virtual Rehabilitation. 2007:121-3.

\section{Piron 2009 \{published data only\}}

Piron L, Turolla A, Agostini M, Zucconi C, Cortese F, Zampolini M, et al. Exercises for paretic upper limb after stroke: a combined 
virtual-reality and telemedicine approach. Journal of Rehabilitation Medicine 2009;41:1016-20.

\section{Piron 2010 \{published data only\}}

Piron L, Turolla A, Agostini M, Zucconi C, Ventura L, Tonin P, et al. Motor learning principles for rehabilitation: a pilot randomized controlled study in poststroke patients. Neurorehabilitation and Neural Repair 2010;24(6):501-8.

\section{Prange 2015 \{published data only\}}

Prange GB, Kottink Al, Buurke JH, Eckhardt MM, KeulenRouweler BJ, Ribbers GM, et al. The effect of arm support combined with rehabilitation games on upper-extremity function in subacute stroke: a randomized controlled trial. Neurorehabilitation and Neural Repair 2015;29(2):174-82.

\section{Rajaratnam 2013 \{published data only\}}

Rajaratnam BS, Gui Kaien J, Lee Jialin K, Sweesin K, Sim Fenru S, Enting L, et al. Does the inclusion of virtual reality games within conventional rehabilitation enhance balance retraining after a recent episode of stroke?. Rehabilitation Research and Practice 2013; Vol. 2013:649561.

\section{Reinkensmeyer 2012 \{published data only\}}

Reinkensmeyer DJ, Wolbrecht ET, Chan V, Chou C, Cramer SC, Bobrow JE. Comparison of three dimensional, assist-asneeded robotic arm/hand movement training provided with Pneu-WREX to conventional tabletop therapy after chronic stroke. American Journal of Physical and Medical Rehabilitation 2012;91(11):S232-S241.

\section{Saposnik 2010 \{published and unpublished data\}}

Saposnik G, Teasell R, Mamdani M, Hall J, Mcllroy W, Cheung D, Stroke Outcome Research Canada (SORCan) Working Group. Effectiveness of virtual reality using Wii gaming technology in stroke rehabilitation: a pilot randomized clinical trial and proof of principle. Stroke 2010;41:1477-84.

\section{Saposnik 2016 \{published data only\}}

Saposnik G, Cohen LG, Mamdani M, Pooyania S, Ploughman M, Cheung D, et al. Efficacy and safety of non-immersive virtual reality exercising in stroke rehabilitation (EVREST): a randomised, multicentre, single blind, controlled trial. Lancet Neurology 2016;15(10):1019-27.

\section{Shin 2014 \{published data only\}}

Shin JH, Ryu H, Jang SH. A task-specific interactive gamebased virtual reality rehabilitation system for patients with stroke: a usability test and two clinical experiments. Journal of NeuroEngineering and Rehabilitation 2014;11:32.

\section{Shin 2015 \{published data only\}}

Shin JH, Kim MY, Lee JY, Jeon YJ, Kim S, Lee S, et al. Effects of virtual reality-based rehabilitation on distal upper extremity function and health related quality of life: a single blinded, randomized controlled trial. Journal of Neuroengineering and Rehabilitation 2016;13(17):doi:10.1186/s12984-016-0125-x.

* Shin JH, Park SB, Jang SH. Effects of game-based virtual reality on health-related quality of life in chronic stroke patients: a randomized, controlled study. Computers in Biology and Medicine 2015;63:92-8.

Sin 2013 \{published data only\}

Sin $\mathrm{HH}$, Lee GC. Additional virtual reality training using Xbox Kinect in stroke survivors with hemiplegia. American Journal of Physical Medicine and Rehabilitation 2013;92:871-80.

Song 2015 \{published data only\}

Song GB, Park EC. Effect of virtual reality games on stroke patients' balance, gait, depression, and interpersonal relationships. Journal of Physical Therapy Science 2015;27(7):2057-60.

\section{Standen 2011 \{unpublished data only\}}

* Standen P, Brown D, Battersby S, Walker M, Connell L, Richardson A, et al. A study to evaluate a low cost virtual reality system for home based rehabilitation of the upper limb following stroke. International Journal on Disability and Human Development 2011;10(4):337-41.

Standen PJ, Threapleton K, Richardson A, Connell L, Brown DJ, Battersby $S$, et al. A low cost virtual reality system for home based rehabilitation of the arm following stroke: a randomised controlled feasibility trial. Clinical Rehabilitation 2017;31(3):340-50.

\section{Subramanian 2013 \{published and unpublished data\}}

Subramanian S, Lourenco C, Chilingaryan G, Sveistrup H, Levin M. Arm motor recovery using a virtual reality intervention in chronic stroke: randomized control trial. Neurorehabilitation and Neural Repair 2013;27(1):13-23.

\section{Sucar 2009 \{published data only\}}

Sucar LE, Leder R, Hernandez J, Sanchez I, Azcarate G. Clinical evaluation of a low-cost alternative for stroke rehabilitation. IEEE 11th International Conference on Rehabilitation Robotics. 2009:863-6

\section{Thielbar 2014 \{published data only\}}

Thielbar KO, Lord TJ, Fischer HC, Lazzaro EC, Barth KC, Stoykov ME, et al. Training finger individuation with a mechatronic-virtual reality system leads to improved fine motor control post-stroke. Journal of NeuroEngineering and Rehabilitation 2014;11(690):171.

\section{Ucar 2014 \{published data only\}}

Ucar D, Paker N, Bugdayci D. Lokomat: a therapeutic chance for patients with chronic hemiplegia. NeuroRehabilitation 2014;34(3):447-53.

\section{Xiang 2014 \{published data only\}}

Xiang X, Yu-rong M, Jiang-li Z, Li L, Guang-qing X, Dong-feng H. Virtual reality enhanced body weight supported treadmill training improved lower limb motor function in patients with cerebral infarction. Chinese Journal of Tissue Engineering Research 2014;18(7):1143-8.

Yang 2008 \{published data only\}

Yang YR, Tsai MP, Chuang TY, Sung WH, Wang RY. Virtual realitybased training improves community ambulation in individuals 
with stroke: a randomized controlled trial. Gait and Posture 2008;28:201-6.

\section{Yang 2011 \{published data only\}}

Yang S, Hwang WH, Tsai YC, Liu FK, Hsieh LF, Chern JS. Improving balance skills in patients who had stroke through virtual reality treadmill training. American Journal of Physical Medicine and Rehabilitation 2011;90:969-78.

\section{Yavuzer 2008 \{published data only\}}

Yavuzer G, Senel A, Atay MBG, Stam HJ. 'Playstation EyeToy games' improve upper extremity-related motor functioning in subacute stroke: a randomized controlled clinical trial. European Journal of Physical and Rehabilitation Medicine 2008;44:237-44.

\section{Yin 2014 \{published data only\}}

Yin CW, Sien NY, Ying LA, Chung SFM, Leng DTM. Virtual reality for upper extremity rehabilitation in early stroke: a pilot randomized controlled trial. Clinical Rehabilitation 2014;28(11):1107-14.

\section{You 2005 \{published data only\}}

You SH, Jang SH, Kim YH, Hallett M, Ahn SH, Kwon YH, et al. Virtual reality-induced cortical reorganization and associated locomotor recovery in chronic stroke: an experimenter-blind randomized study. Stroke 2005;36:1166-71.

\section{Zucconi 2012 \{published and unpublished data\}}

Zucconi C, Valt V, Agostini M, Turolla A, Tonin P, Piron L. Assessment of a virtual teacher feedback for the recovery of the upper limb after stroke. Neurorehabilitation and Neural Repair 2012;26(4):407.

\section{References to studies excluded from this review}

\section{Abdollahi 2014 \{published data only\}}

Abdollahi F, Case Lazarro ED, Listenberger M, Kenyon RV, Kovic M, Bogey RA. Error augmentation enhancing arm recovery in individuals with chronic stroke: randomized crossover design. Neurorehabilitation and Neural Repair 2014;28(2):120-8.

\section{Bower 2014 \{published data only\}}

Bower KJ, Clark RA, McGinley JL, Martin CL, Miller KJ. Clinical feasibility of the Nintendo WiiTM for balance training poststroke: a phase II randomized controlled trial in an inpatient setting. Clinical Rehabilitation 2014;28(9):912-23.

\section{Braun 2016 \{published data only\}}

Braun T, Marks D, Thiel C, Zietz D, Zutter D, Gruneberg C. Effects of additional, dynamic supported standing practice on functional recovery in patients with sub-acute stroke: a randomized pilot and feasibility trial. Clinical Rehabilitation 2016;30(4):374-82.

\section{Broeren 2008 \{published data only\}}

Broeren J, Claesson L, Goude D, Rydmark M, Sunnerhagen K. Virtual rehabilitation in an activity centre for communitydwelling persons with stroke. Cerebrovascular Diseases 2008;26:289-96.

\section{Cameirao 2012 \{published data only\}}

Cameirao M, Badia S, Duarte E, Frisoli A, Verschure P. The combined impact of virtual reality neurorehabilitation and its interfaces on upper extremity functional recovery in patients with chronic stroke. Stroke 2012;43(10):2720-8.

Cho 2013 \{published data only\}

Cho $\mathrm{KH}$, Lee $\mathrm{WH}$. Virtual walking training program using a realworld video recording for patients with chronic stroke. American Journal of Physical Medicine and Rehabilitation 2013;92:371-84.

\section{Cho 2015 \{published data only\}}

Cho KH, Kim MK, Lee HJ, Lee WH. Virtual reality training with cognitive load improves walking function in chronic stroke patients. Tohoku Journal of Experimental Medicine 2015;236(4):273-80.

\section{Chortis 2008 \{published data only\}}

Chortis A, Standen PJ, Walker M. Virtual reality system for upper extremity rehabilitation of chronic stroke patients living in the community. International Conference on Disability, Virtual Reality \& Associated Technologies (ICDVRAT). 2008:221-8.

\section{Cikaljo 2012 \{published data only\}}

Cikaljo I, Rudolf M, Goljar N, Burger H, Matjacic Z. Telerehabilitation using virtual reality task can improve balance in patients with stroke. Disability and Rehabilitation 2012;34(1):13-8.

\section{Der-Yeghiaian 2009 \{published data only\}}

Der-Yeghiaian L, Sharp K, See J, Abidi N, Mai K, Cramer S. Robotic therapy after stroke and the influence of baseline motor status. International Stroke Conference Poster Presentations. 2009:e169.

\section{Edmans 2009 \{published data only\}}

Edmans J, Gladman J, Hilton D, Walker M, Sunderland A, Cobb S, et al. Clinical evaluation of a non-immersive virtual environment in stroke rehabilitation. Clinical Rehabilitation 2009;23:106-16.

\section{Fischer 2007 \{published data only\}}

Fischer HC, Stubblefield K, Kline T, Luo X, Kenyon RV, Kamper DG. Hand rehabilitation following stroke: a pilot study of assisted finger extension training in a virtual environment. Topics in Stroke Rehabilitation 2007;14(1):1-12.

\section{Fritz 2013 \{published data only\}}

Fritz S, Peters D, Merlo A, Donley J. Active video-gaming effects on balance and mobility in individuals with chronic stroke: a randomized controlled trial. Topics in Stroke Rehabilitation 2013;20(3):218-25.

\section{Gnajaraj 2007 \{published data only\}}

Gnajaraj J, Chowdry H, Kumar S. Influence of virtual reality environment on the recovery after stroke. Archives of Physical Medicine and Rehabilitation 2007;88:E3.

\section{Hollenstein 2011 \{published data only\}}

Hollenstein C, Cabri J. Supplementary therapy with computerassisted training system compared to ergotherapeutic arm 
group therapy [Zusatztherapie mit computerunterstütztem Trainingssystem im Vergleich zu ergotherapeutischer Armgruppentherapie]. NeuroRehabilitation 2011;3.01:40-2.

\section{In 2012 \{published data only\}}

In T, Jung K, Lee S, Song C. Virtual reality reflection therapy improves motor recovery and motor function in the upper extremities of people with chronic stroke. Journal of Physical Therapy Science 2012;24(4):339-43.

\section{Katz 2005 \{published data only\}}

Katz N, Ring H, Naveh Y, Kizony R, Feintuch U, Weiss PL. Interactive virtual environment training for safe street crossing of right hemisphere stroke patients with unilateral spatial neglect. Disability and Rehabilitation 2005;27(20):1235-43.

\section{Kim 2012b \{published data only\}}

Kim IC, Lee BH. Effects of augmented reality with functional electric stimulation on muscle strength, balance and gait of stroke patients. Journal of Physical Therapy Science 2012;24(8):755-62.

\section{Kim 2015a \{published data only\}}

Kim HS, Choi WJ, Lee K, Song CH. Virtual dual-task treadmill training using video recording for gait of chronic stroke survivors: a randomized controlled trial. Journal of Physical Therapy Science 2015;27(12):3693-7.

\section{Kim 2015b \{published data only\}}

Kim N, Park Y, Lee BH. Effects of community-based virtual reality treadmill training on balance ability in patients with chronic stroke. Journal of Physical Therapy Science 2015;27(3):655-8.

\section{Krebs 2008 \{published data only\}}

Krebs HI, Mernoff S, Fasoli SE, Hughes R, Stein J, Hogan N. A comparison of functional and impairment-based robotic training in severe to moderate chronic stroke: a pilot study. NeuroRehabilitation 2008;23:81-7.

\section{Lee 2014b \{published data only\}}

Lee $D$, Lee $M$, Lee $K$, Song C. Asymmetric training using virtual reality reflection equipment and the enhancement of upper limb function in stroke patients: a randomized controlled trial. Journal of Stroke and Cerebrovascular Diseases 2014;23(6):1319-26.

\section{Llorens 2014 \{published data only\}}

Llorens R, Albiol S, Gil-Gomez J, Alcaniz M, Colomer C, Noe E. Balance rehabilitation using custom-made Wii Balance Board exercises: clinical effectiveness and maintenance of gains in an acquired brain injury population. International Journal on Disability and Human Development 2014;13(3):327-332.

\section{Masiero 2014 \{published data only\}}

Masiero S, Armani M, Ferlini G, Rosati G, Rossi A. Randomized trial of a robotic assistive device for the upper extremity during early inpatient stroke rehabilitation. Neurorehabilitation and Neural Repair 2014;28(4):377-86.

\section{McEwen 2014 \{published data only\}}

McEwen D, Taillon-Hobson A, Bilodeau M, Sveistrup $H$, Finestone $\mathrm{H}$. Virtual reality exercise improves mobility after stroke: an inpatient randomized controlled trial. Stroke 2014; Vol. 45, issue 6:1853-1855.

\section{Rand 2014 \{published data only\}}

Rand D, Givon N, Weingarden H, Nota A, Zeilig G. Eliciting upper extremity purposeful movements using video games: a comparison with traditional therapy for stroke rehabilitation. Neurorehabilitation and Neural Repair 2014;28(8):733-9.

Rutz-LaPitz 2011 \{published data only\}

Rutz-LaPitz L, Hollenstein C, Baumann Y, Kaufeler R, Gosoniu N. Effectiveness of armeo versus task-oriented arm group as augmentation to upper extremity conventional therapy in acute rehabilitation post stroke. Physiotherapy 2011;97:eS1072-3.

\section{Shin 2010 \{published data only\}}

Shin WS, Lee DY, Lee SW. The effects of rehabilitation exercise using a home video game (PS2) on gait ability of chronic stroke patients. Journal of the Korea Academia-Industrial Cooperation Society 2010;11(1):368-74.

\section{Song 2010 \{published data only\}}

Song $\mathrm{CH}$, Seo SM, Lee GC. Video game-based exercise for upper extremity function rehabilitation of chronic stroke patients: results from a randomized, controlled, single-blind trial. International Journal of Stroke 2010;5:304.

\section{Turolla 2013 \{published data only\}}

Turolla A, Dam M, Ventura L, Tonin P, Agostini M, Zucconi C. Virtual reality for the rehabilitation of the upper limb motor function after stroke: a prospective controlled trial. Journal of NeuroEngineering and Rehabilitation 2013;10(85):doi: 10.1186/1743-0003-10-85.

\section{Viana 2014 \{published data only\}}

Viana RT, Laurentino GE, Souza RJ, Fonseca JB, Silva Filho EM, Dias SN. Effects of the addition of transcranial direct current stimulation to virtual reality therapy after stroke: a pilot randomized controlled trial. Neurorehabilitation 2014;34:437-46.

\section{Wolf 2015 \{published data only\}}

Wolf S, Sahu K, Bay C, Buchanan S, Reiss A, Linder S, et al. The HAAPI (Home Arm Assistance Progression Initiative) Trial. Neurorehabilitation \& Neural Repair 2015;29(10):958-68.

\section{Yom 2015 \{published data only\}}

Yom C, Cho HY, Lee B. Effects of virtual reality-based ankle exercise on the dynamic balance, muscle tone, and gait of stroke patients. Journal of Physical Therapy Science 2015;27(3):845-9.

\section{Yoo 2015 \{published data only\}}

Yoo C, Yong M, Chung J, Yang Y. Effect of computerized cognitive rehabilitation program on cognitive function and activities of living in stroke patients. Journal of Physical Therapy Science 2015;27(8):2487-9 


\section{References to studies awaiting assessment}

Almeida 2014 \{published data only\}

* Almeida J, Castro P, Dos Santoa Moreira C, Battistella LR. Development of a protocol for treatment of post stroke patients with virtual reality: preliminary results. $P M \& R$ : the Journal of Injury, Function, and Rehabilitation 2014;6(8 Suppl 2):S110.

Do Amaral Santos PL, Castro PCG, Dos Santos Moreira C, Battistella LR. Retaining the effects of virtual reality therapy on posture control of patients with stroke: preliminary results. $P M$ $\& R$ : the Journal of Injury, Function, and Rehabilitation 2014;6(8 Suppl 2):S110.

\section{Connor 2016 \{published data only\}}

Connor D, Stockley R, Moss S, Allsop L, Edge W. Using virtual reality for upper limb recovery post stroke: a pilot study. Cerebrovascular Diseases 2016;41:49.

\section{de Paula Oliveira 2015 \{published data only\}}

Oliveira TDP, Miranda CS, Gouvea J, Perez DB, Marques AP, Piemonte MEP. Improvement of balance and gait in patients with stroke after training based on Nintendo Wii fitTM games: randomized controlled trial. Physiotherapy 2015;101:eS1207.

* de Paula Oliveira T, Miranda CS, De Gouva JXM, Perez DB, Marques AP, Piemonte MEP. Balance training in virtual reality in patients with chronic sequels of stroke: effects on ICF domains, preliminary data. 3rd Workshop on ICTs for improving Patients Rehabilitation Research Techniques, REHAB 2015, 1-2 October 2015. 2015

\section{Faria 2016 \{published data only\}}

Faria AL, Andrade A, Soares L, Badia SB. Benefits of virtual reality based cognitive rehabilitation through simulated activities of daily living: a randomized controlled trial with stroke patients. Journal of NeuroEngineering and Rehabilitation 2016;13(1):1-12.

\section{In 2016 \{published data only\}}

In T, Lee K, Song C. Virtual reality reflection therapy improves balance and gait in patients with chronic stroke: randomized controlled trials. Medical Science Monitor 2016;22:4046-53.

\section{Lee 2015c \{published data only\}}

Lee HJ, Kim MK, Lee KB, Lee WH. The effects of treadmill training using real-walk simulation in stroke patients. Physiotherapy 2015;May:eS846.

\section{Lee 2016a \{published data only\}}

Lee M, Son J, Kim J, Pyun SB, Eun SD, Yoon B. Comparison of individualized virtual reality- and group-based rehabilitation in older adults with chronic stroke in community settings: a pilot randomized controlled trial. European Journal of Integrative Medicine 2016;8(5):738-46.

\section{Lee 2016b \{published data only\}}

Lee MM, Shin DC, Song CH. Canoe game-based virtual reality training to improve trunk postural stability, balance, and upper limb motor function in subacute stroke patients: a randomized controlled pilot study. Journal of Physical Therapy Science 2016;28(7):2019-24.

\section{Lin 2015 \{published data only\}}

Lin CH, Chou LW, Luo HJ, Tsai PY, Lieu FK, Chiang AL, et al. Effects of computer-aided interlimb force coupling training on paretic hand and arm motor control following chronic stroke: a randomized controlled trial. PLoS ONE 2015; Vol. 10, issue 7.

\section{Marshall 2016 \{published data only\}}

Marshall J, Booth T, Devane N, Galliers J, Greenwood H, Hilari K, et al. Evaluating the benefits of aphasia intervention delivered in virtual reality: results of a quasi-randomised study. PLoS ONE 2016; Vol. DOI: 10.1371/journal.pone.0160381.

Nijenhuis 2017 \{published data only\}

Nijenhuis SM, Prange-Lasonder GB, Stienen AHA, Rietman JS, Buurke $\mathrm{JH}$. Effects of training with a passive hand orthosis and games at home in chronic stroke: a pilot randomised controlled trial. Clinical Rehabilitation 2017;31(2):207-16.

\section{Simsek 2016 \{published data only\}}

Simsek T, Cekok K. The effects of Nintendo WiiTM-based balance and upper extremity training on activities of daily living and quality of life in patients with sub-acute stroke: a randomized controlled study. International Journal of Neuroscience 2016;126(12):1061-70.

\section{Turkbey 2017 \{published data only\}}

Turkbey T, Kutlay S, Gok H. Clinical feasibility of Xbox Kinect training for stroke rehabilitation: a single blind randomized controlled pilot study. Journal of Rehabilitation Medicine 2017;49(1):22-9.

\section{Zondervan 2016 \{published data only\}}

Zondervan D, Friedman N, Chang E, Zhao X, Augburger R, Reinkensmeyer $\mathrm{D}$, et al. Home-based hand rehabilitation after chronic stroke: randomized, controlled single-blind trial comparing the music glove with a conventional exercise program. Journal of Rehabilitation Research and Development 2016;53(4):457-72.

\section{References to ongoing studies}

\section{ACTRN12614000427673 \{published data only\}}

Bird ML, Cannell J, Callisaya ML, Moles E, Rathjen A, Lane K, et al. "FIND Technology": investigating the feasibility, efficacy and safety of controller-free interactive digital rehabilitation technology in an inpatient stroke population: study protocol for a randomized controlled trial. Trials 2016;17(1):203.

Deutsch 2010 \{published data only\}

Deutsch J. Interactive video gaming compared to optimal standard of care to improve balance and mobility. Personal communication 2010.

\section{Duff 2013 \{published data only\}}

Duff A, Nirme J, Rubio B, Duarte E, Cuxart A, Rodriguez S, et al. The optimal dosage of the rehabilitation gaming system: the longer impact of a longer period of virtual reality based and 
standard occupational training on upper limb recovery in the acute phase of stroke. Cerebrovascular Diseases 2013;35:146.

\section{Dunsky 2014 \{published data only\}}

Dunsky AD, Hutzler YH, Fishbein PF. Dual task training using virtual reality: influence on walking and balance in individuals post-stroke. European Geriatric Medicine 2014;5:S165.

\section{Kairy 2015 \{published data only\}}

Kairy D, Poissant L, Higgins J, Hernandez A, Archambault PS, Norouzi-Gheidari N. Using a virtual reality gaming system to supplement upper extremity rehabilitation post stroke. Archives of Physical Medicine and Rehabilitation 2015;96:e17.

\section{Kairy 2016 \{published data only\}}

Kairy D, Veras M, Archambault P, Hernandez A, Higgins J, Levin $M$, et al. Maximizing post-stroke upper limb rehabilitation using a novel telerehabilitation interactive virtual reality system in the patient's home: study protocol of a randomized clinical trial. Contemporary Clinical Trials 2016;47:49-53.

\section{Karatas 2014 \{published data only\}}

Karatas GK, Karasu AU, Balevi E. Wii-based balance rehabilitation is effective in stroke: a randomized controlled study. Neurorehabilitation and Neural Repair 2012;26:767.

\section{Kiper 2014 \{published data only\}}

Kiper P, Agostini M, Luque-Moreno C, Tonin P, Turolla A. Reinforced feedback in virtual environment for rehabilitation of upper extremity dysfunction after stroke: preliminary data from a randomized controlled trial. BioMed Research International 2014.

\section{Kizony 2013 \{published data only\}}

Kizony R, Weiss PL, Feldman Y, Shani M, Elion O, Kizony R, et al. Evaluation of a tele-health system for upper extremity stroke rehabilitation. 2013 10th International Conference on Virtual Rehabilitation, ICVR 2013, 26-29 August 2013. 2013.

\section{NCT01365858 \{published and unpublished data\}}

NCT01365858. Virtual action planning in stroke: a control rehabilitation study. clinicaltrials.gov/ct2/show/NCT01365858 (accessed December 2013). [NCT01365858]

\section{NCT01806883 \{published data only\}}

Bensmail B. Evaluation of the Effects of Rehabilitation Using the "Wii" on Upper Limb Kinematics in Chronic Stroke Patients. clinicaltrials.gov 2013.

\section{NCT02013999 \{published data only\}}

NCT02013999. The development of upper extremity rehabilitation program using virtual reality for the stroke patients. clinicaltrials.gov/ct2/show/NCT02013999 (accessed December 2013). [NCT02013999]

\section{NCT02079103 \{published data only\}}

Brunner I, Skouen J, Hofstad H, Strand L, Becker F, Sanders AM, et al. Virtual reality training for upper extremity in subacute stroke (VIRTUES): study protocol for a randomized controlled multicenter trial. BMC Neurology 2014; Vol. 14, issue 1.

\section{NCT02553993 \{published data only\}}

Hung, JW. Comparing the Cognitive Effects of Two Exergame Training and Traditional Training in Patients With Chronic Stroke. ClinicalTrials.gov.

\section{NCT02592759 \{published data only\}}

Gil Seo H. Effects of Upper Extremity Rehabilitation Using Smart Glove in Stroke Patients. ClinicalTrials.gov.

\section{NCT02688413 \{published data only\}}

Caso V. Study Evaluating the MindMotionPRO for Early Post-stroke Upper-limb Rehabilitation (MOVE-Rehab). ClinicalTrials.gov.

\section{NCT02857803 \{unpublished data only\}}

* Faria AL, Bermudez i Badia S. Development and evaluation of a web-based cognitive task generator for personalized cognitive training: a proof of concept study with stroke patients. REHAB 2015: 3rd workshop on ICTs for improving patients research techniques. 2015:1-4.

Faria AL, Pinho M, Bermudez i Badia S. Personalizing cognitive rehabilitation through a web-based Task Generator: an evaluation study with stroke patients. International Neuropsychological Society 2016 Mid year meeting. 2016; Vol. 2016.

Faria Al, Vourvopoulos A, Cameirao MS, Fernandes JC, Bermudez i Badia S. An integrative virtual reality cognitivemotor intervention approach in stroke rehabilitation: a pilot study. 10th International Conference, Disability, Virtual Reality and Associated Technologies (ICDVRAT). 2014.

NCT02857803. A randomised controlled trial comparing the impact of virtual reality, paper and pencil and conventional methods on stroke rehabilitation. ClinicalTrials.gov 2016.

Vourvopoulos A, Faria AL, Ponnam K, Bermudez i Badia S. RehabCity: design and validation of a cognitive assessment and rehabilitation tool through gamified simulations of activities of daily living. 11th Advances in Computer Entertainment Technology Conference. November 2014.

NTR2247 \{published data only\}

NTR2247. Effect of virtual reality training on reach after stroke. www.trialregister.nl/trialreg/admin/rctview.asp?TC=2247 (accessed December 2013). [NTR2247]

\section{Piemonte 2014 \{published data only\}}

Piemonte MEP, Oliveira TP, Miranda C, Muzzi J, Perez DB. Motorcognitive intervention based on Nintendo Wii Fit games to improve balance and cognitive functions in patients with stroke: a randomized controlled trial. Personal communication (to be presented at the Neurorehabilitation Congress) 2014.

\section{Rand 2015 \{published data only\}}

Rand D, Yacoby A, Weiss R, Reif S, Malka R, Weingarden H, et al. Home-based self-training using video-games: preliminary data from a randomised controlled trial. Virtual Rehabilitation Proceedings (ICVR), 2015. 2015:86-91. 
Schuster-Amft 2014 \{published data only\}

Schuster-Amft C, Eng K, Thalers I, Lehmann I, Signer S, McCaskey MA, et al. Evaluating efficacy and users' expectations of a virtual reality training system: a multicenter randomized controlled trial. Annals of physical and rehabilitation medicine 2014;57:e85.

\section{Sheehy 2016 \{published data only\}}

Sheehy L, Taillon-Hobson A, Sveistrup H, Bilodeau M, Fergusson D, Levac $D$, et al. Does the addition of virtual reality to a standard program of inpatient rehabilitation improve sitting balance ability and function after stroke? Protocol for a single-blind randomized controlled trial. BMC Neurology 2016; Vol. 16 , issue 42 .

\section{Additional references}

\section{Bagce 2012}

Bagce HF, Saleh S, Adamovich SV, Tunik E. Visuomotor gait distortion alters online motor performance and enhances primary motor cortex excitability in patients with stroke. Neuromodulation 2012;15(4):361-6.

\section{Bohil 2011}

Bohil CJ, Alicea B, Biocca FA. Virtual reality in neuroscience research and therapy. Nature Reviews Neuroscience 2011;12:752-62.

\section{Burridge 2010}

Burridge JJ, Hughes AM. Potential for new technologies in clinical practice. Current Opinion in Neurology 2010;23:671-7.

\section{Cheok 2015}

Cheok G, Tan D, Low A, Hewitt J. Is Nintendo Wii an effective intervention for individuals with stroke? A systematic review and meta-analysis. Journal of the American Medical Directors Association 2015;16(11):923-32.

\section{Corbetta 2015}

Corbetta D, Imeri F, Gatti R. Rehabilitation that incorporates virtual reality is more effective than standard rehabilitation for improving walking speed, balance and mobility after stroke: a systematic review. Journal of Physiotherapy 2015;61(3):117-24.

\section{Crosbie 2007}

Crosbie J, Lennon S, Basford J, McDonough S. Virtual reality in stroke rehabilitation: still more virtual than real. Disability and Rehabilitation 2007;29(14):1139-46.

\section{Darekar 2015}

Darekar A, McFadyen BJ, Lamontagne A, Fung J. Efficacy of virtual reality-based intervention on balance and mobility disorders post-stroke: a scoping review. Journal of Neuroengineering in Rehabilitation 2015;10(12):46.

\section{Deeks 2011}

Deeks JJ, Higgins JPT, Altman DG (editors). Chapter 9: Analysing data and undertaking meta-analyses. In: Higgins JPT, Green $S$ (editors). Cochrane Handbook for Systematic Reviews of
Interventions Version 5.1.0 (updated March 2011). The Cochrane Collaboration, 2011. Available from handbook.cochrane.org.

\section{Demain 2013}

Demain S, Burridge J, Ellis-Hill C. Assistive technologies after stroke: self management or fending for yourself? A focus group study. BMC Health Services Research 2013;13:334.

\section{Feigin 2014}

Feigin VL, Forouzanfar MH, Krishnamurthi R, Mensah GA, Connor M, Bennett DA, et al. Global and regional burden of stroke during 1990-2010: findings from the Global Burden of Disease Study 2010. Lancet 2014;383:245-55.

\section{French 2016}

French B, Thomas L, Coupe J, McMahon N, Connell L, Harrison J, et al. Repetitive task training for improving functional ability after stroke. Cochrane Database of Systematic Reviews 2016, Issue 11. [DOI: 10.1002/14651858.CD006073.pub3]

\section{Fung 2012}

Fung V, Ho A, Shaffer J, Chung E, Gomez M. Use of Nintendo Wii fit in the rehabilitation of outpatients following total knee replacement: a preliminary randomised controlled trial. Physiotherapy 2012;98:183-8.

\section{Gaggioli 2009}

Gaggioli A, Keshner E, Weiss PL, Riva G. Advanced Technologies in Rehabilitation. United States: IOS Press, 2009.

\section{Go 2014}

Go AS, Mozaffarian D, Roger VL, Benjamin EJ, Berry JD, Blaha MJ, et al. Heart disease and stroke statistics-2014 update: a report from the American Heart Association. Circulation 2014;129:e28-e292.

\section{GRADEpro GDT 2015 [Computer program]}

McMaster University (developed by Evidence Prime). GRADEpro GDT. Hamilton (ON): McMaster University (developed by Evidence Prime), 2015.

\section{Guyatt 2008}

Guyatt GH, Oxman AD, Vist G, Kunz R, Falck-Ytter Y, AlonsoCoello P, the GRADE Working Group. Rating quality of evidence and strength of recommendations GRADE: an emerging consensus on rating quality of evidence and strength of recommendations. BMJ 2008;336:924-6.

\section{Higgins 2003}

Higgins JPT, Thompson SG, Deeks JJ, Altman DG. Measuring inconsistency in meta-analyses. BMJ 2003;327:557-60.

\section{Higgins 2011a}

Higgins JPT, Altman DG, Sterne JAC (editors). Chapter 8: Assessing risk of bias in included studies. In: Higgins JPT, Green S (editors). Cochrane Handbook for Systematic Reviews of Interventions Version 5.1.0 (updated March 2011). The Cochrane Collaboration, 2011. Available from www.handbook.cochrane.org. 


\section{Higgins 2011b}

Higgins JPT, Deeks JJ, Altman DG (editors). Chapter 16: Special topics in statistics. In: Higgins JPT, Green S (editors), Cochrane Handbook for Systematic Reviews of Interventions Version 5.1.0 (updated March 2011). The Cochrane Collaboration, 2011. Available from handbook.cochrane.org.

\section{Jiandani 2014}

Jiandani N, Nair SR, Shukla H. Efficacy of virtual reality exposure therapy in the management of symptoms associated with post traumatic stress disorder. Value in Health 2014;17(7):A572.

\section{Kwakkel 2004}

Kwakkel G, Van Peppen R, Wagenaar R, Wood Dauphinee S, Richards C, Ashburn A, et al. Effects of augmented exercise therapy time after stroke. A meta-analysis. Stroke 2004;35:1-11.

\section{Lange 2010}

Lange B, Flynn S, Proffitt R, Chang C, Rizzo A. Development of an interactive game-based rehabilitation tool for dynamic balance training. Topics in Stroke Rehabilitation 2010;17(5):345-52.

\section{Lange 2012}

Lange B, Koenig S, Chang CY, McConnell E, Suma E, Bolas M, et al. Designing informed game-based rehabilitation tasks leveraging advances in virtual reality. Disability and Rehabilitation 2012;34(22):1863-70.

\section{Langhorne 2011}

Langhorne P, Bernhardt J, Kwakkel G. Stroke rehabilitation. Lancet 2011;377(9778):1693-702.

\section{Larsen 2009}

Larsen C, Sorensen J, Grantcharov T, Dalsgaard T, Schouenborg L, Ottosen C, et al. Effect of virtual reality training on laparoscopic surgery: randomised controlled trial. BMJ 2009;338:b1802.

\section{Levac 2015}

Levac D, Espy D, Fox E, Pradhan S, Deutsch J. "Kinect-ing" with clinicians: a knowledge translation resource to support decision making about video game use in rehabilitation. Physical Therapy 2015;95(3):426-40.

Lewis 2012

Lewis GN, Rosie JA. Virtual reality games for movement rehabilitation in neurological conditions: how do we meet the needs and expectations of the users?. Disability and Rehabilitation 2012;34(22):1880-6.

\section{Li 2016}

Li Z, Han XG, Sheng J, Ma SJ. Virtual reality for improving balance in patients after stroke: a systematic review and metaanalysis. Clinical Rehabilitation 2016;30(5):432-40.

\section{Lintern 1990}

Lintern G, Roscoe S, Koonce J, Segal L. Display principles, control dynamics and environmental factors in pilot training and transfer. Human Factors 1990;32:299-317.

\section{Lohse 2014}

Lohse K, Hilderman CGE, Cheung KL, Tatla S, Van der Loos HFM. Virtual reality therapy for adults post-stroke: a systematic review and meta-analysis exploring virtual environments and commercial games in therapy. PLOS ONE 2014;9(3):e93318.

\section{Merians 2002}

Merians A, Jack D, Boian R, Tremaine M, Burdea G, Adamovich S, et al. Virtual reality augmented rehabilitation for patients following stroke. Physical Therapy 2002;82(9):898-915.

\section{Miller 2010}

Miller E, Murray L, Richards L, Zorowitz R, Bakas T, Clark P, et al. Comprehensive overview of nursing and interdisciplinary rehabilitation care of the stroke patient: a scientific statement from the American Heart Association. Stroke 2010;41:2402-48.

\section{Moreira 2013}

Moreira MC, De Amorim Lima AM, Ferraz KM, Benedetti Rodrigues MA. Use of virtual reality in gait recovery among post stroke patients - a systematic literature review. Disability and Rehabilitation Assistive Technology 2013;8(5):357-62.

\section{Nawaz 2015}

Nawaz A, Skjaeret N, Helbostad J, Vereijken B, Boulton E, Svanaes D. Usability and acceptability of balance exergames in older adults: a scoping review. Health Informatics Journal 2015;22(4):911-31.

\section{Patel 2006}

Patel M, Tilling K, Lawrence E, Rudd A, Wolfe C, McKevitt C. Relationships between long-term stroke disability, handicap and health-related quality of life. Age and Ageing 2006;35:273-9.

\section{Raghav 2016}

Raghav K, Van Wijk AJ, Abdullah F, Islam MN, Bernatchez M, De Jongh A. Efficacy of virtual reality exposure therapy for treatment of dental phobia: a randomized control trial. BMC Oral Health 2016; Vol. 16, issue 25.

\section{RevMan 2014 [Computer program]}

Nordic Cochrane Centre, The Cochrane Collaboration. Review Manager 5 (RevMan 5). Version 5.3. Copenhagen: Nordic Cochrane Centre, The Cochrane Collaboration, 2014.

\section{Risedal 2002}

Risedal A, Mattsson B, Dahlqvist P, Nordborg C, Olsson T, Johansson $B$. Environmental influences on functional outcome after a cortical infarct in the rat. Brain Research Bulletin 2002;58:315-21.

\section{Saleh 2014}

Saleh S, Adamovich SV, Tunik E. Mirrored feedback in chronic stroke: recruitment and effective connectivity of ipsilesional sensorimotor networks. Neurorehabilitation and Neural Repair 2014;28(4):344-54.

\section{Saposnik 2011}

Saposnik G, Levin M, Stroke Outcome Research Canada (SORCan) Working Group. Virtual reality in stroke rehabilitation: 
a meta-analysis and implications for clinicians. Stroke 2011;42(5):1380-6.

\section{Schuemie 2001}

Schuemie M, Van der Straaten P, Krijn M, Van der Mast C. Research on presence in virtual reality: a survey. CyberPsychology \& Behavior 2001;4(2):183-201.

\section{Schultheis 2001}

Schultheis M, Rizzo A. The application of virtual reality technology in rehabilitation. Rehabilitation Psychology 2001;46:296-311.

\section{Schulz 2010}

Schulz K, Altman D, Moher D for the CONSORT group. CONSORT 2010 Statement: updated guidelines for reporting parallel group randomised trials. BMJ 2010;340:c332.

\section{Sturm 2004}

Sturm J, Donnan G, Dewey H, Macdonnell R, Gilligan A, Srikanth A, et al. Quality of life after stroke: the North East Melbourne stroke incidence study (NEMESIS). Stroke 2004;35:2340-5.

\section{Teasell 2014}

Teasell RW, Murie-Fernandez M, McIntyre A, Mehta S. Rethinking the continuum of stroke rehabilitation. Archives of Physical Medicine and Rehabilitation 2014;95(4):595-6.

\section{Thomson 2014}

Thomson K, Pollock A, Bugge C, Brady M. Commercial gaming devices for stroke upper limb rehabilitation: a systematic review. International Journal of Stroke 2014;9(4):479-88.

\section{Tunik 2013}

Tunik E, Saleh S, Adamovich SV. Visuomotor discordance during visually guided hand movement in virtual reality modulates sensorimotor cortical activity in healthy and hemiparetic subjects. IEEE Transactions in Neural System Rehabilitation Engineering 2013;21(2):198-207.

\section{Veerbeek 2014}

Veerbeek JM, Van Wegen E, Van Peppen R, Van der Wees PJ, Hendriks $E$, Rietberg $M$, et al. What is the evidence for physical therapy poststroke? A systematic review and meta-analysis. PLOS ONE 2014;9(2):e87987.

\section{CHARACTERISTICS OF STUDIES}

\section{Characteristics of included studies [ordered by study ID]}

\section{Webster 2014}

Webster D, Celik O. Systematic review of Kinect applications in elderly care and stroke rehabilitation. Journal of NeuroEngineering and Rehabilitation 2014;11(1):108.

\section{Weiss 2006}

Weiss P, Kizony R, Feintuch U, Katz N. Virtual reality in neurorehabilitation. In: Selzer M, Cohen L, Gage F, Clarke $\mathrm{S}$, Duncan P editor(s). Textbook of Neural Repair and Rehabilitation. Cambridge University Press, 2006:182-97.

\section{WHO 1989}

World Health Organization Task Force on Stroke and Other Cerebrovascular Disorders. Recommendations on stroke prevention, diagnosis, and therapy: report of the WHO Task Force on stroke and other cerebrovascular disorders. Stroke 1989;20:1407-31.

\section{Wingham 2015}

Wingham J, Adie K, Turner D, Schofield C, Pritchard C. Participant and caregiver experience of the Nintendo Wii Sports ${ }^{\mathrm{TM}}$ after stroke: qualitative study of the trial of $\mathrm{Wii}^{\mathrm{TM}}$ in stroke (TWIST). Clinical Rehabilitation 2015;29(3):295-305.

\section{References to other published versions of this review}

\section{Laver 2010}

Laver KE, George S, Thomas S, Deutsch JE, Crotty M. Virtual reality for stroke rehabilitation. Cochrane Database of Systematic Reviews 2010, Issue 2. [DOI: 10.1002/14651858.CD008349]

\section{Laver 2011}

Laver KE, George S, Thomas S, Deutsch JE, Crotty M. Virtual reality for stroke rehabilitation. Cochrane Database of Systematic Reviews 2011, Issue 9. [DOI: 10.1002/14651858.CD008349.pub2]

\section{Laver 2015}

Laver KE, George S, Thomas S, Deutsch JE, Crotty M. Virtual reality for stroke rehabilitation. Cochrane Database of Systematic Reviews 2015, Issue 2. [DOI: 10.1002/14651858.CD008349.pub3]

* Indicates the major publication for the study

Adie 2017

Methods RCT

Participants

Recruited from 10 stroke centres in the UK

235 participants: 117 intervention, 118 control 
Adie 2017 (Continued)

Inclusion criteria: ischaemic or haemorrhagic stroke within the last 6 months, arm weakness owing to stroke, defined as MRC Scale power $<5$ in any joint plane and able to manipulate the $\mathrm{Wii}^{\mathrm{TM}}$ remote control

Exclusion criteria: severe comorbidity that could impair participation, symptomatic shoulder subluxation, or a pacemaker

Mean (SD) age: intervention group 66.8 (14.6) years, control group 68.0 (11.9) years

$56 \%$ men

Stroke details: $89 \%$ ischaemic

Timing post stroke: intervention group mean (SD) 57.3 (48.3) d, control group mean 56.3 (50.1) d

Interventions

VR intervention: therapists visited the participants home and installed the Wii and taught participants how to use it. Participants were given the choice of any of the Wii sports games. Performed in a seated position

Control intervention: participant-tailored arm exercises (based on the GRASP program) in a seated position

Sessions: participants in both groups were instructed to warm up for $15 \mathrm{~min}$ and then perform the intervention for up to $45 \mathrm{~min} / \mathrm{d}$ for 6 weeks

\begin{tabular}{|c|c|c|}
\hline Outcomes & $\begin{array}{l}\text { Action Research Arm T } \\
\text { Canadian Occupation } \\
\text { Stroke Impact Scale } \\
\text { Modified Rankin Scale } \\
\text { EQ5D } \\
\text { Motor Activity Log Arm } \\
\text { Adverse events }\end{array}$ & $\begin{array}{l}\text { ed at baseline, } 6 \text { weeks, and } 6 \text { months } \\
\text { Performance Measure } \\
\text { Function Test ( } 6 \text { months) }\end{array}$ \\
\hline Notes & - & \\
\hline Risk of bias & & \\
\hline Bias & Authors' judgement & Support for judgement \\
\hline $\begin{array}{l}\text { Random sequence genera- } \\
\text { tion (selection bias) }\end{array}$ & Low risk & Computer generated \\
\hline $\begin{array}{l}\text { Allocation concealment } \\
\text { (selection bias) }\end{array}$ & Low risk & Web-based service \\
\hline $\begin{array}{l}\text { Blinding of outcome as- } \\
\text { sessment (detection bias) } \\
\text { All outcomes }\end{array}$ & Low risk & Blinded assessor \\
\hline $\begin{array}{l}\text { Incomplete outcome data } \\
\text { (attrition bias) } \\
\text { All outcomes }\end{array}$ & Low risk & ITT analysis conducted \\
\hline
\end{tabular}


Adie 2017 (Continued)

Selective reporting (re- Low risk $\quad$ Clinical trial registration and accurate reporting
porting bias)
porting bias)

Akinwuntan 2005

\begin{tabular}{ll}
\hline Methods & RCT \\
\hline Participants & Recruited from 1 rehabilitation unit in Belgium \\
& 83 participants: 42 intervention, 41 control \\
& Inclusion criteria: within 3 months of first stroke, actively driving before stroke, in possession of an ac- \\
& tive driver's licence \\
& Exclusion criteria: $\geq 75$ years, history of epilepsy within previous 6 months, severe motor or sensory \\
& aphasia \\
& Mean (SD) age: intervention group 54 (12) years, control group 54 (11) years \\
& $81 \%$ men
\end{tabular}

Stroke details: $77 \%$ ischaemic, $44 \%$ right hemiparesis

Timing post stroke: intervention group mean (SD) 53 (6) d, control group 54 (6) d

Interventions

VR intervention: driving simulator in full-sized, automatic gear transmission Ford Fiesta; a variety of 5 $\mathrm{km}$ driving scenarios were used including positioning on straight and curvy roads, stopping at crossings and avoiding pedestrians, overtaking and road sign recognition

Control intervention: driving-related cognitive tasks: these included route finding on a paper map, recognition of road signs, commercially available games including 'rush hour' and 'tantrix'

Sessions were $60 \mathrm{~min}, 3$ times a week for 5 weeks ( $15 \mathrm{~h}$ total)

Outcomes Outcomes recorded at baseline, post-intervention and at 6 months with some participants followed up
at 5 years

Cognitive outcome measures: Useful Field of View Test

Activity limitation outcome measures: on-road driving test (using Test Ride for Investigating Practical Fitness to Drive checklist), decision of fitness to drive, Barthel Index (assessed at baseline and 5 years only)

Other outcome measures: binocular acuity, kinetic vision, components of the Stroke Driver Screening Assessment

Other outcome measures assessed at baseline and 5 years only: Hospital Anxiety and Depression Scale, number of km driven/year, number of self-reported traffic tickets and accidents and driving status (actively driving or stopped driving)

Notes -

\section{Risk of bias}

\begin{tabular}{lll} 
Bias & Authors' judgement & Support for judgement \\
\hline $\begin{array}{l}\text { Random sequence genera- } \\
\text { tion (selection bias) }\end{array}$ & Low risk & Computerised number generation \\
\hline
\end{tabular}


Akinwuntan 2005 (Continued)

$\begin{aligned} & \text { Allocation concealment } \\ & \text { (selection bias) }\end{aligned}$ Low risk Allocation managed by an independent person

Blinding of outcome as- Low risk Blind to allocation

sessment (detection bias)

All outcomes

\begin{tabular}{|c|c|c|}
\hline $\begin{array}{l}\text { Incomplete outcome data } \\
\text { (attrition bias) } \\
\text { All outcomes }\end{array}$ & Low risk & $\begin{array}{l}\text { A large amount of missing data due to the number of participants who with- } \\
\text { drew (14\% withdrew from their allocated intervention, } 29 \% \text { of participants } \\
\text { were lost at } 6 \text {-month follow-up); however, the authors completed an ITT } \\
\text { analysis and found that dropout was random and balanced evenly across } \\
\text { groups }\end{array}$ \\
\hline
\end{tabular}

\begin{tabular}{l}
\hline $\begin{array}{l}\text { Selective reporting (re- } \quad \text { Low risk } \\
\text { porting bias) }\end{array}$ \\
\hline
\end{tabular}

Barcala 2013

Methods RCT

Participants Recruited from the physical therapy clinic at a university in Brazil

20 participants: 10 intervention, 10 control

Inclusion criteria: people after stroke receiving weekly physical therapy sessions at the university; able to sit unsupported; able to understand the visual biofeedback; absence of osteoarticular deformities

Exclusion criteria: unspecified comorbidities

Mean (SD) age: intervention group 65.2 (12.5) years, control group 63.5 (14.5) years

$45 \%$ men

Stroke details: $65 \%$ right hemiparesis

Timing post stroke: intervention group mean (SD) 12.3 (7.1) months, control group 15.2 (6.6 months)

Interventions $\quad$ VR intervention: conventional physical therapy plus an additional 30 min of balance training with visual feedback using 3 of the Nintendo Wii Fit program games

Control intervention: convention physical therapy (stretching, joint movement, muscle strengthening, balance training, training of functional activities)

Sessions were twice/week over 5 weeks. Conventional therapy lasted $60 \mathrm{~min}$; the intervention sessions were an additional $30 \mathrm{~min}$ (approximately $5 \mathrm{~h}$ duration of additional training in total)

Outcomes
Gait outcomes: Timed Up and Go Test
Balance outcomes: Berg Balance Scale, centre of pressure data, body symmetry
Activity outcomes: Functional Independence Measure

Notes

$-$

\section{Risk of bias}


Barcala 2013 (Continued)

\begin{tabular}{|c|c|c|}
\hline Bias & Authors' judgement & Support for judgement \\
\hline $\begin{array}{l}\text { Random sequence genera- } \\
\text { tion (selection bias) }\end{array}$ & Low risk & Randomisation table at central office \\
\hline $\begin{array}{l}\text { Allocation concealment } \\
\text { (selection bias) }\end{array}$ & Low risk & Sealed, opaque envelopes \\
\hline $\begin{array}{l}\text { Blinding of outcome as- } \\
\text { sessment (detection bias) } \\
\text { All outcomes }\end{array}$ & Low risk & Blinded assessment \\
\hline $\begin{array}{l}\text { Incomplete outcome data } \\
\text { (attrition bias) } \\
\text { All outcomes }\end{array}$ & Low risk & No dropouts \\
\hline $\begin{array}{l}\text { Selective reporting (re- } \\
\text { porting bias) }\end{array}$ & Unclear risk & No access to study protocol \\
\hline
\end{tabular}

Bower 2015

\begin{tabular}{ll}
\hline Methods & RCT \\
\hline Participants & Recruited from a rehabilitation facility in Melbourne, Australia \\
16 participants: 8 intervention, 8 control \\
Inclusion criteria: adults with stroke who were able to sit unsupported for longer than 10 seconds (Mo- \\
tor Assessment Scale - Sitting Balance $\geq 2$ ) \\
Exclusion criteria: severe dysphasia, significant cognitive deficits (Mini-Mental State Examination $<20$ ), \\
other medical conditions (e.g. progressive neurological condition, severe arthritis, unstable heart con- \\
dition) impacting on their ability to participate in the study, or visual problems such that they were not \\
able to adequately see the games when displayed on the television screen
\end{tabular}

Mean (SD) age: intervention group 60.8 (16.1) years, control 60.9 (14.0) years

$69 \%$ men

Timing post stroke, median (IQR) intervention group 12.8 (3.9 to 137.8) weeks, control group 24.7 (5.8 to 51.1) weeks

VR intervention: customised games developed for the research study. The system used a laptop, depth sensing camera and display on a television screen. The games were designed to encourage dynamic balance and upper limb activities and to be adaptable to users with different levels of balance, motor control and perceptual problems. Games included 'ball maze', 'fridge frenzy', 'tentacle dash' and 'bubble fish'

Control intervention: usual care only (thus the VR therapy group received a greater overall dose of therapy)

The intervention group completed eight 40-min sessions over 4 weeks

Outcomes
Assessed at baseline and post intervention
Lower limb function and activity: 6MWT, step test
Balance: functional reach 
Bower 2015 (Continued)

Global Motor Function: Motor Assessment Scale

Functional Independence Measure (transfers, walking, stairs)

Adverse events

Notes -

\section{Risk of bias}

\begin{tabular}{|c|c|c|}
\hline Bias & Authors' judgement & Support for judgement \\
\hline $\begin{array}{l}\text { Random sequence genera- } \\
\text { tion (selection bias) }\end{array}$ & Low risk & Computer-generated random sequence \\
\hline $\begin{array}{l}\text { Allocation concealment } \\
\text { (selection bias) }\end{array}$ & Low risk & External management \\
\hline $\begin{array}{l}\text { Blinding of outcome as- } \\
\text { sessment (detection bias) } \\
\text { All outcomes }\end{array}$ & Low risk & Blinded to allocation \\
\hline $\begin{array}{l}\text { Incomplete outcome data } \\
\text { (attrition bias) } \\
\text { All outcomes }\end{array}$ & Low risk & Very low rate of withdrawals. ITT analysis conducted \\
\hline $\begin{array}{l}\text { Selective reporting (re- } \\
\text { porting bias) }\end{array}$ & Low risk & Registered clinical trial. All outcomes reported \\
\hline
\end{tabular}

\section{Byl 2013}

\begin{tabular}{ll}
\hline Methods & RCT \\
\hline
\end{tabular}

Participants Recruited via the University of California, USA

15 participants completed the study: 5 intervention, 5 intervention, 5 control

Inclusion criteria: stroke survivors $>6$ months post stroke, 25-75 years of age. Participants were independent in self care and independent in the community with minimal-moderate voluntary function in the upper limb (Upper Limb Fugl Meyer score 16-39). Participants needed to speak English or attend with an interpreter

Exclusion criteria: people were excluded if they suffered from a neurological disease other than stroke, had co-morbidities that would impact on participation, were in severe pain, were not mentally alert or had a skin condition that would prevent wearing the robotic orthosis

Mean (SD) age: intervention group 65.2 (5.4) years, control group 54.2 (20.5) years

Stroke details: $70 \%$ right hemiparesis

Timing post stroke: intervention group 8.4 (4.2), control group 10.2 (5.0) months

Interventions

This trial had 3 arms: 2 of the intervention groups performed VR tasks; 1 of the VR groups performed bilateral tasks and the other group performed unilateral tasks

VR intervention: the participant wore a robotic orthosis. Each session started with a motor-control evaluation task and then followed with treatment in which participants performed repetitive movements while playing task-specific games 
Byl 2013 (Continued)

Control intervention: repetitive task practice involved reaching, grasping, object manipulation and selfcare activities. Dynamic orthoses were not included in training

Sessions were $90 \mathrm{~min}$ for 12 treatment sessions (approximately $18 \mathrm{~h}$ total)

Outcomes recorded at baseline and post-intervention
Upper limb function outcomes: Fugl Meyer, Motor Proficiency Speed (abbreviated Wolf Motor Function
Test and Digital Reaction Time Test)
Hand function outcomes: motor skill performance (Box and Block test and Tapper test)
Activity limitation outcomes: functional independence (CAFE40)
Quality of life outcomes: Stroke Impact Scale
Adverse events

Notes

$-$

\section{Risk of bias}

\begin{tabular}{lll}
\hline Bias & Authors' judgement & Support for judgement \\
\hline $\begin{array}{l}\text { Random sequence genera- } \\
\text { tion (selection bias) }\end{array}$ & Low risk & Computer-generated \\
\hline $\begin{array}{l}\text { Allocation concealment } \\
\text { (selection bias) }\end{array}$ & Low risk & Allocated prospectively using a computer program \\
\hline $\begin{array}{l}\text { Blinding of outcome as- } \\
\text { sessment (detection bias) } \\
\text { All outcomes }\end{array}$ & Low risk & Blinded assessment \\
\hline $\begin{array}{l}\text { Incomplete outcome data } \\
\text { (attrition bias) } \\
\text { All outcomes }\end{array}$ & Low risk & Reporting for all participants following intervention \\
\hline $\begin{array}{l}\text { Selective reporting (re- } \\
\text { porting bias) }\end{array}$ & Low risk & All outcomes reported \\
\hline
\end{tabular}

Cho 2012

\begin{tabular}{ll}
\hline Methods & RCT \\
\hline Participants & Recruited from a hospital in Korea \\
& 29 participants: 15 intervention, 14 control \\
& Inclusion criteria: no VR intervention in the previous 2 years, no surgery in the previous 2 months and \\
no specific medical problems, including psychological problems & \\
& Exclusion criteria: none described \\
& Mean (SD) age: intervention group 64 (7.1) years, control group 63.7 (8.8) years \\
& $62 \%$ men \\
& Stroke details: $41 \%$ hemiparesis
\end{tabular}


Cho 2012 (Continued)

Timing post stroke: not reported

Interventions $\quad$ VR intervention: the Interactive Rehabilitation and Exercise System (IREX) was used for training. The participant performed 6 programs; each program was performed for $5 \mathrm{~min}$

Control intervention: no intervention

Sessions were $60 \mathrm{~min}, 5$ times/week for 4 weeks (approximately $20 \mathrm{~h}$ total)

\begin{tabular}{|c|c|c|}
\hline \multirow[t]{3}{*}{ Outcomes } & \multicolumn{2}{|c|}{ Outcomes recorded at baseline and post-intervention } \\
\hline & \multicolumn{2}{|c|}{ Upper limb function outcomes: Wolf Motor Function Test } \\
\hline & \multicolumn{2}{|c|}{ Other outcomes: Motor Free Visual Perception Test } \\
\hline Notes & - & \\
\hline \multicolumn{3}{|l|}{ Risk of bias } \\
\hline Bias & Authors' judgement & Support for judgement \\
\hline $\begin{array}{l}\text { Random sequence genera- } \\
\text { tion (selection bias) }\end{array}$ & Low risk & Table of random-sampling numbers \\
\hline $\begin{array}{l}\text { Allocation concealment } \\
\text { (selection bias) }\end{array}$ & Unclear risk & Not reported \\
\hline $\begin{array}{l}\text { Blinding of outcome as- } \\
\text { sessment (detection bias) } \\
\text { All outcomes }\end{array}$ & Unclear risk & Not reported \\
\hline $\begin{array}{l}\text { Incomplete outcome data } \\
\text { (attrition bias) } \\
\text { All outcomes }\end{array}$ & High risk & Withdrawals not clearly explained \\
\hline $\begin{array}{l}\text { Selective reporting (re- } \\
\text { porting bias) }\end{array}$ & Unclear risk & Protocol not publicly available \\
\hline
\end{tabular}

Chow 2013

\begin{tabular}{ll}
\hline Methods & RCT \\
\hline Participants & Recruited from outpatient physiotherapy at the Hong Kong Buddhist Hospital \\
& 14 participants (size of each group not reported) \\
Inclusion criteria: diagnosis of stroke & Exclusion criteria: not reported \\
& Mean (SD) age: intervention group 69.14 years (2.73), control group 68.86 (8.25) years \\
& Stroke details: not reported \\
& Timing post stroke: not reported \\
VR intervention: Xbox360 Kinect in addition to conventional physiotherapy training \\
Control intervention: conventional physiotherapy training \\
\hline
\end{tabular}


Chow 2013 (Continued)

Sessions were $60 \mathrm{~min}$, twice/week for 6 weeks

Outcomes recorded at baseline and post intervention
Gait and balance function: 10 metre walk test, Berg Balance scale
Activity limitation: Modified Barthel Index
Other: Sensory organisation test

Notes

\section{Risk of bias}

\begin{tabular}{lll}
\hline Bias & Authors' judgement & Support for judgement \\
\hline $\begin{array}{l}\text { Random sequence genera- } \\
\text { tion (selection bias) }\end{array}$ & Unclear risk & Not reported (conference abstract) \\
\hline $\begin{array}{l}\text { Allocation concealment } \\
\text { (selection bias) }\end{array}$ & Unclear risk & Not reported (conference abstract) \\
\hline $\begin{array}{l}\text { Blinding of outcome as- } \\
\text { sessment (detection bias) } \\
\text { All outcomes }\end{array}$ & Unclear risk & Not reported (conference abstract) \\
\hline $\begin{array}{l}\text { Incomplete outcome data } \\
\text { (attrition bias) } \\
\text { All outcomes }\end{array}$ & Unclear risk & Not reported (conference abstract) \\
\hline $\begin{array}{l}\text { Selective reporting (re- } \\
\text { porting bias) }\end{array}$ & Unclear risk & Not reported (conference abstract) \\
\hline
\end{tabular}

Coupar 2012

\begin{tabular}{ll}
\hline Methods & RCT \\
\hline Participants & Recruited from a stroke unit in Glasgow, UK \\
& 12 participants: 4 high-intensity intervention, 4 low-intensity intervention, 4 control \\
& Inclusion criteria: $\geq 18$ years with a clinical diagnosis of stroke and grade 1-4 on MRC scale of arm im- \\
pairment. Medically stable and within 10 d post stroke. Able to give informed consent, understand and \\
follow simple instruction and sitting balance sufficient to use the device safely \\
Exclusion criteria: orthosis could not be fitted to the affected limb due to previous stroke or other con- \\
dition, bone instability of affected upper limb, no functional use of affected upper limb due to previous \\
stroke or other condition. Pronounced fixed contractures of affected upper limb, open skin lesions on \\
affected upper limb; major sensory deficit of affected upper limb; shoulder instability or excessive pain; \\
severe spasticity; severe spontaneous movements; confused or non-co-operative; isolation due to in- \\
fection; visual, perceptual or cognitive problems precluding participation in study involvement or in- \\
volvement in any other intervention study \\
Mean (SD) age: high-intensity intervention group 65 (14) years, low-intensity 72 (10), control 59 (16) \\
years \\
66\% men \\
Stroke details: $42 \%$ right hemiparesis
\end{tabular}




VR intervention:
Low-intensity: standard care plus Armeo ${ }^{\circledR}$ Spring arm orthosis and VR games for arm rehabilitation used
for $40 \mathrm{~min} / \mathrm{d}, 3 \mathrm{~d} /$ week
High-intensity: standard care plus Armeo ${ }^{\circledR}$ Spring arm orthosis and VR games for arm rehabilitation
used for $60 \mathrm{~min} / \mathrm{d}, 5 \mathrm{~d} /$ week
Games included catching rain drops, picking apples and cleaning a cooker
Control intervention: standard care including standard physiotherapy and OT targeted at arm recovery
Sessions were for 2 weeks or until discharge from the stroke unit (whichever was soonest)

Outcomes

Outcomes recorded at baseline, completion of intervention and 3 months following completion

Upper limb function: Action Research Arm Test, Fugl Meyer UE

Activity restriction: Barthel Index

Other outcomes related to feasibility, acceptability, safety, arm pain, perceived exhaustion and adverse events

\begin{tabular}{|c|c|c|}
\hline Notes & - & \\
\hline \multicolumn{3}{|l|}{ Risk of bias } \\
\hline Bias & Authors' judgement & Support for judgement \\
\hline $\begin{array}{l}\text { Random sequence genera- } \\
\text { tion (selection bias) }\end{array}$ & Low risk & Computer-generated sequence \\
\hline $\begin{array}{l}\text { Allocation concealment } \\
\text { (selection bias) }\end{array}$ & Low risk & Sealed, numbered, opaque envelopes \\
\hline $\begin{array}{l}\text { Blinding of outcome as- } \\
\text { sessment (detection bias) } \\
\text { All outcomes }\end{array}$ & Low risk & Blinded to allocation \\
\hline $\begin{array}{l}\text { Incomplete outcome data } \\
\text { (attrition bias) } \\
\text { All outcomes }\end{array}$ & Low risk & $\begin{array}{l}\text { Few withdrawals and balanced across groups for reasons not clearly related to } \\
\text { the study }\end{array}$ \\
\hline $\begin{array}{l}\text { Selective reporting (re- } \\
\text { porting bias) }\end{array}$ & Low risk & All outcomes reported in thesis \\
\hline
\end{tabular}

Crosbie 2008

\begin{tabular}{ll}
\hline Methods & RCT \\
\hline Participants & Recruited from 2 hospital stroke units and members of Stroke Association Clubs in Northern Ireland \\
& 18 participants: 9 intervention, 9 control \\
& Inclusion criteria: within 2 years of first stroke, medically stable, can follow 2-stage commands, score of \\
& $\geq 25$ on the upper limb Motricity Index
\end{tabular}


Exclusion criteria: mental score $<7 / 10$, neglect (star cancellation $<48 / 52$ ), comorbid conditions impacting on rehabilitation potential, cardiac pacemaker, severe arm pain reported on visual analogue scale

Mean (SD) age: intervention group 56 (15) years, control group 65 (7) years

$55 \%$ men

Stroke details: $39 \%$ right hemiparesis

Timing post stroke: intervention group mean (SD) 10 (6) months, control group 12 (8) months

Interventions

VR intervention: the participant chose from a variety of activities involving reaching and grasping of virtual objects at a variety of heights, speeds and with varied number of targets; the participant wore a head-mounted device and data glove

Control intervention: therapy provided based on the Bobath approach

Sessions were 35-45 min, 3 times/week over 3 weeks (approximately $6 \mathrm{~h}$ total)

\begin{tabular}{ll} 
Outcomes & Outcomes recorded at baseline, post-intervention and at 6 weeks \\
Upper limb function and activity outcomes: Action Research Arm Test, Upper Limb Motricity Index \\
Adverse events were reported \\
$\begin{array}{l}\text { Other outcome measures: an exit questionnaire including questions about enjoyment and perception } \\
\text { of improvement }\end{array}$ \\
\hline Notes
\end{tabular}

\section{Risk of bias}

\begin{tabular}{|c|c|c|}
\hline Bias & Authors' judgement & Support for judgement \\
\hline $\begin{array}{l}\text { Random sequence genera- } \\
\text { tion (selection bias) }\end{array}$ & Low risk & $\begin{array}{l}\text { An independent colleague generated the sequence using a computer random } \\
\text { number generator }\end{array}$ \\
\hline $\begin{array}{l}\text { Allocation concealment } \\
\text { (selection bias) }\end{array}$ & Low risk & Group allocation cards were concealed in sealed, opaque envelopes \\
\hline $\begin{array}{l}\text { Blinding of outcome as- } \\
\text { sessment (detection bias) } \\
\text { All outcomes }\end{array}$ & Low risk & Masked to allocation \\
\hline $\begin{array}{l}\text { Incomplete outcome data } \\
\text { (attrition bias) } \\
\text { All outcomes }\end{array}$ & Low risk & $\begin{array}{l}\text { An ITT analysis was completed. Missing data points were dealt with using the } \\
\text { simple mean imputation method }\end{array}$ \\
\hline $\begin{array}{l}\text { Selective reporting (re- } \\
\text { porting bias) }\end{array}$ & Low risk & No other outcomes were collected \\
\hline
\end{tabular}

da Silva Cameirao 2011

\begin{tabular}{ll}
\hline Methods & RCT \\
\hline Participants & Recruited from a subacute rehabilitation unit in Spain \\
& 19 participants: 13 intervention, 6 control \\
\hline
\end{tabular}


da Silva Cameirao 2011 (Continued)

Inclusion criteria: recruited within 3 weeks of first stroke, severe-moderate upper limb impairment, no moderate-severe aphasia, no other cognitive deficits as assessed by the MMSE and aged $\leq 80$ years

Exclusion criteria: none specified

Mean (SD) age: intervention group 63.7 (11.83) years, control group 59.4 (10.62) years, control group (Wii) 58 (14) years

$47 \%$ men

Stroke details: $37 \%$ right hemiparesis

Timing post stroke: intervention group mean (SD) 11.5 (5.1) d, control group 16.8 (5.0) d, control group (Wii) $13(4.7) \mathrm{d}$

Interventions

VR intervention: Rehabilitation Gaming System (RGS). The main elements of the system are the vision-based analysis and tracking system that capture upper limb movements through colour detection, data gloves to capture finger flexion and a virtual environment where an avatar mimics the movements of the user

Control intervention (OT): OT with emphasis on motor tasks similar to those in the RGS (i.e. object displacement, grasp and release)

Control intervention (Wii): used the Wii gaming system. This intervention involved the gaming features but not the neuro-scientific hypothesis regarding recovery

Sessions were 20 min, 3 times/week for 12 weeks (approximately $12 \mathrm{~h}$ total). This was provided in addition to standard rehabilitation

Outcomes Outcomes recorded at baseline, weeks 5, 12 and 24

Upper limb outcomes: Fugl Meyer, Chedoke Arm and Hand Activity Inventory

Activity outcomes: Barthel Index

Other outcomes: participant satisfaction

Notes -

\section{Risk of bias}

\begin{tabular}{|c|c|c|}
\hline Bias & Authors' judgement & Support for judgement \\
\hline $\begin{array}{l}\text { Random sequence genera- } \\
\text { tion (selection bias) }\end{array}$ & Low risk & Computer-generated program \\
\hline $\begin{array}{l}\text { Allocation concealment } \\
\text { (selection bias) }\end{array}$ & Low risk & Managed externally \\
\hline $\begin{array}{l}\text { Blinding of outcome as- } \\
\text { sessment (detection bias) } \\
\text { All outcomes }\end{array}$ & Low risk & Blinded to allocation \\
\hline $\begin{array}{l}\text { Incomplete outcome data } \\
\text { (attrition bias) } \\
\text { All outcomes }\end{array}$ & High risk & Outliers excluded from the data analysis \\
\hline $\begin{array}{l}\text { Selective reporting (re- } \\
\text { porting bias) }\end{array}$ & Low risk & All outcomes reported \\
\hline
\end{tabular}


da Silva Ribeiro 2015

\begin{tabular}{ll}
\hline Methods & RCT \\
\hline Participants & Recruited from an outpatient setting in Sao Paolo, Brazil \\
& 30 participants: 15 intervention, 15 control \\
& Inclusion criteria: aged 18-60 years with a diagnosis of stroke (based on neurologist assessment) and \\
hemiparesis. Able to ambulate and hold the game controller without assistive devices. $\geq 6$ months post \\
stroke \\
Exclusion criteria: associated disorders (such as hemineglect or pusher syndrome), intellectual disabil- \\
ity that made it difficult to understand the games or a history of orthopaedic diseases that promoted \\
dysfunction in the limbs or prevented the performance of the proposed activity \\
Mean (SD) age: intervention group 53.7 (6.1) years, control group 52.8 (8.6) years \\
37\% men \\
Stroke details: $57 \%$ right hemiparesis \\
Timing post stroke, mean (SD): intervention group 42.1 (26.9) months, control group 60.4 (44.) months
\end{tabular}

Interventions VR intervention: Nintendo Wii projected onto the wall. After full body stretching for 10 min the participants spent 50 min using the Nintendo Wii. The tennis and hula hoop games were used during the 1st session and soccer and boxing used during the second weekly session. The difficulty level of the games was increased as participants progressed

Control intervention: conventional physiotherapy including stretching, passive, active and resisted mobilisation activities, balance and gait activities and gripping activities

Sessions were $60 \mathrm{~min}$, twice/week for 2 months with a physiotherapist

\begin{tabular}{ll}
\hline Outcomes & Outcomes assessed post intervention \\
& Upper limb function and activity: Fugl Meyer \\
Participation and quality of life: SF36
\end{tabular}

Notes

\section{Risk of bias}

\begin{tabular}{lll}
\hline Bias & Authors' judgement & Support for judgement \\
\hline $\begin{array}{l}\text { Random sequence genera- } \\
\text { tion (selection bias) }\end{array}$ & Low risk & Random number allocation (performed online) \\
\hline $\begin{array}{l}\text { Allocation concealment } \\
\text { (selection bias) }\end{array}$ & Unclear risk & Used envelopes but unclear if opaque or not \\
\hline $\begin{array}{l}\text { Blinding of outcome as- } \\
\text { sessment (detection bias) } \\
\text { All outcomes }\end{array}$ & Low risk & Masked to allocation \\
\hline $\begin{array}{l}\text { Incomplete outcome data } \\
\text { (attrition bias) }\end{array}$ & Unclear risk & Unclear \\
All outcomes & & \\
\hline
\end{tabular}


da Silva Ribeiro 2015 (Continued)

Selective reporting (re- Unclear risk $\quad$ Trial register not reported
porting bias)

Fan 2014

\begin{tabular}{|c|c|}
\hline Methods & RCT \\
\hline \multirow[t]{7}{*}{ Participants } & Recruited from a suburban hospital and affiliated nursing home in Taiwan \\
\hline & 20 participants: allocated to 4 different treatment groups \\
\hline & $\begin{array}{l}\text { Inclusion criteria: aged } 20-85 \text { years with evidence of a cerebrovascular accident (confirmed by CT or } \\
\text { MRI). Onset for symptoms for } \geq 6 \text { months and MMSE score of }>24 \text {. Able to produce active shoulder } \\
\text { movements on the side of the hemiparesis (Fugl Meyer of } \geq 21 \text { ). Visual analogue scale of }<4 \text {, Modified } \\
\text { Ashworth Scale of } \leq 2 \text { and no rehabilitation in the past } 3 \text { months }\end{array}$ \\
\hline & $\begin{array}{l}\text { Exclusion criteria: uncontrolled hypertension, unstable angina, history of seizure, artificial pacemaker } \\
\text { and participation in other research }\end{array}$ \\
\hline & Mean (SD) age: varied from 57-67 years across the 4 intervention groups \\
\hline & Stroke details: $90 \%$ ischaemic, $45 \%$ right hemiplegia \\
\hline & Timing post stroke: ranged from an average of 1.8-2.6 years across the 4 intervention groups \\
\hline \multirow[t]{5}{*}{ Interventions } & $\begin{array}{l}\text { VR intervention: used available games including the Nintendo Wii Sports Resort. Participants were su- } \\
\text { pervised by a research staff member. The consoles and controller were not modified in the study. Par- } \\
\text { ticipants were advised to take } \geq 5-10 \text {-min breaks between games }\end{array}$ \\
\hline & $\begin{array}{l}\text { Control intervention: OT involving Bobath and proprioceptive neuromuscular facilitation. Equipment } \\
\text { included bean bags, target bags and cones }\end{array}$ \\
\hline & Control intervention: leisure activities including mahjong, cards and checkers \\
\hline & Control intervention: usual care \\
\hline & Sessions were $60 \mathrm{~min}, 3$ times/week for 3 weeks \\
\hline \multirow[t]{4}{*}{ Outcomes } & Outcomes assessed at baseline, post intervention and 4 weeks after treatment \\
\hline & Arm function: Jebsen Taylor Hand Function Test \\
\hline & Stroke Impact Scale \\
\hline & Intrinsic Motivation Inventory \\
\hline
\end{tabular}

Notes

\section{Risk of bias}

\begin{tabular}{lll}
\hline Bias & Authors' judgement & Support for judgement \\
\hline $\begin{array}{l}\text { Random sequence genera- } \\
\text { tion (selection bias) }\end{array}$ & Low risk & Computer random-number generator \\
\hline $\begin{array}{l}\text { Allocation concealment } \\
\text { (selection bias) }\end{array}$ & Unclear risk & Details not reported \\
\hline
\end{tabular}


Fan 2014 (Continued)

Blinding of outcome as- Low risk Outcome assessor blinded sessment (detection bias)

All outcomes

Incomplete outcome data High risk $\quad$ There were a relatively high proportion of withdrawals
(attrition bias)

All outcomes

Selective reporting (re- Unclear risk Unclear. Trial registry not reported

porting bias)

Galvao 2015

\begin{tabular}{|c|c|}
\hline Methods & $\mathrm{RCT}$ \\
\hline \multirow[t]{5}{*}{ Participants } & Recruited from a physiotherapy clinic in Brazil \\
\hline & 27 participants: intervention 17 , control 10 \\
\hline & Inclusion criteria: stroke, hemiparesis, aged 30-70 years \\
\hline & Exclusion criteria: failure to meet above criteria \\
\hline & Mean (SD) age: 55.06 (11.52) years, control 60.8 (10.83) years \\
\hline \multirow[t]{3}{*}{ Interventions } & VR intervention: exercises with the Nintendo Wii \\
\hline & Control intervention: conventional therapy \\
\hline & $\begin{array}{l}\text { Sessions were } 75 \mathrm{~min} \text { for the Wii group and } 60 \mathrm{~min} \text { for the conventional therapy group and a total of } 10 \\
\text { sessions were provided }\end{array}$ \\
\hline \multirow[t]{3}{*}{ Outcomes } & Outcomes were assessed post intervention \\
\hline & Fugl Meyer UL \\
\hline & Motor Activity Log \\
\hline
\end{tabular}

Notes

\section{Risk of bias}

\begin{tabular}{lll}
\hline Bias & Authors' judgement & Support for judgement \\
\hline $\begin{array}{l}\text { Random sequence genera- } \\
\text { tion (selection bias) }\end{array}$ & Low risk & Computer randomisation program \\
\hline $\begin{array}{l}\text { Allocation concealment } \\
\text { (selection bias) }\end{array}$ & Low risk & Sequentially numbered, opaque, sealed envelopes \\
\hline $\begin{array}{l}\text { Blinding of outcome as- } \\
\text { sessment (detection bias) } \\
\text { All outcomes }\end{array}$ & Low risk & Blinded \\
\hline $\begin{array}{l}\text { Incomplete outcome data } \\
\text { (attrition bias) } \\
\text { All outcomes }\end{array}$ & Unclear risk & Detail not reported \\
\hline
\end{tabular}


Galvao 2015 (Continued)

Selective reporting (re- Unclear risk $\quad$ Detail not reported
porting bias)

Givon 2016

\begin{tabular}{ll}
\hline Methods & RCT \\
\hline
\end{tabular}

Participants

NCT01304017

Recruited from the community in Israel

47 participants: 23 intervention, 24 control

Inclusion criteria: community dwelling, aged $18-8$ years and sustained a stroke $\geq 6$ months prior to the study. Able to walk $\geq 10 \mathrm{~m}$ (with or without aid) and had weakness of the UE and no significant cognitive deficits (score of $\geq 21$ or more on the MMSE)

Exclusion criteria: other neurological conditions or epilepsy

Mean (SD) age: intervention group 56.7 (9.3) years, control group 62.0 (9.3) years

$60 \%$ men

Stroke details: $85 \%$ ischaemic, $57 \%$ right hemiparesis

Timing post stroke: intervention group mean 3 (1.8) years, control group mean 2.6 (1.8) years

Interventions

VR intervention: interactive video games (Kinect, Sony Play Station Eyetoy 2, Sony Playstation 3 MOVE, Nintendo Wii Fit and SeeMe VR system) were set up in 3 workstations. Each session started with a 5-min group warm up playing a Wii Fit walking game. Participants were then divided into workstations. They played games on 1 console then rotated to another console with a new partner. All games were played in pairs while standing. Partners either took turns or played simultaneously

Control intervention: exercises and functional activities from existing community group programs such as the Fitness and Mobility Exercise Program, the GRASP program and task oriented intervention. The session started with a 5-min group warm up and then participants were divided into pairs or triads to perform functional activities such as picking up and transferring objects from 1 side of the room to the other

Sessions were $60 \mathrm{~min}$, twice/week for 3 months. Intervention in both groups delivered by an occupational therapist

Outcomes Outcomes measured at baseline, post intervention and 3 months' follow-up (after the end of intervention)

10-metre walk test

Hand grip strength

Action Research Arm Test

Other outcome measures: number of steps walked per day

Adverse events

Notes

\section{Risk of bias}


Givon 2016 (Continued)

\begin{tabular}{|c|c|c|}
\hline Bias & Authors' judgement & Support for judgement \\
\hline $\begin{array}{l}\text { Random sequence genera- } \\
\text { tion (selection bias) }\end{array}$ & Unclear risk & Detail not reported \\
\hline $\begin{array}{l}\text { Allocation concealment } \\
\text { (selection bias) }\end{array}$ & Unclear risk & Detail not reported \\
\hline $\begin{array}{l}\text { Blinding of outcome as- } \\
\text { sessment (detection bias) } \\
\text { All outcomes }\end{array}$ & Low risk & Assessor masked to allocation \\
\hline $\begin{array}{l}\text { Incomplete outcome data } \\
\text { (attrition bias) } \\
\text { All outcomes }\end{array}$ & Low risk & $\begin{array}{l}\text { Low dropouts. ITT analysis conducted with the last observation carried for- } \\
\text { ward method }\end{array}$ \\
\hline $\begin{array}{l}\text { Selective reporting (re- } \\
\text { porting bias) }\end{array}$ & High risk & Measures reported on the clinical trial registry were not reported in the paper \\
\hline
\end{tabular}

Han 2013

\begin{tabular}{|c|c|}
\hline Methods & RCT \\
\hline \multirow[t]{8}{*}{ Participants } & Recruited from a tertiary hospital in Korea \\
\hline & 12 participants: 6 intervention, 6 control \\
\hline & Inclusion criteria: impaired standing balance (Berg Balance Scale $<40$ ) however can stand for $\geq 1$ min \\
\hline & Exclusion criteria: none reported \\
\hline & Mean (SD) age: total sample 60.1 (17.6) years \\
\hline & $50 \%$ men \\
\hline & Stroke details: not reported \\
\hline & Timing post stroke: not reported \\
\hline \multirow[t]{3}{*}{ Interventions } & VR intervention: IREX system (games: Birds and Balls, Soccer, Conveyor, Drums, Sharkbait) \\
\hline & Control intervention: balance training using tetrataxiometric posturography \\
\hline & Sessions were $30 \mathrm{~min} / \mathrm{day}, 3 \mathrm{~d} /$ week for 3 weeks \\
\hline \multirow[t]{4}{*}{ Outcomes } & Outcomes assessed post intervention \\
\hline & Balance: Berg Balance Scale \\
\hline & Modified Barthel Index \\
\hline & Tetraataxiometric posturography \\
\hline
\end{tabular}

\section{Risk of bias}

Bias Authors' judgement Support for judgement


Han 2013 (Continued)

Random sequence genera- Unclear risk $\quad$ Not reported (conference abstract)
tion (selection bias)

\begin{tabular}{|c|c|}
\hline $\begin{array}{l}\text { Allocation concealment } \\
\text { (selection bias) }\end{array}$ & Unclear risk \\
\hline
\end{tabular}

(selection bias)

$\begin{array}{ll}\text { Blinding of outcome as- } & \text { Unclear risk }\end{array}$ Not reported (conference abstract)

All outcomes

Incomplete outcome data Unclear risk Not reported (conference abstract)
(attrition bias)
All outcomes

Selective reporting (re- Unclear risk $\quad$ Not reported (conference abstract)
porting bias)

Housman 2009

Methods RCT

Participants $\quad$ Recruited from 1 rehabilitation institute in Chicago, USA

34 participants: 17 intervention, 17 control

Inclusion criteria: single stroke $\geq 6$ months ago, Fugl Meyer UE score 10-30

Exclusion criteria: significant pain or instability of the shoulder, current participation in upper limb therapy program, severe cognitive dysfunction, aphasia, neglect, apraxia

Mean (SD) age: intervention group 54 (12) years, control group 56 (13) years

$64 \%$ men

Stroke details: $61 \%$ ischaemic, $29 \%$ right hemiparesis

Timing post stroke: intervention group mean (SD) 85 (96) months, control group 112 (129) months

Interventions

VR intervention: a custom-designed software package ('Vu Therapy') provided activities including grocery shopping, cleaning a stove and playing basketball. The participant wore an arm orthosis (T-WREX), which supports the weight of the arm allowing movement in the horizontal and vertical plane. Position sensors at each joint enable interaction with the virtual environment

Control intervention: UE exercises including passive and active ranging, stretching, strengthening and using the arm in functional tasks

Both groups involved 3 sessions of direct training followed by semi-autonomous practice in the research clinic

Sessions were $60 \mathrm{~min}$, approximately 3 times/week for 6 weeks (approximately $24 \mathrm{~h}$ total)

Outcomes Outcomes recorded at baseline, post-intervention and at 6 months

Upper limb function and activity outcomes: Fugl Meyer UE Scale, Rancho Functional test UE, Reaching ROM (deficit)

Hand function and activity: grip strength (dynamometer)

Participation restriction and quality of life: Motor Activity Log (amount of use and quality of movement) 
Housman 2009 (Continued)

Adverse events reported

Notes $\quad-$

\section{Risk of bias}

\begin{tabular}{lll}
\hline Bias & Authors' judgement & Support for judgement \\
\hline $\begin{array}{l}\text { Random sequence genera- } \\
\text { tion (selection bias) }\end{array}$ & Low risk & $\begin{array}{l}\text { Participants were randomly assigned using a lottery system in which the su- } \\
\text { pervising therapist (with an independent witness) drew a labelled tile from } \\
\text { an opaque container. Randomisation occurred in blocks of } 4 \text { to ensure equal } \\
\text { numbers in each group }\end{array}$ \\
& &
\end{tabular}

\begin{tabular}{|c|c|c|}
\hline $\begin{array}{l}\text { Allocation concealment } \\
\text { (selection bias) }\end{array}$ & High risk & $\begin{array}{l}\text { Participants were allocated in strict sequential order of enrolment. However, } \\
\text { with small blocks of } 4 \text { and the use of tiles it might have been possible to pre- } \\
\text { dict allocation in advance in some cases }\end{array}$ \\
\hline
\end{tabular}
dict allocation in advance in some cases

\begin{tabular}{|c|c|c|}
\hline $\begin{array}{l}\text { Blinding of outcome as- } \\
\text { sessment (detection bias) } \\
\text { All outcomes }\end{array}$ & Low risk & Rater was blinded to allocation \\
\hline $\begin{array}{l}\text { Incomplete outcome data } \\
\text { (attrition bias) } \\
\text { All outcomes }\end{array}$ & Low risk & $\begin{array}{l}\text { Small number of dropouts balanced across groups with similar reasons for } \\
\text { dropout }\end{array}$ \\
\hline $\begin{array}{l}\text { Selective reporting (re- } \\
\text { porting bias) }\end{array}$ & Low risk & No other outcomes were collected \\
\hline
\end{tabular}

\section{Hung 2014}

Methods RCT

Participants $\quad$ Recruited from an outpatient rehabilitation setting in Taiwan

30 participants: 15 intervention group, 15 control group

Inclusion criteria: stroke with resulting hemiplegia $\geq 6$ months prior to enrolment. Aged $>18$ years and had a Berg Balance Scale score $<56$. Able to understand verbal instructions and watch a television screen satisfactorily. Able to walk independently with or without a device for $10 \mathrm{~m}$

Exclusion criteria: bilateral lesions, receptive aphasis, significant visual field deficits or hemineglect and concomitant other neurological diagnoses or conditions that would prevent adherence to the exercise protocol

Mean (SD) age: intervention group 55.38 (9.95) years, control group 53.40 (10.03) years

$60 \%$ men

Stroke details: $53 \%$ ischaemic, $37 \%$ right hemiparesis

Timing post stroke: intervention group mean (SD) 21 (11.26) months, control group 15.93 (8.02) months

Interventions

VR intervention: Nintendo Wii Fit. 7 games (Table tilt, Ski Slalom, Soccer, Balance Bubble, Penguin Slide, Basic Step and Warrior) were selected. At each session the therapist supervised 2-4 games for participants according to their ability, needs and favourites. A walker was placed in front of the balance board for safety.

Control intervention: weight shift and balance exercises 
Hung 2014 (Continued)

Sessions were twice/week for 12 weeks and were run by an occupational therapist

\begin{tabular}{ll}
\hline Outcomes & Outcomes assessed post intervention and at 3 months' follow-up \\
Tetrax Interactive Balance Systems \\
Timed Up and Go Test \\
Forward Reach Test \\
Falls Efficacy Scale International \\
Adverse events \\
\hline Notes
\end{tabular}

\section{Risk of bias}

\begin{tabular}{lll}
\hline Bias & Authors' judgement & Support for judgement \\
\hline $\begin{array}{l}\text { Random sequence genera- } \\
\text { tion (selection bias) }\end{array}$ & Low risk & Random number table \\
\hline $\begin{array}{l}\text { Allocation concealment } \\
\text { (selection bias) }\end{array}$ & Low risk & Sequentially numbered, opaque, sealed envelopes \\
\hline $\begin{array}{l}\text { Blinding of outcome as- } \\
\text { sessment (detection bias) } \\
\text { All outcomes }\end{array}$ & Low risk & Blinded to allocation \\
\hline $\begin{array}{l}\text { Incomplete outcome data } \\
\text { (attrition bias) } \\
\text { All outcomes }\end{array}$ & Low risk & Low attrition with clear rationale. Used data of actual number contributing \\
\hline $\begin{array}{l}\text { Selective reporting (re- } \\
\text { porting bias) }\end{array}$ & Unclear risk & No study protocol or trial registration reported \\
\hline
\end{tabular}

\begin{tabular}{ll}
\hline Jaffe 2004 & RCT \\
\hline Methods & Recruited from community stroke association meetings in California, USA \\
\hline Participants & 20 participants: 10 intervention, 10 control \\
& Inclusion criteria: $>6$ months post stroke with a diagnosis of hemiplegia secondary to single document- \\
& ed lesion, walked independently or with an aid and had an asymmetric gait pattern and short step- \\
& length with either step (<95th percentile of normal step length), scores representing average or mini- \\
& mally impaired in all Cognistat categories unless performance was markedly limited by aphasia making \\
& assessment of cognition difficult \\
& Exclusion criteria: neurological diagnoses of spinal cord injury, multiple sclerosis or brainstem lesion; \\
any progressive critical or long-term illness or unstable cardiovascular, orthopaedic, musculoskeletal \\
or neurological condition that precluded exercise or was not controlled by medication or required oxy- \\
gen during ambulation \\
Mean (SD) age: intervention group 58 (11) years, control group 63 (8) years \\
60\% men
\end{tabular}


Jaffe 2004 (Continued)

Stroke details: $50 \%$ right hemiparesis

Timing post stroke: intervention group 4 years (SD 2), control group 4 years (SD 3)

Interventions

VR intervention: participants walked on a treadmill at a self-selected walking speed and were secured by an overhead harness. The participant wore a head-mounted display that showed real-time video images of their feet walking and virtual objects. The participant was asked to step over the virtual objects and visual, vibrotactile and auditory feedback was provided during any collisions

Control intervention: participants wore a gait belt and stepped over foam obstacles in a hallway. The sessions were videotaped and reviewed for collisions with the obstacles after the session was completed

Sessions were approximately $60 \mathrm{~min}$, for 6 sessions over 2 weeks ( $6 \mathrm{~h}$ total)

\begin{tabular}{|c|c|}
\hline \multirow[t]{3}{*}{ Outcomes } & Outcomes recorded at baseline, post-intervention and 2 weeks post-intervention \\
\hline & $\begin{array}{l}\text { Lower limb function and activity outcomes: } 6 \text {-m walk test, obstacle test, } 6 \mathrm{MWT} \text {, the researcher's own } \\
\text { balance test (adapted from others) that included natural stance, eyes closed, on toes, tandem stance, } \\
\text { left and right leg stand }\end{array}$ \\
\hline & Adverse events reported \\
\hline
\end{tabular}

Notes -

\section{Risk of bias}

\begin{tabular}{lll}
\hline Bias & Authors' judgement & Support for judgement \\
\hline $\begin{array}{l}\text { Random sequence genera- } \\
\text { tion (selection bias) }\end{array}$ & Low risk & $\begin{array}{l}\text { An Excel spreadsheet was generated with a pre-determined computerised ran- } \\
\text { domisation sequence }\end{array}$ \\
\hline $\begin{array}{l}\text { Allocation concealment } \\
\text { (selection bias) }\end{array}$ & High risk & $\begin{array}{l}\text { The allocation in the spreadsheet was not visible due to black font and black } \\
\text { background shading; however, there is the possibility that staff with access to } \\
\text { the spreadsheet could have checked this }\end{array}$
\end{tabular}

Blinding of outcome as- Low risk Unaware of allocation

sessment (detection bias)

All outcomes

$\begin{array}{ll}\begin{array}{l}\text { Incomplete outcome data Low risk } \\ \text { (attrition bias) }\end{array} & \begin{array}{l}\text { No outcome data were missing (according to personal correspondence with } \\ \text { the researcher) }\end{array}\end{array}$

All outcomes the researcher)

Selective reporting (re- Unclear risk Unclear - not privy to protocol porting bias)

\begin{tabular}{ll} 
Jang 2005 & RCT \\
\hline Methods & Study took place in Korea \\
& 10 participants: 5 intervention, 5 control \\
& Inclusion criteria: $>6$ months post first stroke, able to move the elbow against gravity
\end{tabular}


Jang 2005 (Continued)

Exclusion criteria: severe spasticity (Modified Ashworth Score of $>2$ ) or tremor. Severe visual and cognitive impairments

Mean (SD) age: intervention group 60 (8) years, control group 54 (12) years

$60 \%$ men

Stroke details: $60 \%$ ischaemic, $50 \%$ right hemiparesis

Timing post stroke: intervention group 14 months, control group 13 months

Interventions

VR intervention: IREX VR system using a video capture system to capture the participant's whole body movement. The participant was able to view their body movements in real time on a screen in front of them immersed in a virtual environment. The games included soccer and moving objects from a conveyor belt and focused on reaching, lifting and grasping

Control intervention: no intervention provided

Sessions for the VR intervention group were $60 \mathrm{~min}, 5$ times/week for 4 weeks ( $20 \mathrm{~h}$ total)

Outcomes Outcomes recorded at baseline and post-intervention

Upper limb (arm) function and activity outcomes: Fugl Meyer UE Scale, Manual Function Test

Upper limb (hand) function and activity outcomes: Box and Block Test

Participation restriction and quality of life: Motor Activity Log (amount of use and quality of movement)

Other outcomes: functional MRI (laterality index and activated voxels)

Notes -

\section{Risk of bias}

\begin{tabular}{lll}
\hline Bias & Authors' judgement & Support for judgement \\
\hline $\begin{array}{l}\text { Random sequence genera- } \\
\text { tion (selection bias) }\end{array}$ & Unclear risk & Unclear \\
\hline $\begin{array}{l}\text { Allocation concealment } \\
\text { (selection bias) }\end{array}$ & Unclear risk & Unclear \\
\hline $\begin{array}{l}\text { Blinding of outcome as- } \\
\text { sessment (detection bias) } \\
\text { All outcomes }\end{array}$ & Unclear risk & Unclear \\
\hline $\begin{array}{l}\text { Incomplete outcome data } \\
\text { (attrition bias) } \\
\text { All outcomes }\end{array}$ & Unclear risk & Unclear \\
\hline $\begin{array}{l}\text { Selective reporting (re- } \\
\text { porting bias) }\end{array}$ & Unclear risk & Unclear \\
\hline
\end{tabular}

Jannink 2008

\begin{tabular}{ll}
\hline Methods & RCT \\
\hline Participants & Recruited from a rehabilitation centre in the Netherlands \\
\hline
\end{tabular}


Jannink 2008 (Continued)

10 participants: 5 intervention, 5 control

Inclusion criteria: not reported

Exclusion criteria: not reported

Mean (SD) age: intervention group 62 (3) years, control group 58 (13) years

Timing post stroke: intervention group mean (SD) $89 \mathrm{~d}(31)$, control group $112 \mathrm{~d}(50)$

Interventions

VR intervention: the participant sat on an electric scooter with customised interface and completed training in a traffic garden, residential area and a grocery store. The virtual environment was displayed using a head-mounted device as well as a computer display. Training included $50 \%$ of the time using the VR simulation program and 50\% training in the real world

Control intervention: real-world scooter training program

Sessions were $30 \mathrm{~min}$, twice/week for 5 weeks ( $5 \mathrm{~h}$ total)

Outcomes Outcomes recorded at baseline and 5 weeks after training

Other outcome measures: Functional Evaluation Rating Scale, Subjective Experience Questionnaire

Notes -

\section{Risk of bias}

\begin{tabular}{lll}
\hline Bias & Authors' judgement & Support for judgement \\
\hline $\begin{array}{l}\text { Random sequence genera- } \\
\text { tion (selection bias) }\end{array}$ & Unclear risk & Unclear \\
\hline $\begin{array}{l}\text { Allocation concealment } \\
\text { (selection bias) }\end{array}$ & Unclear risk & Unclear \\
\hline $\begin{array}{l}\text { Blinding of outcome as- } \\
\text { sessment (detection bias) } \\
\text { All outcomes }\end{array}$ & Unclear risk & Unclear \\
\hline $\begin{array}{l}\text { Incomplete outcome data } \\
\text { (attrition bias) }\end{array}$ & Unclear risk & Unclear \\
All outcomes & & \\
\hline $\begin{array}{l}\text { Selective reporting (re- } \\
\text { porting bias) }\end{array}$ & Unclear risk & Unclear \\
\hline
\end{tabular}

Jung 2012

\begin{tabular}{ll}
\hline Methods & RCT \\
\hline Participants & Recruited from outpatient community centre in Korea \\
& 21 participants: 11 intervention, 10 control \\
& $\begin{array}{l}\text { Inclusion criteria: participants within } 6 \text { months after first stroke with a history of falling. Able to walk in- } \\
\text { dependently for }>30 \text { min with no cognitive impairment, Brunnstrom Stage }>4 \text { and no cardiovascular, } \\
\text { orthopaedic or other neurological conditions that may interfere with study procedures }\end{array}$ \\
& Exclusion criteria: not reported
\end{tabular}


Jung 2012 (Continued)

Mean (SD) age: intervention group 60.5 (8.6) years, control group 63.6 (5.1) years

$62 \%$ men

Stroke details: $52 \%$ right-sided hemiparesis

Timing post stroke: intervention group mean (SD) 12.6 (3.3) months, control group 15.4 (4.7) months

Interventions $\quad$ VR intervention: treadmill training while viewing a virtual scene through a head-mounted device. The
VR program simulated a park stroll

Control intervention: treadmill training without the VR program

Sessions were $30 \mathrm{~min} / \mathrm{d}, 5$ times a week for 3 weeks (approximately $7.5 \mathrm{~h}$ total)

Outcomes Outcomes recorded at baseline and post-intervention

Gait outcomes: Timed Up and Go Test

Other outcomes: Activity Specific Balance Confidence Scale

\begin{tabular}{|c|c|c|}
\hline Notes & - & \\
\hline \multicolumn{3}{|l|}{ Risk of bias } \\
\hline Bias & Authors' judgement & Support for judgement \\
\hline $\begin{array}{l}\text { Random sequence genera- } \\
\text { tion (selection bias) }\end{array}$ & Low risk & Drawing lots \\
\hline $\begin{array}{l}\text { Allocation concealment } \\
\text { (selection bias) }\end{array}$ & Unclear risk & Not reported \\
\hline $\begin{array}{l}\text { Blinding of outcome as- } \\
\text { sessment (detection bias) } \\
\text { All outcomes }\end{array}$ & Low risk & Blinded assessment \\
\hline $\begin{array}{l}\text { Incomplete outcome data } \\
\text { (attrition bias) } \\
\text { All outcomes }\end{array}$ & Unclear risk & Unclear \\
\hline $\begin{array}{l}\text { Selective reporting (re- } \\
\text { porting bias) }\end{array}$ & Unclear risk & Unclear \\
\hline
\end{tabular}

Kang 2009

\begin{tabular}{ll}
\hline Methods & RCT \\
\hline Participants & Study took place in Korea \\
& 16 participants: 8 intervention, 8 control \\
& Inclusion criteria: left hemiplegia after stroke, MMSE score of $>18 / 30$ and Motor Free Visual Perception \\
& Test standard score $<109$ \\
& Exclusion criteria: significant multiple small lacunar infarct, significantly decreased visual acuity or vi- \\
sual impairment from diabetic retinopathy or senile cataract, hearing difficulty or cranial nerve dys- \\
function
\end{tabular}


Kang 2009 (Continued)

Mean (SD) age: intervention group 60 (11) years, control group 63 (10) years

Timing post stroke: intervention group mean (SD) 64 (37) d, control group 58 (30) d

Interventions $\begin{aligned} & \text { VR intervention: participants were seated and participated in visual spatial and motor tasks using their } \\ & \text { unaffected arm. Software recognised and displayed the movements of the hand through a camera and } \\ & \text { displayed the images on a computer screen }\end{aligned}$
Control intervention: training using the PSS CogRehab program
Sessions were 30 min, 3 times/week for 4 weeks ( 6 h total)

Outcomes

Outcomes recorded at baseline and post-intervention

Cognitive outcome measures: MMSE

Activity limitation outcomes: Modified Barthel Index

Other outcome measures: motor free visual perception test, interest in performing the task

\begin{tabular}{lll}
\hline Notes & - \\
\hline Risk of bias & & \\
\hline Bias & Authors' judgement & Support for judgement \\
\hline $\begin{array}{l}\text { Random sequence genera- } \\
\text { tion (selection bias) }\end{array}$ & Low risk & $\begin{array}{l}\text { Random allocation using block randomisation process. Envelopes were shuf- } \\
\text { fled and the participant drew } 1 \text { after enrolment }\end{array}$ \\
\hline $\begin{array}{l}\text { Allocation concealment } \\
\text { (selection bias) }\end{array}$ & Unclear risk & Whether the envelopes were opaque is unclear \\
\hline $\begin{array}{l}\text { Blinding of outcome as- } \\
\text { sessment (detection bias) } \\
\text { All outcomes }\end{array}$ & Low risk & Blind \\
\hline $\begin{array}{l}\text { Incomplete outcome data } \\
\text { (attrition bias) }\end{array}$ & Low risk & $\begin{array}{l}\text { There does not appear to be any attrition and all outcome measures appear to } \\
\text { All outcomes }\end{array}$ \\
\hline $\begin{array}{l}\text { Selective reporting (re- } \\
\text { porting bias) }\end{array}$ & Unclear risk & \begin{tabular}{l} 
Unclear - not privy to protocol \\
\hline
\end{tabular}
\end{tabular}

Kim 2009

Methods RCT

Participants Study took place in Korea

24 participants: 12 intervention, 12 control

Inclusion criteria: $\geq 1$ year post stroke with plateau in motor recovery after conventional rehabilitation and the ability to stand for $30 \mathrm{~min}$ and walk indoors independently (approximately $30 \mathrm{~m}$ )

Exclusion criteria: severe visual or cognitive impairment or musculoskeletal disorders that could interfere with tests

Mean (SD) age: intervention group 52 (10) years, control group 52 (7) years 
Kim 2009 (Continued)

\section{$54 \%$ men}

Timing post stroke: intervention group mean (SD) 26 (10) months, control group 24 (9) months

Interventions

VR intervention: IREX VR system using a video capture system to capture the participant's whole body movement. The participant was able to view their body movements in real time on a screen in front of them immersed in a virtual environment. Games included stepping up/down, shark bait (capturing stars while avoiding eels and sharks by weight shift) and snowboarding. Participants were challenged by increasing resistance (e.g. adding weights) or increasing the speed.

Control intervention: conventional physiotherapy designed to facilitate standing balance function during walking. Included practice of weight shift, muscle strengthening, functional reach or picking up objects

Sessions for VR group: 30 min, 4 times/week for 4 weeks ( 8 h) of VR plus conventional physiotherapy 40 $\mathrm{min}, 4$ times/week for 4 weeks (approximately $10.5 \mathrm{~h}$ ) (approximately $18.5 \mathrm{~h}$ total)

Sessions for control group: $40 \mathrm{~min}, 4$ times/week for 4 weeks (approximately $10.5 \mathrm{~h}$ total)

Outcomes Outcomes recorded at baseline and post intervention

Lower limb function and activity outcomes: 10-m walk test, GAIT-RITE gait analysis system, Berg balance scale, Balance performance monitor

Global motor function outcomes: modified Motor Assessment Scale

\section{Notes}

\section{Risk of bias}

\begin{tabular}{lll}
\hline Bias & Authors' judgement & Support for judgement \\
\hline $\begin{array}{l}\text { Random sequence genera- } \\
\text { tion (selection bias) }\end{array}$ & Low risk & The sequence was generated using a lottery system \\
\hline $\begin{array}{l}\text { Allocation concealment } \\
\text { (selection bias) }\end{array}$ & Low risk & Using sealed, opaque envelopes \\
\hline $\begin{array}{l}\text { Blinding of outcome as- } \\
\text { sessment (detection bias) } \\
\text { All outcomes }\end{array}$ & Low risk & Blind \\
\hline
\end{tabular}

\begin{tabular}{l}
\hline $\begin{array}{l}\text { Incomplete outcome data Low risk Does not appear to have any missing data } \\
\text { (attrition bias) } \\
\text { All outcomes }\end{array}$ \\
\hline
\end{tabular}

Selective reporting (re- Low risk No other outcomes were collected
porting bias)

\begin{tabular}{ll} 
Kim 2011a & \\
\hline Methods & RCT \\
\hline Participants & 28 participants: 15 intervention, 13 control \\
& Inclusion criteria: not stated
\end{tabular}


Kim 2011a (Continued)

Exclusion criteria: people with a MMSE-K score of < 10; people presenting with severe cognitive impairment of aphasia and unable to understand instructions. People with poor sitting balance such that they could not sit on a chair with back and armrests. People with limited ROM of the neck due to orthopaedic problems, and people with loss of visual acuity such that they could not perceive content on a computer screen

Mean (SD) age: intervention group 66.5 (11) years, control group 62 (15.8) years

$39 \%$ men

Stroke details: $39 \%$ right hemiparesis

Timing post stroke: intervention group mean (SD) 18.2 (11.3) d, control group 24 (31.1) d

Interventions

VR intervention: IREX system (30 min 3 times/week) plus computer-assisted cognitive rehabilitation (30 min twice/week)

Control intervention: computer-assisted rehabilitation (30 min 5 times/week)

Sessions were 30 min, 5 times/week over 4 weeks (approximately 6 h of VR in total)

Outcomes recorded at baseline and post intervention
Upper limb function outcomes: Motricity index
Lower limb function outcomes: Motricity index
Cognitive function: computerised neuropsychological test and Tower of London test
Activity limitation outcome: Korean modified Barthel Index

Notes

\section{Risk of bias}

\begin{tabular}{|c|c|c|}
\hline Bias & Authors' judgement & Support for judgement \\
\hline $\begin{array}{l}\text { Random sequence genera- } \\
\text { tion (selection bias) }\end{array}$ & Unclear risk & Not reported \\
\hline $\begin{array}{l}\text { Allocation concealment } \\
\text { (selection bias) }\end{array}$ & Unclear risk & Not reported \\
\hline $\begin{array}{l}\text { Blinding of outcome as- } \\
\text { sessment (detection bias) } \\
\text { All outcomes }\end{array}$ & High risk & Not blinded \\
\hline $\begin{array}{l}\text { Incomplete outcome data } \\
\text { (attrition bias) } \\
\text { All outcomes }\end{array}$ & Low risk & No withdrawals \\
\hline $\begin{array}{l}\text { Selective reporting (re- } \\
\text { porting bias) }\end{array}$ & Low risk & No other outcome data collected \\
\hline
\end{tabular}

Kim 2011b

\begin{tabular}{ll}
\hline Methods & RCT \\
\hline Participants & Recruited from Department of Rehabilitation, Korea \\
\hline
\end{tabular}


Kim 2011b (Continued)

24 participants: 12 intervention, 12 control

Inclusion criteria: participants diagnosed with unilateral spatial neglect through the line bisection test or star cancellation test

Exclusion criteria: severe cognitive impairment or aphasia; insufficient sitting balance to sit on a chair with a back and armrests; restricted neck movement, poor eyesight or unable to recognise objects on a screen

Mean (SD) age: intervention group 62.3 (10.2) years, control group 67.2 (13.9) years

$58 \%$ men

Timing post stroke: intervention group 22.8 (7.6) d, control group 25.5 (18.5) d

\begin{tabular}{ll}
\hline Interventions & VR intervention: IREX \\
& $\begin{array}{l}\text { Control intervention: conventional rehabilitation tasks such as visual tracking, reading and writing, } \\
\text { drawing and puzzles }\end{array}$ \\
& Sessions were $30 \mathrm{~min}, 5 \mathrm{~d} /$ week for 3 weeks (approximately $7.5 \mathrm{~h}$ total)
\end{tabular}

Outcomes

Outcomes recorded at baseline and post-intervention

Activity limitation outcomes: Korean Modified Barthel Index

Other outcomes: Star cancellation test, Line bisection test, Catherine Bergego Scale

\begin{tabular}{lll}
\hline Notes & - \\
\hline Risk of bias & \\
\hline Bias & Authors' judgement & Support for judgement \\
\hline $\begin{array}{l}\text { Random sequence genera- } \\
\text { tion (selection bias) }\end{array}$ & Unclear risk & Not reported \\
\hline $\begin{array}{l}\text { Allocation concealment } \\
\text { (selection bias) }\end{array}$ & Unclear risk & Not reported \\
\hline $\begin{array}{l}\text { Blinding of outcome as- } \\
\text { sessment (detection bias) } \\
\text { All outcomes }\end{array}$ & Low risk & Blinded to allocation \\
\hline $\begin{array}{l}\text { Incomplete outcome data } \\
\begin{array}{l}\text { (attrition bias) } \\
\text { All outcomes }\end{array}\end{array}$ & Low risk & No withdrawals \\
\hline $\begin{array}{l}\text { Selective reporting (re- } \\
\text { porting bias) }\end{array}$ & Low risk & No other outcome data collected \\
\hline
\end{tabular}

Kim 2012a

\begin{tabular}{ll}
\hline Methods & RCT \\
\hline Participants & Recruited from an inpatient setting in Korea \\
& 20 participants: 10 intervention, 10 control \\
\hline
\end{tabular}


Kim 2012a (Continued)

Inclusion criteria: > 6 months post diagnosis of stroke. Score of $\geq 19 / 30$ on the MMSE. Able to maintain upright posture without any assistance

Exclusion criteria: orthopaedic surgery, history of arthritis, hand or upper limb pain, epilepsy, psychiatric illnesses

Mean age: not reported

Timing post stroke: intervention group mean (SD) 12.6 (7.12) months, control group 12.85 (6.06) months

\begin{tabular}{|c|c|c|}
\hline Interventions & \multicolumn{2}{|c|}{$\begin{array}{l}\text { VR intervention: Nintendo Wii Sports (boxing and tennis) } \\
\text { Control intervention: no intervention } \\
\text { Sessions were } 30 \text { min, } 3 \text { times/week for } 3 \text { weeks }\end{array}$} \\
\hline Outcomes & $\begin{array}{l}\text { Outcomes recorded a } \\
\text { Gait outcomes: postur } \\
\text { Global motor function } \\
\text { Activity limitation out }\end{array}$ & $\begin{array}{l}\text { laseline and post intervention } \\
\text { assessment scale } \\
\text { utcomes: modified Motor Assessment Scale } \\
\text { mes: Functional Independence Measure }\end{array}$ \\
\hline Notes & \multicolumn{2}{|l|}{-} \\
\hline \multicolumn{3}{|l|}{ Risk of bias } \\
\hline Bias & Authors' judgement & Support for judgement \\
\hline $\begin{array}{l}\text { Random sequence genera- } \\
\text { tion (selection bias) }\end{array}$ & Unclear risk & Not reported \\
\hline $\begin{array}{l}\text { Allocation concealment } \\
\text { (selection bias) }\end{array}$ & Unclear risk & Not reported \\
\hline $\begin{array}{l}\text { Blinding of outcome as- } \\
\text { sessment (detection bias) } \\
\text { All outcomes }\end{array}$ & Unclear risk & Not reported \\
\hline $\begin{array}{l}\text { Incomplete outcome data } \\
\text { (attrition bias) } \\
\text { All outcomes }\end{array}$ & Unclear risk & Not reported in adequate detail to make judgement \\
\hline $\begin{array}{l}\text { Selective reporting (re- } \\
\text { porting bias) }\end{array}$ & Unclear risk & No access to protocol \\
\hline
\end{tabular}

Kiper 2011

\begin{tabular}{ll}
\hline Methods & RCT \\
\hline Participants & Recruited from an institute of rehabilitation, Italy \\
& 80 participants: 40 intervention, 40 control \\
& Inclusion criteria: diagnosis of stroke within 1 year of enrolment and score of $>24 / 30$ on the MMSE
\end{tabular}


Kiper 2011 (Continued)

Exclusion criteria: clinical evidence of cognitive impairment, apraxia, neglect, language disturbance, complete paralysis of the UE, upper limb sensory disorders or post-traumatic injury, which prevented the execution of exercises

Mean (SD) age: 64 (16.4) years

$58 \%$ men

Time since onset of stroke: mean (SD) 5.7 (3.5) months

Interventions $\quad$ VR intervention: reinforced feedback in virtual environment (RFVE). Participants in the intervention group received $1 \mathrm{~h}$ of traditional rehabilitation and $1 \mathrm{~h}$ of RFVE. The RFVE involved sitting in front of a wall screen grasping a sensorised real object (ball, disc or cube) with the affected hand. The target objects were displayed on the wall screen. The physiotherapist created a sequence of virtual tasks that the participant had to perform on his workstation (e.g. pouring water from a glass, using a hammer)

Control intervention: traditional neuromotor rehabilitation including postural control, exercises for hand pre-configuration, manipulative and functional skills, proximal-distal exercises

Sessions were $1 \mathrm{~h} / \mathrm{d}, 5 \mathrm{~d} /$ week for 4 weeks (approximately $20 \mathrm{~h}$ total)

\begin{tabular}{ll}
\hline Outcomes & Outcomes recorded at baseline and post intervention \\
Upper limb function outcomes: Fugl Meyer \\
Activity limitation outcomes: Functional Independence Measure \\
Other outcomes: Modified Ashworth Scale (spasticity) \\
Adverse events reported \\
\hline Notes
\end{tabular}

\section{Risk of bias}

\begin{tabular}{lll}
\hline Bias & Authors' judgement & Support for judgement \\
\hline $\begin{array}{l}\text { Random sequence genera- } \\
\text { tion (selection bias) }\end{array}$ & Low risk & Computer-generated sequence \\
\hline $\begin{array}{l}\text { Allocation concealment } \\
\text { (selection bias) }\end{array}$ & Low risk & Opaque envelopes \\
\hline $\begin{array}{l}\text { Blinding of outcome as- } \\
\text { sessment (detection bias) } \\
\text { All outcomes }\end{array}$ & Low risk & Masked to allocation \\
\hline $\begin{array}{l}\text { Incomplete outcome data } \\
\text { (attrition bias) }\end{array}$ & Low risk \\
$\begin{array}{ll}\text { All outcomes } \\
\text { Selective reporting (re- } \\
\text { porting bias) }\end{array}$ & Low risk & No dropouts \\
\hline
\end{tabular}

\section{Klamroth-Marganska 2014}

\begin{tabular}{ll}
\hline Methods & RCT \\
\hline Participants & 77 participants: 39 VR group, 38 control group \\
\hline
\end{tabular}

Virtual reality for stroke rehabilitation (Review) 
Klamroth-Marganska 2014 (Continued)

Recruited from 4 clinical settings in Switzerland

Main inclusion criteria: diagnosis of 1 , first ever cerebrovascular accident verified by brain imaging (MRI or CT); chronic impairment after stroke (minimum 6 months); moderate-severe arm paresis, as indicated by a score of 8-38 on arm section of Fugl-Meyer assessment (which has a maximum of 66 points); aged $\geq 18$ years; able to sit in a chair without any additional support and without leaning on the back rest; passive ROM in the shoulder as assessed with the neutral zero method: anteversion/retroversion $80^{\circ} / 0^{\circ} / 20^{\circ}$, abduction/adduction $60^{\circ} / 0^{\circ} / 10^{\circ}$, inner and outer rotation $20^{\circ} / 0^{\circ} / 20^{\circ}$; passive ROM in the elbow as assessed with the neutral zero method; flexion/extension $100^{\circ} / 40^{\circ} / 40^{\circ}$; no excessive spasticity of the affected arm (modified Ashworth Scale $\leq 3$ ); no serious medical or psychiatric disorder as assessed by their physician; no cybersickness (nausea when looking at a screen or playing computer games); no pacemaker or other implanted electric devices; bodyweight < $120 \mathrm{~kg}$; no serious cognitive defects or aphasia

Mean age (SD): intervention group 55 (13), control group 58 (14) years

$60 \%$ men

Timing post stroke: mean (SD) 52 (44) months intervention group, 40 (45) months control group

Interventions VR intervention: during the robotic therapy with ARM in, each of 3 therapy modes (mobilisation, games, and training for $A D L$ ) had to be done for $\geq 10 \mathrm{~min}$

Control intervention: common neurorehabilitation treatment given to patients after stroke in outpatient facilities, namely OT or physiotherapy. Therapists were asked to give regular therapy, usually including mobilisation, games, ADL, or any combination of the 3 . Their only restriction was not to use automated technical devices that might be available in therapy settings.

For both groups, therapy was given 3 times/week in the centres for a period of 8 weeks (total 24 sessions) and sessions were $\geq 45 \mathrm{~min}$

Outcomes

Outcomes assessed 3-4 weeks before assignment, immediately before therapy (baseline), after 4 weeks of therapy, at the end of 8 weeks of therapy, and 16 weeks and 34 weeks after baseline

Upper limb function: Fugl Meyer UE, Wolf Motor Function Test, Motor Activity Log (quality of movement)

Quality of life and participation: Stroke Impact Scale, Goal attainment scale

Adverse events reported

Notes NCT00719433

\section{Risk of bias}

\begin{tabular}{lll}
\hline Bias & Authors' judgement & Support for judgement \\
\hline $\begin{array}{l}\text { Random sequence genera- } \\
\text { tion (selection bias) }\end{array}$ & Low risk & Computer-generated list \\
\hline $\begin{array}{l}\text { Allocation concealment } \\
\text { (selection bias) }\end{array}$ & Low risk & Tamper-evident envelopes \\
\hline $\begin{array}{l}\text { Blinding of outcome as- } \\
\text { sessment (detection bias) } \\
\text { All outcomes }\end{array}$ & Low risk & Assessors were masked to treatment allocation \\
\hline $\begin{array}{l}\text { Incomplete outcome data } \\
\text { (attrition bias) } \\
\text { All outcomes }\end{array}$ & Low risk & Few withdrawals. ITT analysis conducted \\
\hline
\end{tabular}


Klamroth-Marganska 2014 (Continued)

Selective reporting (re- Low risk $\quad$ Registered on clinical trial
porting bias)

Ko 2015

\begin{tabular}{ll}
\hline Methods & RCT \\
\hline Participants & Recruited via a hospital in Korea \\
& 2 participants: 26 intervention, 26 control \\
& Inclusion criteria: 1865 years old and diagnosed with stroke within the last 6 months; able to walk > 10 \\
m without or with assisting devices such as orthotics, a walker, or a cane; no symptoms with any low- & er motor neuron lesion and orthopedic diseases; a score $>24$ points on the MMSE; and able to read the \\
words on a monitor 60 cm away at eye level & \\
& Exclusion criteria: failure to meet inclusion criteria \\
& Mean (SD) age: intervention group 48.1 (4.4) years, control group 45.3 (4.2) years \\
& $69 \%$ men
\end{tabular}

Interventions

VR intervention: the Space Balance 3D training system is equipped with 2 wireless force plates. 3 kinds of balance training were implemented using Space Balance 3D, which can be used for both training and testing. According to the participants' movement, the real-time tilting angle and foot plates are indicated on a computer screen. The participant moves to 'hit' a predetermined target. Intervention was provided in addition to conventional rehabilitation exercises

Control intervention: conventional rehabilitation only

Sessions were 30 min, 5 times/week for 3 weeks. The control group only participated in usual rehabilitation thus there was a difference between groups in the amount of therapy received

\begin{tabular}{ll}
\hline Outcomes & Outcomes assessed post intervention \\
Balance: Berg Balance Scale \\
Postural Assessment Scale for Stroke Patients \\
Timed Up and Go Test
\end{tabular}

Notes -

\section{Risk of bias}

\begin{tabular}{lll}
\hline Bias & Authors' judgement & Support for judgement \\
\hline $\begin{array}{l}\text { Random sequence genera- } \\
\text { tion (selection bias) }\end{array}$ & Unclear risk & Method not described \\
\hline $\begin{array}{l}\text { Allocation concealment } \\
\text { (selection bias) }\end{array}$ & Unclear risk & Method not described \\
\hline $\begin{array}{l}\text { Blinding of outcome as- } \\
\text { sessment (detection bias) } \\
\text { All outcomes }\end{array}$ & Unclear risk & Not described \\
\hline $\begin{array}{l}\text { Incomplete outcome data } \\
\text { (attrition bias) }\end{array}$ & Unclear risk & Details not described \\
\hline
\end{tabular}

Virtual reality for stroke rehabilitation (Review) 
Ko 2015 (Continued)

All outcomes

Selective reporting (re- Unclear risk $\quad$ Protocol or clinical trial register not mentioned
porting bias)

Selective reporting (re-

porting bias)

Kong 2014

\begin{tabular}{|c|c|}
\hline Methods & $\mathrm{RCT}$ \\
\hline \multirow[t]{6}{*}{ Participants } & Recruited from inpatients in a tertiary rehabilitation setting in Singapore \\
\hline & 105 participants \\
\hline & Inclusion criteria: within first 6 weeks after stroke \\
\hline & Exclusion criteria: none reported \\
\hline & Mean (SD) age: $57.5(9.8)$ years in the total sample \\
\hline & Timing post stroke: mean 13.7 (8.9) d in the total sample \\
\hline \multirow[t]{4}{*}{ Interventions } & VR intervention: Nintendo Wii gaming therapy in addition to standard conventional rehabilitation \\
\hline & Control intervention: conventional therapy in addition to standard rehabilitation \\
\hline & Control intervention: usual care \\
\hline & Sessions were 4 times/week for 3 weeks \\
\hline \multirow[t]{5}{*}{ Outcomes } & Outcomes assessed post intervention and at 4 and 8 weeks after the completion of intervention \\
\hline & Upper limb: Fugl Meyer Assessment \\
\hline & Upper limb: Action Research Arm Test \\
\hline & Functional Independence Measure \\
\hline & Stroke Impact Scale \\
\hline
\end{tabular}

Notes

\section{Risk of bias}

Bias Authors' judgement Support for judgement

Random sequence genera- Low risk Computer generated

tion (selection bias)

\begin{tabular}{ll}
\hline $\begin{array}{l}\text { Allocation concealment } \\
\text { (selection bias) }\end{array}$ & Low risk
\end{tabular}

\begin{tabular}{lll}
\hline $\begin{array}{l}\text { Blinding of outcome as- } \\
\text { sessment (detection bias) }\end{array}$ & Low risk & Blinded \\
All outcomes & \\
\hline $\begin{array}{l}\text { Incomplete outcome data } \\
\text { (attrition bias) }\end{array}$ & Low risk & Low attrition. ITT analysis with baseline values used \\
All outcomes & & \\
\hline
\end{tabular}


Kong 2014 (Continued)

Selective reporting (re- $\quad$ Low risk $\quad$ All outcomes reported
porting bias)
porting bias)

Kwon 2012

\begin{tabular}{ll}
\hline Methods & RCT \\
\hline Participants & Recruited from a hospital in Korea \\
& 26 participants: 13 intervention, 13 control \\
& Inclusion criteria: adults within 3 months of stroke with the capacity to understand and follow simple \\
instructions. Able to grasp and release affected hand, with manual muscle test $\geq$ grade 3. Able to main- \\
tain standing or sitting position independently and no visual deficit \\
Exclusion criteria: failure to meet above criteria \\
Mean (SD) age: intervention group 57.15 (15.42) years, control group 57.92 (12.32) years \\
Timing post stroke: intervention group mean (SD) 24.69 (15.59) d, control group 23.92 (20.70) d
\end{tabular}

Interventions VR intervention: conventional therapy plus additional therapy time using IREX

Control intervention: conventional therapy alone

Sessions were $30 \mathrm{~min}, 5 \mathrm{~d} /$ week for 4 weeks

\begin{tabular}{ll}
\hline Outcomes & Outcomes recorded at baseline and post-intervention \\
& Upper limb function outcomes: Fugl Meyer, Manual Function Test \\
& Activity limitation outcomes: Korean Modified Barthel \\
\hline Notes & -
\end{tabular}

\section{Risk of bias}

\begin{tabular}{lll}
\hline Bias & Authors' judgement & Support for judgement \\
\hline $\begin{array}{l}\text { Random sequence genera- } \\
\text { tion (selection bias) }\end{array}$ & Unclear risk & Not reported \\
\hline $\begin{array}{l}\text { Allocation concealment } \\
\text { (selection bias) }\end{array}$ & Unclear risk & Not reported \\
\hline $\begin{array}{l}\text { Blinding of outcome as- } \\
\text { sessment (detection bias) } \\
\text { All outcomes }\end{array}$ & Low risk & Blinded to allocation \\
\hline $\begin{array}{l}\text { Incomplete outcome data } \\
\text { (attrition bias) } \\
\text { All outcomes }\end{array}$ & Unclear risk & Not reported in adequate detail to make judgement \\
\hline $\begin{array}{l}\text { Selective reporting (re- } \\
\text { porting bias) }\end{array}$ & Unclear risk & Protocol not available \\
\hline
\end{tabular}


Lam 2006

\begin{tabular}{ll}
\hline Methods & RCT \\
\hline Participants & Recruited from rehabilitation units in Hong Kong \\
& 58 participants: 20 VR, 16 video-based program, 22 no treatment \\
& Inclusion criteria: $50-85$ years old, medically stable with no previous psychiatric history, able to follow \\
simple instructions and write with a pen in Chinese or English, consistent volitional motor response, \\
good visual tracking, discrimination ability and figure ground skills, sustained attention span of $\geq 10$ \\
min \\
Exclusion criteria: computer-related phobia or previous training in Mass Transit Railway Skills \\
Mean (SD) age: VR group 71 (16) years, video-based program group 71 (15) years, no treatment group 73 \\
(10) years \\
31\% men \\
Timing post stroke: VR group mean (SD) 4 (4) years, video-based program group 3 (3) years, no treat- \\
ment group 5 (3) years
\end{tabular}

Interventions VR intervention: a VR program designed to retrain skills using the Mass Transit Railway. Activities included crossing the road and using the facilities at the station

Video based program intervention: a video-based program included instruction, modelling, demonstration, role playing, coaching and feedback on using the Mass Transit Railway

No treatment group: no treatment

10 sessions of unspecified duration were provided for the participants in the VR and video program group
Outcomes
Outcomes recorded at baseline and post-intervention
Other outcomes: behavioural rating scale, Mass Transit Railway Self Efficacy Scale

\begin{tabular}{|c|c|c|}
\hline Notes & - & \\
\hline \multicolumn{3}{|l|}{ Risk of bias } \\
\hline Bias & Authors' judgement & Support for judgement \\
\hline $\begin{array}{l}\text { Random sequence genera- } \\
\text { tion (selection bias) }\end{array}$ & Low risk & $\begin{array}{l}\text { Participants were randomly allocated into } 2 \text { groups using a statistical package } \\
\text { random number generator tool }\end{array}$ \\
\hline $\begin{array}{l}\text { Allocation concealment } \\
\text { (selection bias) }\end{array}$ & Low risk & Allocation was computer-generated \\
\hline $\begin{array}{l}\text { Blinding of outcome as- } \\
\text { sessment (detection bias) } \\
\text { All outcomes }\end{array}$ & Low risk & Blind \\
\hline $\begin{array}{l}\text { Incomplete outcome data } \\
\text { (attrition bias) } \\
\text { All outcomes }\end{array}$ & Low risk & There were no missing data \\
\hline $\begin{array}{l}\text { Selective reporting (re- } \\
\text { porting bias) }\end{array}$ & Low risk & No other outcomes were collected \\
\hline
\end{tabular}


Lee 2013

\begin{tabular}{ll}
\hline Methods & RCT \\
\hline Participants & Recruited from inpatients at a hospital in Seoul \\
& 22 Participants: 12 intervention group, 10 control group \\
& Inclusion criteria: $>6$ months after stroke; could sit independently for $\geq 30$ min, who had a MMSE-K \\
& score of $>21$ points, who had not participated in any balance training program during the previous 6 \\
months, who had no orthopedic problems, such as a fracture, deformity, or severe osteoarthritis, and \\
who were not taking any drugs for balance maintenance were included
\end{tabular}

Exclusion criteria: failure to meet above criteria

Mean (SD) age: intervention group 60.6 (8.8) years, control group 63.7 (4.7) years

$27 \%$ men

Interventions

VR intervention: Visual Feedback Training (VFT) was performed individually in a dedicated room containing the required equipment. VFT was performed using BIORescue (RM INGENIERIE, Rodez, France) equipment, which consists of a computer, a monitor, and a force plate. This force plate detects the posture and movements made by participants and this information is transferred to the computer, and processed for display on the monitor. This system encourages adoption of the correct posture by providing visual feedback and allows for design of customised exercise programs based on pre-test data. The system also allows different exercise times and intensities for selected games, and within-session variable rest times. In the study, the participants sat $1 \mathrm{~m}-1.5 \mathrm{~m}$ away from the monitor on a pressure platform. Four types of exercise were performed during each session. The first exercise was training for stability and weight shift by balancing the amount of water in a flask. The second was training for stability and weight shift by driving a vehicle. The third exercise was skiing, which involved shifting the body in the anterior, posterior, left, and right directions in three-dimensional space; and the fourth exercise used a memory recall program, during which the participant had to remember 4 pictures and to match the picture

Control intervention: general physical therapy

Both groups received general physical therapy. In addition, those in the intervention group received additional 30-min sessions, $5 \mathrm{~d}$ /week for 4 weeks

\begin{tabular}{ll}
\hline Outcomes & Outcomes assessed following intervention \\
& Static balance measured using the Good Balance System \\
& Balance: Functional Reach Test \\
& Visual perception: Motor Free Visual Perception Test \\
\hline Notes & -
\end{tabular}

\section{Risk of bias}

\begin{tabular}{lll}
\hline Bias & Authors' judgement & Support for judgement \\
\hline $\begin{array}{l}\text { Random sequence genera- } \\
\text { tion (selection bias) }\end{array}$ & Low risk & Random allocation software \\
\hline $\begin{array}{l}\text { Allocation concealment } \\
\text { (selection bias) }\end{array}$ & Unclear risk & Not described \\
\hline $\begin{array}{l}\text { Blinding of outcome as- } \\
\text { sessment (detection bias) }\end{array}$ & Unclear risk & Not described \\
\hline
\end{tabular}


Lee 2013 (Continued)

All outcomes

\begin{tabular}{lll}
\hline $\begin{array}{l}\text { Incomplete outcome data } \\
\text { (attrition bias) } \\
\text { All outcomes }\end{array}$ & $\begin{array}{l}\text { Some dropouts but details of this and method for dealing with this not de- } \\
\text { scribed }\end{array}$ \\
\hline $\begin{array}{l}\text { Selective reporting (re- } \\
\text { porting bias) }\end{array}$ & Unclear risk & Protocol or clinical trial register not mentioned \\
\hline
\end{tabular}

Lee $2014 a$

\begin{tabular}{ll}
\hline Methods & RCT \\
\hline Participants & Recruited from a hospital in Korea \\
& 21 participants: 10 intervention group, 11 control group \\
& Inclusion criteria: $>6$ months post stroke, not taking medication that can affect balance, MMSE score \\
$<24 / 30$, no pain or disability associated with acute musculoskeletal conditions, sitting to sidelying wing & moderate assistance, sitting for $>10$ s without support and standing without support for 1 min \\
& Exclusion criteria: Pusher syndrome \\
& Mean (SD) age: intervention group 47.9 (12) years, control group 54 (11.9) years \\
& $67 \%$ men \\
& Timing post stroke: intervention group mean (SD) 11.7 (4.5) months, control group mean 11.0 (4.7) \\
months
\end{tabular}

VR intervention: augmented reality had 3 stages and 16 scopes. The stages progressed from exercise programs in lying position to sitting to standing using a therapeutic ball or foothold. The VR included videos of postural control training for guiding the participants to perform ideal postural control motions. The head-mounted device showed 2 views: the modelled movement was on one side and the actual movement on the other side. The participant could watch the modelled movement and listen to a recorded sound in order to compare the normal movement with his/her own movement. This was completed in addition to usual physiotherapy sessions

Control intervention: no intervention except for usual physiotherapy sessions

Sessions were $30 \mathrm{~min} / \mathrm{d}$ for 4 weeks

Outcomes Outcomes assessed post intervention

Timed Up and Go Test

Berg Balance Scale

Gait (measured using the GAITRite system - gait velocity, cadence, step length, and stride length)

\begin{tabular}{lll}
\hline Notes & - \\
\hline Risk of bias & \\
\hline Bias & Authors' judgement & Support for judgement \\
\hline $\begin{array}{lll}\text { Random sequence genera- } \\
\text { tion (selection bias) }\end{array}$ & High risk & Drawing lots \\
\hline
\end{tabular}


Lee 2014a (Continued)

Allocation concealment High risk Participant selection from box (paper had either number 1 or 2 on)
(selection bias)

Blinding of outcome as- Low risk

Blinded outcome assessor

sessment (detection bias)

All outcomes

$\begin{array}{ll}\begin{array}{l}\text { Incomplete outcome data } \\ \text { (attrition bias) }\end{array} & \text { Low risk } \\ \text { All outcomes } & \text { forward) }\end{array}$

All outcomes

Selective reporting (re- Unclear risk No mention of protocol or clinical trial registry

porting bias)

Lee 2015a

\begin{tabular}{ll}
\hline Methods & RCT \\
\hline Participants & Recruited from a hospital in Seoul \\
& 24 participants: 12 intervention, 12 control \\
& Inclusion criteria: stroke of $>6$ months duration; a score of $>24$ points on the MMSE-K; ability to walk a \\
& distance of 10 m with or without an auxiliary device; no history of orthopedic conditions involving the \\
lower limbs; ability to follow instructions and perform the exercise programs; and no visual or hearing \\
impairment \\
Exclusion criteria: failure to meet above criteria \\
Mean (SD) age: intervention group 45.91 (12.28) years control group 49.16 (12.85) years \\
$66 \%$ men
\end{tabular}

Interventions $\quad$ VR intervention: Wii and Wii Balance Board provided by Nintendo (Kyoto, Japan) and the Wii Fit Plus software were used. The VR-based program was selected depending on the participants' interests and motivation, and the levels of difficulty were decided based on information provided in previous studies regarding suitable levels for balance improvement. The program consisted of: (1) sitting posture, (2) the knee bend and the other leg knee extend, (3) tightrope walking, (4) penguin teeter-totter seesaw, (5) balance skiing, (6) rolling marble board, and (7) balance Wii

Control intervention: the duration of the task-oriented training program was $30 \mathrm{~min}$. Each task took 3 min to perform, and a 1-min break was provided between tasks. Each of the warm-up and cooldown phases lasted for $2 \mathrm{~min}$. The level of difficulty and frequency for each task were gradually increased during the 6 weeks with the participants' consent, starting with 3 sets (12 times/set)

All the participants also received general exercise therapy for $60 \mathrm{~min} / \mathrm{d}, 5 \mathrm{~d} /$ week for 6 weeks. They participated in the VR-based training program or task-oriented training for an additional $30 \mathrm{~min} / \mathrm{d}, 3 \mathrm{~d} /$ week for 6 weeks.

Outcomes Measured outcomes post intervention

Balance: Functional reach test

\begin{tabular}{ll}
\hline Notes & - \\
\hline Risk of bias & \\
\hline Bias Authors' judgement Support for judgement \\
\hline
\end{tabular}

Virtual reality for stroke rehabilitation (Review) 
Lee 2015a (Continued)

$\begin{aligned} & \text { Random sequence genera- } \\ & \text { tion (selection bias) }\end{aligned}$
Unclear risk $\quad$ Not reported

\begin{tabular}{lll}
\hline $\begin{array}{l}\text { Allocation concealment } \\
\text { (selection bias) }\end{array}$ & Unclear risk & Not reported
\end{tabular}

\begin{tabular}{|c|c|c|}
\hline $\begin{array}{l}\text { Blinding of outcome as- } \\
\text { sessment (detection bias) } \\
\text { All outcomes }\end{array}$ & Unclear risk & Not reported \\
\hline
\end{tabular}

\begin{tabular}{lll}
\hline $\begin{array}{l}\text { Incomplete outcome data } \\
\text { (attrition bias) }\end{array}$ & Unclear risk & Not reported \\
All outcomes & \\
\hline $\begin{array}{l}\text { Selective reporting (re- } \\
\text { porting bias) }\end{array}$ & Unclear risk & Not reported \\
\hline
\end{tabular}

\section{Lee 2015b}

\begin{tabular}{|c|c|}
\hline Methods & $\mathrm{RCT}$ \\
\hline \multirow[t]{7}{*}{ Participants } & Recruited from a general hospital in Korea \\
\hline & 18 participants: 10 intervention, 8 control \\
\hline & $\begin{array}{l}\text { Inclusion criteria: diagnosed with stroke and hemiparesis; able to follow verbal instructions; } \geq 6 \text { months } \\
\text { post-stroke diagnosed by a physician; able to communicate (i.e. MMSE language section score from } \\
24-30 \text { ), and a Modified Ashworth Scale (MAS) score }<2 \text { for the UE }\end{array}$ \\
\hline & Exclusion criteria: diplegia or a visual field defect \\
\hline & Mean (SD) age: intervention group 69.2 (5.5) years, control group 73.1 (8.9) years \\
\hline & $45 \%$ men, $55 \%$ right hemiparesis \\
\hline & Timing post stroke: intervention group mean (SD) 16.2 (6.5) months, control group 17 (6.5) months \\
\hline \multirow[t]{4}{*}{ Interventions } & $\begin{array}{l}\text { VR intervention: the VR-based bilateral training (VRBT) involved a visual expression technique using an- } \\
\text { imations and provided cognitive information for feedback. The animation consisted of symmetric and } \\
\text { asymmetric upper-extremity training as well as symmetric and asymmetric upper-extremity training } \\
\text { at } 45^{\circ} \text { in a VR environment. The participants performed each movement for } 4 \text { min and then rested for } \\
1 \text { min to minimise fatigue. Depending on the severity of the deficits, the participant either grasped the } \\
\text { handles or the affected hand was strapped to the handle. An UE instrument was used to control the in- } \\
\text { clination and width. A laptop, webcam, and monitor were used to create the VR environment }\end{array}$ \\
\hline & Control intervention: the therapy program involved only bilateral UE exercises \\
\hline & Both groups received conventional physical therapy: sessions were $30 \mathrm{~min}, 3$ times/week for 6 weeks \\
\hline & $\begin{array}{l}\text { Both groups received additional therapy (either intervention or control) for } 30 \mathrm{~min}, 3 \text { times/week for } 6 \\
\text { weeks }\end{array}$ \\
\hline \multirow[t]{2}{*}{ Outcomes } & Outcomes were assessed post intervention \\
\hline & Electroencephalography \\
\hline Notes & - \\
\hline
\end{tabular}


Lee 2015b (Continued)

Risk of bias

\begin{tabular}{|c|c|c|}
\hline Bias & Authors' judgement & Support for judgement \\
\hline $\begin{array}{l}\text { Random sequence genera- } \\
\text { tion (selection bias) }\end{array}$ & Unclear risk & Not reported \\
\hline $\begin{array}{l}\text { Allocation concealment } \\
\text { (selection bias) }\end{array}$ & Unclear risk & Not reported \\
\hline $\begin{array}{l}\text { Blinding of outcome as- } \\
\text { sessment (detection bias) } \\
\text { All outcomes }\end{array}$ & Unclear risk & Not reported \\
\hline $\begin{array}{l}\text { Incomplete outcome data } \\
\text { (attrition bias) } \\
\text { All outcomes }\end{array}$ & Unclear risk & Not reported \\
\hline $\begin{array}{l}\text { Selective reporting (re- } \\
\text { porting bias) }\end{array}$ & Unclear risk & Not reported \\
\hline
\end{tabular}

Levin 2012

\begin{tabular}{ll}
\hline Methods & RCT \\
\hline
\end{tabular}

Participants Recruited from an outpatient rehabilitation centre in Israel

12 participants: 6 intervention, 6 control

Inclusion criteria: unilateral left- or right-sided stroke $>3$ months previously. No hemispatial neglect or uncorrected visual field deficits including hemianopia and could understand and follow instructions (no receptive aphasia, MMSE evaluation)

Exclusion criteria: shoulder or arm pain, lack of endurance as judged by their treating physician

Mean (SD) age: intervention group 58.1 (14.6) years, control group 59.8 (15.1) years

$50 \%$ men

Stroke details: $58 \%$ right hemiplegia

Timing post stroke: intervention group mean 2.6 (1.2) years, control group mean $3.8(0.9)$ years

Interventions

VR intervention: goal-directed reaching tasks using the affected arm in a virtual environment (virtual supermarket, birds and balls, soccer, volleyball, VMall). Practice involved reaching but not grasp or manipulation. Task difficulty was matched to capabilities

Control intervention: OT including exercises reaching for and holding cones, cups and other objects with and without external loading

Sessions were $45 \mathrm{~min}$ for 9 sessions over a 3-week period

\section{Outcomes}

\section{Assessed post intervention and 4 weeks after the end of intervention}

Fugl Meyer Arm Scale

Composite Spasticity Index

Reach Performance Scale for Stroke 
Levin 2012 (Continued)

Upper limb activity: box and blocks test

Upper limb activity: Wolf Motor Function Test

Motor Activity Log

Adverse events

Notes NCT01388400

\section{Risk of bias}

\begin{tabular}{lll}
\hline Bias & Authors' judgement & Support for judgement \\
\hline $\begin{array}{l}\text { Random sequence genera- } \\
\text { tion (selection bias) }\end{array}$ & High risk & Coin toss \\
\hline $\begin{array}{l}\text { Allocation concealment } \\
\text { (selection bias) }\end{array}$ & Low risk & As above - coin toss \\
\hline $\begin{array}{l}\text { Blinding of outcome as- } \\
\text { sessment (detection bias) } \\
\text { All outcomes }\end{array}$ & Low risk & Blinded assessor \\
\hline $\begin{array}{l}\text { Incomplete outcome data } \\
\text { (attrition bias) } \\
\text { All outcomes }\end{array}$ & Low risk & Small number of withdrawals \\
\hline $\begin{array}{l}\text { Selective reporting (re- } \\
\text { porting bias) }\end{array}$ & Low risk & Reported on clinical trial registry \\
\hline
\end{tabular}

Linder 2015

\begin{tabular}{ll}
\hline Methods RCT \\
\hline
\end{tabular}

Participants

Recruited from outpatient services in the USA

99 participants: 51 intervention, 48 control

Inclusion criteria: unilateral stroke within the previous 6 months with some voluntary UE movement (score of 11-55 on the Fugl Meyer Assessment). Limited access to an organised stroke rehabilitation program and preserved cognitive function

Exclusion criteria: lack of independence before the stroke (Modified Rankin Scale score of $>1$ ) and injection to manage hypertonicity in the UE since stroke. Neglect (measured by $>3$ errors on the star cancellation test), sensory loss score of $\geq 2$ on the sensory item of the National Institutes of Health Stroke Scale and score of $\geq 3$ on the Modified Ashworth Scale

Mean (SD) age: intervention group 59.4 (13.6) years, control group 55.5 (12.6) years

$65 \%$ men

Stroke details: $49 \%$ right hemiplegia

Timing post stroke: intervention group mean 117 (50.9) d, control group 125 (47) d

Interventions

VR intervention: Hand Mentor Pro Robot assisted device uses a pneumatic pump to facilitate active-assisted movement of the wrist and fingers. The device consists of 3 components: a computer control box, an arm unit and data-collection device and a communications module. The arm unit stabilises 
the forearm so that the user is able to isolate the wrist and finger movement with the assistance of the pneumatic pump and the computer control box provides targeted goals with corresponding visual and auditory feedback. Feedback from the session is displayed on the screen and stored (including time of use, attempted and successful repetitions, wrist angle and pneumatic pressure)

Control intervention: UE home exercise program prescribed by a therapist from a pool of exercises and activities. Weekly telephone calls were made to progress the program. Each participant was given an exercise book with instructions

Robotic sessions were $2 \mathrm{~h} / \mathrm{d}, 5 \mathrm{~d} /$ week for 8 weeks within a 12-week period

Home exercise program was $1 \mathrm{~h} / \mathrm{d}, 5 \mathrm{~d} /$ week for 8 weeks within a 12-week period

Sessions were conducted with a physiotherapist or occupational therapist

\begin{tabular}{ll}
\hline Outcomes & Outcomes assessed post intervention \\
& Stroke Impact Scale \\
& Center for Epidemiologic Studies Depression Scale (CES-D) \\
\hline Notes & $\begin{array}{l}\text { Disclosure: one author was Chairman of the Scientific Advisory Board and was previously a paid consul- } \\
\text { tant for Kinetic Muscles. A second author was a paid consultant for Kinetic Muscles for this study } \\
\text { NCTO1144715 }\end{array}$
\end{tabular}

\section{Risk of bias}

\begin{tabular}{lll}
\hline Bias & Authors' judgement & Support for judgement \\
\hline $\begin{array}{l}\text { Random sequence genera- } \\
\text { tion (selection bias) }\end{array}$ & Low risk & Computer-generated program \\
\hline $\begin{array}{l}\text { Allocation concealment } \\
\text { (selection bias) }\end{array}$ & Low risk & Computer-based program \\
\hline $\begin{array}{l}\text { Blinding of outcome as- } \\
\text { sessment (detection bias) } \\
\text { All outcomes }\end{array}$ & Low risk & Blinded assessor \\
\hline $\begin{array}{l}\text { Incomplete outcome data } \\
\text { (attrition bias) } \\
\text { All outcomes }\end{array}$ & Low risk & ITT analysis conducted \\
\hline $\begin{array}{l}\text { Selective reporting (re- } \\
\text { porting bias) }\end{array}$ & High risk & Paper only reports 2 outcomes but others were described in the protocol \\
\hline
\end{tabular}

Llorens 2015

\begin{tabular}{ll}
\hline Methods & RCT \\
\hline Participants & Recruited from an outpatient rehabilitation unit in Spain \\
& 20 participants: 10 intervention, 10 control \\
& $\begin{array}{l}\text { Inclusion criteria: people with stroke attending a rehabilitation program. Had hemiparesis and were } \\
\text { aged } 40+\text { years but } \leq 70 \text { years. Had a stroke }>6 \text { months ago and had absence of cognitive impairment } \\
\text { (MMSE of } \geq 24 / 30) \text {. Able to follow instructions and able to maintain stride-standing position for } 30 \mathrm{~s} \\
\text { without assistance from another person }\end{array}$ \\
\hline
\end{tabular}


Llorens 2015 (Continued)

Exclusion criteria: severe dementia or aphasia (Mississippi Aphasia Screening Test $<45$ ), visual or hearing impairment restricting ability to interact with the intervention, hemispatial neglect and ataxia or cerebellar symptoms

Mean (SD) age: intervention group 58.3 (11.6) years, control group 55.0 (11.6) years

$45 \%$ men

Stroke details: $65 \%$ ischaemic

Timing post stroke: intervention group mean 407 (232) d, control group mean 587 (222) d

Intervention: 30 min conventional training plus 30 min of virtual rehabilitation. The set-up consisted of
a computer, audiovisual output system and motion tracking system. The output system consisted of
a video display and audio system. The participant was immersed in a 3D environment; their feet were
represented by 2 shoes that mimicked their movement in the real world. The objective of the task was
to reach the items with 1 foot while maintaining the other foot within the circle. Conducted by a physio-
therapist

Control intervention: $1 \mathrm{~h}$ of conventional physiotherapy including balance exercises, task-specific reaching, stepping and walking under different conditions. Conducted by a physiotherapist

Sessions were $60 \mathrm{~min}, 5$ times/week for 4 weeks

Outcomes
Berg Balance Scale
Balance and gait subscales of the Tinetti Performance Oriented Mobility Assessment
Brunel Balance Assessment
10 m walking test
Adverse events reported

Notes -

\section{Risk of bias}

\begin{tabular}{lll}
\hline Bias & Authors' judgement & Support for judgement \\
\hline $\begin{array}{l}\text { Random sequence genera- } \\
\text { tion (selection bias) }\end{array}$ & Low risk & Computer-generated sequence \\
\hline $\begin{array}{l}\text { Allocation concealment } \\
\text { (selection bias) }\end{array}$ & Unclear risk & Concealed in envelopes. Not clear whether they were opaque or not \\
\hline $\begin{array}{l}\text { Blinding of outcome as- } \\
\text { sessment (detection bias) } \\
\text { All outcomes }\end{array}$ & Low risk & Blinded therapist \\
\hline $\begin{array}{l}\text { Incomplete outcome data } \\
\text { (attrition bias) } \\
\begin{array}{l}\text { All outcomes } \\
\text { Selective reporting (re- }\end{array}\end{array}$ & Low risk & Low withdrawals and analysis included only those contributing data \\
\hline \begin{tabular}{l} 
porting bias) \\
\hline
\end{tabular} & & No mention of protocol or trial registration \\
\hline
\end{tabular}


Low 2012

\begin{tabular}{|c|c|c|}
\hline Methods & \multicolumn{2}{|l|}{$\mathrm{RCT}$} \\
\hline Participants & $\begin{array}{l}20 \text { participants: } 10 \text { int } \\
\text { Inclusion criteria: dia: } \\
\text { Mean age } 60.4(13.3) \text { y } \\
65 \% \text { men } \\
\text { Timing post stroke: } 14\end{array}$ & $\begin{array}{l}\text { vention, } 10 \text { control } \\
\text { osis of stroke and medically stable } \\
\text { ars (total sample) } \\
1(5.5) \mathrm{d}\end{array}$ \\
\hline Interventions & \multicolumn{2}{|c|}{$\begin{array}{l}\text { VR intervention: locally developed VR program } \\
\text { Control intervention: usual care } \\
\text { The VR group received an additional } 30 \text { min of daily VR therapy for } 2 \text { weeks }\end{array}$} \\
\hline Outcomes & $\begin{array}{l}\text { Fugl Meyer Motor Sca } \\
\text { Action Research Arm } \\
\text { Berg Balance Scale } \\
\text { Functional Independe } \\
\text { Gait speed }\end{array}$ & $\begin{array}{l}\text { (upper limb) } \\
\text { st } \\
\text { ce Measure }\end{array}$ \\
\hline Notes & \multicolumn{2}{|l|}{-} \\
\hline \multicolumn{3}{|l|}{ Risk of bias } \\
\hline $\begin{array}{l}\text { Random sequence genera- } \\
\text { tion (selection bias) }\end{array}$ & Unclear risk & Not reported (conference abstract) \\
\hline $\begin{array}{l}\text { Allocation concealment } \\
\text { (selection bias) }\end{array}$ & Unclear risk & Not reported (conference abstract) \\
\hline $\begin{array}{l}\text { Blinding of outcome as- } \\
\text { sessment (detection bias) } \\
\text { All outcomes }\end{array}$ & Unclear risk & Not reported (conference abstract) \\
\hline $\begin{array}{l}\text { Incomplete outcome data } \\
\text { (attrition bias) } \\
\text { All outcomes }\end{array}$ & Unclear risk & Not reported (conference abstract) \\
\hline $\begin{array}{l}\text { Selective reporting (re- } \\
\text { porting bias) }\end{array}$ & Unclear risk & Not reported (conference abstract) \\
\hline
\end{tabular}

Manlapaz 2010

\begin{tabular}{ll}
\hline Methods & RCT \\
\hline Participants & Recruited from rehabilitation centres in Manila, Phillipines \\
& 16 participants: 8 intervention, 8 control
\end{tabular}


Manlapaz 2010 (Continued)

Inclusion and exclusion criteria: not reported

Mean age: 55.69 (9.88) for the total sample

$69 \%$ men

Timing post stroke: mean 38.56 (14.51) months

$\begin{array}{ll}\text { Interventions } & \text { VR intervention: Nintendo Wii } \\ \text { Control intervention: not reported } \\ \text { Intervention was provided twice/week for } 6 \text { weeks }\end{array}$

\begin{tabular}{ll}
\hline Outcomes & Outcomes assessed post intervention \\
& Fugl Meyer \\
& Motor Assessment Scale \\
& Fast Fourier Transform (FFT) analysis \\
\hline Notes & -
\end{tabular}

\section{Risk of bias}

Bias Authors' judgement Support for judgement

Random sequence genera- Unclear risk States that participants were randomised using the 'fishbowl' method
tion (selection bias)

\begin{tabular}{lll}
\hline $\begin{array}{l}\text { Allocation concealment } \\
\text { (selection bias) }\end{array}$ & Low risk & Sealed opaque envelopes \\
\hline $\begin{array}{l}\text { Blinding of outcome as- } \\
\text { sessment (detection bias) } \\
\text { All outcomes }\end{array}$ & Low risk & Assessor blinded \\
\hline
\end{tabular}

Incomplete outcome data Low risk No missing data
(attrition bias)

All outcomes

Selective reporting (re- Unclear risk Details not reported (conference abstract)
porting bias)

\section{Mao 2015}

\begin{tabular}{ll}
\hline Methods & RCT \\
\hline Participants & Recruited from an inpatient hospital in China \\
& 23 participants: 11 intervention, 12 control \\
& $\begin{array}{l}\text { Inclusion criteria: stroke (confirmed by CT or MRI), stable vital signs, aged } 40-78 \text { years, able to walk in- } \\
\text { dependently for } 10 \text { m, unilateral hemipareses for }<3 \text { months resulting from first stroke and residual } \\
\text { gait impairment (reduced walking speed) and adequate mental and physical capacity to attempt the } \\
\text { tasks as instructed }\end{array}$
\end{tabular}


Exclusion criteria: history of recent deep vein thrombosis of the lower limbs, other neurological or orthopedic pathology, or serious visual deficits

Mean (SD) age: intervention group 58.18 (11.15) years, control group 63.09 (11.51) years

$78 \%$ men

Timing post stroke: intervention group mean 48.91 (17.01) d, control group mean 48.91 (17.92) d

Interventions

VR intervention: a series of videos (e.g. climbing a mountain, crossing a street) was shown on screen and synced with treadmill velocity. The participant wore a harness to support body weight

Control intervention: individualised walking training on the ground according to neurodevelopmental therapy

Both of the groups received training of $20-40 \mathrm{~min} / \mathrm{d}, 5 \mathrm{~d} /$ week, for 3 weeks

$\begin{array}{ll}\text { Outcomes } & \text { Outcomes assessed post intervention } \\ \text { Motion analysis system (Vicon) to measure pelvic tilt, obliquity and rotation }\end{array}$

Notes -

\section{Risk of bias}

\begin{tabular}{lll}
\hline Bias & Authors' judgement & Support for judgement \\
\hline $\begin{array}{l}\text { Random sequence genera- } \\
\text { tion (selection bias) }\end{array}$ & Low risk & Computer randomisation program \\
\hline $\begin{array}{l}\text { Allocation concealment } \\
\text { (selection bias) }\end{array}$ & Low risk & Sequentially-numbered, opaque, sealed envelopes \\
\hline $\begin{array}{l}\text { Blinding of outcome as- } \\
\text { sessment (detection bias) } \\
\text { All outcomes }\end{array}$ & Unclear risk & Blinded to allocation \\
\hline $\begin{array}{l}\text { Incomplete outcome data } \\
\text { (attrition bias) } \\
\text { All outcomes }\end{array}$ & Unclear risk & Not described in sufficient detail to make judgement \\
\hline $\begin{array}{l}\text { Selective reporting (re- } \\
\text { porting bias) }\end{array}$ & Low risk & Registered on clinical trial and all measures reported \\
\hline
\end{tabular}

\section{Matsuo 2013}

\begin{tabular}{ll}
\hline Methods & RCT \\
\hline Participants & Recruited from a rehabilitation inpatient unit in Japan \\
& 28 participants \\
& No further details reported \\
\hline Interventions & VR intervention: 10 sessions of upper limb exercises via a Nintendo Wii over 2 weeks in addition to con- \\
& ventional rehabilitation \\
& Control intervention: conventional rehabilitation \\
\hline
\end{tabular}


Matsuo 2013 (Continued)

Outcomes
Outcomes assessed post intervention and 2 weeks after the end of intervention

Fugl Meyer Assessment of Upper Limb Motor Function

Wolf Motor Function Test

Box and Block Test

Motor Activity Log

\section{Notes}

\section{Risk of bias}

\begin{tabular}{lll}
\hline Bias & Authors' judgement & Support for judgement \\
\hline $\begin{array}{l}\text { Random sequence genera- } \\
\text { tion (selection bias) }\end{array}$ & Unclear risk & Details not reported (conference abstract) \\
\hline $\begin{array}{l}\text { Allocation concealment } \\
\text { (selection bias) }\end{array}$ & Unclear risk & Details not reported (conference abstract) \\
\hline $\begin{array}{l}\text { Blinding of outcome as- } \\
\text { sessment (detection bias) } \\
\text { All outcomes }\end{array}$ & Unclear risk & Details not reported (conference abstract) \\
\hline $\begin{array}{l}\text { Incomplete outcome data } \\
\text { (attrition bias) } \\
\text { All outcomes }\end{array}$ & Unclear risk & Details not reported (conference abstract) \\
\hline $\begin{array}{l}\text { Selective reporting (re- } \\
\text { porting bias) }\end{array}$ & Unclear risk & Details not reported (conference abstract) \\
\hline
\end{tabular}

Mazer 2005

Methods RCT

\section{Participants}

Recruited from a rehabilitation hospital in Quebec, 2 driving evaluation centres in Montreal and from a private driving evaluation clinic

39 participants: 20 intervention, 19 control

Inclusion criteria (for stroke participants): people with a diagnosis of stroke that did not pass the driving tests at a recognised driving evaluation service. Had licence to drive and were driving prior to the stroke and desire to return to driving

Exclusion criteria: medical condition precluding driving (for example, hemianopia, seizures), received their driving evaluation $>2$ years post diagnosis, unable to communicate in English or French, inadequate communication of basic verbal instructions or judged as dangerous by the therapist in the onroad evaluation

Mean (SD) age: intervention group 68 (14) years, control group 69 (9) years

Stroke details: $31 \%$ right hemiparesis

Timing post stroke: intervention group mean (SD) 1.4 (1) years, control group 1.7 (1) years 
were familiarised with the simulator and controls; level 2 involved a simulated road circuit without traffic; level 3 focused on performing different driving manoeuvres and level 4 involved a variety of traffic conditions (for example, rain, wind, reduced visibility, pedestrians). Instant feedback was provided by the simulator when errors were made

Control intervention: no intervention provided

Sessions were $60 \mathrm{~min}$, twice/week for 8 weeks ( $16 \mathrm{~h}$ total)

\begin{tabular}{ll}
\hline Outcomes & Outcomes recorded at baseline and post-intervention (or after 8 weeks for the control group) \\
& Activity limitation outcomes: DriveAble Testing Ltd Driver Evaluation \\
\hline Notes & $\begin{array}{l}\text { Note that this study also recruited } 6 \text { participants with traumatic brain injury. However, data for partici- } \\
\text { pants with stroke were able to be separated. This review reports on the stroke data only }\end{array}$
\end{tabular}

\section{Risk of bias}

\begin{tabular}{|c|c|c|}
\hline Bias & Authors' judgement & Support for judgement \\
\hline $\begin{array}{l}\text { Random sequence genera- } \\
\text { tion (selection bias) }\end{array}$ & Low risk & Used a computer program to generate \\
\hline $\begin{array}{l}\text { Allocation concealment } \\
\text { (selection bias) }\end{array}$ & Low risk & Opaque, sealed envelopes \\
\hline $\begin{array}{l}\text { Blinding of outcome as- } \\
\text { sessment (detection bias) } \\
\text { All outcomes }\end{array}$ & Low risk & Blind \\
\hline $\begin{array}{l}\text { Incomplete outcome data } \\
\text { (attrition bias) } \\
\text { All outcomes }\end{array}$ & Low risk & $\begin{array}{l}7 \text { participants ( } 5 \text { control group, } 2 \text { simulator group) did not complete the out- } \\
\text { come evaluation and were therefore considered to have dropped out from } \\
\text { the study. Analysis was completed based on the actual number of participants } \\
\text { contributing data. ITT analyses were conducted }\end{array}$ \\
\hline $\begin{array}{l}\text { Selective reporting (re- } \\
\text { porting bias) }\end{array}$ & Low risk & No other outcomes were collected \\
\hline
\end{tabular}

McNulty 2015

\begin{tabular}{ll}
\hline Methods & RCT \\
\hline
\end{tabular}

\section{Participants}

Recruited from hospitals in Australia

41 participants: 21 intervention group, 20 control group

Inclusion criteria: ischaemic lesion or haemorrhagic stroke with upper limb motor impairment; 2-48 months post stroke; $\geq 10^{\circ}$ active movement at the shoulder, elbow, wrist and $\geq 2$ digits; English speaking and $\geq 18$ years

Exclusion criteria: MMSE score of < 24/30; peripheral neuropathy significantly affecting sensorimotor function; unstable blood pressure; and formal upper limb therapy during the trial.

Mean (SD) age: intervention group 59.9 (13.8) years, control group 56.1 (17) years

$76 \%$ men

Stroke details: $79 \%$ ischaemic 
McNulty 2015 (Continued)

Timing post stroke: intervention group mean (SD) 11.0 (3.1) months, control group 6.5 (2.1) months

Interventions $\quad$ VR intervention: Nintendo Wii Sports (golf, boxing, baseball, bowling and tennis) with the controller used in the person's more affected hand. Rather than playing each game, specific drills were introduced and varied. For people with poor grip strength, a self-adhesive wrap was applied. Therapy was performed in standing position wherever possible

Control intervention: modified constraint-induced movement therapy: participants wore the mitt on the less affected hand for up to $90 \%$ of waking hours. Therapy included shaping practice tailored to each person's motor function with increasing task complexity, strength, dexterity, movement distance and speed. Training tasks included everyday activities using the more affected arm for 15-20 min of continuous activity

Therapy for both groups was delivered in the research institute or the person's home by a trained therapist. Dose was matched

Sessions were 60 min on 10 consecutive weekdays augmented by progressively increasing home practice

Outcomes assessed post intervention and at 6 months
Upper limb outcomes: Wolf Motor Function Test timed tasks
Motor Activity Log Quality of Movement Scale
Fugl Meyer assessment
Wolf Motor Function Test, maximal strength and submaximal strength
Active and passive ROM
Modified Ashworth Scale
Box and Block Test
Self-perceived improvement and participant satisfaction questionnaire
Adverse events reported

Notes -

\section{Risk of bias}

\begin{tabular}{lll}
\hline Bias & Authors' judgement & Support for judgement \\
\hline $\begin{array}{l}\text { Random sequence genera- } \\
\text { tion (selection bias) }\end{array}$ & Low risk & Computer-generated schedule \\
\hline $\begin{array}{l}\text { Allocation concealment } \\
\text { (selection bias) }\end{array}$ & Low risk & $\begin{array}{l}\text { Allocations were concealed in numbered, opaque envelopes prior to trial com- } \\
\text { mencement by a person not involved with assessments or therapy and opened } \\
\text { by the therapist after baseline assessments }\end{array}$ \\
\hline
\end{tabular}

Blinding of outcome as- Low risk Blinded therapist
sessment (detection bias)

All outcomes

Incomplete outcome data Low risk $\quad$ Transparent reporting and ITT analysis conducted
(attrition bias)


McNulty 2015 (Continued)

Selective reporting (reporting bias)

Unclear risk Could not find reference to study protocol or trial registration

Mirelman 2008

\begin{tabular}{ll}
\hline Methods & RCT \\
\hline Participants & Study took place in New Jersey, USA \\
& 18 participants: 9 intervention, 9 control \\
& $\begin{array}{l}\text { Inclusion criteria: chronic hemiparesis after stroke with residual gait deficits, partial antigravity dorsi- } \\
\text { flexion, able to walk } 15 \text { metres without the assistance of another person, sufficient communication and } \\
\text { cognitive ability to participate }\end{array}$
\end{tabular}

cognitive ability to participate

Exclusion criteria: motion sickness and receiving concurrent therapy

Mean (SD) age: intervention group 62 (10) years, control group 61 (8) years

$83 \%$ men

Stroke details: $44 \%$ right hemiparesis

Timing post stroke: intervention group mean (SD) 38 (25) months, control group 58 (26) months

Interventions

VR intervention: Rutgers ankle rehabilitation system (a 6-degree-of-freedom platform force-feedback system) that allows participants to exercise the lower extremity by navigating through a virtual environment displayed on a desktop computer. Participants executed the exercises by using the foot movements to navigate a plane or a boat through a virtual environment that consisted of a series of targets

Control intervention: Rutgers ankle rehabilitation system without the virtual environment. Participants were instructed by the therapist on which direction to move their foot and were paced by a metronome cueing them to complete a comparable number of repetitions

Sessions were $60 \mathrm{~min}, 3$ times/week for 4 weeks ( $12 \mathrm{~h}$ total)

Outcomes Outcomes recorded at baseline, post intervention and at 3 months

Lower limb function and activity outcomes: gait speed over 7-m walkway, 6MWT, Patient Activity Monitor (distance walked, number of steps/d, average speed, step length, top speed)

Notes -

\section{Risk of bias}

\begin{tabular}{lll}
\hline Bias & Authors' judgement & Support for judgement \\
\hline $\begin{array}{l}\text { Random sequence genera- } \\
\text { tion (selection bias) }\end{array}$ & Low risk & $\begin{array}{l}\text { Randomisation was performed based on the table of numbers method (gener- } \\
\text { ated by a computer) }\end{array}$ \\
\hline $\begin{array}{l}\text { Allocation concealment } \\
\text { (selection bias) }\end{array}$ & Low risk & $\begin{array}{l}\text { Allocation was done by an external person to the project and held in a data- } \\
\text { base spreadsheet on a computer in his office which was password protected }\end{array}$ \\
\hline $\begin{array}{l}\text { Blinding of outcome as- } \\
\text { sessment (detection bias) } \\
\text { All outcomes }\end{array}$ & Low risk & Blind \\
\hline $\begin{array}{l}\text { Incomplete outcome data } \\
\text { (attrition bias) }\end{array}$ & Low risk & $\begin{array}{l}\text { 1 participant in the robotic-VR group was lost to follow-up because of personal } \\
\text { reasons. 1 outlier was identified in the robotic-VR group following the descrip- }\end{array}$ \\
\hline
\end{tabular}

Virtual reality for stroke rehabilitation (Review) 
Mirelman 2008 (Continued)

All outcomes tive analysis of the endurance test (6MWT), the values presented for this individual were 2 SD from the mean therefore he was excluded from the analysis

\begin{tabular}{l}
$\begin{array}{l}\text { Selective reporting (re- Low risk } \\
\text { porting bias) }\end{array}$ \\
\hline
\end{tabular}

\section{Morone 2014}

Methods RC

Participants

Recruited from a rehabilitation unit in Italy

50 participants: 25 intervention, 25 control

Inclusion criteria: hemiparesis in the subacute phase ( $<3$ months from onset), with moderate gait deficits (FAC $\geq 2$ ) caused by a first ever stroke and aged $18-85$ years

Exclusion criteria: motor or cognitive sequale from prior cardiovascular accidents, other chronic disabling pathologies, orthopaedic injuries that could impair locomotion, spasticity that limited lower extremity ROM to $<80 \%$, sacral skin lesions, MMSE score $<24 / 30$ and hemispatial neglect, attention or memory deficit

Mean (SD) age: intervention group 58.36 (9.62) years, control group 61.96 (10.31) years

Stroke details: $58 \%$ right hemiparesis

Timing post stroke: intervention group mean (SD) 61 (36.47) d, control group mean (SD) 41.65 (36.89) d

Interventions VR intervention: balance therapy using the Nintendo Wii Fit. During the intervention, 3 games were carried out in order to train balance, co-ordination and endurance under the supervision of a physiotherapist: hula hoop, bubble blower and sky slalom

Control intervention: balance therapy focusing on trunk stabilisation, weight transfer to the paretic leg and exercise with Freeman board for balance and proprioception

Sessions for the VR and control interventions were $20 \mathrm{~min}, 3$ times/week for 4 weeks. This was in addition to usual physical therapy which was $40 \mathrm{~min}$, twice/d

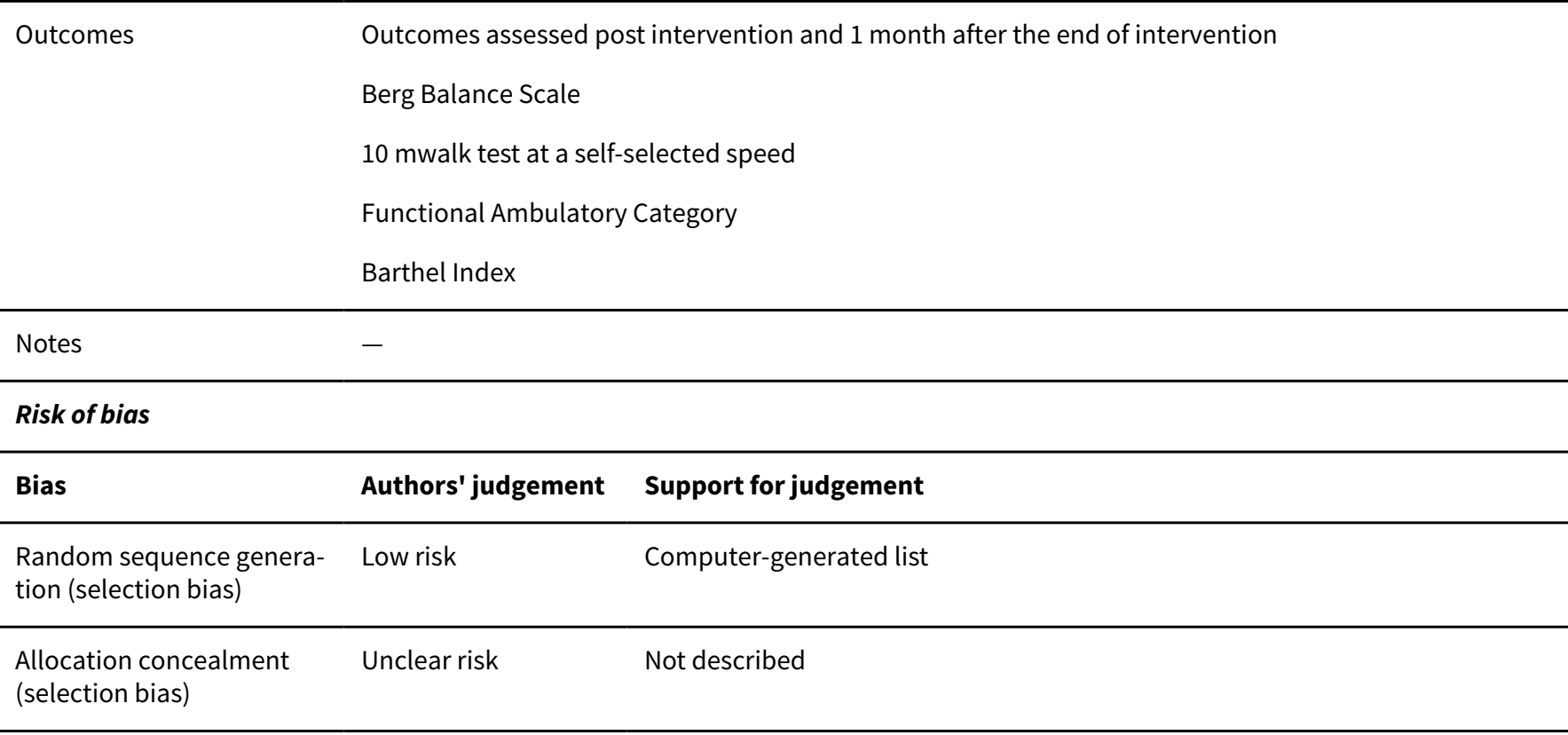


Morone 2014 (Continued)

Blinding of outcome as- Low risk Blinded assessor sessment (detection bias)

All outcomes

\begin{tabular}{lll}
$\begin{array}{l}\text { Incomplete outcome data } \\
\text { (attrition bias) } \\
\text { All outcomes }\end{array}$ & High risk & Multiple withdrawals and unbalanced across groups \\
\hline $\begin{array}{l}\text { Selective reporting (re- } \\
\text { porting bias) }\end{array}$ & Unclear risk & Protocol or trial registration not reported \\
\hline
\end{tabular}

Nara 2015

\begin{tabular}{|c|c|}
\hline Methods & $\mathrm{RCT}$ \\
\hline \multirow[t]{5}{*}{ Participants } & Recruited in Korea \\
\hline & 20 participants: 10 intervention group, 10 control group \\
\hline & $\begin{array}{l}\text { Inclusion criteria: history of stroke onset of }>6 \text { months prior to the study; ability to walk without using } \\
\text { a walking aid for a minimum of } 15 \mathrm{~m} \text {; MMSE score of }>24 / 30 \text {; able to comprehend and follow simple in- } \\
\text { structions }\end{array}$ \\
\hline & Exclusion criteria: other neurological condition, orthopaedic disease or visual impairment \\
\hline & Participant details not reported \\
\hline
\end{tabular}

Interventions VR intervention: community-based VR scene exposure combined with treadmill training. A VR video was displayed on a screen $3 \mathrm{~m}$ in front of the treadmill using a video projector. The VR video comprised images of community ambulation, such as walking on sidewalks, level walking, slope walking and walking over obstacles. 5 min of treadmill training was followed by 2 min rest to minimise fatigue

Control intervention: muscle strengthening, balance training, indoor and outdoor gait training

Both groups had conventional physical therapy for $60 \mathrm{~min} / \mathrm{d}, 5 \mathrm{~d} /$ week for 4 weeks

The VR and control intervention was an additional $30 \mathrm{~min} / \mathrm{d}, 3 \mathrm{~d} /$ week for 4 weeks

\begin{tabular}{lll}
\hline Outcomes & $\begin{array}{l}\text { Outcomes assessed post intervention } \\
\text { Static balance ability (postural sway path length and speed at the center of pressure) }\end{array}$ \\
\hline Notes & - \\
\hline Risk of bias & Authors' judgement & Support for judgement \\
\hline Bias & Unclear risk & Not described \\
\hline $\begin{array}{l}\text { Random sequence genera- } \\
\text { tion (selection bias) }\end{array}$ & \\
\hline $\begin{array}{l}\text { Allocation concealment } \\
\text { (selection bias) }\end{array}$ & Unclear risk & Not described \\
\hline $\begin{array}{l}\text { Blinding of outcome as- } \\
\text { sessment (detection bias) } \\
\text { All outcomes }\end{array}$ & Unclear risk & Not reported \\
\hline
\end{tabular}


Nara 2015 (Continued)

Incomplete outcome data High risk Excluded participants with low participation rate (attrition bias)

All outcomes

Selective reporting (re- Unclear risk Unclear
porting bias)

\section{Piron 2007}

\begin{tabular}{ll}
\hline Methods & RCT \\
\hline Participants & Study took place in Italy \\
& 38 participants: 25 intervention, 13 control \\
& Inclusion criteria: mild-intermediate arm motor impairment due to ischaemic stroke in the MCA territo- \\
ry within the past 3 months & \\
Exclusion criteria: cognitive impairment, neglect, apraxia, aphasia interfering with comprehension & Mean (SD) age: intervention group 62 (9) years, control group 61 (7) years \\
& $66 \%$ men \\
& Timing post stroke: intervention group mean (SD) 2.5 (1.5) months, control group 2.6 (1.6) months
\end{tabular}

VR intervention: magnetic receivers were positioned on the participant's arm. As the participant grasped and moved real objects, software created a virtual environment, which displayed virtual handling and target objects, for example an envelope and a mailbox, a hammer and a nail, a glass and a carafe. While performing the virtual tasks such as putting the envelope in the mailbox the participant moves the real envelope and sees on screen the trajectory of the corresponding virtual objects toward the virtual mailbox. Participants could see not only their own movement but also the correct trajectory that they had to execute, pre-recorded by the therapist. This allowed participants to easily perceive motion errors and adjust them during the task

Control intervention: 'conventional' rehabilitation focused on the upper limb

Sessions were 60 min, 5 times/week for 5-7 weeks (approximately 25-35 h total)

\begin{tabular}{ll}
\hline Outcomes & Outcomes recorded at baseline and post-intervention \\
& Upper limb function and activity outcomes (arm): Fugl Meyer UE Scale \\
& Activity limitation outcomes: Functional Independence Measure \\
& Adverse events reported \\
Notes & -
\end{tabular}

\section{Risk of bias}

\begin{tabular}{lll}
\hline Bias & Authors' judgement & Support for judgement \\
\hline $\begin{array}{l}\text { Random sequence genera- } \\
\text { tion (selection bias) }\end{array}$ & Low risk & $\begin{array}{l}\text { Personal correspondence with the study author reports the use of a simple } \\
\text { computer-generated sequence }\end{array}$ \\
\hline $\begin{array}{l}\text { Allocation concealment } \\
\text { (selection bias) }\end{array}$ & Low risk & Sealed, opaque envelopes \\
\hline
\end{tabular}


Piron 2007 (Continued)

Blinding of outcome as-
sessment (detection bias)

All outcomes

\begin{tabular}{lll}
\hline $\begin{array}{l}\text { Incomplete outcome data } \\
\text { (attrition bias) } \\
\text { All outcomes }\end{array}$ & High risk & $\begin{array}{l}\text { There were } 3 \text { dropouts from the control group and the analysis was per-proto- } \\
\text { col }\end{array}$ \\
\hline $\begin{array}{l}\text { Selective reporting (re- } \\
\text { porting bias) }\end{array}$ & Low risk & No other outcomes were collected \\
\hline
\end{tabular}

Piron 2009

\begin{tabular}{ll}
\hline Methods & RCT \\
\hline Participants & Study took place in Italy \\
& 36 participants: 18 intervention, 18 control \\
& Inclusion criteria: single ischaemic stroke in the MCA region with mild to intermediate arm motor im- \\
pairment (Fugl Meyer UE score 30-55) & \\
& Exclusion criteria: clinical evidence of cognitive impairment, apraxia (<62 points on the 'De Renzi' test), \\
& neglect or language disturbance interfering with verbal comprehension (> 40 errors on the Token test) \\
& Mean (SD) age: intervention group 66 (8) years, control group 64 (8) years \\
& $58 \%$ men \\
& Stroke details: 44\% right hemiparesis \\
& Timing post stroke: intervention group mean (SD) 15 (7) months, control group 12 (4) months
\end{tabular}

Interventions VR intervention: the telerehabilitation program used 1 computer workstation at the participant's home and 1 at the rehabilitation hospital. The system used a 3D motion tracking system to record arm movements through a magnetic receiver into a virtual image. The participant moved a real object following the trajectory of a virtual object displayed on the screen in accordance with the requested virtual task. 5 virtual tasks comprising simple arm movements were devised for training

Control intervention: specific exercises for the upper limb with progressive complexity. Started with control of isolated movements without postural control, then postural control including touching different targets and manipulating objects

Sessions were $60 \mathrm{~min}, 5$ times/week for 4 weeks ( $20 \mathrm{~h}$ total)

Outcomes recorded at baseline, post intervention and at 1 month
Upper limb function and activity outcomes (arm): Fugl Meyer UE Scale
Participation restriction and quality of life outcomes: Abilhand scale
Other outcome measures: Modified Ashworth Scale

Notes

$-$

\section{Risk of bias}


Piron 2009 (Continued)

$\begin{array}{ll}\begin{array}{l}\text { Random sequence genera- } \\ \text { tion (selection bias) }\end{array} & \text { Low risk }\end{array}$

\begin{tabular}{l} 
Allocation concealment $\begin{array}{l}\text { (selection bias) } \\
\text { (sisk }\end{array}$ Opque, sequentially numbered envelopes \\
\hline
\end{tabular}

$\begin{array}{lll}\text { Blinding of outcome as- } & \text { Low risk } & \text { Blind } \\ \text { sessment (detection bias) } & & \\ \text { All outcomes } & \end{array}$

Incomplete outcome data Low risk There were no missing data
(attrition bias)
All outcomes

All outcomes

Selective reporting (re- Low risk No other outcomes were collected
porting bias)

\section{Piron 2010}

\begin{tabular}{ll}
\hline Methods & RCT \\
\hline
\end{tabular}

Participants Recruited from a rehabilitation hospital in Rome, Italy

50 participants: 27 intervention, 23 control

Inclusion criteria: single ischaemic stroke in the MCA territory $>6$ months ago demonstrated by CT or MRI, received conventional physiotherapy early after stroke, mild-intermediate motor impairments of the arm (score of 20-60 on the Fugl Meyer UE Scale)

Exclusion criteria: clinical history or evidence of cognitive impairments, neglect, apraxia or aphasia interfering with verbal comprehension

Mean (SD) age: intervention group 59 (8) years, control group 62 (10) years

$58 \%$ men

Stroke details: $58 \%$ right hemiparesis

Timing post stroke: intervention group mean 15 (13) months, control group 15 (12) months

Interventions $\quad$ VR intervention: participants were asked to perform motor tasks with real objects (for example an envelope or a glass), which were displayed as tasks within the virtual environment (for example putting an envelope in the mailbox, breaking eggs, moving a glass over a table, placing a ball in a basket). A 3D magnetic receiver was used to record the motions. Participants were asked to emulate the tasks as per the therapist's pre-recorded movement

Control intervention: participants were asked to perform specific exercises for the arm, for example touching different targets, manipulating objects and following trajectories on a plan

Sessions were $60 \mathrm{~min}, 5$ times/week for 4 weeks ( $20 \mathrm{~h}$ total)

\section{Outcomes}

Outcomes recorded at baseline and post-intervention

Upper limb function and activity outcomes (arm): Fugl Meyer UE Scale

Activity limitation outcomes: Functional Independence Measure

Adverse events reported 
Piron 2010 (Continued)

Notes

\section{Risk of bias}

\begin{tabular}{|c|c|c|}
\hline Bias & Authors' judgement & Support for judgement \\
\hline $\begin{array}{l}\text { Random sequence genera- } \\
\text { tion (selection bias) }\end{array}$ & Low risk & $\begin{array}{l}\text { Personal correspondence with the study author reports the use of a simple } \\
\text { computer-generated sequence }\end{array}$ \\
\hline $\begin{array}{l}\text { Allocation concealment } \\
\text { (selection bias) }\end{array}$ & Low risk & Sequentially-numbered, opaque, sealed envelopes \\
\hline $\begin{array}{l}\text { Blinding of outcome as- } \\
\text { sessment (detection bias) } \\
\text { All outcomes }\end{array}$ & Low risk & Blind \\
\hline $\begin{array}{l}\text { Incomplete outcome data } \\
\text { (attrition bias) } \\
\text { All outcomes }\end{array}$ & Low risk & $\begin{array}{l}\text { ITT analysis was completed. In the case of missing data the authors used } \\
\text { a 'best, worst and likely' approach to data imputation. There was a small } \\
\text { amount of attrition and the reasons for this were reported. }\end{array}$ \\
\hline $\begin{array}{l}\text { Selective reporting (re- } \\
\text { porting bias) }\end{array}$ & Low risk & No other outcomes were collected \\
\hline
\end{tabular}

Prange 2015

Methods RC

\section{Participants}

Recruited from an inpatient rehabilitation centre in the Netherlands

70 participants: 37 intervention, 33 control

Inclusion criteria: first stroke 1-12 weeks ago, medically stable, display limited arm function but have active control of the elbow/shoulder of $\geq 15^{\circ}$, be free from other conditions or pain, be able to follow instructions and understand (and see) the visual game display

Exclusion criteria: treated with botulinum toxin and/or electrical stimulation to improve arm function before or during participation

Mean (SD) age: intervention group 60.3 (9.7) years, 58 (11.4) years

Stroke details: $78 \%$ ischaemic, $60 \%$ right hemiparesis

Timing post stroke: intervention group mean 7.3 (3.4) years, control group mean 6.8 (3.1) years

Interventions

VR intervention: training using a customised arm support program. Training consisted of playing games with the affected arm, supported by the device, working toward maximising movement ability with as little arm support as possible. The training involved mostly shoulder and elbow movements with exercises structured according to categorisation of the games for increasing difficulty (1D, 2D and 3D)

Conventional therapy: standard set of exercises to reflect usual physiotherapy and OT

Sessions were $30 \mathrm{~min}, 3$ times/week for 6 weeks

Outcomes

Outcomes assessed post intervention

Fugl-Meyer assessment UE

Maximal reach distance 
Visual Analogue Scale for arm pain

Intrinsic Motivation Inventory post training

\begin{tabular}{ll}
\hline Notes NTR2539 & NT2
\end{tabular}

\section{Risk of bias}

\begin{tabular}{lll}
\hline Bias & Authors' judgement & Support for judgement \\
\hline $\begin{array}{l}\text { Random sequence genera- } \\
\text { tion (selection bias) }\end{array}$ & Unclear risk & Method not described \\
\hline $\begin{array}{l}\text { Allocation concealment } \\
\text { (selection bias) }\end{array}$ & Low risk & Concealed envelopes \\
\hline $\begin{array}{l}\text { Blinding of outcome as- } \\
\text { sessment (detection bias) } \\
\text { All outcomes }\end{array}$ & Low risk & Blinded assessor \\
\hline $\begin{array}{l}\text { Incomplete outcome data } \\
\text { (attrition bias) } \\
\text { All outcomes }\end{array}$ & Low risk & $\begin{array}{l}\text { Only 2 withdrawals and both withdrew due to inadvertent concurrent treat- } \\
\text { ment }\end{array}$ \\
\hline $\begin{array}{l}\text { Selective reporting (re- } \\
\text { porting bias) }\end{array}$ & Low risk & Outcomes reported as per trial registration \\
\hline
\end{tabular}

\section{Rajaratnam 2013}

\begin{tabular}{ll}
\hline Methods & RCT \\
\hline
\end{tabular}

\section{Participants}

Recruited from a community rehabilitation hospital in Singapore

19 participants: 10 intervention, 9 control

Inclusion criteria: recent first stroke with moderate or moderate-severe disability (Modified Rankin Scale Grade 3 or 4) Participants were haemodynamically stable and had a MMSE score of $>23$

Exclusion criteria: terminal illness, uncontrolled hypertension and angina and severe spatial neglect or visual impairments

Mean (SD) age: intervention group 58.67 (8.62) years, control group 65.33 (9.59) years

$37 \%$ men

Stroke details: $42 \%$ right hemiparesis

Timing post stroke: intervention group mean (SD) 14.7 (7.5) d, control group 15.2 (6.3) d

VR intervention: used either a Nintendo Wii Fit or Microsoft Kinect program during rehabilitation. The Nintendo Wii Fit was performed in standing and the Kinect was performed in sitting and standing. Sessions involved $40 \mathrm{~min}$ of conventional therapy and $20 \mathrm{~min}$ of VR

Control intervention: conventional therapy (not described). Sessions involved 60 min of conventional therapy

Sessions were $60 \mathrm{~min}$ for 15 sessions (approximately $15 \mathrm{~h}$ ) 
Rajaratnam 2013 (Continued)

Outcomes Outcomes recorded at baseline and post-intervention

Gait outcomes: Timed Up and Go Test

Balance function: Berg Balance Scale, Functional Reach Test, centre of pressure

Notes Activity limitation outcomes: Modified Barthel Index

\section{Risk of bias}

\begin{tabular}{|c|c|c|}
\hline Bias & Authors' judgement & Support for judgement \\
\hline $\begin{array}{l}\text { Random sequence genera- } \\
\text { tion (selection bias) }\end{array}$ & Low risk & Computer-generated \\
\hline $\begin{array}{l}\text { Allocation concealment } \\
\text { (selection bias) }\end{array}$ & Unclear risk & Not described \\
\hline $\begin{array}{l}\text { Blinding of outcome as- } \\
\text { sessment (detection bias) } \\
\text { All outcomes }\end{array}$ & Low risk & Blind \\
\hline $\begin{array}{l}\text { Incomplete outcome data } \\
\text { (attrition bias) } \\
\text { All outcomes }\end{array}$ & Unclear risk & Unable to ascertain \\
\hline $\begin{array}{l}\text { Selective reporting (re- } \\
\text { porting bias) }\end{array}$ & Unclear risk & Unclear \\
\hline
\end{tabular}

\section{Reinkensmeyer 2012}

\begin{tabular}{|c|c|}
\hline Methods & $\mathrm{RCT}$ \\
\hline \multirow[t]{7}{*}{ Participants } & Recruited from local hospitals and stroke support groups in Orange County, California \\
\hline & 26 participants: 13 intervention, 13 control \\
\hline & $\begin{array}{l}\text { Inclusion criteria: single stroke and } \geq 3 \text { months post stroke; moderate-severe weakness in their affected } \\
\text { upper limbs, defined by the upper limb Fugl Meyer Motor Scale (score of 10-35/66) }\end{array}$ \\
\hline & $\begin{array}{l}\text { Exclusion criteria: significant pain, instability or subluxation of the affected shoulder, severe elbow } \\
\text { or wrist contractures, concurrent severe medical problems, cognitive dysfunction to the extent that } \\
\text { would interfere with therapy participation, visual deficits, severe neglect or apraxia and current enrol- } \\
\text { ment in ongoing upper limb therapy }\end{array}$ \\
\hline & Mean (SD) age: intervention group 60 (10) years, control group 61 (13) years \\
\hline & Stroke details: $50 \%$ ischaemic, $31 \%$ haemorrhagic, $19 \%$ unknown \\
\hline & Timing post stroke: intervention group mean (SD) 65 (47) months, control group 67 (56) months \\
\hline Interventions & $\begin{array}{l}\text { VR intervention: Pneu-WREX is a robotic device (4-degree-of-freedom robot based on a passive arm } \\
\text { support (WREX)). It is a lightweight exoskeleton that allows a wide ROM of the arm in a 3D space. The } \\
\text { degrees of freedom are elbow flexion/extension, shoulder abduction/adduction, shoulder flexion/ex- } \\
\text { tension and shoulder forward/backward translation. The device can provide assistance as needed for a } \\
\text { patient to actively participate and to be able to perform 3D tasks. Hand training through grasp and re- } \\
\text { lease is incorporated through a grip sensor that measures the pressure of a water-filled cylinder blad- } \\
\text { der that the user holds, to detect even trace finger movement. A software package called Vu Therapy al- }\end{array}$ \\
\hline
\end{tabular}


Reinkensmeyer 2012 (Continued)

lowed for interface between the hardware and software. Tasks included grocery shopping, cleaning a window, playing basketball and driving a car. Auditory and visual feedback and a game score were provided to maintain attention and interest

Control intervention: conventional exercises including ROM and task-oriented movements

Sessions were 60 min, 3 times/week for 8-9 weeks (total $=24$ ) for both groups

$\begin{array}{ll}\text { Outcomes } & \text { Outcomes assessed post intervention and } 3 \text { months following the end of intervention } \\ \text { Arm Motor section of the Fugl Meyer Scale } \\ \text { Rancho Functional Test for the hemiplegic UE } \\ \text { Motor Activity Log } \\ \text { Box and Blocks Test } \\ \text { Grip strength (Jamar) } \\ \text { Adverse events reported } \\ \text { Disclosure reported that the lead author has a financial interest in Hocoma, a company that makes ro- } \\ \text { botic therapy devices }\end{array}$

\section{Risk of bias}

\begin{tabular}{|c|c|c|}
\hline Bias & Authors' judgement & Support for judgement \\
\hline $\begin{array}{l}\text { Random sequence genera- } \\
\text { tion (selection bias) }\end{array}$ & Low risk & Computer-generated randomisation \\
\hline $\begin{array}{l}\text { Allocation concealment } \\
\text { (selection bias) }\end{array}$ & Unclear risk & Method not described \\
\hline $\begin{array}{l}\text { Blinding of outcome as- } \\
\text { sessment (detection bias) } \\
\text { All outcomes }\end{array}$ & Low risk & Blinded assessor \\
\hline $\begin{array}{l}\text { Incomplete outcome data } \\
\text { (attrition bias) } \\
\text { All outcomes }\end{array}$ & Unclear risk & Not reported in detail \\
\hline $\begin{array}{l}\text { Selective reporting (re- } \\
\text { porting bias) }\end{array}$ & Unclear risk & Unable to ascertain (does not mention protocol or trial registration) \\
\hline
\end{tabular}

Saposnik 2010

\begin{tabular}{ll}
\hline Methods & RCT \\
\hline Participants & Recruited from a subacute rehabilitation facility in Toronto, Canada \\
& 22 participants: 11 intervention, 11 control \\
& Inclusion criteria: $18-85$ years with first time ischaemic or haemorrhagic stroke within the last 6 months, \\
Chedoke McMaster scale (UE) score of $>3$ in the arm or hand \\
Exclusion criteria: unable to follow instructions, pre-stroke Modified Rankin Score of $\geq 2$, medically un- \\
stable or with uncontrolled hypertension, severe illness with life expectancy of $<3$ months, unstable
\end{tabular}


angina, recent MI (within 3 months), history of seizures or epilepsy, participating in another clinical trial involving an investigational drug or physical therapy, any condition that might put the patient at risk (for example, known shoulder subluxation)

Mean age: intervention group 55 years, control group 67 years

$64 \%$ men

Stroke details: $45 \%$ right hemiparesis

Timing post stroke: intervention group mean (SD) 27 (16) d, control group 23 (9) d

Interventions intervention: participants used the Nintendo Wii gaming console playing 'Wii sports' and 'Cooking
Mama'
Control intervention: leisure activities including cards, bingo and Jenga
Sessions were 60 min for 8 sessions ( $8 \mathrm{~h}$ total)
Outcomes recorded at baseline, post intervention and at 1 month
Upper limb function and activity outcomes (arm): abbreviated version of the Wolf Motor Function Test
Upper limb function and activity outcomes (hand): Box and Block test, Grip strength (kg)
Participation restriction and quality of life: Stroke Impact Scale (hand function, composite function,
perception of recovery)
Adverse events reported
Other outcomes: therapy time

Notes -

\section{Risk of bias}

\begin{tabular}{|c|c|c|}
\hline Bias & Authors' judgement & Support for judgement \\
\hline $\begin{array}{l}\text { Random sequence genera- } \\
\text { tion (selection bias) }\end{array}$ & Low risk & $\begin{array}{l}\text { Participants were randomly allocated using a basic computer random number } \\
\text { generator }\end{array}$ \\
\hline $\begin{array}{l}\text { Allocation concealment } \\
\text { (selection bias) }\end{array}$ & Unclear risk & Unclear \\
\hline $\begin{array}{l}\text { Blinding of outcome as- } \\
\text { sessment (detection bias) } \\
\text { All outcomes }\end{array}$ & Low risk & Blind \\
\hline $\begin{array}{l}\text { Incomplete outcome data } \\
\text { (attrition bias) } \\
\text { All outcomes }\end{array}$ & Low risk & $\begin{array}{l}\text { Some attrition was reported. Outcomes were calculated based on the number } \\
\text { of participants and there was no reporting of imputation of data. ITT analysis } \\
\text { was completed }\end{array}$ \\
\hline $\begin{array}{l}\text { Selective reporting (re- } \\
\text { porting bias) }\end{array}$ & Low risk & Reports on all measures reported in the study protocol paper \\
\hline
\end{tabular}

Saposnik 2016

\begin{tabular}{ll}
\hline Methods RCT \\
\hline
\end{tabular}


Saposnik 2016 (Continued)

Participants

Recruited from rehabilitation units in 4 countries: Canada, Argentina, Peru, Thailand

141 participants: 71 intervention group, 70 control group

Inclusion criteria: $18-85$ years with first time ischaemic stroke within 3 months of enrolment and with mild to moderate motor disability (Chedoke McMaster Stroke Assessment stage > 3 )

Exclusion criteria: no disability in the UE (arm components of the Chedoke McMaster scale $=7$ ), were unable to follow instructions, pre-stroke Modified Rankin score of $\geq 2$, medically unstable or uncontrolled hypertension; severe illness with a life expectancy of $<3$ months, unstable angina or MI within 3 months, history of seizures or epilepsy (except for febrile seizures of childhood); participating in another clinical trial involving an investigational drug or physical therapy or had any condition that might put the patient at risk (e.g. known shoulder subluxation)

Mean (SD) age: intervention group 62 (13) years, control group 62 (12) years

Stroke details: $100 \%$ ischaemic; right hemiparesis $47 \%$

Timing post stroke: intervention group mean $27 \mathrm{~d}$, control group mean $24.5 \mathrm{~d}$

Interventions

VR intervention: Nintendo Wii Sports and Game Party 3. Progression through the intervention allowed participants to choose some specific activities within those games (last $3 \mathrm{~min}$ of the intervention) based on their capabilities and interest with the goals of enhancing flexibility, ROM, strength and co-ordination of the affected arm

Control intervention: recreational therapy with progression through activities such as cards, bingo, Jenga or a ball game

Administered $1: 1$ by a rehabilitation therapist

Sessions were $60 \mathrm{~min}, 5$ times/week for 2 weeks

Outcomes were recorded at 2 weeks (post intervention) and 4 weeks
Abbreviated Wolf Motor Function Test
Box and Block Test
Quality of life after stroke - Stroke Impact Scale
Functional Independence Measure, Barthel Index, Modified Rankin Scale
Grip strength (dynamometer)
Hand function - Stroke Impact Scale
Adverse events reported

Notes NCT01406912

\section{Risk of bias}

\begin{tabular}{lll}
\hline Bias & Authors' judgement & Support for judgement \\
\hline $\begin{array}{l}\text { Random sequence genera- } \\
\text { tion (selection bias) }\end{array}$ & Low risk & Computer-generated assignment \\
\hline $\begin{array}{l}\text { Allocation concealment } \\
\text { (selection bias) }\end{array}$ & Low risk & Assignment at the point enrolment \\
\hline $\begin{array}{l}\text { Blinding of outcome as- } \\
\text { sessment (detection bias) }\end{array}$ & Low risk & Blinded assessor \\
\hline
\end{tabular}


Saposnik 2016 (Continued)

All outcomes

Incomplete outcome data Low risk ITT analysis conducted. Details of withdrawals reported transparently
(attrition bias)

All outcomes

Selective reporting (re- Low risk $\quad$ All outcomes reported
porting bias)

porting bias)

Shin 2014

\begin{tabular}{ll}
\hline Methods & RCT \\
\hline Participants & Recruited from 2 rehabilitation units and the neurorehabilitation ward of a hospital in Kore \\
& 16 participants: 9 intervention, 7 control \\
& Inclusion criteria: hemiparetic upper limb dysfunction due to first-ever stroke, mild-to-severe \\
the paretic UE (2-4 on the MRC Scale and 2-5 on the Brunnstrom Stage of motor recovery) & Exclusion criteria: pre-existing arm impairment, any painful condition affecting the upper limb \\
culty in sitting for $\geq 20$ min, severe cognitive impairment (MMSE score < 10 points) and seve & Mean (SD) age: intervention group 46.6 (5.8) years, control group 52.0 (11.9) years \\
& 50\% men \\
& Stroke details: $38 \%$ right lesion \\
& Timing post stroke: intervention group mean (SD) 76.6 (28.5) d, control group 67.1 (45.3) d
\end{tabular}

Interventions $\quad$ VR intervention: RehabMaster ${ }^{\mathrm{TM}}$. The participant sits in a chair in front of a monitor. The therapist can control the program and level of difficulty. Rehabilitation games were designed to combine rehabilitation exercises with gaming elements. The 4 games suggested were goalkeeper, bug hunter, underwater fire and rollercoaster

Control intervention: conventional OT

Sessions were $20 \mathrm{~min}$ of OT. The intervention group received an additional $20 \mathrm{~min}$ of VR. The duration of intervention was 10 sessions over 2 weeks

\section{Outcomes}

Outcomes recorded at baseline and post intervention

Upper limb function outcomes: Fugl Meyer

Activity limitation outcomes; Modified Barthel Index

Other outcomes: passive ROM of the upper limb, MRC Score

\begin{tabular}{lll}
\hline Notes & - \\
\hline Risk of bias & & \\
\hline Bias & Authors' judgement & Support for judgement \\
\hline $\begin{array}{l}\text { Random sequence genera- } \\
\text { tion (selection bias) }\end{array}$ & Low risk & Computer-generated \\
\hline
\end{tabular}


Shin 2014 (Continued)

\begin{tabular}{|c|c|c|}
\hline $\begin{array}{l}\text { Allocation concealment } \\
\text { (selection bias) }\end{array}$ & Low risk & Opaque envelopes \\
\hline $\begin{array}{l}\text { Blinding of outcome as- } \\
\text { sessment (detection bias) } \\
\text { All outcomes }\end{array}$ & Low risk & Blinded to allocatio \\
\hline
\end{tabular}

\begin{tabular}{lll}
\hline $\begin{array}{l}\text { Incomplete outcome data } \\
\text { (attrition bias) } \\
\text { All outcomes }\end{array}$ & Low risk & No dropouts \\
\hline $\begin{array}{l}\text { Selective reporting (re- } \\
\text { porting bias) }\end{array}$ & Low risk & $\begin{array}{l}\text { All outcomes reported except for the SF36 measure, which will be reported in a } \\
\text { subsequent publication }\end{array}$ \\
\hline
\end{tabular}

Shin 2015

\begin{tabular}{ll}
\hline Methods & RCT \\
\hline Participants & Recruited from a rehabilitation hospital in Seoul, Korea \\
& 35 participants: 18 intervention, 17 control \\
& Inclusion criteria: aged $\geq 18$ years with chronic hemiparetic upper limb dysfunction, secondary to a first \\
& ever stroke. MRC Scale scores of 2-4 (inclusive) and a Brunnstrom motor recovery stage for the proximal \\
& UE of 2-5 inclusive
\end{tabular}

Exclusion criteria: severe cognitive impairment or aphasia, pre-existing mental illness or arm impairment, difficulty in sitting for $\geq 30 \mathrm{~min}$ and/or uncontrolled medical illness

Mean (SD) age: intervention group 53.3 (11.8) years, control group 54.6 (13.4) years

$69 \%$ men

Stroke details: $50 \%$ right hemiparesis

Timing post stroke: intervention group mean (SD) 202 (89), control group 165 (87) d

VR intervention: game-based VR using 10 min of rehabilitation training and 20 min of rehabilitation games selected by an occupational therapist to encourage active arm and trunk movements. Participants sat in a chair in front of the monitor and depth sensor and moved according to the training protocol. The difficulty was set by manipulating the ROM or speed of the activity or by manipulating the number, size, location, speed or trajectories of the targets

Control intervention: conventional OT including exercises, table top activities and training for ADL

Sessions for the VR group were $30 \mathrm{~min}$ of VR plus $30 \mathrm{~min}$ of conventional OT, $5 \mathrm{~d} /$ week for 4 weeks

Sessions for the control group were $60 \mathrm{~min}$ of OT, $5 \mathrm{~d}$ /week for 4 weeks

\begin{tabular}{ll}
\hline Outcomes & Outcomes assessed post intervention \\
& Korean SF36 \\
& Korean Hamilton Depression Rating Scale \\
& Fugl Meyer Assessment UE \\
& Adverse events reported
\end{tabular}


Shin 2015 (Continued)

Notes

\section{Risk of bias}

\begin{tabular}{lll}
\hline Bias & Authors' judgement & Support for judgement \\
\hline $\begin{array}{l}\text { Random sequence genera- } \\
\text { tion (selection bias) }\end{array}$ & Low risk & Computer-generated \\
\hline $\begin{array}{l}\text { Allocation concealment } \\
\text { (selection bias) }\end{array}$ & Unclear risk & Method not reported \\
\hline $\begin{array}{l}\text { Blinding of outcome as- } \\
\text { sessment (detection bias) } \\
\text { All outcomes }\end{array}$ & Low risk & Blinded outcome assessor \\
\hline $\begin{array}{l}\text { Incomplete outcome data } \\
\text { (attrition bias) } \\
\text { All outcomes }\end{array}$ & Low risk & $\begin{array}{l}\text { Minor loss to follow-up. Method of dealing with this in the analysis is not re- } \\
\text { ported }\end{array}$ \\
\hline $\begin{array}{l}\text { Selective reporting (re- } \\
\text { porting bias) }\end{array}$ & Unclear risk & No mention of protocol or trial registration \\
\hline
\end{tabular}

$\sin 2013$

\begin{tabular}{ll}
\hline Methods & RCT \\
\hline
\end{tabular}

Participants

Recruited from a rehabilitation hospital in Korea

35 participants: 18 intervention, 17 control

Inclusion criteria: > 6 months post stroke, no problems with auditory or visual functioning, active ROM of the shoulder, elbow, wrist and fingers of $>10^{\circ}$, ability to walk $>10 \mathrm{~m}$ independently not taking any medication that could influence balance or gait and no severe cognitive disorders (MMSE score of > 16/30)

Exclusion criteria: uncontrolled blood pressure or angina, history of seizure, any intervention other than conventional therapy, or refusal to use a video game

Mean (SD) age: intervention group 71.78 (9.42) years, control group 75.59 (5.55) years

$43 \%$ men

Stroke details: $66 \%$ right hemiparesis

Timing post stroke: intervention group mean (SD) 7.22 (1.21) months, control group 8.47 (2.98) months

Interventions VR intervention: use of Xbox Kinect for 30 min followed by conventional OT for 30 min. Kinect programs that required use of the UEs were selected

Control intervention: conventional OT, which focused on retraining UE and hand function and ADL Sessions were performed 3 times/week for 6 weeks

\begin{tabular}{ll}
\hline Outcomes & Outcomes recorded at baseline and post-intervention \\
& Upper limb outcomes: Fugl Meyer UE, Box and Block test \\
Other outcomes: UE Active ROM
\end{tabular}


Sin 2013 (Continued)

Notes

\section{Risk of bias}

\begin{tabular}{lll}
\hline Bias & Authors' judgement & Support for judgement \\
\hline $\begin{array}{l}\text { Random sequence genera- } \\
\text { tion (selection bias) }\end{array}$ & Low risk & Random number tables \\
\hline $\begin{array}{l}\text { Allocation concealment } \\
\text { (selection bias) }\end{array}$ & Unclear risk & Not reported \\
\hline $\begin{array}{l}\text { Blinding of outcome as- } \\
\text { sessment (detection bias) } \\
\text { All outcomes }\end{array}$ & Low risk & Blinded to allocation \\
\hline $\begin{array}{l}\text { Incomplete outcome data } \\
\text { (attrition bias) } \\
\text { All outcomes }\end{array}$ & Unclear risk & To be determined \\
\hline $\begin{array}{l}\text { Selective reporting (re- } \\
\text { porting bias) }\end{array}$ & Unclear risk & To be determined \\
\hline
\end{tabular}

Song 2015

\begin{tabular}{ll}
\hline Methods & RCT \\
\hline Participants & Recruited from a hospital in South Korea \\
& 40 participants: 20 intervention group, 20 control group \\
& Inclusion criteria: no visual field deficit, no abnormality in the vestibular organs, no orthopaedic dis- \\
ease, an unrestricted ROM, able to understand and perform the exercise as instructed by the researcher \\
and a score of $\geq 24$ on the MMSE-K \\
Exclusion criteria: none reported \\
Mean (SD) age: intervention group mean (SD) 51.37 (40.6) years, control group 50.10 (7.83) years \\
55\% men \\
Stroke details: $48 \%$ right hemiparesis \\
Timing post stroke: intervention group 14.75 (6.06) months, 14.30 (3.40) months
\end{tabular}

Interventions

VR intervention: Xbox Kinect including Kinect Sport, Kinect Sport Season 2, Kinect Adventure, Kinect Gunstringer. Mostly sports programs such as bowling, skiing, golf, ground walking, walking over obstacles and climbing stairs were used for training

Control intervention: ergometer bicycle training using a Motomed Viva 2. The Motomed provides detailed feedback, software-controlled therapy programs and motivation and training games

Sessions for both interventions were $30 \mathrm{~min}, 5 \mathrm{~d} /$ week for 8 weeks

$\begin{array}{ll}\text { Outcomes } & \begin{array}{l}\text { Outcomes assessed post intervention } \\ \text { Balance (biofeedback analysis system) } \\ \text { Timed Up and Go Test }\end{array}\end{array}$


Song 2015 (Continued)

10 Minute Walk Test

\section{Notes}

\section{Risk of bias}

\begin{tabular}{lll}
\hline Bias & Authors' judgement & Support for judgement \\
\hline $\begin{array}{l}\text { Random sequence genera- } \\
\text { tion (selection bias) }\end{array}$ & Unclear risk & Detail not reported \\
\hline $\begin{array}{l}\text { Allocation concealment } \\
\text { (selection bias) }\end{array}$ & Unclear risk & Detail not reported \\
\hline $\begin{array}{l}\text { Blinding of outcome as- } \\
\text { sessment (detection bias) } \\
\text { All outcomes }\end{array}$ & Unclear risk & Detail not reported \\
\hline $\begin{array}{l}\text { Incomplete outcome data } \\
\text { (attrition bias) } \\
\text { All outcomes }\end{array}$ & Unclear risk & Detail not reported \\
\hline $\begin{array}{l}\text { Selective reporting (re- } \\
\text { porting bias) }\end{array}$ & Unclear risk & No mention of protocol or trial registration \\
\hline
\end{tabular}

Standen 2011

\begin{tabular}{ll}
\hline Methods & RCT \\
\hline Participants & Study took place in the UK \\
& 27 participants: 17 intervention, 10 control \\
& Inclusion criteria: $\geq 18$ years, no longer receiving any other intensive rehabilitation and still had residual \\
& upper limb dysfunction \\
& Exclusion criteria: failure to meet above criteria \\
& Mean (SD) age: intervention group 59 (12.03) years, control group 63 (14.6) years \\
& $59 \%$ men \\
& Timing post stroke: intervention group mean (SD) 38 (41.28) weeks, control group 24 (36.26) weeks
\end{tabular}

Interventions VR intervention: virtual glove which translates the position of the hand into gameplay. Participants
were instructed to use the program at home

Control intervention: usual care (no specific intervention)

Sessions were $20 \mathrm{~min}, 3$ times/d for 8 weeks (approximately $52 \mathrm{~h}$ )

Outcomes recorded at baseline, 4 weeks and post intervention (8 weeks)
Upper limb function outcome: Wolf Motor Function Test, Nine Hole Peg Test
Other: Motor Activity Log
Activity outcomes: Nottingham Extended ADL Scale (NEADL)


Standen 2011 (Continued)

Notes

\title{
Risk of bias
}

\begin{tabular}{lll}
\hline Bias & Authors' judgement & Support for judgement \\
\hline $\begin{array}{l}\text { Random sequence genera- } \\
\text { tion (selection bias) }\end{array}$ & Low risk & Computerised random number generator \\
\hline $\begin{array}{l}\text { Allocation concealment } \\
\text { (selection bias) }\end{array}$ & Low risk & Managed externally \\
\hline $\begin{array}{l}\text { Blinding of outcome as- } \\
\text { sessment (detection bias) } \\
\text { All outcomes }\end{array}$ & Low risk & Blinded to allocation \\
\hline $\begin{array}{l}\text { Incomplete outcome data } \\
\text { (attrition bias) } \\
\text { All outcomes }\end{array}$ & High risk & Large number of dropouts in the intervention group \\
\hline $\begin{array}{l}\text { Selective reporting (re- } \\
\text { porting bias) }\end{array}$ & Low risk & Unpublished data obtained via personal communication \\
\hline
\end{tabular}

Subramanian 2013

\begin{tabular}{ll}
\hline Methods & RCT \\
\hline
\end{tabular}

\section{Participants}

\author{
Study took place in Canada \\ 32 participants: 16 intervention, 16 control
}

Inclusion criteria: aged 40-80 years, sustained single ischaemic or haemorrhagic stroke 6-60 months previously, scored 3-6 on the Chedoke McMaster Stroke Assessment arm subscale and had no other neurologic or neuromuscular/orthopaedic problems affecting the upper limb and trunk

Exclusion criteria: brainstem or cerebellar lesions, comprehension difficulties and marked apraxia, attention or visual field deficits

Mean (SD) age: intervention group 62 (9.7) years, control group 60 (11) years

$72 \%$ men

Stroke details: $47 \%$ right hemiparesis

Timing post stroke: intervention group mean (SD) 3.7 (2.2) years, control group 3.0 (1.9) years

Interventions

VR intervention: a 3D virtual environment (CAREN system) simulated a supermarket scene. Participants had to reach for objects in the virtual environment. Training was high in intensity with 72 trials of reaching in each session

Control intervention: pointing at targets in a physical environment

Sessions were $45 \mathrm{~min}$ for $12 \mathrm{~d}$ spaced over 4 weeks

Outcomes were recorded at baseline, post intervention and 3 months following intervention
Upper limb outcomes: Fugl Meyer, Reaching Performance Scale for Stroke, Wolf Motor Function Test
Adverse events reported


Subramanian 2013 (Continued)

Other outcomes: Motor Activity Log-AS

Other outcomes: Motivation Task Evaluation Questionnaire

Other outcomes: kinematic data

\begin{tabular}{|c|c|c|}
\hline Notes & - & \\
\hline \multicolumn{3}{|l|}{ Risk of bias } \\
\hline Bias & Authors' judgement & Support for judgement \\
\hline $\begin{array}{l}\text { Random sequence genera- } \\
\text { tion (selection bias) }\end{array}$ & Low risk & Computer-generated \\
\hline $\begin{array}{l}\text { Allocation concealment } \\
\text { (selection bias) }\end{array}$ & Low risk & Managed by external personnel \\
\hline $\begin{array}{l}\text { Blinding of outcome as- } \\
\text { sessment (detection bias) } \\
\text { All outcomes }\end{array}$ & Low risk & Blinded to allocation \\
\hline $\begin{array}{l}\text { Incomplete outcome data } \\
\text { (attrition bias) } \\
\text { All outcomes }\end{array}$ & Low risk & $\begin{array}{l}\text { All completed the assessments. Small number of intervention dropouts and } \\
\text { balanced across groups }\end{array}$ \\
\hline $\begin{array}{l}\text { Selective reporting (re- } \\
\text { porting bias) }\end{array}$ & Low risk & All outcomes reported as per entry on clinical trial registry \\
\hline
\end{tabular}

Sucar 2009

Methods Quasi RCT

Participants Recruited from the National Institute of Neurology in Mexico City, Mexico

22 participants: 11 intervention, 11 control

Inclusion criteria: $\geq 6$ months after stroke

Exclusion criteria: none reported

Mean age: intervention group 51 years, control group 52 years

Timing post stroke: intervention group 22 months, control group 26 months

Interventions VR intervention: participants used a 'Gesture Therapy' program designed by the researchers. Movements of the participant's upper limbs are tracked by a camera and the person interacts with on-screen games. Games included shopping in the supermarket, making breakfast, playing basketball, cleaning, painting and driving

Control intervention: a variety of exercises guided by the therapist using equipment such as cones and balls

Sessions were $60 \mathrm{~min}, 3$ times/week for 5 weeks ( $15 \mathrm{~h}$ total)

Outcomes Outcomes recorded at baseline and post intervention

Upper limb function and activity outcomes (arm): Fugl Meyer UE scale, Motricity Index 
Sucar 2009 (Continued)

\section{Adverse events reported}

Other outcomes: level of interest, competence, effort, pressure and utility of the intervention

Notes

\section{Risk of bias}

\begin{tabular}{|c|c|c|}
\hline Bias & Authors' judgement & Support for judgement \\
\hline $\begin{array}{l}\text { Random sequence genera- } \\
\text { tion (selection bias) }\end{array}$ & High risk & Alternate allocation based on odd or even numbers \\
\hline $\begin{array}{l}\text { Allocation concealment } \\
\text { (selection bias) }\end{array}$ & Unclear risk & Unclear \\
\hline $\begin{array}{l}\text { Blinding of outcome as- } \\
\text { sessment (detection bias) } \\
\text { All outcomes }\end{array}$ & High risk & Not blinded \\
\hline $\begin{array}{l}\text { Incomplete outcome data } \\
\text { (attrition bias) } \\
\text { All outcomes }\end{array}$ & Low risk & There were no missing data \\
\hline $\begin{array}{l}\text { Selective reporting (re- } \\
\text { porting bias) }\end{array}$ & Low risk & No additional outcomes were collected \\
\hline
\end{tabular}

Thielbar 2014

\begin{tabular}{ll}
\hline Methods & RCT \\
\hline Participants & Recruited from an outpatient clinic in the USA \\
& 14 participants: 7 intervention, 7 control \\
& Inclusion criteria: chronic hemiparesis resulting from a single stroke $\geq 6$ months prior with mild-mod- \\
& erate hand impairment as evidenced by a score of 5 or 6 on the Hand subsection of the Chedoke Mc- \\
& Master Stroke Assessment scale. Limitations with fine motor control but able to perform 2 of 3 specified \\
& hand movements \\
& Exclusion criteria: receiving outpatient physical or OT, biomechanical limitations which limited passive \\
digit extension to $20^{\circ}$ of finger flexion; had received botulinum toxin < 6 months prior to enrolment; \\
cognitive deficits limiting simple 1-step commands or significant UE pain
\end{tabular}

Mean (SD) age: intervention group 54 (7) years, control group 59 (6) years

Stroke details: right hemiparesis $43 \%$

Timing post stroke: intervention group 46.6 (32.5) months, control group 47.9 (47.4) months

Interventions

VR intervention: trained with the actuated virtual keyboard (AVK) system to practice movements of different combinations. Participants wore a PneuGlove and pressed virtual keys. Visual displays guided the user as did the therapist. Each key played a unique tone which would play whenever the key was struck

Control intervention: high-intensity task-oriented OT centred on fine motor control, dexterity, in-hand manipulation and isolated finger movements. Examples of activities included practise of buttoning, typing, tying knots, writing and using tools 
Thielbar 2014 (Continued)

Both group had sessions of 60 min, 3 times a week for 6 weeks

Outcomes assessed post intervention and 1 month after the end of intervention
Action Research Arm Test
Jebsen Taylor Hand Function Test
Fugl Meyer (UE)
Grip strength (Jamar dynamometer)
Other: Kinematic actuation

Notes - -

\section{Risk of bias}

\begin{tabular}{|c|c|c|}
\hline Bias & Authors' judgement & Support for judgement \\
\hline $\begin{array}{l}\text { Random sequence genera- } \\
\text { tion (selection bias) }\end{array}$ & High risk & Drawing lots \\
\hline $\begin{array}{l}\text { Allocation concealment } \\
\text { (selection bias) }\end{array}$ & Low risk & Drawing lots \\
\hline $\begin{array}{l}\text { Blinding of outcome as- } \\
\text { sessment (detection bias) } \\
\text { All outcomes }\end{array}$ & Low risk & Blinded therapist \\
\hline $\begin{array}{l}\text { Incomplete outcome data } \\
\text { (attrition bias) } \\
\text { All outcomes }\end{array}$ & Low risk & Minimal dropout \\
\hline $\begin{array}{l}\text { Selective reporting (re- } \\
\text { porting bias) }\end{array}$ & Unclear risk & No mention of protocol or trial registration \\
\hline
\end{tabular}

Ucar 2014

\begin{tabular}{ll}
\hline Methods & RCT \\
\hline Participants & Recruited from an outpatient unit in Turkey \\
& 22 participants: 11 intervention, 11 control \\
& Inclusion criteria: adult male $>18$ years), capability to ambulate $10 \mathrm{~m}$ without personal assistance and \\
& not receiving any other physical therapy \\
& Exclusion criteria: body weight $>135 \mathrm{~kg}$, FAC score $<3$; unable to walk consistently or independent- \\
ly within the community, cognitive deficits, cardiac disease, spasticity of the lower limbs preventing \\
them from robotic walking, traumatic stroke, intracranial space occupying lesion-induced strokes and \\
seizures \\
Mean age: intervention group 56.2 years, control group 61.5 years \\
100\% men \\
Stroke details not reported \\
\hline
\end{tabular}


Ucar 2014 (Continued)

Interventions
VR intervention: robotic (Lokomat) training with a computer monitor placed in front of the participants. It provided them with biofeedback of their performance

Control intervention: conventional physiotherapy in the home environment. Home exercise focused on gait and body weight support on the paretic leg. Also included active assisted exercises, leg strengthening and balance training

Both groups received 30-min sessions, $5 \mathrm{~d} /$ week for 2 weeks

Outcomes assessed post intervention
10 m Timed Walking Speed Test
Timed Up and Go Test
MMSE
Hospital Anxiety and Depression Scale
Functional Ambulation Category

Notes

\section{Risk of bias}

\begin{tabular}{lll}
\hline Bias & Authors' judgement & Support for judgement \\
\hline $\begin{array}{l}\text { Random sequence genera- } \\
\text { tion (selection bias) }\end{array}$ & Unclear risk & Detail not reported \\
\hline $\begin{array}{l}\text { Allocation concealment } \\
\text { (selection bias) }\end{array}$ & Unclear risk & Detail not reported \\
\hline $\begin{array}{l}\text { Blinding of outcome as- } \\
\text { sessment (detection bias) } \\
\text { All outcomes }\end{array}$ & High risk & Assessor not blinded \\
\hline $\begin{array}{l}\text { Incomplete outcome data } \\
\text { (attrition bias) } \\
\text { All outcomes }\end{array}$ & Unclear risk & Detail not reported in enough detail to make a judgement \\
\hline $\begin{array}{l}\text { Selective reporting (re- } \\
\text { porting bias) }\end{array}$ & Unclear risk & No mention of protocol or trial registration \\
\hline
\end{tabular}

Xiang 2014

\begin{tabular}{ll}
\hline Methods & RCT \\
\hline Participants & Recruited from a hospital in China \\
& 20 participants: 10 intervention, 10 control \\
& Inclusion criteria: aged $40-80$ years within 3 months of first onset of stroke. Abnormal $10 \mathrm{~m}$ walking time \\
but could walk $>10 \mathrm{~m}$ with no more than the assistance of 1 person & \\
& Exclusion criteria: cerebellum/brainstem infarct; impairment in all 4 limbs, reduced consciousness, res- \\
piratory or heart failure, Parkinson's Disease, recent Ml, recent leg fracture, recent deep vein thrombo- \\
sis, recent stroke with gait disorder
\end{tabular}


Xiang 2014 (Continued)

Mean (SD) age: intervention group 57.1 (10.43) years, control group $62.2(10.21)$ years

$70 \%$ men

Stroke details: $45 \%$ right hemiparesis

Timing post stroke: intervention group mean (SD) 44.4 (14.78) d, control group 40.80 (16.52) d

Interventions
Control intervention: muscle strength training, stretching and balance exercises
Both groups participated in 15 sessions of conventional therapy; the VR intervention group received an
additional 20-40 min of training at each session

\begin{tabular}{ll}
\hline Outcomes & Outcomes assessed post intervention \\
& $10 \mathrm{~m}$ walking speed \\
& Fugl Meyer (LE) \\
Brunel Balance Assessment
\end{tabular}

Notes -

\section{Risk of bias}

\begin{tabular}{lll}
\hline Bias & Authors' judgement & Support for judgement \\
\hline $\begin{array}{l}\text { Random sequence genera- } \\
\text { tion (selection bias) }\end{array}$ & Unclear risk & Detail not reported \\
\hline $\begin{array}{l}\text { Allocation concealment } \\
\text { (selection bias) }\end{array}$ & Unclear risk & Detail not reported \\
\hline $\begin{array}{l}\text { Blinding of outcome as- } \\
\text { sessment (detection bias) } \\
\text { All outcomes }\end{array}$ & High risk & Assessor not blinded \\
\hline $\begin{array}{l}\text { Incomplete outcome data } \\
\text { (attrition bias) }\end{array}$ & Unclear risk & Not reported in sufficient detail to make judgement \\
$\begin{array}{l}\text { All outcomes } \\
\text { Selective reporting (re- } \\
\text { porting bias) }\end{array}$ & Unclear risk & Unable to find protocol or trial registration \\
\hline
\end{tabular}

\begin{tabular}{ll} 
Yang 2008 & RCT \\
\hline Methods & Study took place in Taiwan \\
\hline Participants & 24 participants: 12 intervention, 12 control \\
& $\begin{array}{l}\text { Inclusion criteria: hemiparesis resulting from a single stroke occurring }>6 \text { months earlier, limited } \\
\text { household walker, unlimited household walker or most-limited community walker by functional walk- } \\
\text { ing category, not presently receiving any rehabilitation services, no visual field deficit or hemianopia, } \\
\text { stable medical condition to allow participation in the testing protocol and intervention, ability to un- } \\
\text { derstand instructions and follow commands }\end{array}$ \\
\hline
\end{tabular}


Yang 2008 (Continued)

Exclusion criteria: any comorbidity or disability other than stroke that would preclude gait training, uncontrolled health condition for which exercise was contraindicated, neurological or orthopaedic disease that might interfere with the study

Mean (SD) age: intervention group 55 (12) years, control group 61 (9) years

$50 \%$ men

Stroke details: $45 \%$ right hemiparesis

Timing post stroke: intervention group mean (SD) 6 (4) years, control group 6 (10) years

Interventions

VR intervention: the participant walked on a treadmill as virtual environments were displayed on a screen in front of the person with a wide field of view. Speed and incline of the treadmill was able to be varied in conjunction with scenery changes. Leg movements were tracked by an electromagnetic system to detect collisions with virtual objects. The virtual environment was designed to simulate a typical community in Taipei. Scenarios consisted of lane walking, street crossing, negotiating obstacles and strolling through the park

Control intervention: treadmill training. While walking on the treadmill the participant was asked to execute different tasks. The tasks included lifting the legs to simulate stepping over obstacles, uphill and downhill walking and fast walking

Sessions were $20 \mathrm{~min}, 3$ times/week for 3 weeks ( $3 \mathrm{~h}$ total)

Outcomes Outcomes recorded at baseline, post intervention and at 1 month

Lower limb function and activity outcomes: walking speed $(\mathrm{m} / \mathrm{s})$, community walk test

Participation restriction and quality of life: walking ability questionnaire, Activities Specific Balance Confidence Scale

Notes -

\section{Risk of bias}

\begin{tabular}{lll}
\hline Bias & Authors' judgement & Support for judgement \\
\hline $\begin{array}{l}\text { Random sequence genera- } \\
\text { tion (selection bias) }\end{array}$ & Low risk & $\begin{array}{l}\text { An independent person picked } 1 \text { of the sealed envelopes before the start of the } \\
\text { intervention }\end{array}$ \\
\hline $\begin{array}{l}\text { Allocation concealment } \\
\text { (selection bias) }\end{array}$ & Unclear risk & Unclear whether envelopes were opaque \\
\hline $\begin{array}{l}\text { Blinding of outcome as- } \\
\text { sessment (detection bias) }\end{array}$ & Low risk & Blind \\
All outcomes & \\
\hline $\begin{array}{l}\text { Incomplete outcome data } \\
\text { (attrition bias) } \\
\text { All outcomes }\end{array}$ & Unclear risk & Unclear \\
\hline $\begin{array}{l}\text { Selective reporting (re- } \\
\text { porting bias) }\end{array}$ & Unclear risk & Unclear \\
\hline
\end{tabular}

\section{Yang 2011}

\section{Methods}

RCT 
Yang 2011 (Continued)
Participants
Recruited from a hospital in Taiwan
14 participants: 7 intervention, 7 control
Inclusion criteria: hemiplegia resulting from a stroke $>6$ months ago. Able to understand the treadmill exercises
Exclusion criteria: inability to walk independently (without using an assistive device), abnormal neu- ro-opthalmologic findings after examination and visual acuity problems after correction
Mean (SD) age: intervention group 56.3 (10.2) years, control group 65.7 (5.9) years
Stroke details: $36 \%$ right hemiparesis
Timing post stroke: intervention group mean (SD) 17 (8.6) months, control group 16.3 (10.4) months

VR intervention: standard OT and physiotherapy program plus VR treadmill training. The treadmill was
co-ordinated with the interactive scenes so that a stepping switch turned the scenes left or right as if
the person was turning a corner. Participants had to make 16 turns/session
Control intervention: treadmill training facing a window
Sessions were $20 \mathrm{~min}, 3$ times/week for 3 weeks (approximately $3 \mathrm{~h}$ total)

Outcomes Outcomes recorded at baseline and post-intervention

Gait outcomes: bilateral limb loading symmetric index, paretic limb stance time, number of steps of the paretic limb, contact areas of the paretic foot during quiet stance, sit-to-stand transfer and level walking

Balance outcomes: centre of pressure

\begin{tabular}{|c|c|c|}
\hline Notes & - & \\
\hline \multicolumn{3}{|l|}{ Risk of bias } \\
\hline Bias & Authors' judgement & Support for judgement \\
\hline $\begin{array}{l}\text { Random sequence genera- } \\
\text { tion (selection bias) }\end{array}$ & Unclear risk & Not reported \\
\hline $\begin{array}{l}\text { Allocation concealment } \\
\text { (selection bias) }\end{array}$ & Unclear risk & Not reported \\
\hline $\begin{array}{l}\text { Blinding of outcome as- } \\
\text { sessment (detection bias) } \\
\text { All outcomes }\end{array}$ & Low risk & Blinded to allocation \\
\hline $\begin{array}{l}\text { Incomplete outcome data } \\
\text { (attrition bias) } \\
\text { All outcomes }\end{array}$ & Unclear risk & Insufficient detail reported to tell \\
\hline $\begin{array}{l}\text { Selective reporting (re- } \\
\text { porting bias) }\end{array}$ & Unclear risk & Protocol not available \\
\hline
\end{tabular}

\section{Yavuzer 2008}

\begin{tabular}{ll}
\hline Methods & RCT \\
\hline
\end{tabular}


Yavuzer 2008 (Continued)

Participants
Recruited from an inpatient rehabilitation centre in Turkey

20 participants: 10 intervention, 10 control

Inclusion criteria: first episode of unilateral stroke with hemiparesis during the previous 12 months, score of 1-4 on the Brunnstrom stages for the UE, able to understand and follow simple verbal instructions, no severe cognitive disorders that would interfere with the study's purpose (MMSE score of > $16 / 30)$

Mean (SD) age: intervention group 58 (10) years, control group 64 (11) years

$45 \%$ men

Stroke details: $45 \%$ right hemiparesis

Timing post stroke: intervention group mean (SD) 3 (3) months, control group 5 (1) months

Interventions

VR intervention: active use of the Playstation EyeToy games involving use of the upper limbs

Control intervention: watched the Playstation EyeToy games but did not get physically involved

Sessions were $30 \mathrm{~min}, 5$ times/week for 4 weeks ( $10 \mathrm{~h}$ total)

Sessions were in addition to the conventional rehabilitation programme that both groups were participating in, which involved approximately $60 \mathrm{~min}$ of therapy for the upper limb

\begin{tabular}{|c|c|c|}
\hline Notes & - & \\
\hline \multicolumn{3}{|l|}{ Risk of bias } \\
\hline Bias & Authors' judgement & Support for judgement \\
\hline $\begin{array}{l}\text { Random sequence genera- } \\
\text { tion (selection bias) }\end{array}$ & Low risk & Sequence generated using a computer-generated random number list \\
\hline $\begin{array}{l}\text { Allocation concealment } \\
\text { (selection bias) }\end{array}$ & Low risk & An independent doctor operated the random number program \\
\hline $\begin{array}{l}\text { Blinding of outcome as- } \\
\text { sessment (detection bias) } \\
\text { All outcomes }\end{array}$ & Low risk & Blind \\
\hline $\begin{array}{l}\text { Incomplete outcome data } \\
\text { (attrition bias) } \\
\text { All outcomes }\end{array}$ & Low risk & $\begin{array}{l}\text { There does not appear to be any attrition and all outcome measures appear to } \\
\text { have been reported in full }\end{array}$ \\
\hline $\begin{array}{l}\text { Selective reporting (re- } \\
\text { porting bias) }\end{array}$ & Unclear risk & Unclear \\
\hline
\end{tabular}


Yin 2014

\begin{tabular}{|c|c|}
\hline Methods & RCT \\
\hline \multirow[t]{8}{*}{ Participants } & Recruited from an inpatient rehabilitation unit in Singapore \\
\hline & 23 participants: 11 intervention, 12 control \\
\hline & $\begin{array}{l}\text { Inclusion criteria: medically stable to participate in active rehabilitation, }>21 \text { years old, able to stand } \\
\text { unsupported for } 30 \mathrm{~s} \text {, Fugl Meyer Assessment for the UE score of }<62 \text { and MMSE score of }>20\end{array}$ \\
\hline & $\begin{array}{l}\text { Exclusion criteria: epilepsy, photophobia or known side effects from watching digital media, were preg- } \\
\text { nant, had implanted electronic devices including pacemakers or defibrillators, joint pain that could } \\
\text { limit participation, severe visual deficits and presented with a spasticity score of }>2 \text { in the affected limb } \\
\text { quantified by the Modified Ashworth Scale }\end{array}$ \\
\hline & Median age: intervention group 62 years, control group 56 years \\
\hline & $70 \%$ men \\
\hline & Stroke details: $35 \%$ right hemiparesis \\
\hline & Timing post stroke: intervention group median $15 \mathrm{~d}$, control group median $14 \mathrm{~d}$ \\
\hline \multirow[t]{3}{*}{ Interventions } & $\begin{array}{l}\text { VR intervention: the VR system comprised a hand-held remote controller detected with a base move- } \\
\text { ment sensor, laptop computer, customised rehabilitation gaming software and a } 80 \text { centimetre, liquid } \\
\text { crystal display screen. The tasks were highly repetitive but functional tasks in an enriched motivating } \\
\text { environment, with customisable but challenging difficulty levels. The virtual environment consisted of a } \\
\text { local supermarket setting to increase familiarity and engagement of participants. Participants were in- } \\
\text { structed to pick a virtual fruit from a shelf and release it into a virtual basket as many times as possible } \\
\text { within a 2-min trial. This reaching practice was carried out standing, simulating real-life }\end{array}$ \\
\hline & Control intervention: conventional rehabilitation training \\
\hline & $\begin{array}{l}\text { The experimental group received } 30 \text { min of non-immersive VR training for } 9 \text { weekdays within } 2 \text { weeks } \\
(5 \mathrm{~d} / \text { week) in addition to conventional therapy. The control group received only conventional therapy. } \\
\text { The total dose provided was comparable ( } 17 \mathrm{~h} \text { intervention vs } 15.5 \mathrm{~h} \text { control) }\end{array}$ \\
\hline
\end{tabular}

$\begin{array}{ll}\text { Outcomes } & \text { Outcomes assessed post intervention and at } 4 \text { weeks } \\ \text { Fugl Meyer Assessment } \\ \text { Action Research Arm Test } \\ \text { Motor Activity Log } \\ \text { Functional Independence Measure } \\ \text { Adverse events reproted }\end{array}$

Notes -

\section{Risk of bias}

\begin{tabular}{lll}
\hline Bias & Authors' judgement & Support for judgement \\
\hline $\begin{array}{l}\text { Random sequence genera- } \\
\text { tion (selection bias) }\end{array}$ & Unclear risk & Method not clear \\
\hline $\begin{array}{l}\text { Allocation concealment } \\
\text { (selection bias) }\end{array}$ & Unclear risk & Allocation was concealed using opaque envelopes. Not clear if sealed \\
\hline $\begin{array}{l}\text { Blinding of outcome as- } \\
\text { sessment (detection bias) }\end{array}$ & High risk & Not blinded \\
\hline
\end{tabular}


Yin 2014 (Continued)

All outcomes

\begin{tabular}{lll}
\hline $\begin{array}{l}\text { Incomplete outcome data } \\
\text { (attrition bias) }\end{array}$ & Low risk & \\
$\begin{array}{l}\text { All outcomes } \\
\text { Selective reporting (re- }\end{array}$ & Unclear risk & No mention of protocol \\
porting bias) & & \\
\hline
\end{tabular}

You 2005

Methods RCT

Participants

Study took place in Korea

10 participants: 5 intervention, 5 control

Inclusion criteria: $\geq 1$ year after first stroke, plateau in the maximum motor recovery after conventional neurorehabilitation, $>60^{\circ}$ extension at the knee

Exclusion criteria: severe spasticity (modified Ashworth scale $>2$ ) or tremor, severe visual and cognitive impairment

Mean age: intervention group 55 years, control group 55 years

$70 \%$ men

Stroke details: $30 \%$ right hemiparesis

Timing post stroke: intervention group 18 months, control group 19 months

$\begin{array}{ll}\text { Interventions } & \text { VR intervention: IREX VR system using a video capture system to capture the participant's whole body } \\ \text { movement. The participant is able to view their body movements in real time on a screen in front of } \\ \text { them immersed in a virtual environment. Games included stepping up/down, 'shark bait' and snow- } \\ \text { boarding } \\ \text { Control intervention: no intervention provided } \\ \text { Sessions for the VR group were } 60 \text { min, } 5 \text { times/week for } 4 \text { weeks (20 h total) } \\ \text { Outcomes recorded at baseline and post intervention } \\ \text { Lower limb function and activity outcomes: Functional Ambulation Category } \\ \text { Global motor function: modified Motor Assessment Scale } \\ \text { Imaging studies: functional MRI - laterality index }\end{array}$

Notes

$-$

\section{Risk of bias}

\begin{tabular}{lll}
\hline Bias & Authors' judgement & Support for judgement \\
\hline $\begin{array}{l}\text { Random sequence genera- } \\
\text { tion (selection bias) }\end{array}$ & Unclear risk & Unclear \\
\hline $\begin{array}{l}\text { Allocation concealment } \\
\text { (selection bias) }\end{array}$ & Unclear risk & Unclear \\
\hline \hline
\end{tabular}


You 2005 (Continued)

Blinding of outcome as- Low risk Blind sessment (detection bias)

All outcomes

Incomplete outcome data Unclear risk Unclear
(attrition bias)
All outcomes

Selective reporting (re- Unclear risk Unclear
porting bias)

\section{Zucconi 2012}

\begin{tabular}{ll}
\hline Methods & RCT (3 arms) \\
\hline Participants & Recruited from a neurorehabilitation ward in Italy \\
& 33 participants: 11 intervention, 11 control, 11 control \\
& Inclusion criteria: stroke in the MCA territory $\geq 6$ months before enrolment, absence of ideomotor \\
& apraxia, neglect and aphasia interfering with verbal comprehension \\
& Exclusion criteria: apraxia, neglect and language disturbances \\
& Median (IQR) age: intervention group 60 (57.25-76) years, control group 60 (49-74.25) years, control \\
& group 64.5 (54.50-69) years \\
& 39\% men \\
& Timing post stroke: intervention group median (IQR) 10.05 (4.05-17.90) months, control group 8.75 \\
& $(2.75-24.95)$ months, control group 5.05 (1.75-17.90) months
\end{tabular}

(2.75-24.95) months, control group 5.05 (1.75-17.90) months

VR intervention (Ever teacher group): Reinforced Feedback in Virtual Environment (RFVE). Participants were asked to manipulate sensorised objects (ball, plastic cup or cylinder). Specific feedback was provided (like a virtual teacher) to encourage the participant to emulate the correct movement

VR intervention (No teacher group): VR intervention but with no feedback

Control intervention: conventional rehabilitation programme

Sessions were $60 \mathrm{~min}, 5$ times/week for 4 weeks

Outcomes

Outcomes recorded at baseline and post intervention

Upper limb outcomes: Fugl Meyer UE, Reaching performance scale

Other outcomes: Modified Ashworth Scale, kinematics

Activity outcomes: Functional Independence Measure

\begin{tabular}{lll}
\hline Notes & - & \\
\hline Risk of bias & & \\
\hline Bias & Authors' judgement & Support for judgement \\
\hline $\begin{array}{l}\text { Random sequence genera- } \\
\text { tion (selection bias) }\end{array}$ & Low risk & Computer-generated \\
\hline
\end{tabular}


Zucconi 2012 (Continued)

\begin{tabular}{lll}
$\begin{array}{l}\text { Allocation concealment } \\
\text { (selection bias) }\end{array}$ & Low risk & Sequentially numbered, opaque, sealed envelopes \\
\hline $\begin{array}{l}\text { Blinding of outcome as- } \\
\text { sessment (detection bias) } \\
\text { All outcomes }\end{array}$ & Low risk & Blinded to allocation \\
\hline
\end{tabular}

Incomplete outcome data Low risk No dropouts
(attrition bias)
All outcomes

Selective reporting (re- Low risk No other outcomes collected
porting bias)

6MWT: 6-minute walk test

$A D L$ : activities of daily living

CT: computerised tomography

ITT: intention-to-treat

IQR: interquartile range

MCA: middle cerebral artery

MI: myocardial infarction

MMSE(-K): Mini Mental State Examination( - Korean)

MRC: Medical Research Council

MRI: magnetic resonance imaging

OT: occupational therapy

$\mathrm{RCT}$ : randomised controlled trial

ROM: range of motion

SD: standard deviation

UE: upper extremity

VR: virtual reality

Characteristics of excluded studies [ordered by study ID]

\begin{tabular}{ll}
\hline Study & Reason for exclusion \\
\hline Abdollahi 2014 & Cross-over design \\
\hline Bower 2014 & Both the intervention and control group receive VR \\
\hline Braun 2016 & Did not meet the definition of VR intervention \\
\hline Broeren 2008 & Study design: not a RCT \\
\hline Cameirao 2012 & Compares different types of VR \\
\hline Cho 2013 & $\begin{array}{l}\text { Did not meet the definition of VR (no real 'interaction' between the person and the virtual environ- } \\
\text { ment) }\end{array}$ \\
\hline Cho 2015 & Both intervention and control group received VR \\
\hline Chortis 2008 & Study design: not a RCT \\
\hline Cikaljo 2012 & Study design: not a RCT \\
\hline Der-Yeghiaian 2009 & Study design: not a RCT \\
\hline
\end{tabular}




\begin{tabular}{|c|c|}
\hline Study & Reason for exclusion \\
\hline Edmans 2009 & Study design: not a RCT \\
\hline Fischer 2007 & Compares different types of VR \\
\hline Fritz 2013 & Not considered to be properly randomised or quasi-randomised \\
\hline Gnajaraj 2007 & Did not meet the definition of a VR intervention \\
\hline Hollenstein 2011 & Cross-over design \\
\hline In 2012 & Did not meet the definition of a VR intervention \\
\hline Katz 2005 & Study design: not all participants were randomised \\
\hline Kim 2012b & Did not meet the definition of a VR intervention \\
\hline Kim 2015a & $\begin{array}{l}\text { It did not appear that the participant had control over the interaction with the virtual environment. } \\
\text { We emailed the study authors to clarify this but there was no response }\end{array}$ \\
\hline Kim 2015b & Not clear that the VR is synced with real interaction between the person and the system \\
\hline Krebs 2008 & Study design: participants were not randomly allocated to groups \\
\hline Lee $2014 b$ & Compared assymetric training with symmetric training. Both groups had VR \\
\hline Llorens 2014 & $\begin{array}{l}\text { Outlines two studies: both included participants with acquired brain injury and did not report the } \\
\text { results for different diagnoses separately }\end{array}$ \\
\hline Masiero 2014 & Not considered VR intervention matching the definition in this review \\
\hline McEwen 2014 & Compares groups VR in standing with VR in sitting \\
\hline Rand 2014 & Secondary analysis of a subgroup of participants from a larger study \\
\hline Rutz-LaPitz 2011 & Cross-over design \\
\hline Shin 2010 & Study design: participants were not randomly allocated to groups \\
\hline Song 2010 & Unable to obtain further information to confirm inclusion criteria or obtain basic study data \\
\hline Turolla 2013 & Not randomised \\
\hline Viana 2014 & Examines VR with or without transcranial direct current stimulation \\
\hline Wolf 2015 & Did not meet definition of VR used in this review \\
\hline Yom 2015 & There is not genuine interaction between the participant and the virtual environment \\
\hline Yoo 2015 & Not VR intervention \\
\hline
\end{tabular}

$\mathrm{RCT}$ : randomised controlled trial VR: virtual reality 
Characteristics of studies awaiting assessment [ordered by study ID]

Almeida 2014

\begin{tabular}{ll}
\hline Methods & RCT \\
\hline Participants & People post stroke \\
\hline Interventions & Physical therapy associated with VR therapy \\
\hline Outcomes & Berg Balance Scale \\
\hline Notes & $\begin{array}{l}\text { Conference abstract. Appears to be preliminary results for an ongoing trial. Study authors did not } \\
\text { respond to queries regarding study }\end{array}$ \\
\hline
\end{tabular}

Connor 2016

$\begin{array}{ll}\text { Methods } & \text { RCT }\end{array}$

\begin{tabular}{ll}
\hline Participants & People with stroke $\geq 6$ months earlier \\
\hline Interventions & Intervention group: 18 individualised training sessions using the YouGrabber over 12 weeks \\
& Control group: usual rehabilitation within the gym \\
\hline Outcomes & Interviews, other outcome measures not described \\
\hline Notes & \\
\hline
\end{tabular}

de Paula Oliveira 2015

\begin{tabular}{ll}
\hline Methods & RCT \\
\hline Participants & People in the chronic phase post stroke \\
\hline Interventions & Nintendo Wii Fit \\
\hline Outcomes & Fugl Meyer-Lower Extremity, QOL \\
\hline Notes & $\begin{array}{l}\text { Conference paper. States preliminary results. Study authors did not respond to queries regarding } \\
\text { study }\end{array}$ \\
\hline
\end{tabular}

Faria 2016

\begin{tabular}{ll}
\hline Methods & RCT \\
\hline Participants & Individuals within 6 months of stroke \\
\hline Interventions & $\begin{array}{l}\text { VR: VR motor-cognitive task group performed a VR motor and cognitive attention/memory task } \\
\text { customised to each user in terms of the positive content }\end{array}$
\end{tabular}


Faria 2016 (Continued)

Control: standard rehabilitation group performed conventional motor and cognitive rehabilitation tasks

\begin{tabular}{ll}
\hline Outcomes & Primary outcome: Fugl Meyer \\
\hline Notes & NCT02539914. Co-investigator AL Faria \\
\hline
\end{tabular}

In 2016

\begin{tabular}{ll}
\hline Methods & RCT \\
\hline Participants & People in the chronic phase post stroke \\
\hline Interventions & VR: VR reflection therapy in addition to usual rehabilitation \\
& Control group: conventional rehabilitation and placebo VR \\
\hline Outcomes & Berg Balance Scale, Functional Reach test, Timed Up and Go Test \\
\hline Notes & \\
\hline
\end{tabular}

\section{Lee 2015c}

\begin{tabular}{ll}
\hline Methods & RCT \\
\hline Participants & People with stroke \\
\hline Interventions & Treadmill training-based, real-walk simulation \\
\hline Outcomes & Motor-Free Visual Perception Test, Berg Balance Scale \\
\hline Notes & Conference abstract only and unable to source further study details \\
\hline
\end{tabular}

\section{Lee $2016 a$}

\begin{tabular}{ll}
\hline Methods & RCT \\
\hline Participants & People in the chronic phase of stroke \\
\hline Interventions & VR-based rehabilitation group \\
& Group-based rehabilitation group \\
\hline Outcomes & $\begin{array}{l}\text { Fugl Meyer-Upper Extremity, manual function test, Box and Block Test, Modified Barthel Index, } \\
\text { SF-12 }\end{array}$ \\
\hline Notes & ISRCTN04144761 \\
\hline
\end{tabular}


Lee $2016 b$

\begin{tabular}{ll}
\hline Methods & RCT \\
\hline Participants & People following stroke \\
\hline Interventions & VR group received additional 30 min of therapy utilising canoe-based game \\
& Control group received conventional rehabilitation program \\
\hline Outcomes & Trunk postural stability, balance and upper limb motor function \\
\hline Notes & \\
\hline
\end{tabular}

Lin 2015

\begin{tabular}{ll}
\hline Methods & RCT \\
\hline Participants & People in the chronic phase post stroke \\
\hline Interventions & Computer-aided interlimb force coupling training task with visual feedback \\
\hline Outcomes & Barthel Index, Fugl Meyer Assessment, Motor Assessment Score, Wolf Motor Function Test \\
\hline Notes & $\begin{array}{l}\text { Contacted authors to clarify details of intervention and whether this met our criteria for inclusion } \\
\text { but received no response }\end{array}$ \\
\hline
\end{tabular}

\section{Marshall 2016}

\begin{tabular}{ll}
\hline Methods & Quasi RCT \\
\hline Participants & People after stroke with aphasia \\
\hline Interventions & Intervention: daily language stimulation sessions in 'EVA Park' with a support worker \\
& Control group: waitlist control group \\
\hline Outcomes & $\begin{array}{l}\text { Communication ADL, Verbal fluency task, Word finding in conversation (POWERS), narrative pro- } \\
\text { duction, Communication Confidence Rating Scale for Aphasia, Friendship Scale }\end{array}$ \\
\hline
\end{tabular}

\section{Notes}

Nijenhuis 2017

\begin{tabular}{ll}
\hline Methods & RCT \\
\hline Participants & People in the chronic phase following stroke \\
\hline Interventions & $\begin{array}{l}\text { Intervention: self-administered, home-based arm and hand training using either a passive or dy- } \\
\text { namic wrist and hand orthosis combined with computerised gaming exercises }\end{array}$ \\
Control: prescribed conventional exercises from a book
\end{tabular}


Nijenhuis 2017 (Continued)

Outcomes

Action Research Arm Test, Intrinsic Motivation Inventory, Fugl Meyer Assessment, Motor Activity Log, Stroke Impact Scale, grip strength

Notes

Simsek 2016

$\begin{array}{ll}\text { Methods RCT } & \text { RT }\end{array}$

\begin{tabular}{ll}
\hline Participants & Adults following stroke \\
\hline Interventions & Intervention: Nintendo Wii for upper limb and balance \\
& Control: Bobath NDT
\end{tabular}

\section{Outcomes}

Functional Independence Measure, Nottingham Health Profile

\section{Notes}

Turkbey 2017

\begin{tabular}{ll}
\hline Methods & RCT \\
\hline Participants & People following stroke \\
\hline Interventions & Additional therapy using the Xbox Kinect \\
& Control group received usual therapy \\
\hline Outcomes & Feasibility and safety (treatment attendance, patient feedback, adverse events, Borg Scale) \\
\hline Notes & \\
\hline
\end{tabular}

\section{Zondervan 2016}

\begin{tabular}{ll}
\hline Methods & RCT \\
\hline Participants & People with chronic stroke \\
\hline Interventions & $\begin{array}{l}\text { Participants were allocated to } 3 \text { weeks of home-based MusicGlove therapy or conventional table- } \\
\text { top exercises }\end{array}$ \\
\hline Outcomes & Primary outcome: Box and Blocks test \\
\hline Notes & \\
\hline
\end{tabular}

NDT: neurodevelopmental treatment

OT: occupational therapy

QOL: quality of life

$\mathrm{RCT}$ : randomised controlled trial 
VR: virtual reality

Characteristics of ongoing studies [ordered by study ID]

\section{ACTRN12614000427673}

Trial name or title

'FIND Technology': investigating the feasibility, efficacy and safety of controller-free interactive digital rehabilitation technology in an inpatient stroke population: study protocol for a randomized controlled trial

\begin{tabular}{ll}
\hline Methods & RCT \\
\hline Participants & Inpatient stroke population \\
\hline Interventions & Intervention group receive Jintronix JRS Wave in addition to their individualised targeted therapy \\
& Control group receive repetitive exercises in addition to their individualised targeted therapy \\
\hline Outcomes & $\begin{array}{l}\text { Activity (measured using accelerometer), Modified Motor Assessment Scale (upper extremity com- } \\
\text { ponent), sitting balance, standing balance, dynamic balance, mobility }\end{array}$ \\
\hline Starting date & April 2014 \\
\hline Contact information & Dr Marie-Louise Bird \\
\hline Notes & birdm@utas.edu.au \\
\hline
\end{tabular}

\section{Deutsch 2010}

\begin{tabular}{ll}
\hline Trial name or title & Interactive video gaming compared with optimal standard of care to improve balance and mobility \\
\hline Methods & Single-blind pilot RCT \\
\hline Participants & Individuals post stroke ( $>6$ months), able to walk $\geq 50$ m, follow instructions \\
\hline Interventions & VR intervention: Wii-based balance and mobility training \\
& Control: optimal standard of care \\
& Dosing 3 h/week for 4 weeks \\
\hline Outcomes & $\begin{array}{l}\text { Gait variables (gait rite), } 6 \text {-Minute Walk Test, Dynamic Gait Index, Timed Up and Go, Activities Bal- } \\
\text { ance Questionnaire, Canadian Occupational Performance Measure, Postural Control }\end{array}$ \\
\hline Starting date & Commenced Summer 2008 \\
\hline Contact information & Professor Judith Deutsch: deutsch@umdnj.edu \\
\hline Notes & Data collection completed with results to be presented at upcoming conferences
\end{tabular}


Duff 2013

\begin{tabular}{ll}
\hline Trial name or title & $\begin{array}{l}\text { The optimal dosage of the rehabilitation gaming system: the impact of a longer period of VR-based } \\
\text { and standard OT on upper limb recovery in the acute phase of stroke }\end{array}$ \\
\hline Methods & RCT \\
\hline Participants & People after acute stroke \\
\hline Interventions & VR intervention: rehabilitation gaming system \\
\hline Outcomes & Unclear \\
\hline Starting date & Unclear \\
\hline Contact information & Professor Armin Duff \\
& armin.duff@gmail.com \\
\hline Notes & -
\end{tabular}

Dunsky 2014

\begin{tabular}{ll}
\hline Trial name or title & $\begin{array}{l}\text { Dual-task training using virtual reality: influence on walking and balance in individuals post- } \\
\text { stroke }\end{array}$ \\
\hline Methods & RCT \\
\hline Participants & 1 year following stroke \\
\hline Interventions & VR intervention: 'SeeMe' video capture system \\
\hline Outcomes & Control intervention: unclear \\
\hline Starting date & Primary outcome: gait speed \\
\hline Contact information & Unclear \\
\hline Notes & Dr Ayelet Dunsky \\
\hline
\end{tabular}

\section{Kairy 2015}

\begin{tabular}{ll}
\hline Trial name or title & Using a virtual reality gaming system to supplement upper extremity rehabilitation post stroke \\
\hline Methods & RCT \\
\hline Participants & People following stroke with upper extremity impairment \\
\hline Interventions & Intervention group: upper extremity VR
\end{tabular}


Kairy 2015 (Continued)

$$
\text { Control group: usual care }
$$

Outcomes Fugl Meyer, Box and Blocks Test, Stroke Impact Scale

\begin{tabular}{ll}
\hline Starting date & Unknown \\
\hline Contact information & Professor Dahlia Kairy \\
& dahlia.kairy@umontreal.ca \\
\hline Notes & - \\
\hline
\end{tabular}

\section{Kairy 2016}

\begin{tabular}{ll}
\hline Trial name or title & $\begin{array}{l}\text { Maximizing post-stroke upper limb rehabilitation using a novel telerehabilitation interactive virtual } \\
\text { reality system in the patient's home: study protocol of a randomized clinical trial }\end{array}$ \\
\hline Methods & RCT \\
\hline Participants & People following stroke with upper extremity impairment \\
\hline Interventions & $\begin{array}{l}\text { Intervention: telerehabilitation VR (Jintronix system) } \\
\text { Control: continuation of exercises or GRASP program }\end{array}$ \\
\hline Outcomes & Primary outcome: Fugl Meyer \\
\hline Starting date & Unknown \\
\hline Contact information & Professor Dahlia Kairy \\
\hline Notes & dahlia.kairy@umontreal.ca \\
\hline
\end{tabular}

\section{Karatas 2014}

\begin{tabular}{ll}
\hline Trial name or title & Wii-based rehabilitation in stroke \\
\hline Methods & RCT \\
\hline Participants & Individuals post stroke \\
\hline Interventions & VR intervention: traditional balance rehabilitation plus Nintendo Wii Fit \\
& Control intervention: traditional balance rehabilitation \\
\hline Outcomes & Berg Balance Scale, Functional Reach Test, postural assessment scale for stroke patients \\
\hline Starting date & Timed Up and Go Test (TUG) and static balance index \\
\hline Contact information & Unknown \\
\hline
\end{tabular}


Karatas 2014 (Continued)

Notes

\section{Kiper 2014}

Trial name or title Reinforced feedback in virtual environment for rehabilitation of upper extremity dysfunction after stroke: preliminary data from a randomized controlled trial

\begin{tabular}{ll}
\hline Methods & RCT \\
\hline Participants & People $\geq 1$ year post stroke \\
\hline Interventions & Intervention: reinforced feedback in virtual environment \\
& Control: traditional rehabilitation \\
\hline Outcomes & Primary outcome: Fugl Meyer-upper extremity \\
\hline Starting date & Unsure \\
\hline Contact information & Dr Pawel Kiper \\
\hline Notes & pawel.kiper@ospedalesancamillo.net \\
\hline
\end{tabular}

\section{Kizony 2013}

\begin{tabular}{ll}
\hline Trial name or title & Evaluation of a tele-health system for upper extremity stroke rehabilitation \\
\hline Methods & RCT \\
\hline Participants & People following stroke \\
\hline Interventions & $\begin{array}{l}\text { Intervention: quasi-home-based tele-motion-rehabilitation (TMR) program using the Gertner Sys- } \\
\text { tem }\end{array}$ \\
\hline Cutcomes & Nontrol: self-training upper extremity home exercise group \\
\hline Starting date & - \\
\hline Contact information & racheli.kizony@gmail.com \\
\hline Notes & -
\end{tabular}

\section{NCT01365858}

\begin{tabular}{ll}
\hline Trial name or title & Virtual action planning in stroke: a control rehabilitation study \\
\hline Methods & RCT
\end{tabular}


NCT01365858 (Continued)

\begin{tabular}{ll} 
Participants & Individuals with stroke \\
\hline Interventions & $\begin{array}{l}\text { VR intervention: rehabilitation using the 'Virtual Action Planning supermarket' } \\
\text { Control intervention: conventional rehabilitation }\end{array}$ \\
\hline Outcomes & Primary outcome: ability to perform shopping test in real supermarket \\
\hline Starting date & May 2011 \\
\hline Contact information & Professor Pierre-Alain Joseph: pierre-alain.joseph@chu-bordeaux.fr \\
\hline Notes & Date accessed December 2013 \\
\hline
\end{tabular}

\section{NCT01806883}

Trial name or title

Evaluation of the effects of rehabilitation using the 'Wii' on upper limb kinematics in chronic stroke patients

\begin{tabular}{ll}
\hline Methods & RCT \\
\hline Participants & Post-stroke hemiparetic patients ( $\geq 6$ months post stroke) \\
\hline Interventions & VR: Nintendo Wii based therapy \\
& Control: traditional physiotherapy \\
\hline Outcomes & Primary outcome: degree of elbow extension during an active reaching task \\
\hline Starting date & - \\
\hline Contact information & Dr Djamel Bensmail \\
& djamel.bensmail@rpc.aphp.fr \\
\hline Notes & NCT01806883
\end{tabular}

\section{NCT02013999}

\begin{tabular}{ll}
\hline Trial name or title & $\begin{array}{l}\text { The development of upper extremity rehabilitation program using virtual reality for the stroke pa- } \\
\text { tients }\end{array}$ \\
\hline Methods & RCT \\
\hline Participants & Individuals with stroke \\
\hline Interventions & Control intervention: standard OT \\
\hline Outcomes & Primary outcome: Fugl Meyer Upper Extremity Scale \\
\hline Starting date & October 2013 \\
\hline
\end{tabular}


NCT02013999 (Continued)

Contact information

Professor Nam-Jong Paik, Department of Rehabilitation Medicine, Seoul National University Email:njpaik@snu.ac.kr

Notes

Date accessed December 2013

NCT02079103

\begin{tabular}{ll}
\hline Trial name or title & VIrtual Reality Training for Upper Extremity after Stroke (VIRTUES) \\
\hline Methods & RCT \\
\hline Participants & $1-12$ weeks post stroke \\
\hline Interventions & $\begin{array}{l}\text { VR intervention: VR training using the YouGrabber }{ }^{\circledR} \text { for participants with impaired arm motor } \\
\text { function after stroke. The YouGrabber exercises focus on intensity, repetitions, and motivating } \\
\text { tasks , and are adapted to the patient's motor abilities }\end{array}$ \\
& $\begin{array}{l}\text { Control: participants receive supervised self-training exercises with focus on functional tasks } \\
\text { adapted to their motor abilities }\end{array}$ \\
\hline Outcomes & Primary outcome: Action Research Arm Test \\
\hline Starting date & Unclear \\
\hline Contact information & Dr Iris Brunner \\
\hline Iris.Brunner@igs.uib.no
\end{tabular}

NCT02553993

\begin{tabular}{ll}
\hline Trial name or title & $\begin{array}{l}\text { Comparing the cognition effects of two exergame systems and traditional weight shifting training } \\
\text { in patients with chronic stroke: a pilot randomized comparison trial }\end{array}$ \\
\hline Methods & RCT \\
\hline Participants & People in the chronic phase after stroke \\
\hline Interventions & Intervention arm 1: Wii Fit \\
& $\begin{array}{l}\text { Intervention arm 2: Tetrax biofeedback } \\
\text { Control: conventional weight shifting }\end{array}$ \\
\hline Outcomes & Primary outcome measure: Cognitive Abilities Screening Instrument Scale Chinese version \\
\hline Starting date & 2015 \\
\hline Contact information & Dr Jen Wen Hung \\
\hline Notes & hungjw@yahoo.com.tw \\
\hline \hline
\end{tabular}


NCT02592759

\section{Trial name or title}

\begin{tabular}{ll}
\hline Methods & RCT
\end{tabular}

\begin{tabular}{ll}
\hline Participants & People following stroke \\
\hline Interventions & $\begin{array}{l}\text { Intervention: participants will be treated with conventional OT for } 30 \text { min and smart glove treat- } \\
\text { ment for } 30 \text { min. } 5 \text { treatments/week will be conducted for a total of } 2 \text { weeks }\end{array}$ \\
& $\begin{array}{l}\text { Control: participants will be treated with conventional OT for } 30 \text { min and upper extremity rehabil- } \\
\text { itation homework which means the self-training at bedside, for } 30 \text { min. } 5 \text { treatments/week will be } \\
\text { conducted for a total of } 2 \text { weeks }\end{array}$
\end{tabular}

\begin{tabular}{ll}
\hline Outcomes & Primary outcome measure: Fugl Meyer UE \\
\hline Starting date & Unclear \\
\hline Contact information & A/Prof Han Gil Seo \\
& hangil_seo@snuh.org \\
\hline Notes & NCT02592759 \\
\hline
\end{tabular}

\section{NCT02688413}

\begin{tabular}{ll}
\hline Trial name or title & Evaluating the MindMotionPRO for early post-stroke upper-limb rehabilitation (MOVE-Rehab) \\
\hline Methods & RCT \\
\hline Participants & \begin{tabular}{l}
$1-6$ weeks following first stroke \\
\hline Interventions
\end{tabular} \\
$\begin{array}{l}\text { VR intervention: MindMotionPRO exercises in addition to standard practice for upper limb rehabili- } \\
\text { Control intervention: self-directed prescribed exercises }\end{array}$ \\
\hline Outcomes & Primary outcome: dose of therapy \\
\hline Starting date & 2016 \\
\hline Contact information & - \\
\hline Notes & NCT02688413
\end{tabular}

\section{NCT02857803}

$\begin{array}{ll}\text { Trial name or title } & \begin{array}{l}\text { A randomised controlled trial comparing the impact of virtual reality, paper and pencil and con- } \\ \text { ventional methods on stroke rehabilitation }\end{array}\end{array}$

\section{Methods}

RCT ventional methods on stroke rehabilitation

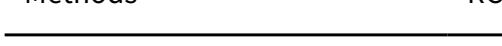




\begin{tabular}{ll}
$\begin{array}{l}\text { NCT02857803 (Continued) } \\
\text { Participants }\end{array}$ & Post stroke \\
\hline Interventions & Paper and Pencil \\
& Conventional therapy \\
& All provided for 30 min, 3 times/week until 12 sessions \\
\hline Outcomes & Montreal Cognitive Assessment, Stroke Impact Scale, Positive and Negative Affect Scale \\
\hline Starting date & August 2016 \\
\hline Contact information & Ana Lúcia Faria, ana.faria@m-iti.org \\
\hline Notes & NCT02857803 \\
\hline
\end{tabular}

\section{NTR2247}

\begin{tabular}{ll}
\hline Trial name or title & Effect of virtual reality training on reach after stroke \\
\hline Methods & RCT \\
\hline Participants & Individuals in the chronic phase post stroke \\
\hline Interventions & VR intervention: reach training using a VR program \\
& Control intervention: reach training in a traditional therapy setting \\
\hline Outcomes & Primary outcomes: Action Research Arm test, Fugl-Meyer assessment, Intrinsic Motivation Invento- \\
\hline Starting date & April 2010 \\
\hline Contact information & Dr Kottink: a.hutten@rrd.nl \\
\hline Notes & Date accessed December 2013 \\
\hline
\end{tabular}

Piemonte 2014

\begin{tabular}{ll}
\hline Trial name or title & Effects of training in a virtual environment in chronic stroke patients \\
\hline Methods & RCT \\
\hline Participants & People in the chronic phase after stroke \\
\hline Interventions & VR intervention: Nintendo Wii Fit Plus balance and mobility games \\
& Control intervention: conventional balance and mobility training \\
\hline Outcomes & Balance, cognition and functional assessments \\
\hline
\end{tabular}


Piemonte 2014 (Continued)

\begin{tabular}{ll} 
Starting date & Unknown \\
\hline Contact information & Dr Maria Piemonte: elisapp@usp.br \\
\hline
\end{tabular}

Notes

$-$

Rand 2015

\begin{tabular}{ll}
\hline Trial name or title & Home-based self training using video games: preliminary data from a randomised controlled trial \\
\hline Methods & RCT \\
\hline Participants & People following stroke 6-36 months earlier \\
\hline Interventions & Intervention: video game self-training group using PS2 EyeToy, PS3 MOVE or Xbox Kinect \\
& Control: self-training program \\
\hline Outcomes & Box and Block Test, ARAT, Functional Reach Test \\
\hline Starting date & - \\
\hline Contact information & drand@post.tau.ac.il \\
\hline Notes & -
\end{tabular}

Schuster-Amft 2014

\begin{tabular}{ll}
\hline Trial name or title & $\begin{array}{l}\text { Using mixed methods to evaluate efficacy and user expectations of a virtual reality based train- } \\
\text { ing system for upper limb recovery in patients after stroke: a study protocol for a randomised con- } \\
\text { trolled trial }\end{array}$ \\
\hline Methods & PCT \\
\hline Participants & Intervention: 16 YouGrabber training sessions \\
\hline Interventions & Control: 16 conventional therapy sessions \\
\hline Outcomes & Primary outcome: Box and Block Test \\
\hline Starting date & Unclear \\
\hline Contact information & C.schuster@reha-rhf.ch \\
\hline Notes & NCT01774669 \\
\hline
\end{tabular}


Sheehy 2016

Trial name or title Virtual reality exercise for stroke rehabilitation in inpatients who are unable to stand

\begin{tabular}{ll}
\hline Methods & RCT \\
\hline Participants & Stroke inpatients unable to stand
\end{tabular}

Interventions

VR: each participant will engage in 10-12 sessions of 30-50 min each of VR training (VRT) using Jintronix Rehabilitation Software and 3-dimensional motion capture technology. A camera captures the movements of the participant and allows him or her to control an avatar, which interacts with the game. Exercises challenge sitting balance control, reaching and shifting the base of support; for example, controlling a ball as it rolls down a maze or reaching to put dishes away in a virtual kitchen. The difficulty of the games is monitored to maintain a challenge to sitting balance. The participant sits on a CONFORMat pressure mat which continuously monitors his or her centre of pressure to ensure that the participant is adequately challenged during the VRT

Control: each participant will engage in 10-12 sessions of 30-50 min each of VRT using Jintronix Rehabilitation Software and 3-dimensional motion capture technology. A camera captures the movements of the participant and allows him or her to control an avatar, which interacts with the game. Control group exercises require limited hand and arm movements; for example, using an arm to move a fish along a simple pathway or using the arms to pop balloons without reaching. Control group participants are strapped into their chair to minimise trunk movement. The participant sits on a CONFORMat pressure mat which continuously monitors his or her centre during the VRT

\begin{tabular}{ll}
\hline Outcomes & Primary outcome: change in the Function in Sitting Test \\
\hline Starting date & 2014 \\
\hline Contact information & Dr Lisa Sheehy \\
& LSheehy@bruyere.org \\
\hline Notes & - \\
\hline
\end{tabular}

$\mathrm{RCT}$ : randomised controlled trial VR: virtual reality

\section{DATA AND ANALYSES}

Comparison 1. Virtual reality versus conventional therapy: effect on upper limb function post intervention

\begin{tabular}{lllll}
\hline Outcome or subgroup title & No. of studies & $\begin{array}{l}\text { No. of partici- } \\
\text { pants }\end{array}$ & Statistical method & Effect size \\
\hline $\begin{array}{l}1 \text { Upper limb function post intervention } \\
\text { (composite measure) }\end{array}$ & 22 & 1038 & $\begin{array}{l}\text { Std. Mean Difference (IV, } \\
\text { Fixed, 95\% Cl) }\end{array}$ & $0.07[-0.05,0.20]$ \\
\hline $\begin{array}{l}2 \text { Upper limb function post intervention } \\
\text { (Fugl Meyer) }\end{array}$ & 16 & 599 & $\begin{array}{l}\text { Mean Difference (IV, Fixed, } \\
95 \% \text { Cl) }\end{array}$ & $2.85[1.06,4.65]$ \\
\hline $\begin{array}{l}\text { 3 Hand function post intervention (grip } \\
\text { strength) }\end{array}$ & 6 & 266 & Std. Mean Difference (IV, & -0.02 [-0.27, 0.22] \\
\hline $\begin{array}{l}\text { 4 Upper limb function post intervention: } \\
\text { amount of use (subjective) }\end{array}$ & 5 & 161 & Fixed, 95\% Cl) & $\begin{array}{l}\text { Std. Mean Difference (IV, } \\
\text { Fixed, 95\% Cl) }\end{array}$ \\
\hline
\end{tabular}




\begin{tabular}{lllll}
\hline Outcome or subgroup title & No. of studies & $\begin{array}{l}\text { No. of partici- } \\
\text { pants }\end{array}$ & Statistical method & Effect size \\
\hline $\begin{array}{l}5 \text { Upper limb function at short term fol- } \\
\text { low-up (up to 3 months) }\end{array}$ & 9 & 366 & $\begin{array}{l}\text { Std. Mean Difference (IV, } \\
\text { Fixed, 95\% Cl) }\end{array}$ & $0.11[-0.10,0.32]$ \\
\hline
\end{tabular}

Analysis 1.1. Comparison 1 Virtual reality versus conventional therapy: effect on upper limb function post intervention, Outcome 1 Upper limb function post intervention (composite measure).

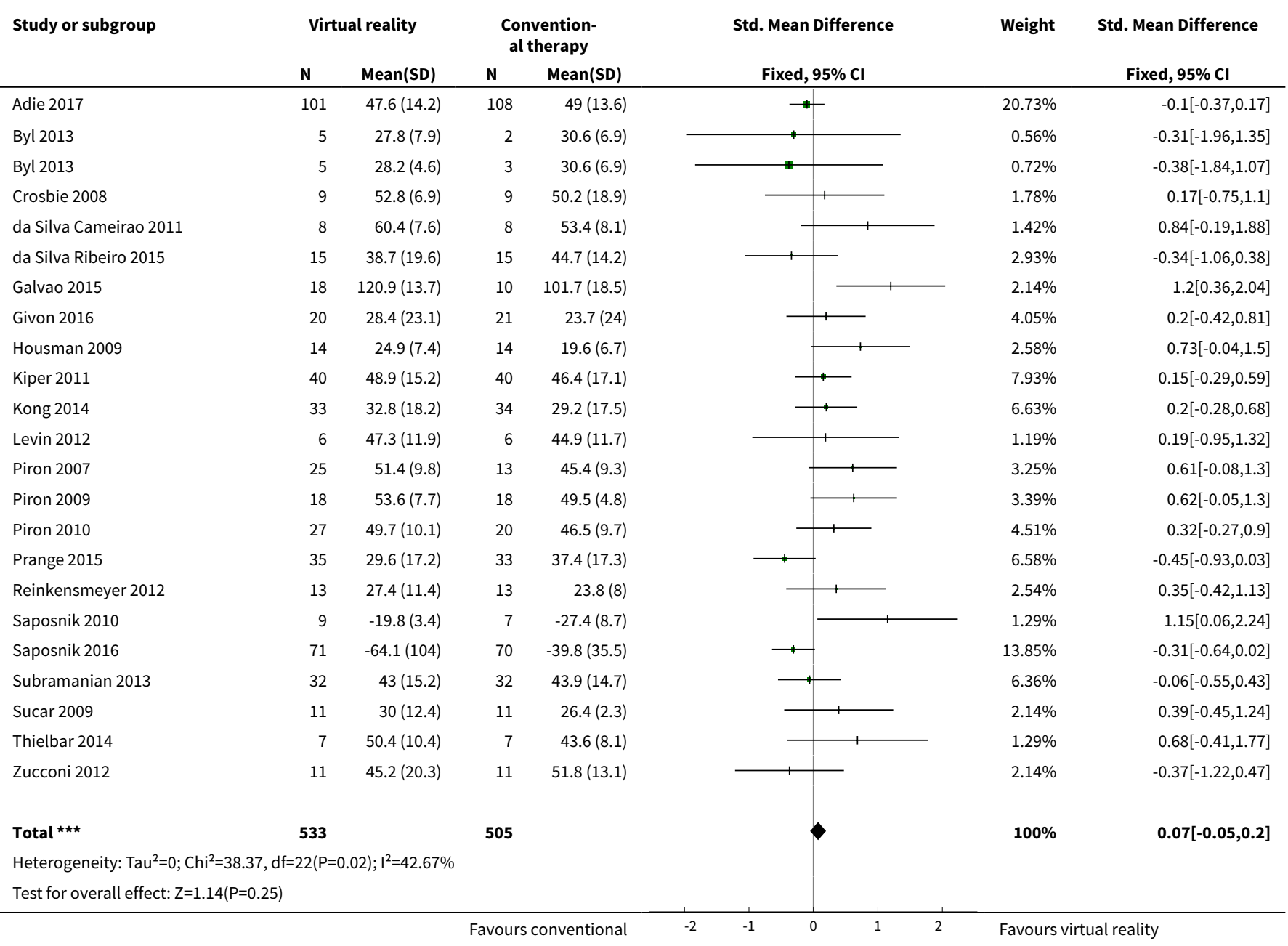

Analysis 1.2. Comparison 1 Virtual reality versus conventional therapy: effect on upper limb function post intervention, Outcome 2 Upper limb function post intervention (Fugl Meyer).

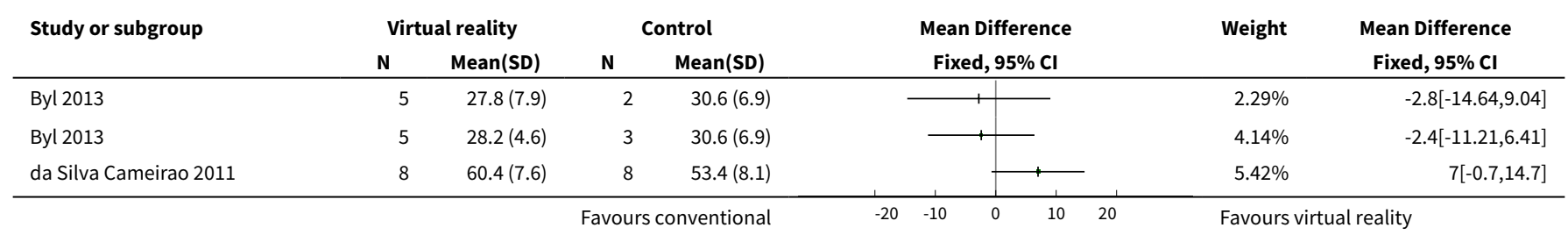




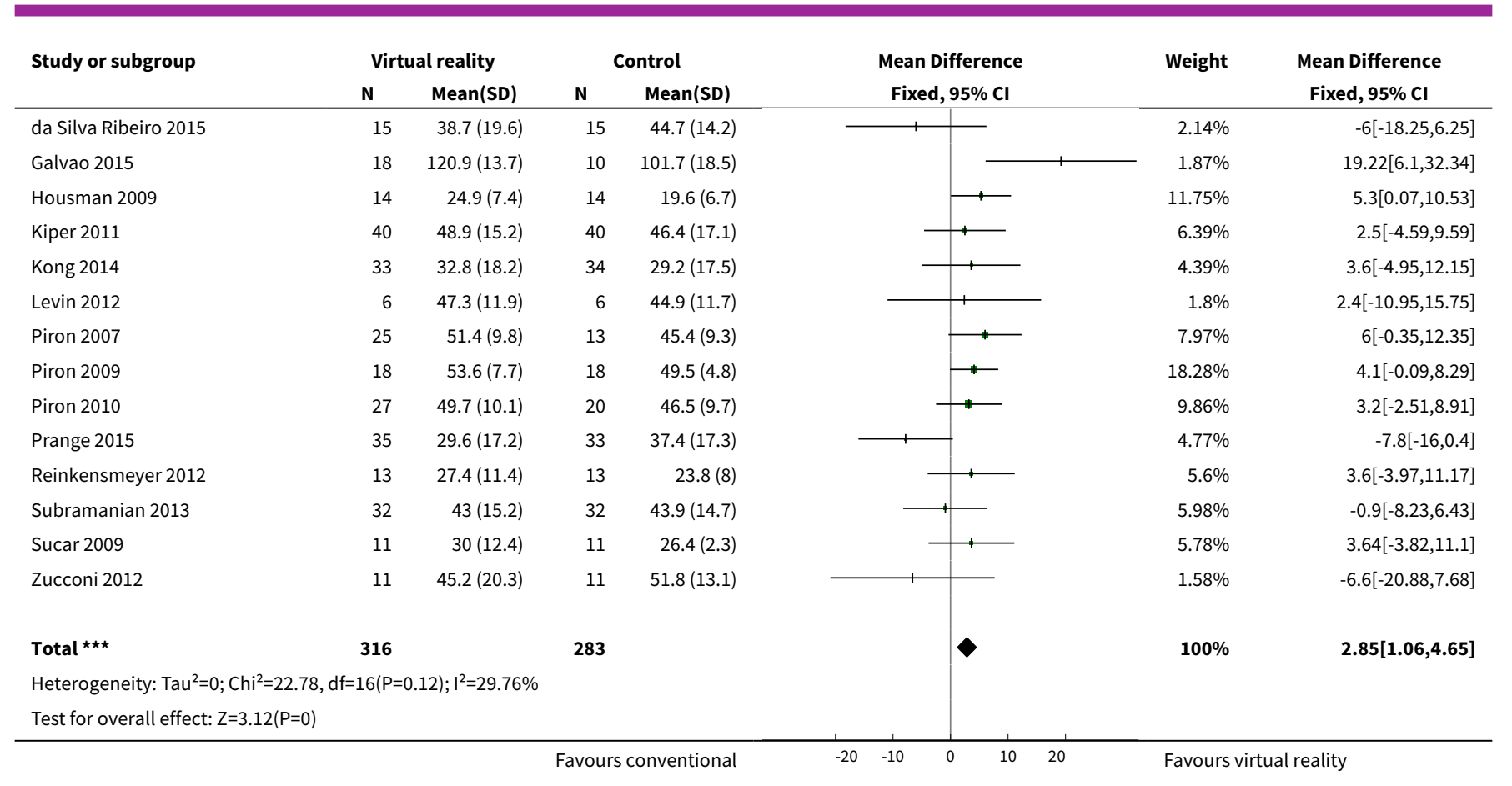

Analysis 1.3. Comparison 1 Virtual reality versus conventional therapy: effect on upper limb function post intervention, Outcome 3 Hand function post intervention (grip strength).

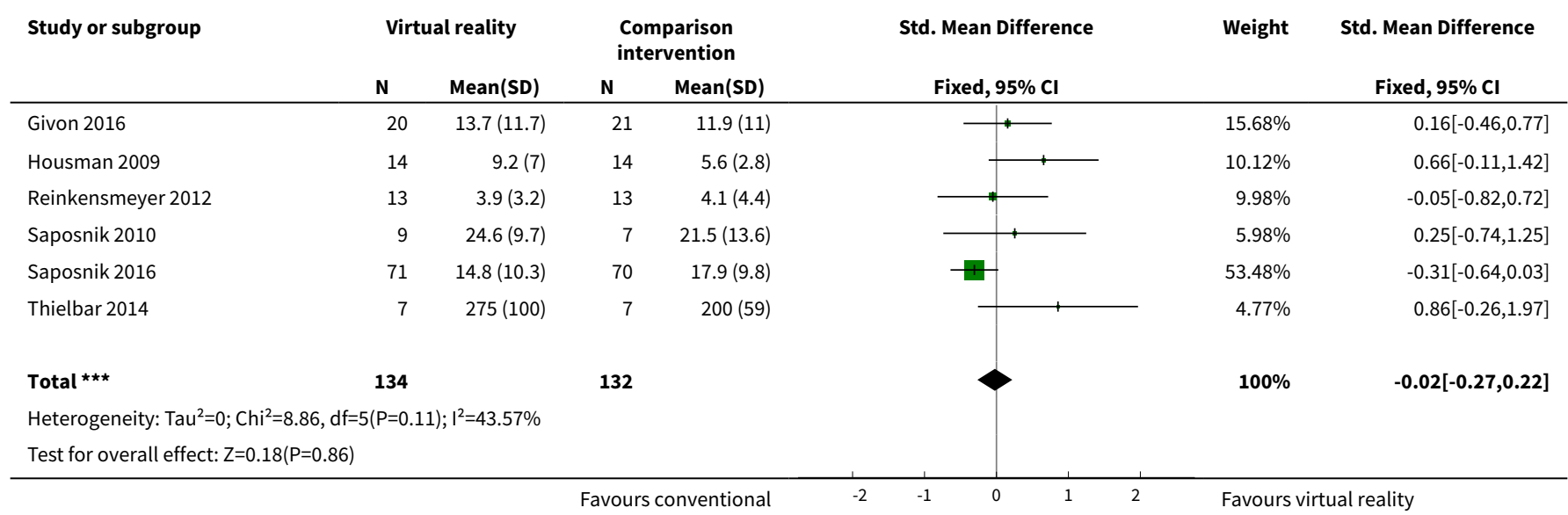

\section{Analysis 1.4. Comparison 1 Virtual reality versus conventional therapy: effect on upper limb function post intervention, Outcome 4 Upper limb function post intervention: amount of use (subjective).}

\begin{tabular}{|c|c|c|c|c|c|c|c|}
\hline \multirow[t]{2}{*}{ Study or subgroup } & \multicolumn{2}{|c|}{ Virtual reality } & \multicolumn{2}{|c|}{$\begin{array}{l}\text { Convention- } \\
\text { al therapy }\end{array}$} & \multirow{2}{*}{$\begin{array}{c}\text { Std. Mean Difference } \\
\text { Fixed, } 95 \% \mathrm{Cl} \\
\end{array}$} & \multirow{3}{*}{$\begin{array}{l}\text { Weight } \\
16.32 \%\end{array}$} & \multirow{3}{*}{$\begin{array}{l}\text { Std. Mean Difference } \\
\qquad \begin{array}{c}\text { Fixed, 95\% Cl } \\
-0.11[-0.89,0.66]\end{array}\end{array}$} \\
\hline & $\mathbf{N}$ & Mean(SD) & $\mathbf{N}$ & $\operatorname{Mean}(S D)$ & & & \\
\hline Galvao 2015 & 18 & $138.4(79.6)$ & 10 & $147(63)$ & $\longrightarrow$ & & \\
\hline Housman 2009 & 15 & $0.2(0.4)$ & 16 & $0.1(0.3)$ & $\rightarrow$ & $19.47 \%$ & $0.28[-0.43,0.99]$ \\
\hline Levin 2012 & 6 & $1.1(1.1)$ & 6 & $1.7(1.9)$ & & $7.47 \%$ & $-0.34[-1.49,0.8]$ \\
\hline
\end{tabular}




\begin{tabular}{|c|c|c|c|c|c|c|c|}
\hline \multirow[t]{2}{*}{ Study or subgroup } & \multicolumn{2}{|c|}{ Virtual reality } & \multicolumn{2}{|c|}{$\begin{array}{l}\text { Convention- } \\
\text { al therapy }\end{array}$} & \multirow{2}{*}{$\begin{array}{l}\text { Std. Mean Difference } \\
\text { Fixed, } 95 \% \mathrm{Cl}\end{array}$} & \multirow[t]{2}{*}{ Weight } & \multirow{2}{*}{$\begin{array}{l}\text { Std. Mean Difference } \\
\text { Fixed, } 95 \% \mathrm{Cl} \\
\end{array}$} \\
\hline & $\mathbf{N}$ & $\operatorname{Mean}(S D)$ & $\mathbf{N}$ & $\operatorname{Mean}(S D)$ & & & \\
\hline Reinkensmeyer 2012 & 13 & $0.3(0.4)$ & 13 & $0.3(0.4)$ & & $16.53 \%$ & $0[-0.77,0.77]$ \\
\hline Subramanian 2013 & 32 & $2.9(1.2)$ & 32 & $3.2(0.8)$ & - & $40.22 \%$ & $-0.29[-0.78,0.2]$ \\
\hline Total $\star \star \star ~$ & 84 & & 77 & & & $100 \%$ & $-0.11[-0.42,0.21]$ \\
\hline \multicolumn{8}{|c|}{ Heterogeneity: $\mathrm{Tau}^{2}=0 ; \mathrm{Chi}^{2}=1.9, \mathrm{df}=4(\mathrm{P}=0.75) ; \mathrm{I}^{2}=0 \%$} \\
\hline \multicolumn{8}{|c|}{ Test for overall effect: $Z=0.67(P=0.5)$} \\
\hline
\end{tabular}

Analysis 1.5. Comparison 1 Virtual reality versus conventional therapy: effect on upper limb function post intervention, Outcome 5 Upper limb function at short term follow-up (up to 3 months).

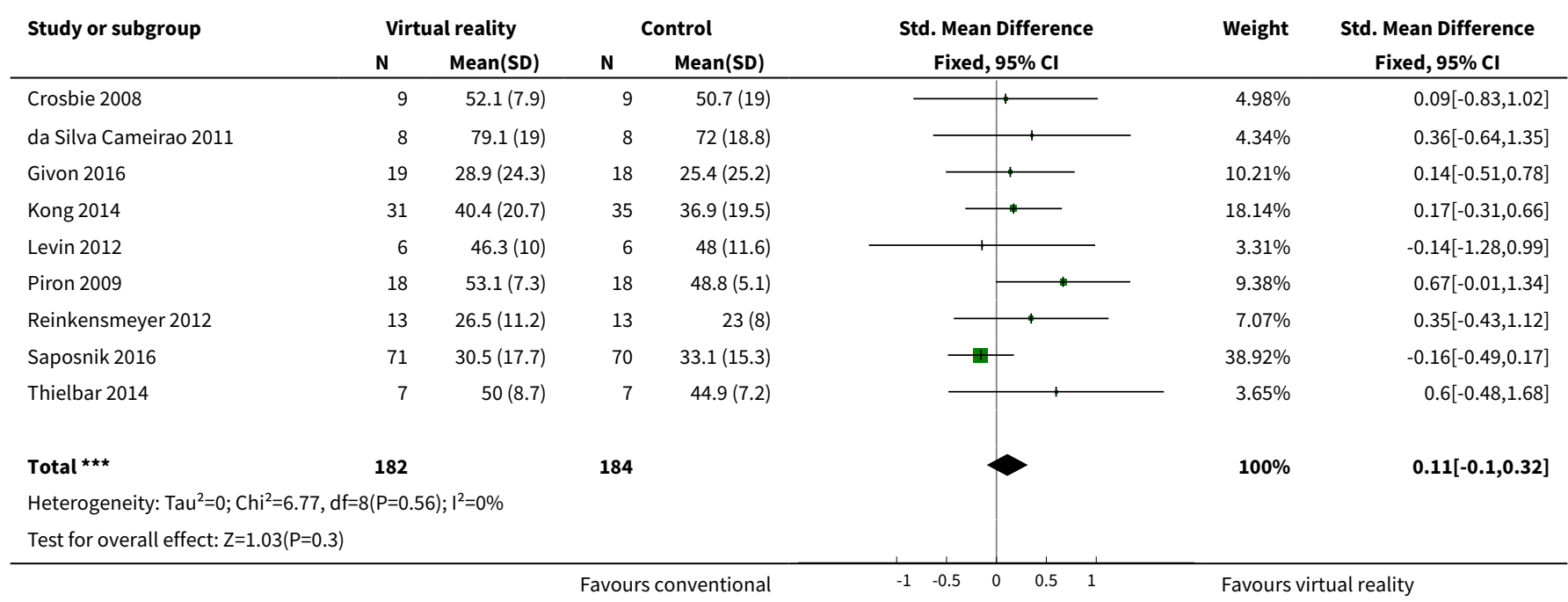

\section{Comparison 2. Virtual reality versus conventional therapy: upper limb function: subgroup analyses}

\begin{tabular}{|c|c|c|c|c|}
\hline $\begin{array}{l}\text { Outcome or subgroup ti- } \\
\text { tle }\end{array}$ & No. of studies & $\begin{array}{l}\text { No. of partici- } \\
\text { pants }\end{array}$ & Statistical method & Effect size \\
\hline 1 Dose of intervention & 22 & 1038 & Std. Mean Difference (IV, Fixed, 95\% CI) & $0.07[-0.05,0.20]$ \\
\hline $\begin{array}{l}1.1 \text { Less than } 15 \text { hours of } \\
\text { intervention }\end{array}$ & 9 & 430 & Std. Mean Difference (IV, Fixed, 95\% CI) & $-0.01[-0.20,0.18]$ \\
\hline $\begin{array}{l}1.2 \text { More than } 15 \text { hours of } \\
\text { intervention }\end{array}$ & 13 & 608 & Std. Mean Difference (IV, Fixed, 95\% CI) & $0.13[-0.03,0.29]$ \\
\hline $\begin{array}{l}2 \text { Time since onset of } \\
\text { stroke }\end{array}$ & 20 & 930 & Std. Mean Difference (IV, Fixed, 95\% CI) & $0.04[-0.09,0.17]$ \\
\hline 2.1 Less than 6 months & 7 & 555 & Std. Mean Difference (IV, Fixed, 95\% CI) & $-0.06[-0.23,0.11]$ \\
\hline 2.2 More than 6 months & 13 & 375 & Std. Mean Difference (IV, Fixed, 95\% CI) & $0.19[-0.02,0.39]$ \\
\hline
\end{tabular}




\begin{tabular}{|c|c|c|c|c|}
\hline $\begin{array}{l}\text { Outcome or subgroup ti- } \\
\text { tle }\end{array}$ & No. of studies & $\begin{array}{l}\text { No. of partici- } \\
\text { pants }\end{array}$ & Statistical method & Effect size \\
\hline 3 Specialised or gaming & 22 & 1038 & Std. Mean Difference (IV, Fixed, 95\% Cl) & $0.07[-0.05,0.20]$ \\
\hline 3.1 Specialised & 15 & 506 & Std. Mean Difference (IV, Fixed, 95\% Cl) & $0.17[-0.00,0.35]$ \\
\hline 3.2 Gaming & 7 & 532 & Std. Mean Difference (IV, Fixed, 95\% CI) & $-0.02[-0.20,0.15]$ \\
\hline 4 Severity of impairment & 21 & 998 & Std. Mean Difference (IV, Fixed, 95\% CI) & $0.07[-0.06,0.19]$ \\
\hline $\begin{array}{l}4.1 \text { Mild to moderate im- } \\
\text { pairment }\end{array}$ & 13 & 678 & Std. Mean Difference (IV, Fixed, 95\% Cl) & $0.10[-0.06,0.25]$ \\
\hline $\begin{array}{l}4.2 \text { Moderate to severe im- } \\
\text { pairment }\end{array}$ & 8 & 320 & Std. Mean Difference (IV, Fixed, 95\% Cl) & $0.01[-0.22,0.23]$ \\
\hline
\end{tabular}

Analysis 2.1. Comparison 2 Virtual reality versus conventional therapy: upper limb function: subgroup analyses, Outcome 1 Dose of intervention.

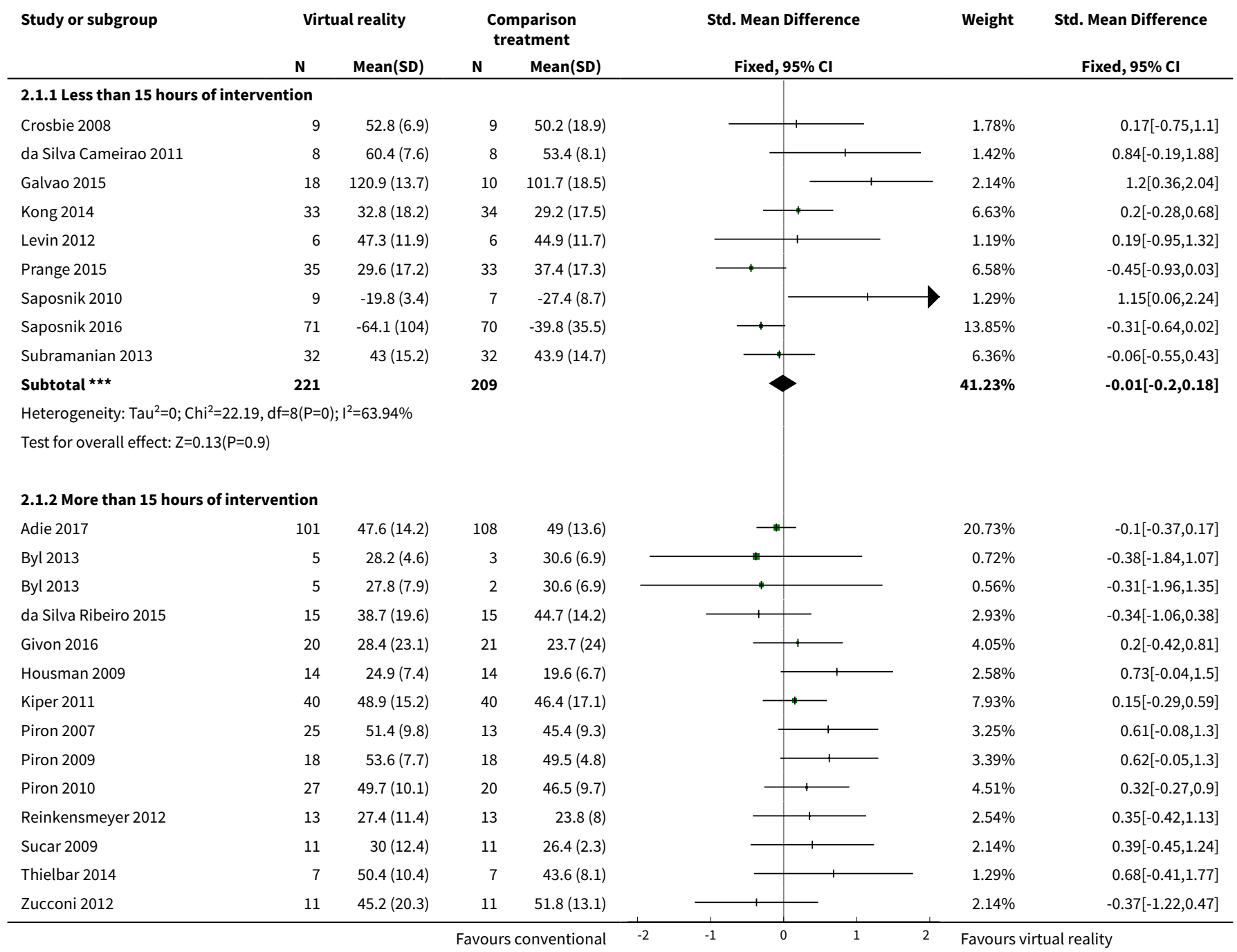




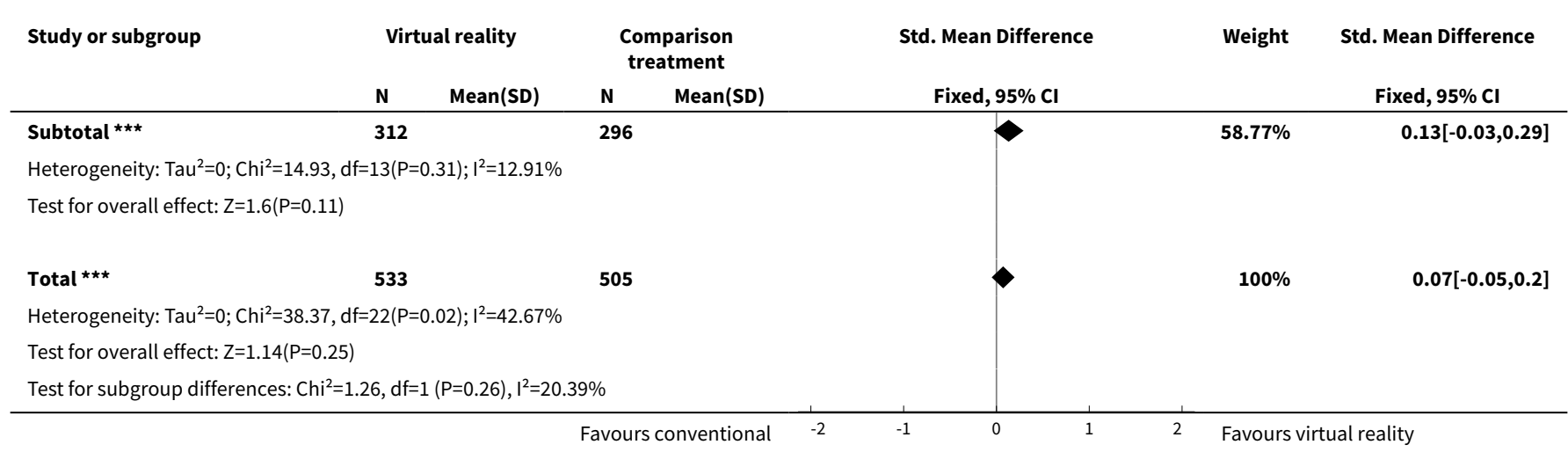

\section{Analysis 2.2. Comparison 2 Virtual reality versus conventional therapy: upper limb function: subgroup analyses, Outcome 2 Time since onset of stroke.}

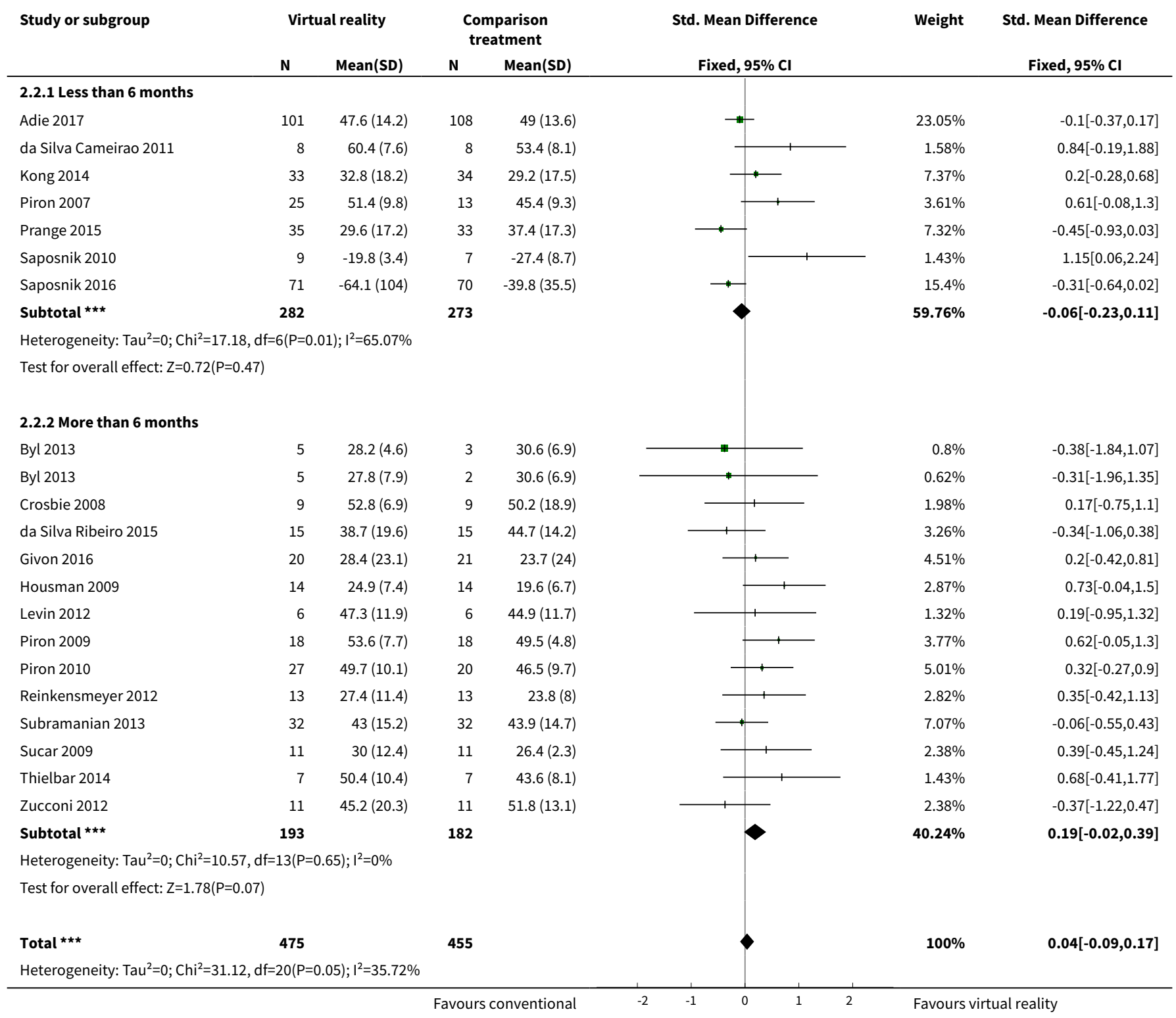




\begin{tabular}{|c|c|c|c|c|c|c|c|c|}
\hline \multirow[t]{2}{*}{ Study or subgroup } & Virtual reality & \multicolumn{2}{|c|}{$\begin{array}{c}\text { Comparison } \\
\text { treatment }\end{array}$} & \multirow{2}{*}{\multicolumn{3}{|c|}{$\begin{array}{l}\text { Std. Mean Difference } \\
\text { Fixed, } 95 \% \mathrm{Cl} \\
\end{array}$}} & \multirow[t]{2}{*}{ Weight } & \multirow{2}{*}{$\begin{array}{l}\text { Std. Mean Difference } \\
\text { Fixed, } 95 \% \mathrm{Cl} \\
\end{array}$} \\
\hline & $\operatorname{Mean}(S D)$ & $\mathbf{N}$ & Mean(SD) & & & & & \\
\hline \multicolumn{9}{|c|}{ Test for overall effect: $Z=0.57(P=0.57)$} \\
\hline \multicolumn{9}{|c|}{ Test for subgroup differences: $\mathrm{Chi}^{2}=3.36, \mathrm{df}=1(\mathrm{P}=0.07), \mathrm{I}^{2}=70.28 \%$} \\
\hline
\end{tabular}

Analysis 2.3. Comparison 2 Virtual reality versus conventional therapy: upper limb function: subgroup analyses, Outcome 3 Specialised or gaming.

\begin{tabular}{|c|c|c|c|c|c|c|c|}
\hline \multirow{3}{*}{$\begin{array}{l}\text { Study or subgroup } \\
\text { 2.3.1 Specialised }\end{array}$} & \multicolumn{2}{|c|}{ Virtual reality } & \multicolumn{2}{|c|}{$\begin{array}{c}\text { Comparison } \\
\text { treatment }\end{array}$} & \multirow{2}{*}{$\begin{array}{c}\text { Std. Mean Difference } \\
\text { Fixed, } 95 \% \mathrm{Cl} \\
\end{array}$} & \multirow{2}{*}{ Weight } & \multirow{2}{*}{$\begin{array}{l}\text { Std. Mean Difference } \\
\qquad \text { Fixed, } 95 \% \mathrm{Cl} \\
\end{array}$} \\
\hline & \multirow[t]{2}{*}{$\mathbf{N}$} & \multirow[t]{2}{*}{ Mean(SD) } & \multirow[t]{2}{*}{$\mathbf{N}$} & \multirow[t]{2}{*}{ Mean(SD) } & & & \\
\hline & & & & & & & \\
\hline Byl 2013 & 5 & $28.2(4.6)$ & 3 & $30.6(6.9)$ & & $0.72 \%$ & $-0.38[-1.84,1.07]$ \\
\hline Byl 2013 & 5 & $27.8(7.9)$ & 2 & $30.6(6.9)$ & & $0.56 \%$ & $-0.31[-1.96,1.35]$ \\
\hline Crosbie 2008 & 9 & $52.8(6.9)$ & 9 & $50.2(18.9)$ & & $1.78 \%$ & $0.17[-0.75,1.1]$ \\
\hline Housman 2009 & 14 & $24.9(7.4)$ & 14 & $19.6(6.7)$ & & $2.58 \%$ & $0.73[-0.04,1.5]$ \\
\hline Kiper 2011 & 40 & $48.9(15.2)$ & 40 & $46.4(17.1)$ & & $7.93 \%$ & $0.15[-0.29,0.59]$ \\
\hline Levin 2012 & 6 & $47.3(11.9)$ & 6 & $44.9(11.7)$ & t & $1.19 \%$ & $0.19[-0.95,1.32]$ \\
\hline Piron 2007 & 25 & $51.4(9.8)$ & 13 & $45.4(9.3)$ & & $3.25 \%$ & $0.61[-0.08,1.3]$ \\
\hline Piron 2009 & 18 & $53.6(7.7)$ & 18 & $49.5(4.8)$ & & $3.39 \%$ & $0.62[-0.05,1.3]$ \\
\hline Piron 2010 & 27 & $49.7(10.1)$ & 20 & $46.5(9.7)$ & & $4.51 \%$ & $0.32[-0.27,0.9]$ \\
\hline Reinkensmeyer 2012 & 13 & $27.4(11.4)$ & 13 & $23.8(8)$ & 1 & $2.54 \%$ & $0.35[-0.42,1.13]$ \\
\hline Subramanian 2013 & 32 & $43(15.2)$ & 32 & $43.9(14.7)$ & & $6.36 \%$ & $-0.06[-0.55,0.43]$ \\
\hline Sucar 2009 & 11 & $30(12.4)$ & 11 & $26.4(2.3)$ & & $2.14 \%$ & $0.39[-0.45,1.24]$ \\
\hline Thielbar 2014 & 7 & $50.4(10.4)$ & 7 & $43.6(8.1)$ & & $1.29 \%$ & $0.68[-0.41,1.77]$ \\
\hline Zucconi 2012 & 11 & $45.2(20.3)$ & 11 & $51.8(13.1)$ & & $2.14 \%$ & $-0.37[-1.22,0.47]$ \\
\hline 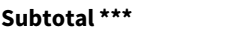 & 266 & & 240 & & & $48.38 \%$ & $0.17[-0,0.35]$ \\
\hline \multicolumn{8}{|c|}{ Heterogeneity: $\mathrm{Tau}^{2}=0 ; \mathrm{Chi}^{2}=18.16, \mathrm{df}=15(\mathrm{P}=0.25) ; \mathrm{I}^{2}=17.42 \%$} \\
\hline \multicolumn{8}{|c|}{ Test for overall effect: $Z=1.92(P=0.06)$} \\
\hline \multicolumn{8}{|l|}{ 2.3.2 Gaming } \\
\hline Adie 2017 & 101 & $47.6(14.2)$ & 108 & $49(13.6)$ & $\rightarrow$ & $20.73 \%$ & $-0.1[-0.37,0.17]$ \\
\hline da Silva Ribeiro 2015 & 15 & $38.7(19.6)$ & 15 & $44.7(14.2)$ & & $2.93 \%$ & $-0.34[-1.06,0.38]$ \\
\hline Galvao 2015 & 18 & $120.9(13.7)$ & 10 & $101.7(18.5)$ & & $2.14 \%$ & $1.2[0.36,2.04]$ \\
\hline Saposnik 2010 & 9 & $-19.8(3.4)$ & 7 & $-27.4(8.7)$ & & $1.29 \%$ & $1.15[0.06,2.24]$ \\
\hline Saposnik 2016 & 71 & $-64.1(104)$ & 70 & $-39.8(35.5)$ & $\longrightarrow$ & $13.85 \%$ & $-0.31[-0.64,0.02]$ \\
\hline Subtotal $\star \star \star ~$ & 267 & & 265 & & & $51.62 \%$ & $-0.02[-0.2,0.15]$ \\
\hline \multicolumn{8}{|c|}{ Heterogeneity: $\mathrm{Tau}^{2}=0 ; \mathrm{Chi}^{2}=17.76, \mathrm{df}=6(\mathrm{P}=0.01) ; \mathrm{I}^{2}=66.22 \%$} \\
\hline \multicolumn{8}{|c|}{ Test for overall effect: $Z=0.27(P=0.79)$} \\
\hline Total $\star \star \star$ & 533 & & 505 & & & $100 \%$ & $0.07[-0.05,0.2]$ \\
\hline \multicolumn{8}{|c|}{ Heterogeneity: $\operatorname{Tau}^{2}=0 ; \mathrm{Chi}^{2}=38.37, \mathrm{df}=22(\mathrm{P}=0.02) ; \mathrm{I}^{2}=42.67 \%$} \\
\hline \multicolumn{8}{|c|}{ Test for overall effect: $\mathrm{Z}=1.14(\mathrm{P}=0.25)$} \\
\hline \multicolumn{8}{|c|}{ Test for subgroup differences: $\mathrm{Chi}^{2}=2.45, \mathrm{df}=1(\mathrm{P}=0.12), \mathrm{I}^{2}=59.11 \%$} \\
\hline & & & & nventional & $-1 \quad-0.5$ & Favours & ality \\
\hline
\end{tabular}


Analysis 2.4. Comparison 2 Virtual reality versus conventional therapy: upper limb function: subgroup analyses, Outcome 4 Severity of impairment.

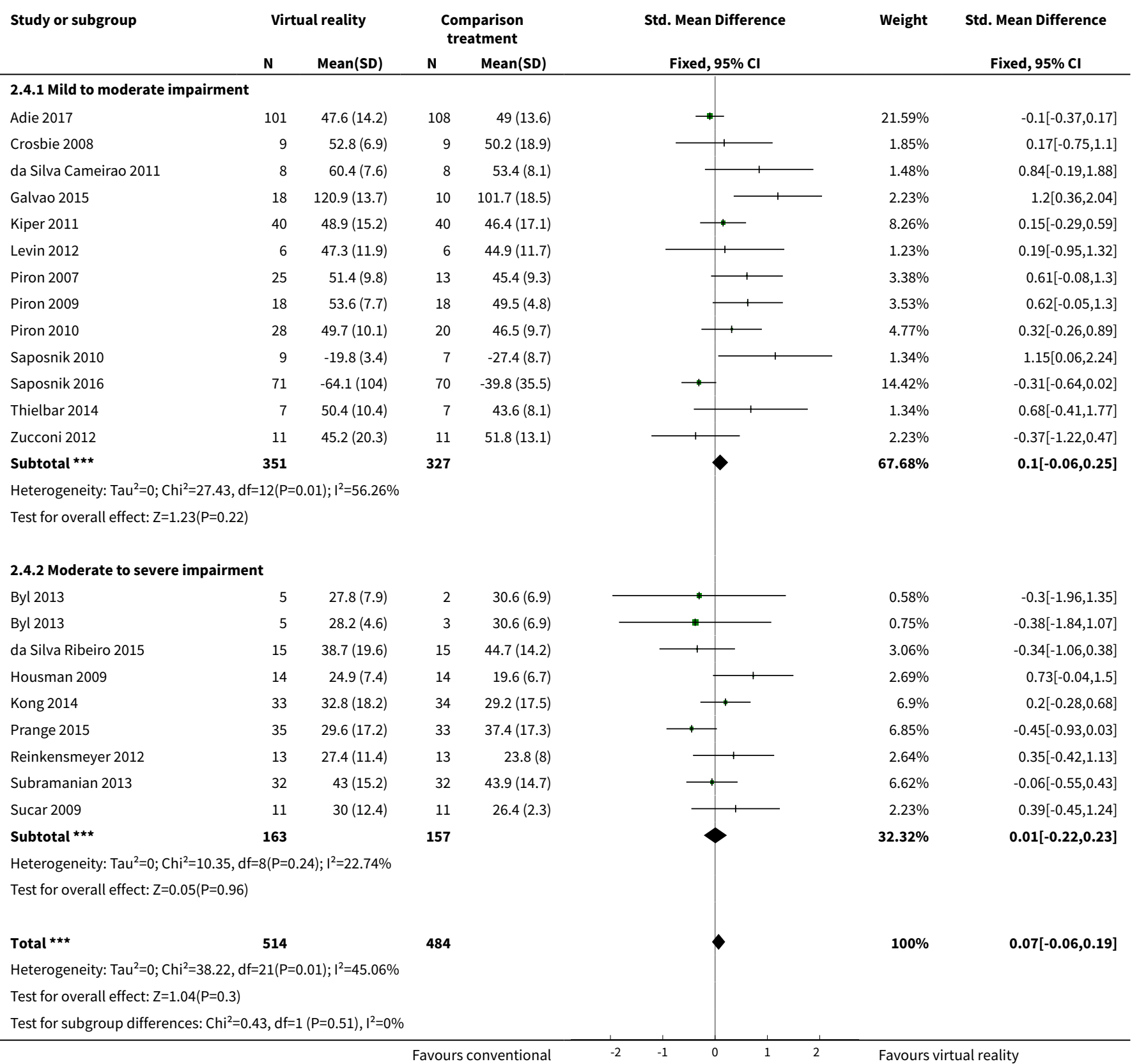

\section{Comparison 3. Additional virtual reality intervention: effect on upper limb function post intervention}

\begin{tabular}{lllll}
\hline Outcome or subgroup title & No. of studies & $\begin{array}{l}\text { No. of partici- } \\
\text { pants }\end{array}$ & Statistical method & Effect size \\
\hline $\begin{array}{l}1 \text { Upper limb function (composite } \\
\text { measure) }\end{array}$ & 10 & 210 & $\begin{array}{l}\text { Std. Mean Difference (IV, Fixed, } \\
95 \% \mathrm{Cl})\end{array}$ & $0.49[0.21,0.77]$ \\
\hline
\end{tabular}


Analysis 3.1. Comparison 3 Additional virtual reality intervention: effect on upper limb function post intervention, Outcome 1 Upper limb function (composite measure).

\begin{tabular}{|c|c|c|c|c|c|c|c|}
\hline \multirow{3}{*}{$\begin{array}{l}\text { Study or subgroup } \\
\text { Cho } 2012\end{array}$} & \multicolumn{2}{|c|}{ Virtual reality } & \multicolumn{2}{|c|}{ No intervention } & \multirow{2}{*}{$\begin{array}{c}\text { Std. Mean Difference } \\
\text { Fixed, } 95 \% \mathrm{Cl}\end{array}$} & \multirow[t]{2}{*}{ Weight } & \multirow{2}{*}{$\begin{array}{c}\text { Std. Mean Difference } \\
\text { Fixed, } 95 \% \mathrm{Cl}\end{array}$} \\
\hline & $\mathbf{N}$ & Mean(SD) & $\mathbf{N}$ & Mean(SD) & & & \\
\hline & 15 & $21.6(5.4)$ & 14 & $17.7(3.4)$ & $\longrightarrow$ & $13.45 \%$ & $0.83[0.07,1.6]$ \\
\hline Coupar 2012 & 4 & $40.8(17.2)$ & 2 & $44.3(25)$ & & $2.71 \%$ & $-0.14[-1.85,1.56]$ \\
\hline Coupar 2012 & 4 & $44(16)$ & 2 & $44.3(25)$ & & $2.73 \%$ & $-0.01[-1.71,1.69]$ \\
\hline Jang 2005 & 5 & $58(6.2)$ & 5 & $55(3.7)$ & & $4.83 \%$ & $0.53[-0.75,1.8]$ \\
\hline Kim 2011a & 15 & $64(26.7)$ & 13 & $61.2(18.2)$ & & $14.21 \%$ & $0.12[-0.63,0.86]$ \\
\hline Manlapaz 2010 & 8 & $21(2)$ & 8 & $18.5(1.3)$ & $\longrightarrow$ & $6.18 \%$ & $1.4[0.27,2.53]$ \\
\hline Shin 2014 & 9 & $51.1(7.8)$ & 7 & $40.7(9.8)$ & & $6.66 \%$ & $1.13[0.04,2.21]$ \\
\hline $\operatorname{Sin} 2013$ & 18 & $47.7(15.3)$ & 17 & $34.6(20.7)$ & + & $16.7 \%$ & $0.71[0.02,1.39]$ \\
\hline Standen 2011 & 9 & $-2.7(1.6)$ & 9 & $-2.9(1.4)$ & + & $9.18 \%$ & $0.11[-0.81,1.04]$ \\
\hline Yavuzer 2008 & 10 & $3(1.5)$ & 10 & $2.8(0.9)$ & - & $10.18 \%$ & $0.15[-0.72,1.03]$ \\
\hline \multicolumn{8}{|c|}{ Heterogeneity: $\mathrm{Tau}^{2}=0 ; \mathrm{Chi}^{2}=8.36, \mathrm{df}=10(\mathrm{P}=0.59) ; \mathrm{I}^{2}=0 \%$} \\
\hline \multicolumn{3}{|c|}{ Test for overall effect: $Z=3.43(P=0)$} & & & & & \\
\hline
\end{tabular}

Comparison 4. Additional virtual reality intervention: effect on upper limb function post intervention: subgroup analyses

\begin{tabular}{|c|c|c|c|c|}
\hline $\begin{array}{l}\text { Outcome or subgroup ti- } \\
\text { tle }\end{array}$ & No. of studies & $\begin{array}{l}\text { No. of partici- } \\
\text { pants }\end{array}$ & Statistical method & Effect size \\
\hline 1 Dose of intervention & 10 & 210 & Std. Mean Difference (IV, Fixed, 95\% Cl) & $0.49[0.21,0.77]$ \\
\hline $\begin{array}{l}1.1 \text { Less than } 15 \text { hours of } \\
\text { intervention }\end{array}$ & 7 & 153 & Std. Mean Difference (IV, Fixed, 95\% CI) & $0.47[0.14,0.80]$ \\
\hline $\begin{array}{l}1.2 \text { More than } 15 \text { hours of } \\
\text { intervention }\end{array}$ & 3 & 57 & Std. Mean Difference (IV, Fixed, 95\% CI) & $0.54[0.00,1.07]$ \\
\hline $\begin{array}{l}2 \text { Time since onset of } \\
\text { stroke }\end{array}$ & 9 & 181 & Std. Mean Difference (IV, Fixed, 95\% CI) & $0.44[0.14,0.74]$ \\
\hline 2.1 Less than 6 months & 5 & 102 & Std. Mean Difference (IV, Fixed, 95\% Cl) & $0.28[-0.12,0.67]$ \\
\hline 2.2 More than 6 months & 4 & 79 & Std. Mean Difference (IV, Fixed, 95\% Cl) & $0.65[0.19,1.11]$ \\
\hline 3 Specialised or gaming & 10 & 210 & Std. Mean Difference (IV, Fixed, 95\% Cl) & $0.49[0.21,0.77]$ \\
\hline 3.1 Specialised & 7 & 139 & Std. Mean Difference (IV, Fixed, 95\% CI) & $0.40[0.06,0.75]$ \\
\hline 3.2 Gaming & 3 & 71 & Std. Mean Difference (IV, Fixed, 95\% CI) & $0.67[0.18,1.15]$ \\
\hline
\end{tabular}


Analysis 4.1. Comparison 4 Additional virtual reality intervention: effect on upper limb function post intervention: subgroup analyses, Outcome 1 Dose of intervention.

\begin{tabular}{|c|c|c|c|c|c|c|c|}
\hline \multirow[t]{2}{*}{ Study or subgroup } & \multicolumn{2}{|c|}{ Experimental } & \multicolumn{2}{|c|}{ Control } & \multirow{2}{*}{$\begin{array}{c}\text { Std. Mean Difference } \\
\text { Fixed, } 95 \% \mathrm{Cl}\end{array}$} & \multirow[t]{2}{*}{ Weight } & \multirow{2}{*}{$\begin{array}{l}\text { Std. Mean Difference } \\
\text { Fixed, } 95 \% \mathrm{Cl}\end{array}$} \\
\hline & $\mathbf{N}$ & Mean(SD) & $\mathbf{N}$ & $\operatorname{Mean}(S D)$ & & & \\
\hline \multicolumn{5}{|c|}{ 4.1.1 Less than 15 hours of intervention } & & & \\
\hline Coupar 2012 & 4 & $44(16)$ & 2 & $44.3(25)$ & & $2.73 \%$ & $-0.01[-1.71,1.69]$ \\
\hline Coupar 2012 & 4 & $40.8(17.2)$ & 2 & $44.3(25)$ & & $2.71 \%$ & $-0.14[-1.85,1.56]$ \\
\hline Kim 2011a & 15 & $64(26.7)$ & 13 & $61.2(18.2)$ & . & $14.21 \%$ & $0.12[-0.63,0.86]$ \\
\hline Kwon 2012 & 13 & $62.9(3.5)$ & 13 & $61.9(4.5)$ & & $13.16 \%$ & $0.26[-0.52,1.03]$ \\
\hline Shin 2014 & 9 & $51.1(7.8)$ & 7 & $40.7(9.8)$ & & $6.66 \%$ & $1.13[0.04,2.21]$ \\
\hline $\operatorname{Sin} 2013$ & 18 & $47.7(15.3)$ & 17 & $34.6(20.7)$ & & $16.7 \%$ & $0.71[0.02,1.39]$ \\
\hline Yavuzer 2008 & 10 & $3(1.5)$ & 10 & $2.8(0.9)$ & & $10.18 \%$ & $0.15[-0.72,1.03]$ \\
\hline Subtotal $\star \star \star ~$ & 81 & & 72 & & & $72.53 \%$ & $0.47[0.14,0.8]$ \\
\hline \multicolumn{8}{|c|}{ Heterogeneity: $\operatorname{Tau}^{2}=0 ; \mathrm{Chi}^{2}=6.93, \mathrm{df}=7(\mathrm{P}=0.44) ;\left.\right|^{2}=0 \%$} \\
\hline \multicolumn{8}{|c|}{ Test for overall effect: $\mathrm{Z}=2.81(\mathrm{P}=0.01)$} \\
\hline \multicolumn{8}{|c|}{ 4.1.2 More than 15 hours of intervention } \\
\hline Cho 2012 & 15 & $21.6(5.4)$ & 14 & $17.7(3.4)$ & & $13.45 \%$ & $0.83[0.07,1.6]$ \\
\hline Jang 2005 & 5 & $58(6.2)$ & 5 & $55(3.7)$ & & $4.83 \%$ & $0.53[-0.75,1.8]$ \\
\hline Standen 2011 & 9 & $-2.7(1.6)$ & 9 & $-2.9(1.4)$ & + & $9.18 \%$ & $0.11[-0.81,1.04]$ \\
\hline Subtotal $\star \star \star$ & 29 & & 28 & & & $27.47 \%$ & $0.54[0,1.07]$ \\
\hline \multicolumn{8}{|c|}{ Heterogeneity: $\mathrm{Tau}^{2}=0 ; \mathrm{Chi}^{2}=1.38, \mathrm{df}=2(\mathrm{P}=0.5) ; \mathrm{I}^{2}=0 \%$} \\
\hline \multicolumn{8}{|c|}{ Test for overall effect: $Z=1.98(P=0.05)$} \\
\hline Total $\star \star \star ~$ & 110 & & 100 & & & $100 \%$ & $0.49[0.21,0.77]$ \\
\hline \multicolumn{8}{|c|}{ Heterogeneity: $\mathrm{Tau}^{2}=0 ; \mathrm{Chi}^{2}=8.36, \mathrm{df}=10(\mathrm{P}=0.59) ; \mathrm{I}^{2}=0 \%$} \\
\hline \multicolumn{8}{|c|}{ Test for overall effect: $\mathrm{Z}=3.43(\mathrm{P}=0)$} \\
\hline Test for subgroup dif & $04, d f=$ & $P=0.83), I^{2}=0 \%$ & & & & & \\
\hline
\end{tabular}

Analysis 4.2. Comparison 4 Additional virtual reality intervention: effect on upper limb function post intervention: subgroup analyses, Outcome 2 Time since onset of stroke.

\begin{tabular}{|c|c|c|c|c|c|c|c|}
\hline \multirow[t]{2}{*}{ Study or subgroup } & \multicolumn{2}{|c|}{ Experimental } & \multicolumn{2}{|c|}{ Control } & \multirow{2}{*}{$\begin{array}{l}\text { Std. Mean Difference } \\
\text { Fixed, } 95 \% \mathrm{Cl}\end{array}$} & \multirow[t]{2}{*}{ Weight } & \multirow{2}{*}{$\begin{array}{c}\text { Std. Mean Difference } \\
\text { Fixed, } 95 \% \mathrm{Cl}\end{array}$} \\
\hline & $\mathbf{N}$ & Mean(SD) & $\mathbf{N}$ & $\operatorname{Mean}(S D)$ & & & \\
\hline \multicolumn{8}{|c|}{ 4.2.1 Less than 6 months } \\
\hline Coupar 2012 & 4 & $44(16)$ & 2 & $44.3(25)$ & & $3.15 \%$ & $-0.01[-1.71,1.69]$ \\
\hline Coupar 2012 & 4 & $40.8(17.2)$ & 2 & $44.3(25)$ & & $3.13 \%$ & $-0.14[-1.85,1.56]$ \\
\hline Kim 2011a & 15 & $64(26.7)$ & 13 & $61.2(18.2)$ & 4 & $16.42 \%$ & $0.12[-0.63,0.86]$ \\
\hline Kwon 2012 & 13 & $62.9(3.5)$ & 13 & $61.9(4.5)$ & & $15.21 \%$ & $0.26[-0.52,1.03]$ \\
\hline Yavuzer 2008 & 10 & $3(1.5)$ & 10 & $2.8(0.9)$ & 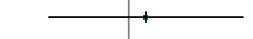 & $11.77 \%$ & $0.15[-0.72,1.03]$ \\
\hline Subtotal $\star \star \star$ & 55 & & 47 & & & $57.37 \%$ & $0.28[-0.12,0.67]$ \\
\hline \multicolumn{8}{|c|}{ Heterogeneity: $\operatorname{Tau}^{2}=0 ; \mathrm{Chi}^{2}=2.96, \mathrm{df}=5(\mathrm{P}=0.71) ; \mathrm{I}^{2}=0 \%$} \\
\hline \multicolumn{8}{|c|}{ Test for overall effect: $Z=1.36(P=0.17)$} \\
\hline \multicolumn{8}{|c|}{ 4.2.2 More than 6 months } \\
\hline Manlapaz 2010 & 8 & $21(2)$ & 8 & $18.5(1.3)$ & & $7.14 \%$ & $1.4[0.27,2.53]$ \\
\hline $\operatorname{Sin} 2013$ & 18 & $47.7(15.3)$ & 17 & $34.6(20.7)$ & 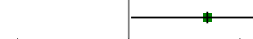 & $19.3 \%$ & $0.71[0.02,1.39]$ \\
\hline
\end{tabular}




\begin{tabular}{|c|c|c|c|c|c|c|c|}
\hline \multirow{3}{*}{$\begin{array}{l}\text { Study or subgroup } \\
\text { Standen } 2011\end{array}$} & \multicolumn{2}{|c|}{ Experimental } & \multicolumn{2}{|c|}{ Control } & \multirow{2}{*}{$\begin{array}{l}\text { Std. Mean Difference } \\
\text { Fixed, } 95 \% \mathrm{Cl}\end{array}$} & \multirow[t]{2}{*}{ Weight } & \multirow{2}{*}{$\begin{array}{l}\text { Std. Mean Difference } \\
\text { Fixed, } 95 \% \mathrm{Cl}\end{array}$} \\
\hline & $\mathbf{N}$ & $\operatorname{Mean}(S D)$ & $\mathbf{N}$ & Mean(SD) & & & \\
\hline & 9 & $-2.7(1.6)$ & 9 & $-2.9(1.4)$ & \begin{tabular}{l|l} 
& +
\end{tabular} & $10.61 \%$ & $0.11[-0.81,1.04]$ \\
\hline Subtotal $* \star \star$ & 40 & & 39 & & & $42.63 \%$ & $0.65[0.19,1.11]$ \\
\hline \multicolumn{8}{|c|}{ Heterogeneity: $\mathrm{Tau}^{2}=0 ; \mathrm{Chi}^{2}=3.04, \mathrm{df}=3(\mathrm{P}=0.39) ; \mathrm{I}^{2}=1.41 \%$} \\
\hline \multicolumn{8}{|c|}{ Test for overall effect: $Z=2.77(P=0.01)$} \\
\hline 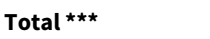 & 95 & & 86 & & & $100 \%$ & $0.44[0.14,0.74]$ \\
\hline \multicolumn{8}{|c|}{ Heterogeneity: $\operatorname{Tau}^{2}=0 ; \mathrm{Chi}^{2}=7.46, \mathrm{df}=9(\mathrm{P}=0.59) ; \mathrm{I}^{2}=0 \%$} \\
\hline \multicolumn{8}{|c|}{ Test for overall effect: $\mathrm{Z}=2.84(\mathrm{P}=0)$} \\
\hline \multicolumn{8}{|c|}{ Test for subgroup differences: $\mathrm{Chi}^{2}=1.46, \mathrm{df}=1(\mathrm{P}=0.23), \mathrm{I}^{2}=31.3 \%$} \\
\hline & & & urs $n$ & tervention & -1 & Favours & Ial reality \\
\hline
\end{tabular}

Analysis 4.3. Comparison 4 Additional virtual reality intervention: effect on upper limb function post intervention: subgroup analyses, Outcome 3 Specialised or gaming.

\begin{tabular}{|c|c|c|c|c|c|c|c|}
\hline \multirow{3}{*}{$\begin{array}{l}\text { Study or subgroup } \\
\text { 4.3.1 Specialised }\end{array}$} & \multicolumn{2}{|c|}{ Experimental } & \multicolumn{2}{|c|}{ Control } & \multirow{2}{*}{$\begin{array}{c}\text { Std. Mean Difference } \\
\text { Fixed, } 95 \% \mathrm{Cl}\end{array}$} & \multirow[t]{2}{*}{ Weight } & \multirow{2}{*}{$\begin{array}{c}\text { Std. Mean Difference } \\
\text { Fixed, } 95 \% \mathrm{Cl}\end{array}$} \\
\hline & \multirow[t]{2}{*}{$\mathbf{N}$} & \multirow[t]{2}{*}{ Mean(SD) } & \multirow[t]{2}{*}{$\mathbf{N}$} & \multirow[t]{2}{*}{ Mean(SD) } & & & \\
\hline & & & & & & & \\
\hline Cho 2012 & 15 & $21.6(5.4)$ & 14 & $17.7(3.4)$ & $\longrightarrow$ & $13.45 \%$ & $0.83[0.07,1.6]$ \\
\hline Coupar 2012 & 4 & $40.8(17.2)$ & 2 & $44.3(25)$ & & $2.71 \%$ & $-0.14[-1.85,1.56]$ \\
\hline Coupar 2012 & 4 & $44(16)$ & 2 & $44.3(25)$ & & $2.73 \%$ & $-0.01[-1.71,1.69]$ \\
\hline Jang 2005 & 5 & $58(6.2)$ & 5 & $55(3.7)$ & 1 & $4.83 \%$ & $0.53[-0.75,1.8]$ \\
\hline Kwon 2012 & 13 & $62.9(3.5)$ & 13 & $61.9(4.5)$ & $\longrightarrow$ & $13.16 \%$ & $0.26[-0.52,1.03]$ \\
\hline Shin 2014 & 9 & $51.1(7.8)$ & 7 & $40.7(9.8)$ & $\longrightarrow$ & $6.66 \%$ & $1.13[0.04,2.21]$ \\
\hline Standen 2011 & 9 & $-2.7(1.6)$ & 9 & $-2.9(1.4)$ & . & $9.18 \%$ & $0.11[-0.81,1.04]$ \\
\hline Subtotal $* \star \star$ & 74 & & 65 & & & $66.94 \%$ & $0.4[0.06,0.75]$ \\
\hline \multicolumn{8}{|c|}{ Heterogeneity: $\mathrm{Tau}^{2}=0 ; \mathrm{Chi}^{2}=4.67, \mathrm{df}=7(\mathrm{P}=0.7) ; \mathrm{I}^{2}=0 \%$} \\
\hline \multicolumn{8}{|c|}{ Test for overall effect: $Z=2.3(P=0.02)$} \\
\hline \multicolumn{8}{|l|}{ 4.3.2 Gaming } \\
\hline Manlapaz 2010 & 8 & $21(2)$ & 8 & $18.5(1.3)$ & & $6.18 \%$ & $1.4[0.27,2.53]$ \\
\hline $\operatorname{Sin} 2013$ & 18 & $47.7(15.3)$ & 17 & $34.6(20.7)$ & $\longrightarrow$ & $16.7 \%$ & $0.71[0.02,1.39]$ \\
\hline Yavuzer 2008 & 10 & $3(1.5)$ & 10 & $2.8(0.9)$ & & $10.18 \%$ & $0.15[-0.72,1.03]$ \\
\hline Subtotal $\star \star \star$ & 36 & & 35 & & & $33.06 \%$ & $0.67[0.18,1.15]$ \\
\hline \multicolumn{8}{|c|}{ Heterogeneity: $\operatorname{Tau}^{2}=0 ; \mathrm{Chi}^{2}=2.93, \mathrm{df}=2(\mathrm{P}=0.23) ; \mathrm{I}^{2}=31.84 \%$} \\
\hline \multicolumn{8}{|c|}{ Test for overall effect: $Z=2.68(P=0.01)$} \\
\hline Total $* \star \star$ & 110 & & 100 & & & $100 \%$ & $0.49[0.21,0.77]$ \\
\hline \multicolumn{8}{|c|}{ Heterogeneity: $\mathrm{Tau}^{2}=0 ; \mathrm{Chi}^{2}=8.36, \mathrm{df}=10(\mathrm{P}=0.59) ; \mathrm{I}^{2}=0 \%$} \\
\hline \multicolumn{8}{|c|}{ Test for overall effect: $\mathrm{Z}=3.43(\mathrm{P}=0)$} \\
\hline Test for subgroup dif & $75, \mathrm{df}=$ & $(P=0.39), I^{2}=0 \%$ & & & & & \\
\hline
\end{tabular}


Comparison 5. Virtual reality versus conventional therapy: effect on lower limb activity post intervention

\begin{tabular}{lllll}
\hline $\begin{array}{l}\text { Outcome or sub- } \\
\text { group title }\end{array}$ & No. of studies & $\begin{array}{l}\text { No. of partici- } \\
\text { pants }\end{array}$ & Statistical method & Effect size \\
\hline 1 Gait speed & 6 & 139 & Mean Difference (IV, Fixed, 95\% CI) & $0.09[-0.04,0.22]$ \\
\hline $\begin{array}{l}\text { 2 Timed Up and Go } \\
\text { Test }\end{array}$ & 3 & 89 & Mean Difference (IV, Fixed, 95\% CI) & $-1.76[-4.67,1.16]$ \\
\hline 3 Balance & 3 & 72 & Std. Mean Difference (IV, Fixed, 95\% Cl) & $0.39[-0.09,0.86]$ \\
\hline
\end{tabular}

Analysis 5.1. Comparison 5 Virtual reality versus conventional therapy: effect on lower limb activity post intervention, Outcome 1 Gait speed.

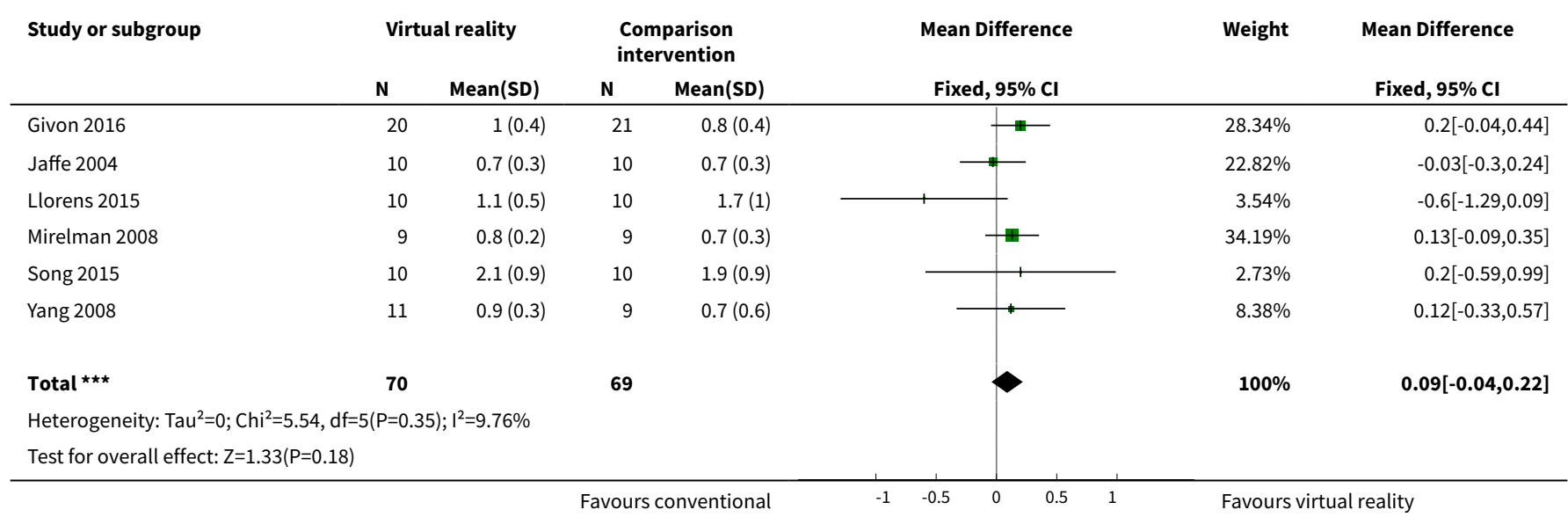

Analysis 5.2. Comparison 5 Virtual reality versus conventional therapy: effect on lower limb activity post intervention, Outcome 2 Timed Up and Go Test.

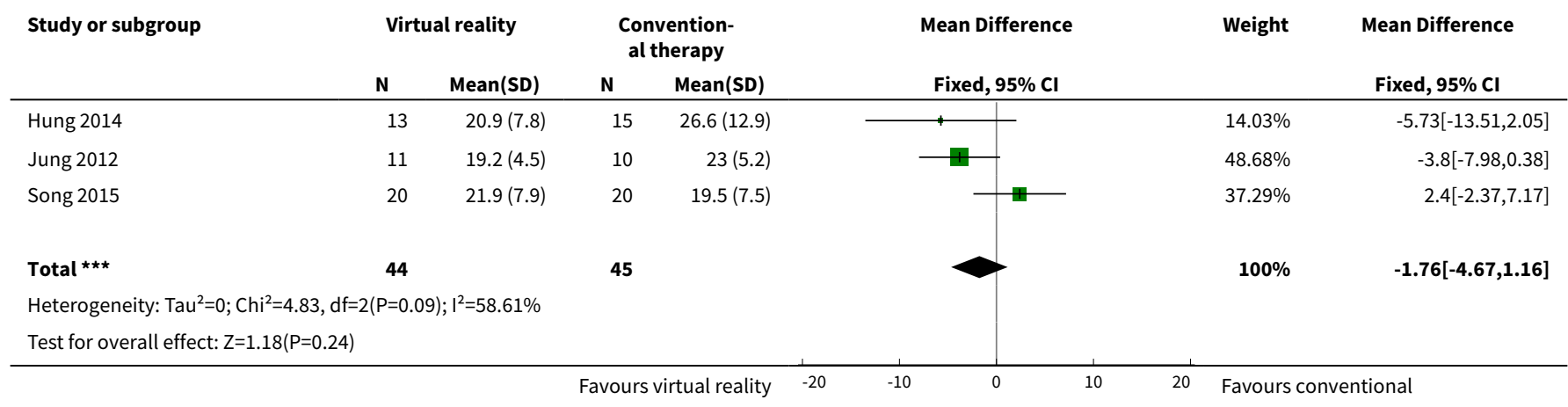


Analysis 5.3. Comparison 5 Virtual reality versus conventional therapy: effect on lower limb activity post intervention, Outcome 3 Balance.

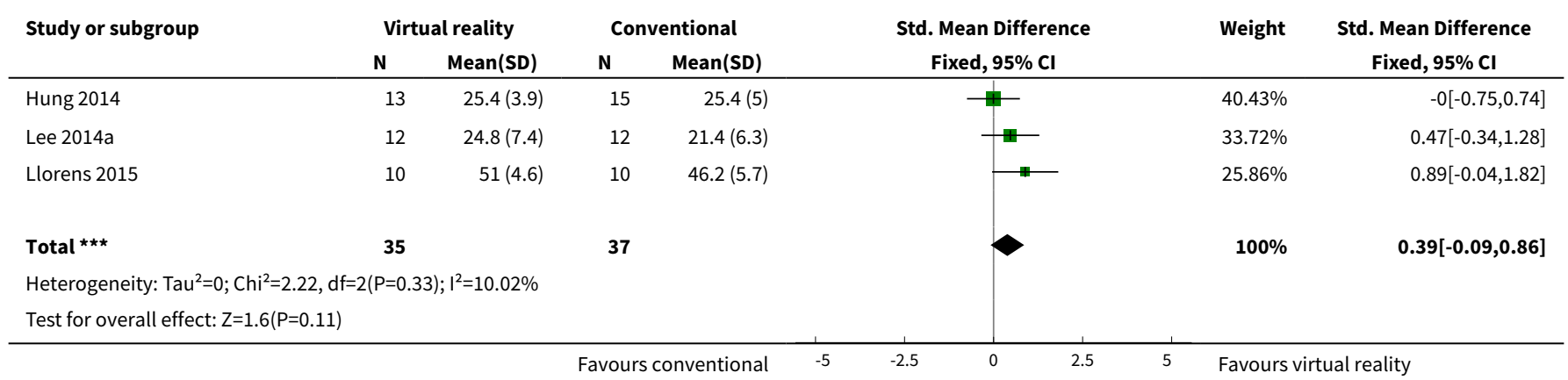

Comparison 6. Virtual reality versus conventional therapy: effect on lower limb activity post intervention: subgroup analyses

\begin{tabular}{lllll}
\hline Outcome or subgroup title & No. of studies & $\begin{array}{l}\text { No. of partici- } \\
\text { pants }\end{array}$ & Statistical method & Effect size \\
\hline $\begin{array}{l}\text { 1 Dose of intervention: effect on gait } \\
\text { speed }\end{array}$ & 6 & 139 & $\begin{array}{l}\text { Mean Difference (IV, Fixed, 95\% } \\
\text { Cl) }\end{array}$ & $0.09[-0.04,0.22]$ \\
\hline $\begin{array}{l}1.1 \text { Less than 10 hours of interven- } \\
\text { tion }\end{array}$ & 2 & 40 & $\begin{array}{l}\text { Mean Difference (IV, Fixed, 95\% } \\
\text { Cl) }\end{array}$ & $0.01[-0.22,0.24]$ \\
\hline $\begin{array}{l}1.2 \text { More than 10 hours of interven- } \\
\text { tion }\end{array}$ & 4 & 99 & $\begin{array}{l}\text { Mean Difference (IV, Fixed, 95\% } \\
\text { Cl) }\end{array}$ & $0.12[-0.03,0.28]$ \\
\hline
\end{tabular}

Analysis 6.1. Comparison 6 Virtual reality versus conventional therapy: effect on lower limb activity post intervention: subgroup analyses, Outcome 1 Dose of intervention: effect on gait speed.

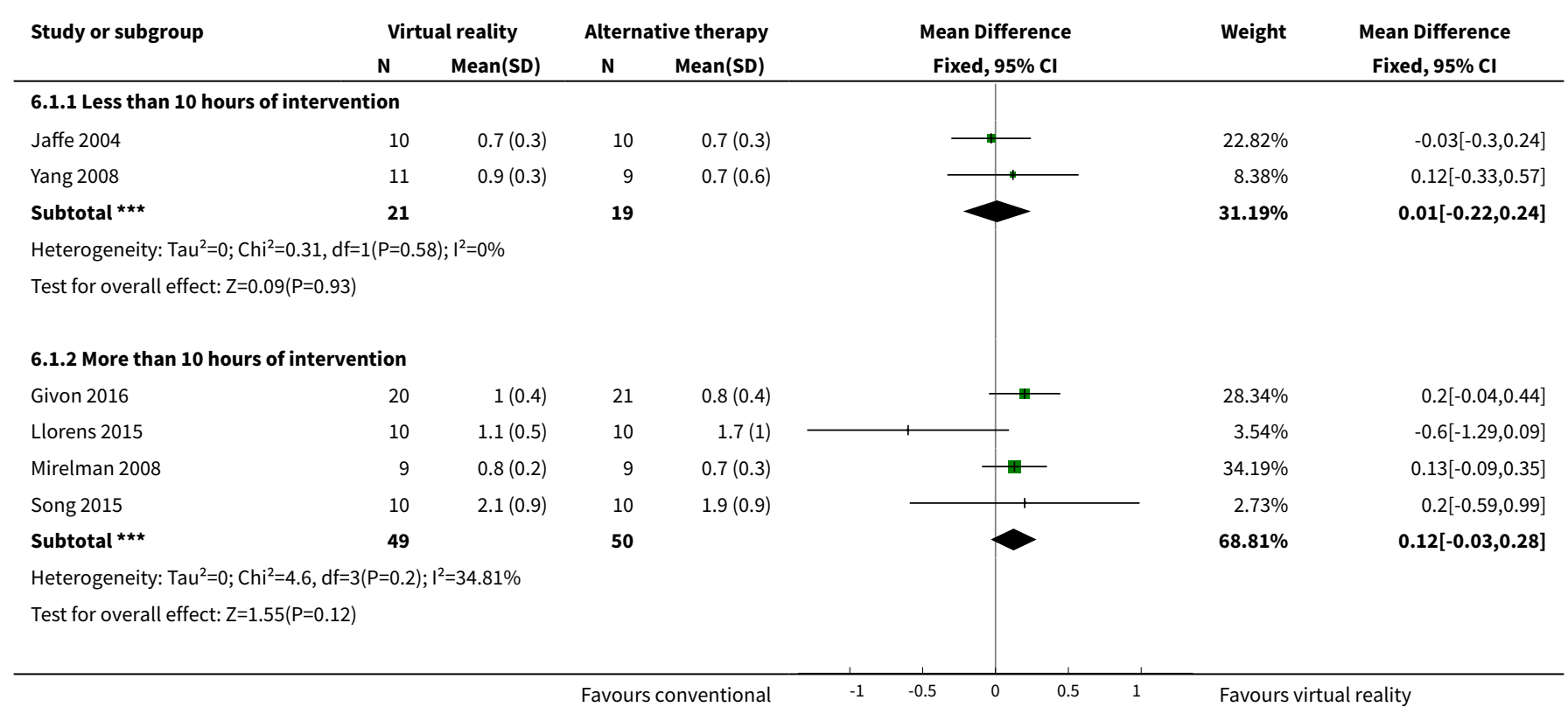




\begin{tabular}{|c|c|c|c|c|c|c|}
\hline \multirow[t]{2}{*}{ Study or subgroup } & \multicolumn{2}{|c|}{ Virtual reality } & Alternative therapy & \multirow{2}{*}{$\begin{array}{c}\text { Mean Difference } \\
\text { Fixed, } 95 \% \mathrm{Cl}\end{array}$} & \multirow[t]{2}{*}{ Weight } & \multirow{2}{*}{$\begin{array}{c}\text { Mean Difference } \\
\text { Fixed, } 95 \% \mathrm{Cl}\end{array}$} \\
\hline & $\mathbf{N}$ & Mean(SD) & Mean(SD) & & & \\
\hline Total $\star \star \star$ & 70 & & 69 & & $100 \%$ & $0.09[-0.04,0.22]$ \\
\hline \multicolumn{7}{|c|}{ Heterogeneity: $\mathrm{Tau}^{2}=0 ; \mathrm{Chi}^{2}=5.54, \mathrm{df}=5(\mathrm{P}=0.35) ; \mathrm{I}^{2}=9.76 \%$} \\
\hline \multicolumn{7}{|c|}{ Test for overall effect: $Z=1.33(P=0.18)$} \\
\hline \multicolumn{7}{|c|}{ Test for subgroup differences: $\mathrm{Chi}^{2}=0.63, \mathrm{df}=1(\mathrm{P}=0.43), \mathrm{I}^{2}=0 \%$} \\
\hline & & & Favours conventional & -0.5 & Favours & I reality \\
\hline
\end{tabular}

Comparison 7. Additional virtual reality intervention: effect on lower limb activity post intervention

\begin{tabular}{lllll}
\hline $\begin{array}{l}\text { Outcome or subgroup } \\
\text { title }\end{array}$ & No. of studies & $\begin{array}{l}\text { No. of partici- } \\
\text { pants }\end{array}$ & Statistical method & Effect size \\
\hline 1 Gait speed & 3 & 57 & Mean Difference (IV, Fixed, 95\% Cl) & $0.08[-0.05,0.21]$ \\
\hline $\begin{array}{l}\text { 2 Functional mobility } \\
\text { (Timed Up and Go) }\end{array}$ & 3 & 93 & Mean Difference (IV, Fixed, 95\% Cl) & $-4.76[-8.91,-0.61]$ \\
\hline 3 Balance & 7 & 173 & Std. Mean Difference (IV, Fixed, 95\% Cl) & $0.59[0.28,0.90]$ \\
\hline
\end{tabular}

Analysis 7.1. Comparison 7 Additional virtual reality intervention: effect on lower limb activity post intervention, Outcome 1 Gait speed.

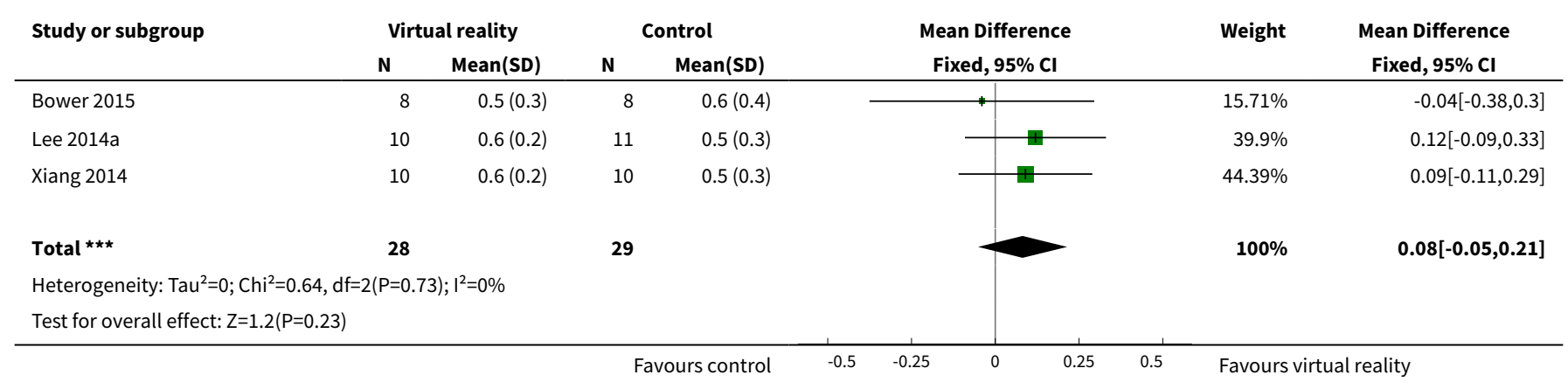

Analysis 7.2. Comparison 7 Additional virtual reality intervention: effect on lower limb activity post intervention, Outcome 2 Functional mobility (Timed Up and Go).

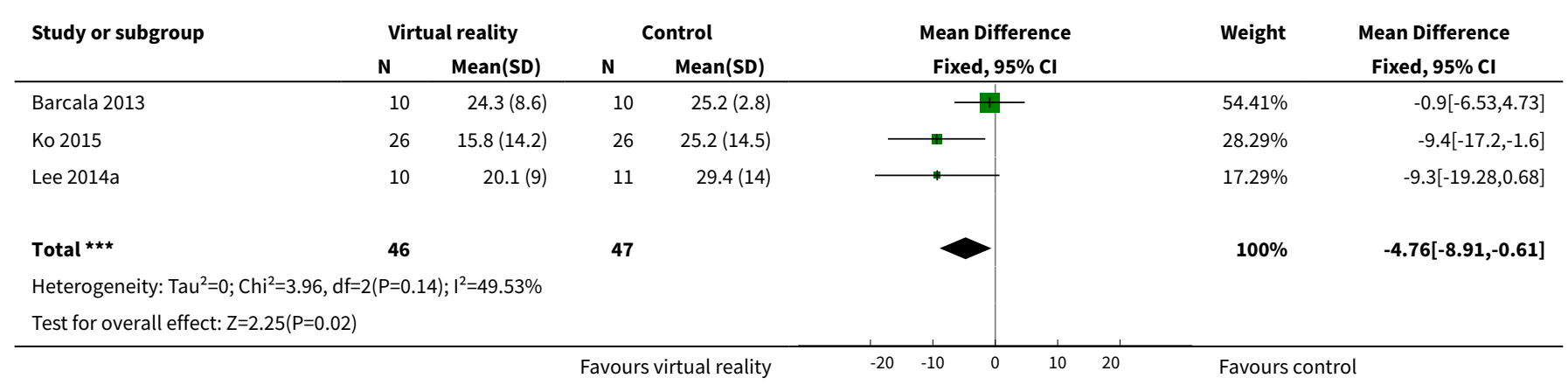


Analysis 7.3. Comparison 7 Additional virtual reality intervention: effect on lower limb activity post intervention, Outcome 3 Balance.

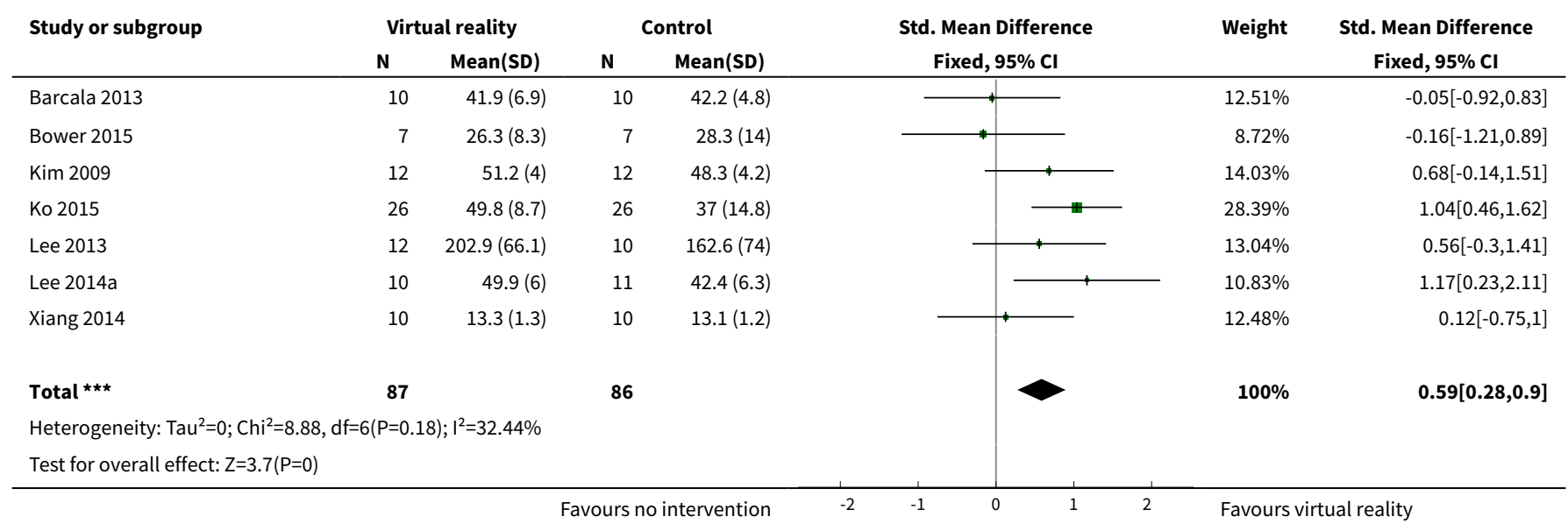

Comparison 8. Additional virtual reality intervention: effect on global motor function post intervention

\begin{tabular}{lllll}
\hline Outcome or subgroup title & No. of studies & $\begin{array}{l}\text { No. of partici- } \\
\text { pants }\end{array}$ & Statistical method & Effect size \\
\hline 1 Global motor function & 3 & 43 & $\begin{array}{l}\text { Std. Mean Difference (IV, Fixed, 95\% } \\
\text { Cl) }\end{array}$ & $0.01[-0.60,0.61]$ \\
\hline
\end{tabular}

Analysis 8.1. Comparison 8 Additional virtual reality intervention: effect on global motor function post intervention, Outcome 1 Global motor function.

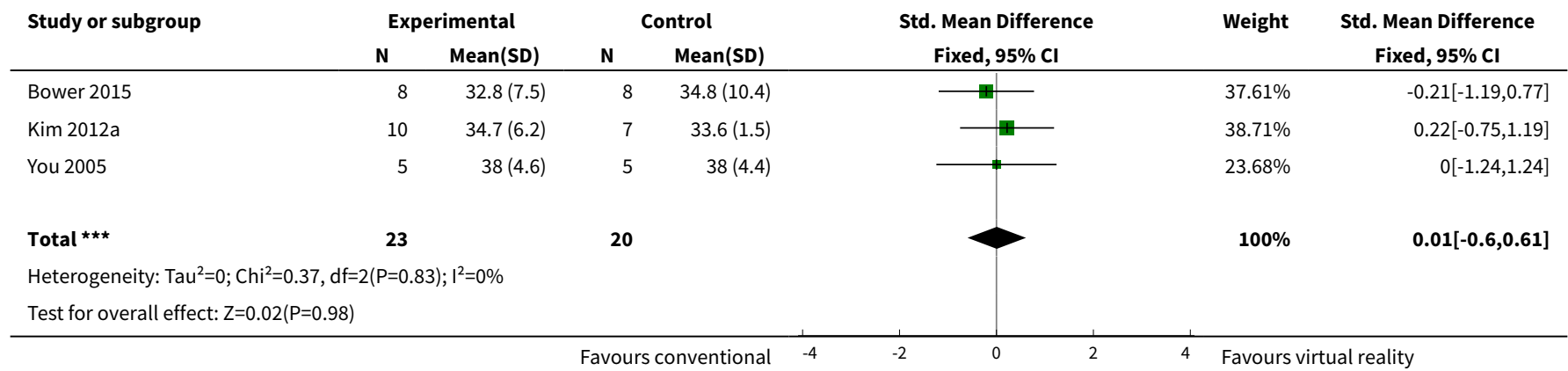

Comparison 9. Virtual reality versus conventional therapy: effect on activity limitation

\begin{tabular}{lllll}
\hline $\begin{array}{l}\text { Outcome or subgroup ti- } \\
\text { tle }\end{array}$ & No. of studies & $\begin{array}{l}\text { No. of partici- } \\
\text { pants }\end{array}$ & Statistical method & Effect size \\
\hline 1 ADL outcome & 10 & 466 & Std. Mean Difference (IV, Fixed, 95\% Cl) & $0.25[0.06,0.43]$ \\
\hline
\end{tabular}


Analysis 9.1. Comparison 9 Virtual reality versus conventional therapy: effect on activity limitation, Outcome 1 ADL outcome.

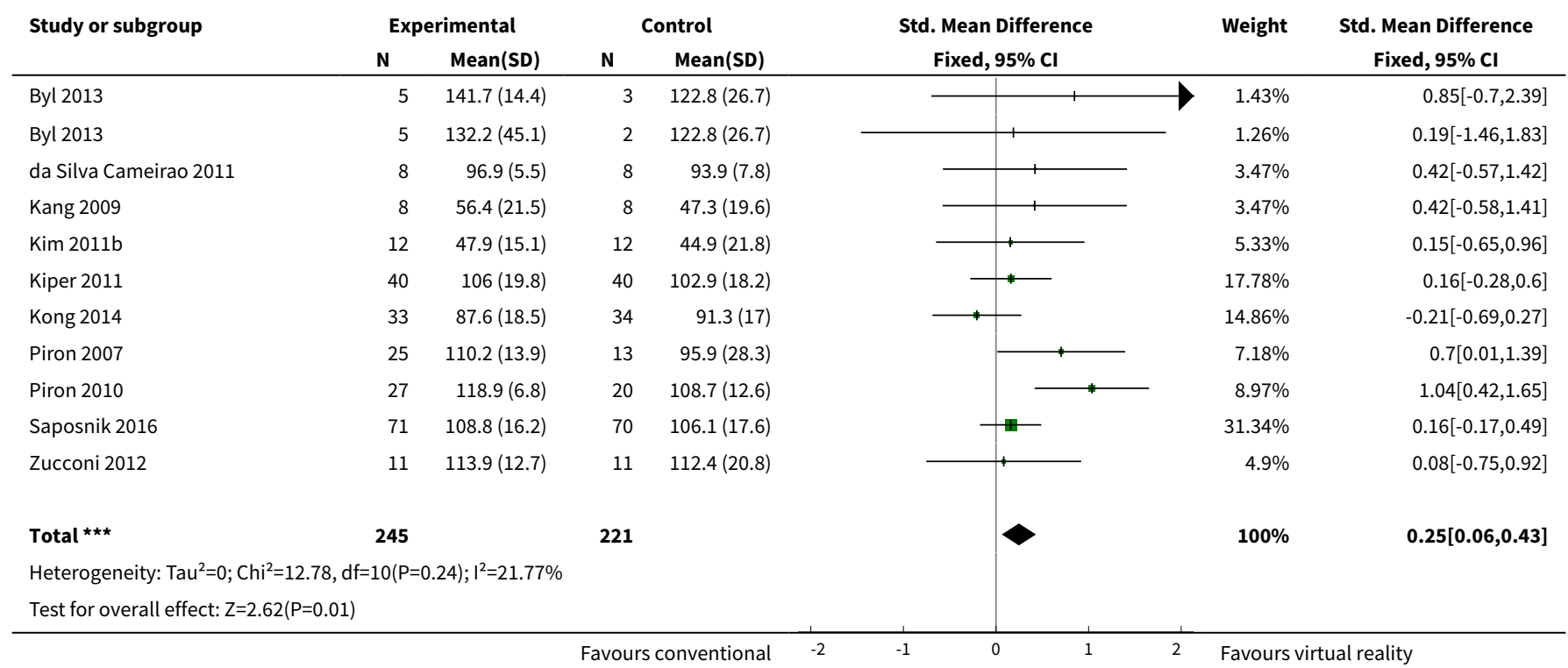

Comparison 10. Additional virtual reality intervention: effect on activity limitation

\begin{tabular}{lllll}
\hline $\begin{array}{l}\text { Outcome or subgroup ti- } \\
\text { tle }\end{array}$ & No. of studies & $\begin{array}{l}\text { No. of partici- } \\
\text { pants }\end{array}$ & Statistical method & Effect size \\
\hline 1 ADL outcome & 8 & 153 & Std. Mean Difference (IV, Fixed, 95\% CI) & $0.44[0.11,0.76]$ \\
\hline
\end{tabular}

Analysis 10.1. Comparison 10 Additional virtual reality intervention: effect on activity limitation, Outcome 1 ADL outcome.

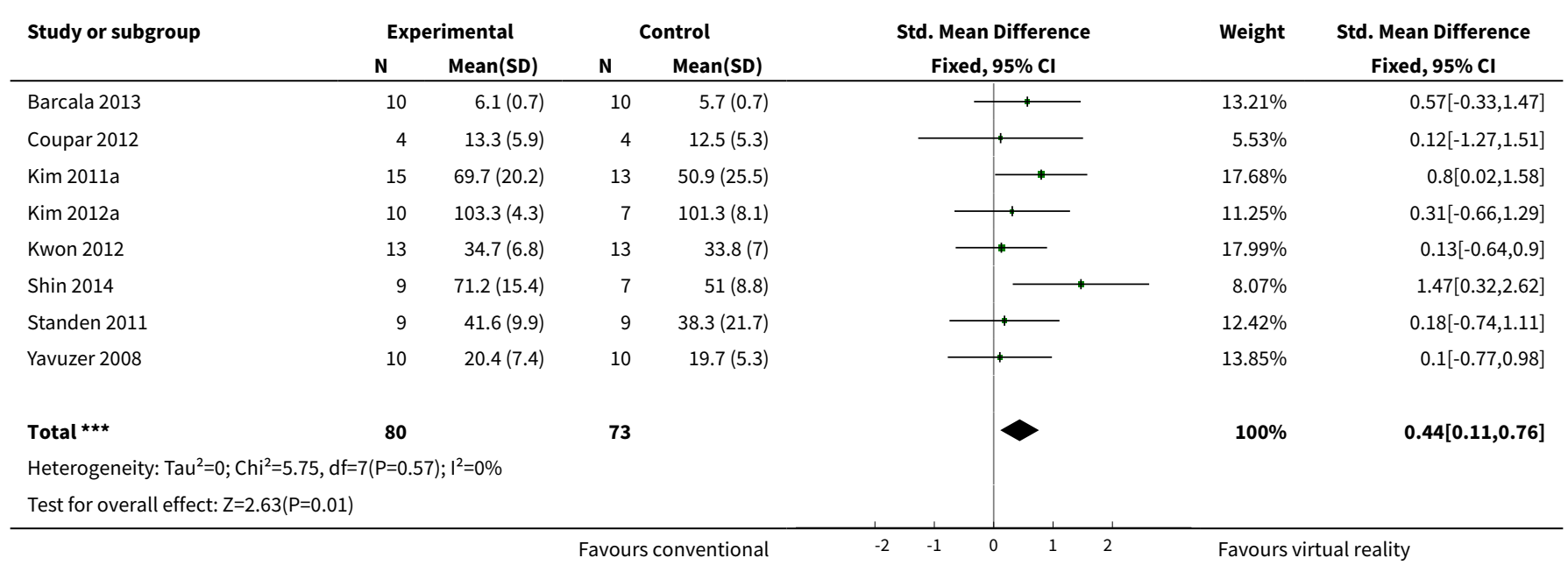




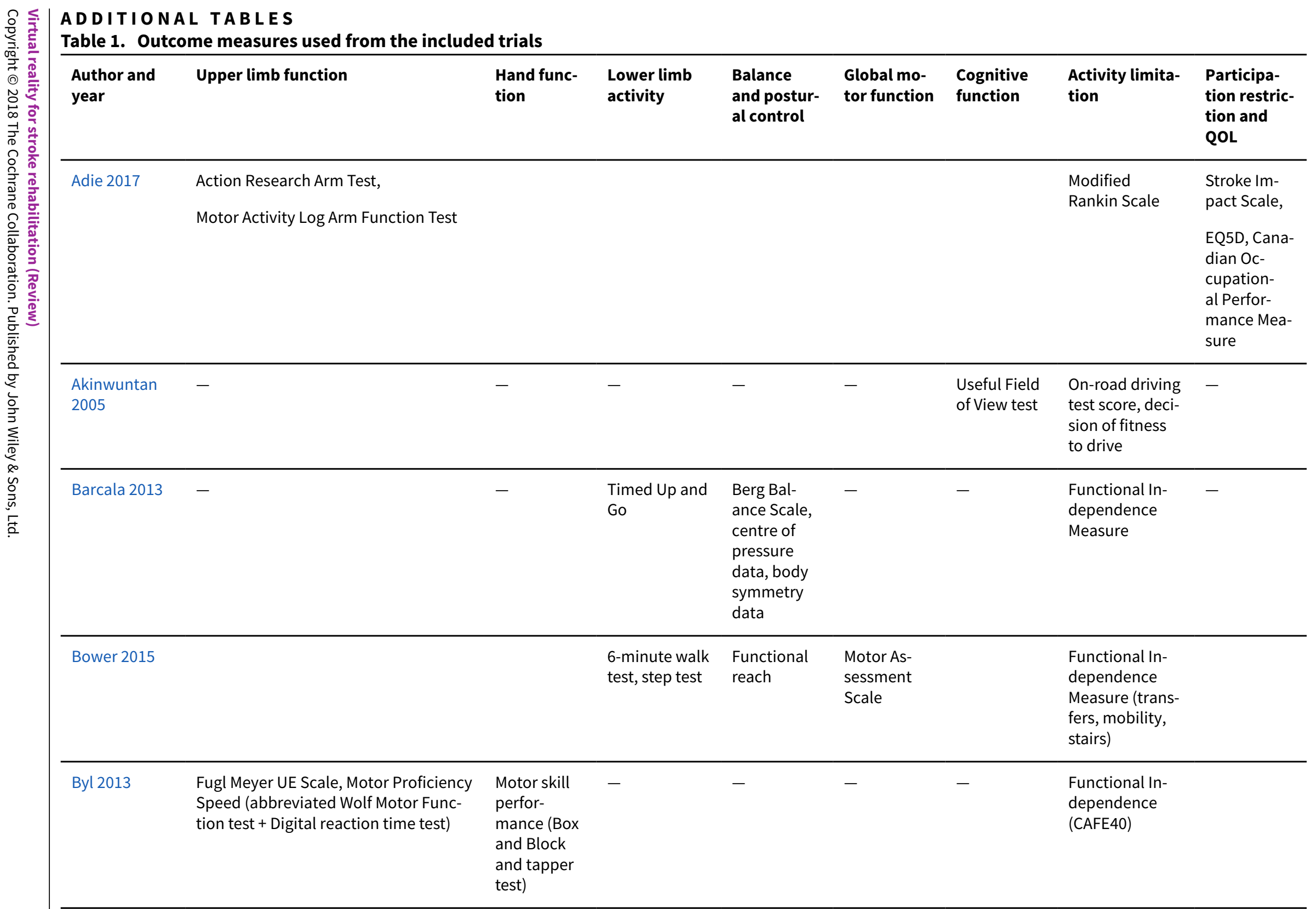




\begin{tabular}{|c|c|c|c|c|c|c|c|c|}
\hline Cho 2012 & Wolf Motor Function Test & - & - & - & - & $\begin{array}{l}\text { Motor Free } \\
\text { Visual Per- } \\
\text { ception Test }\end{array}$ & - & - \\
\hline Chow 2013 & & & $\begin{array}{l}10-\mathrm{m} \text { walk } \\
\text { test }\end{array}$ & $\begin{array}{l}\text { Berg Bal- } \\
\text { ance Scale }\end{array}$ & & & $\begin{array}{l}\text { Modified } \\
\text { Barthel Index }\end{array}$ & \\
\hline Crosbie 2008 & $\begin{array}{l}\text { Action Research Arm Test, Upper Limb } \\
\text { Motricity Index }\end{array}$ & - & - & - & - & - & - & - \\
\hline $\begin{array}{l}\text { da Silva } \\
\text { Ribeiro } 2015\end{array}$ & Fugl Meyer & & & $\begin{array}{l}\text { Dynamic } \\
\text { Gait Index }\end{array}$ & & & & SF36 \\
\hline $\begin{array}{l}\text { da Silva } \\
\text { Cameirao } \\
2011\end{array}$ & $\begin{array}{l}\text { Fugl Meyer UE, Chedoke Arm and } \\
\text { Hand Inventory }\end{array}$ & - & - & - & - & - & Barthel Index & - \\
\hline Fan 2014 & Jebsen Taylor Hand Function Test & & & & & & & $\begin{array}{l}\text { Stroke Im- } \\
\text { pact Scale }\end{array}$ \\
\hline Galvao 2015 & Fugl Meyer, Motor Activity Log & & & & & & & \\
\hline Givon 2016 & Action Research Arm Test & $\begin{array}{l}\text { Grip } \\
\text { strength }\end{array}$ & $\begin{array}{l}10-\mathrm{m} \text { walk } \\
\text { test }\end{array}$ & & & & & \\
\hline Han 2013 & & & & $\begin{array}{l}\text { Berg Bal- } \\
\text { ance Scale }\end{array}$ & & & $\begin{array}{l}\text { Modified } \\
\text { Barthel Index }\end{array}$ & \\
\hline $\begin{array}{l}\text { Housman } \\
2009\end{array}$ & $\begin{array}{l}\text { Fugl Meyer UE Scale, Rancho Function- } \\
\text { al Test, } \\
\text { Motor Activity Log (amount of use and } \\
\text { quality of movement) }\end{array}$ & $\begin{array}{l}\text { Grip } \\
\text { strength } \\
(\mathrm{kg})\end{array}$ & - & - & - & - & - & - \\
\hline Hung 2014 & & & $\begin{array}{l}\text { Timed Up and } \\
\text { Go Test }\end{array}$ & $\begin{array}{l}\text { Forward } \\
\text { Reach Test }\end{array}$ & & & & $\begin{array}{l}\text { Falls Effica- } \\
\text { cy Scale In- } \\
\text { ternational }\end{array}$ \\
\hline Jaffe 2004 & - & - & $\begin{array}{l}\text { 6-m walk test, } \\
\text { Obstacle Test, } \\
6 \text {-minute walk } \\
\text { test }\end{array}$ & $\begin{array}{l}\text { Customised } \\
\text { balance test } \\
\text { designed } \\
\text { by the re- } \\
\text { searchers }\end{array}$ & - & - & - & - \\
\hline
\end{tabular}




\begin{tabular}{|c|c|c|c|c|c|c|c|c|}
\hline Jang 2005 & $\begin{array}{l}\text { Fugl Meyer UE Scale, Manual Function } \\
\text { Test, Motor Activity Log (amount of use } \\
\text { and quality of movement) }\end{array}$ & $\begin{array}{l}\text { Box and } \\
\text { Block Test }\end{array}$ & - & - & - & - & - & \\
\hline Jannink 2008 & - & - & - & - & - & - & - & - \\
\hline Jung 2012 & - & - & $\begin{array}{l}\text { Timed Up and } \\
\text { Go }\end{array}$ & - & - & - & - & - \\
\hline Kang 2009 & - & - & - & - & - & $\begin{array}{l}\text { Mini Mental } \\
\text { State Exami- } \\
\text { nation }\end{array}$ & $\begin{array}{l}\text { Modified } \\
\text { Barthel Index }\end{array}$ & - \\
\hline Kim 2009 & - & - & $\begin{array}{l}\text { 10-m walk } \\
\text { test, GAIT- } \\
\text { RITE gait } \\
\text { analysis sys- } \\
\text { tem }\end{array}$ & $\begin{array}{l}\text { Berg Bal- } \\
\text { ance Scale, } \\
\text { balance per- } \\
\text { formance } \\
\text { monitor }\end{array}$ & $\begin{array}{l}\text { Modified } \\
\text { Motor As- } \\
\text { sessment } \\
\text { Scale }\end{array}$ & - & - & - \\
\hline Kim 2011a & Motricity Index & - & $\begin{array}{l}\text { Motricity In- } \\
\text { dex }\end{array}$ & - & - & $\begin{array}{l}\text { Comput- } \\
\text { erised neu- } \\
\text { ropsycho- } \\
\text { logical test } \\
\text { and Tower } \\
\text { of London } \\
\text { test }\end{array}$ & $\begin{array}{l}\text { Korean Modi- } \\
\text { fied Barthel In- } \\
\text { dex }\end{array}$ & - \\
\hline Kim 2011b & - & - & - & - & - & $\begin{array}{l}\text { Measures of } \\
\text { spatial ne- } \\
\text { glect (star } \\
\text { cancella- } \\
\text { tion, line } \\
\text { bisection } \\
\text { test, Cather- } \\
\text { ine Bergego } \\
\text { Scale) }\end{array}$ & $\begin{array}{l}\text { Korean Modi- } \\
\text { fied Barthel In- } \\
\text { dex }\end{array}$ & - \\
\hline Kim 2012a & - & - & - & $\begin{array}{l}\text { Postural as- } \\
\text { sessment } \\
\text { scale }\end{array}$ & $\begin{array}{l}\text { Modified } \\
\text { Motor As- } \\
\text { sessment } \\
\text { Scale }\end{array}$ & - & $\begin{array}{l}\text { Functional In- } \\
\text { dependence } \\
\text { Measure }\end{array}$ & - \\
\hline
\end{tabular}




\begin{tabular}{|c|c|c|c|c|c|c|c|c|}
\hline Kiper 2011 & Fugl Meyer UE & - & - & - & - & - & $\begin{array}{l}\text { Functional In- } \\
\text { dependence } \\
\text { Measure }\end{array}$ & - \\
\hline $\begin{array}{l}\text { Klam- } \\
\text { roth-Margans- } \\
\text { ka } 2014\end{array}$ & $\begin{array}{l}\text { Fugl Meyer UE, Wolf Motor Function } \\
\text { Test, Motor Activity Log (quality of } \\
\text { movement) }\end{array}$ & - & - & - & - & - & - & $\begin{array}{l}\text { Stroke Im- } \\
\text { pact Scale, } \\
\text { Goal attain- } \\
\text { ment scale }\end{array}$ \\
\hline Ko 2015 & & & $\begin{array}{l}\text { Timed Up and } \\
\text { Go Test }\end{array}$ & $\begin{array}{l}\text { Berg Bal- } \\
\text { ance Scale }\end{array}$ & & & & \\
\hline Kong 2014 & Fugl Meyer, Action Research Arm Test & & & & & & $\begin{array}{l}\text { Functional In- } \\
\text { dependence } \\
\text { Measure }\end{array}$ & $\begin{array}{l}\text { Stroke Im- } \\
\text { pact Scale }\end{array}$ \\
\hline Kwon 2012 & Fugl Meyer UE, Manual Function Test & - & - & - & - & - & $\begin{array}{l}\text { Korean Modi- } \\
\text { fied Barthel In- } \\
\text { dex }\end{array}$ & - \\
\hline Lam 2006 & - & - & - & - & - & - & - & - \\
\hline Lee 2013 & & & & $\begin{array}{l}\text { Functional } \\
\text { Reach Test }\end{array}$ & & & & \\
\hline Lee $2014 a$ & & & $\begin{array}{l}\text { Timed Up and } \\
\text { Go Test }\end{array}$ & $\begin{array}{l}\text { Berg Bal- } \\
\text { ance Scale }\end{array}$ & & & & \\
\hline Lee 2015a & & & & $\begin{array}{l}\text { Functional } \\
\text { Reach Test }\end{array}$ & & & & \\
\hline Lee $2015 b$ & & & & & & & & \\
\hline Levin 2012 & $\begin{array}{l}\text { Fugl Meyer UE Scale, Reach Perfor- } \\
\text { mance Scale for Stroke, Box and } \\
\text { Blocks Test, Wolf Motor Function Test, } \\
\text { Motor Activity Log }\end{array}$ & & & & & & & \\
\hline Linder 2015 & & & & & & & & $\begin{array}{l}\text { Stroke Im- } \\
\text { pact Scale }\end{array}$ \\
\hline Llorens 2015 & & & $\begin{array}{l}\text { Tinetti Perfor- } \\
\text { mance Orient- } \\
\text { ed Mobility }\end{array}$ & $\begin{array}{l}\text { Berg Bal- } \\
\text { ance Scale, } \\
\text { Brunel Bal- }\end{array}$ & & & & \\
\hline
\end{tabular}




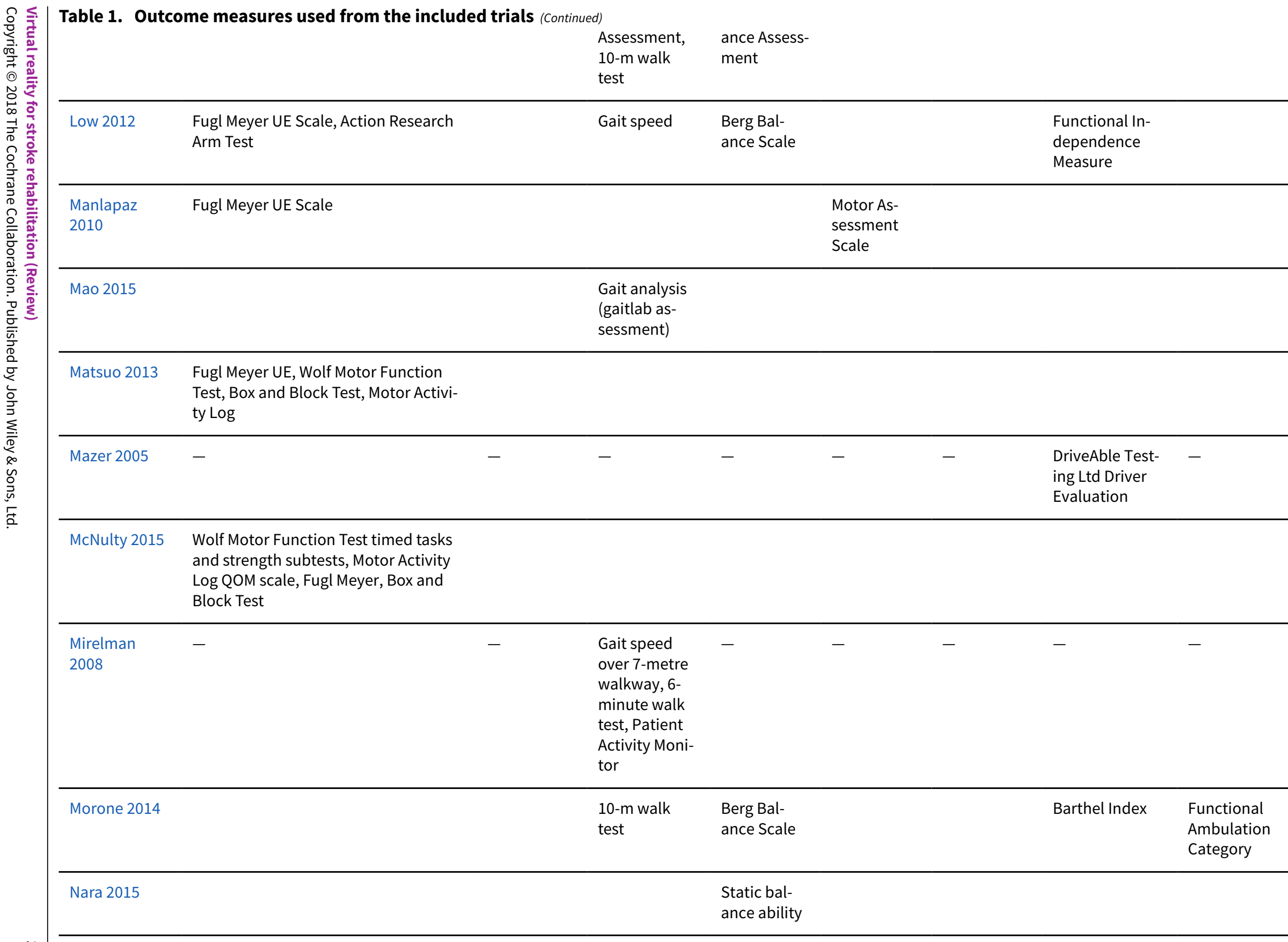




\begin{tabular}{|c|c|c|c|c|c|c|c|c|}
\hline Piron 2007 & Fugl Meyer UE Scale & - & - & - & - & - & $\begin{array}{l}\text { Functional In- } \\
\text { dependence } \\
\text { Measure }\end{array}$ & - \\
\hline Piron 2009 & Fugl Meyer UE Scale, Abilhand Scale & - & - & - & - & - & - & - \\
\hline Piron 2010 & Fugl Meyer UE Scale & - & - & - & - & - & $\begin{array}{l}\text { Functional In- } \\
\text { dependence } \\
\text { Measure }\end{array}$ & - \\
\hline Prange 2015 & $\begin{array}{l}\text { Fugl Meyer UE, Stroke Upper Limb Ca- } \\
\text { pacity Sclae }\end{array}$ & & & & & & & \\
\hline $\begin{array}{l}\text { Rajaratnam } \\
2013\end{array}$ & - & - & $\begin{array}{l}\text { Timed Up and } \\
\text { Go }\end{array}$ & $\begin{array}{l}\text { Berg Bal- } \\
\text { ance Scale, } \\
\text { functional } \\
\text { reach, cen- } \\
\text { tre of pres- } \\
\text { sure }\end{array}$ & - & - & - & - \\
\hline $\begin{array}{l}\text { Reinkensmey- } \\
\text { er } 2012\end{array}$ & $\begin{array}{l}\text { Fugl Meyer UE, Ranchos Functional } \\
\text { Test for UE, Motor Activity Log, Box } \\
\text { and Blocks Test }\end{array}$ & $\begin{array}{l}\text { Grip } \\
\text { strength }\end{array}$ & & & & & & \\
\hline $\begin{array}{l}\text { Saposnik } \\
2010\end{array}$ & Abbreviated Wolf Motor Function Test & $\begin{array}{l}\text { Box and } \\
\text { Block } \\
\text { Test, grip } \\
\text { strength } \\
(\mathrm{kg})\end{array}$ & - & - & - & - & - & $\begin{array}{l}\text { Stroke Im- } \\
\text { pact Scale } \\
\text { (hand func- } \\
\text { tion, com- } \\
\text { posite func- } \\
\text { tion, per- } \\
\text { ception of } \\
\text { recovery) }\end{array}$ \\
\hline $\begin{array}{l}\text { Saposnik } \\
2016\end{array}$ & $\begin{array}{l}\text { Abbreviated Wolf Motor Function Test, } \\
\text { Box and Block Test }\end{array}$ & $\begin{array}{l}\text { Grip } \\
\text { strength }\end{array}$ & & & & & $\begin{array}{l}\text { Function- } \\
\text { al Indepen- } \\
\text { dence Mea- } \\
\text { sure, Barthel In- } \\
\text { dex, Modified } \\
\text { Rankin Scale }\end{array}$ & $\begin{array}{l}\text { Stroke Im- } \\
\text { pact Scale }\end{array}$ \\
\hline Shin 2014 & Fugl Meyer UE & - & - & - & - & - & $\begin{array}{l}\text { Modified } \\
\text { Barthel Index }\end{array}$ & - \\
\hline
\end{tabular}




\begin{tabular}{|c|c|c|c|c|c|c|c|c|}
\hline Shin 2015 & Fugl Meyer UE & & & & & & & SF36 \\
\hline Sin 2013 & Fugl Meyer UE, Box and Block Test & & - & - & - & - & - & - \\
\hline Song 2015 & & & $\begin{array}{l}\text { Timed Up and } \\
\text { Go Test, 10- } \\
\text { minute walk } \\
\text { test }\end{array}$ & $\begin{array}{l}\text { Balance } \\
\text { (Biofeed- } \\
\text { back sys- } \\
\text { tem) }\end{array}$ & & & & \\
\hline Standen 2011 & $\begin{array}{l}\text { Wolf Motor Function Test, Motor Activi- } \\
\text { ty Log, Nine Hole Peg Test }\end{array}$ & & - & - & - & - & $\begin{array}{l}\text { Nottingham Ex- } \\
\text { tended Activi- } \\
\text { ties of Daily Liv- } \\
\text { ing Scale }\end{array}$ & \\
\hline $\begin{array}{l}\text { Subramanian } \\
2013\end{array}$ & $\begin{array}{l}\text { Fugl Meyer UE, Wolf Motor Function } \\
\text { test, Reaching performance scale for } \\
\text { stroke, Motor Activity Log }\end{array}$ & - & - & - & - & - & - & \\
\hline Sucar 2009 & $\begin{array}{l}\text { Fugl Meyer UE Scale, Upper Limb } \\
\text { Motricity Index }\end{array}$ & - & - & - & - & - & - & - \\
\hline Thielbar 2014 & $\begin{array}{l}\text { Action Research Arm Test, Jebsen Tay- } \\
\text { lor Hand Function Test, Fugl Meyer UE }\end{array}$ & $\begin{array}{l}\text { Grip } \\
\text { strength }\end{array}$ & & & & & & \\
\hline Ucar 2014 & & & $\begin{array}{l}\text { Timed walk- } \\
\text { ing speed } \\
\text { test, Timed } \\
\text { Up and Go }\end{array}$ & & & $\begin{array}{l}\text { Mini Mental } \\
\text { State Exami- } \\
\text { nation }\end{array}$ & & $\begin{array}{l}\text { Functional } \\
\text { Ambulation } \\
\text { Category }\end{array}$ \\
\hline Xiang 2014 & & & $\begin{array}{l}\text { 10-m walking } \\
\text { speed, Fugl } \\
\text { Meyer (LE) }\end{array}$ & $\begin{array}{l}\text { Brunel Bal- } \\
\text { ance Assess- } \\
\text { ment }\end{array}$ & & & & \\
\hline Yang 2008 & - & - & $\begin{array}{l}\text { Walking } \\
\text { speed, Com- } \\
\text { munity Walk } \\
\text { Test }\end{array}$ & - & - & - & - & $\begin{array}{l}\text { Walking } \\
\text { Ability Ques- } \\
\text { tionnaire, } \\
\text { Activities } \\
\text { Specific Bal- } \\
\text { ance Confi- } \\
\text { dence Scale }\end{array}$ \\
\hline
\end{tabular}




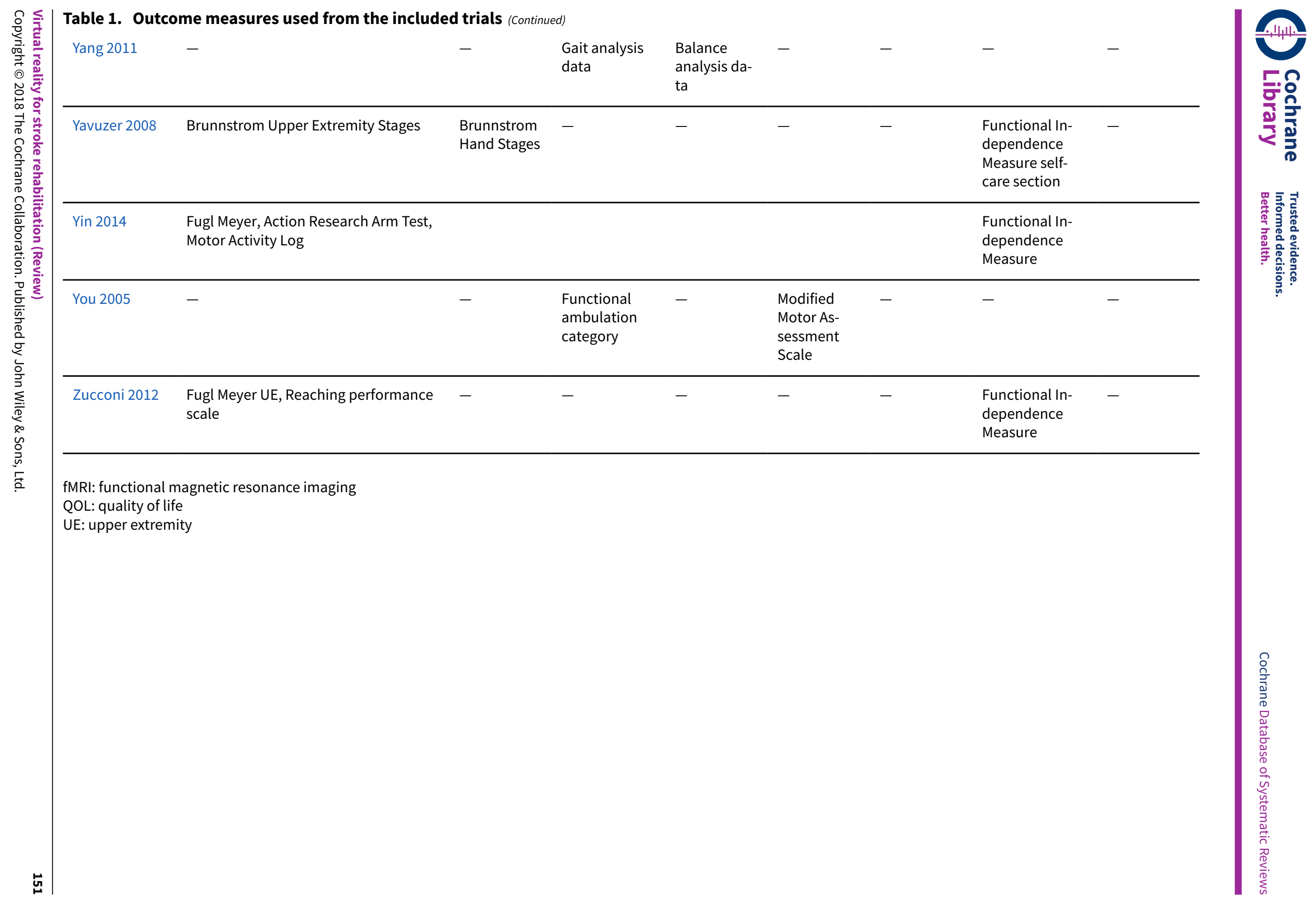




\section{APPENDICES}

\section{Appendix 1. CENTRAL search strategy}

\#1. [mh ^"cerebrovascular disorders"] or [mh "basal ganglia cerebrovascular disease"] or [mh "brain ischemia"] or [mh "carotid artery diseases"] or [mh "intracranial arterial diseases"] or [mh "intracranial arteriovenous malformations"] or [mh "intracranial embolism and thrombosis"] or [mh "intracranial hemorrhages"] or [mh^^stroke] or [mh "brain infarction"]

\#2. [mh^"brain injuries"] or [mh^^"brain injury, chronic"]

\#3. (stroke or cva or poststroke or "post-stroke" or cerebrovasc* or cerebral next vasc $\left.{ }^{\star}\right): t i, a b$

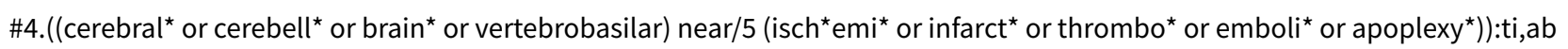

\#5. ((brain* or cerebral* or subarachnoid) near/5 (haemorrhage* or hemorrhage* or haematoma* or hematoma* or bleed $\left.\left.{ }^{\star}\right)\right):$ ti,ab $^{\star}$

\#6. [mh ^hemiplegia] or [mh paresis]

\#7. (hemipleg ${ }^{\star}$ or hemipar $^{\star}$ or paresis or paretic or brain next injur ${ }^{\star}$ :ti,ab

\#8. [mh^"gait disorders, neurologic"]

\#9. \#1 or \#2 or \#3 or \#4 or \#5 or \#6 or \#7 or \#8

\#10. [mh^"user-computer interface"]

\#11. [mh ^computers] or [mh microcomputers] or [mh^"computer systems"] or [mh ^software]

\#12. [mh^"computer simulation"] or [mh^"computer-assisted instruction"] or [mh ^"therapy, computer-assisted"]

\#13. [mh^"computer graphics"] or [mh ^"video games"] or [mh touch [mj]]

\#14. (Virtual next reality* or "virtual-reality" or VR):ti,ab

\#15. (virtual near/3 (environment* or object* or world* or treatment* or system or program* or rehabilitation* or therap* or driving or drive* or car or tunnel or vehicle)):ti,ab

\#16. (computer near/3 (simulat ${ }^{\star}$ or graphic* or game* or interact $\left.\left.{ }^{\star}\right)\right):$ ti,ab

\#17. (computer next assist* next (therap* or treat*)):ti,ab

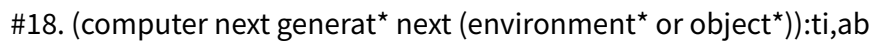

\#19. (video game* or video next gaming or gaming next console* or interactive next game or interactive next gaming or Nintendo next Wii or gaming next program*):ti,ab

\#20. (haptics or haptic next device*):ti,ab

\#21. (simulat ${ }^{\star}$ near/3 (environment ${ }^{\star}$ or object $^{\star}$ or event $^{\star}$ or events or driving or drive* or car or tunnel or vehicle)):ti,ab

\#22. (user next computer next interface):ti,ab

\#23. \#10 or \#11 or \#12 or \#13 or \#14 or \#15 or \#16 or \#17 or \#18 or \#19 or \#20 or \#21 or \#22

$\# 24$. $\# 9$ and \#23

\section{Appendix 2. MEDLINE search strategy}

We used the following search strategy for MEDLINE (Ovid) and adapted it to search the other databases.

1. cerebrovascular disorders/ or exp basal ganglia cerebrovascular disease/ or exp brain ischemia/ or exp carotid artery diseases/ or exp intracranial arterial diseases/ or exp intracranial arteriovenous malformations/ or exp "intracranial embolism and thrombosis"/ or exp intracranial hemorrhages/ or stroke/ or exp brain infarction/

2. brain injuries/ or brain injury, chronic/

3. (stroke\$ or cva or poststroke or post-stroke or cerebrovasc\$ or cerebral vascular).tw. 
4. ((cerebral or cerebellar or brain\$ or vertebrobasilar) adj5 (infarct\$ or isch?emi\$ or thrombo or emboli\$ or apoplexy)).tw.

5. ((cerebral or brain or subarachnoid) adj5 (haemorrhage or hemorrhage or haematoma or hematoma or bleed\$)).tw.

6. exp hemiplegia/ or exp paresis/

7. (hempar\$ or hemipleg\$ or paresis or paretic or brain injur\$).tw.

8. Gait Disorders, Neurologic/

9.1 or 2 or 3 or 4 or 5 or 6 or 7 or 8

10. user-computer interface/

11. computers/ or exp microcomputers/ or computer systems/ or software/

12. computer simulation/ or computer-assisted instruction/ or therapy, computer-assisted/

13. computer graphics/ or video games/ or *touch/

14. (virtual reality\$ or virtual-reality\$ or VR).tw.

15. (virtual adj3 (environment\$ or object\$ or world\$ or treatment\$ or system $\$$ or program $\$$ or rehabilitation\$ or therap\$ or driving or drive $\$$ or car or tunnel or vehicle)).tw.

16. (computer adj3 (simulat\$ or graphic\$ or game\$ or interact\$)).tw.

17. (computer adj1 assist\$ adj1 (therap\$ or treat\$)).tw.

18. (computer adj1 generat\$ adj1 (environment\$ or object\$)).tw.

19. (video game\$ or video gaming or gaming console\$ or interactive game or interactive gaming or Nintendo Wii or gaming program\$).tw.

20. (haptics or haptic device\$).tw.

21. (simulat\$ adj3 (environment\$ or object\$ or event $\$ 1$ or driving or drive $\$$ or car or tunnel or vehicle)).tw.

22. (user adj1 computer adj1 interface).tw.

23. or/10-22

24. Randomized Controlled Trials as Topic/

25. random allocation/

26. Controlled Clinical Trials as Topic/

27. control groups/

28. clinical trials as topic/

29. double-blind method/

30. single-blind method/

31. Placebos/

32. placebo effect/

33. cross-over studies/

34. Research Design/

35. randomized controlled trial.pt.

36. controlled clinical trial.pt.

37. clinical trial.pt. 
38. (random\$ or RCT or RCTs).tw.

39. (controlled adj5 (trial\$ or stud\$)).tw.

40. (clinical\$ adj5 trial\$).tw.

41. ((control or treatment or experiment\$ or intervention) adj5 (group\$ or subject\$ or patient\$)).tw.

42. (quasi-random\$ or quasi random\$ or pseudo-random $\$$ or pseudo random\$).tw.

43. ((control or experiment\$ or conservative) adj5 (treatment or therapy or procedure or manage\$)).tw.

44. ((singl\$ or doubl\$ or tripl\$ or trebl\$) adj5 (blind\$ or mask\$)).tw.

45. (cross-over or cross over or crossover).tw.

46. (placebo\$ or sham).tw.

47. trial.ti.

48. (assign\$ or allocat\$).tw.

49. or $/ 24-48$

50.9 and 23 and 49

51. limit 50 to ed $=20100301-20170401$

\section{Appendix 3. Embase search strategy}

1. cerebrovascular disease/ or exp basal ganglion hemorrhage/ or exp brain hematoma/ or exp brain hemorrhage/ or exp brain infarction/ or exp brain ischemia/ or exp carotid artery disease/ or cerebral artery disease/ or exp cerebrovascular accident/ or exp cerebrovascular malformation/ or exp intracranial aneurysm/ or exp occlusive cerebrovascular disease/ or stroke/ or stroke unit/ or stroke patient/

2. brain injury/ or acquired brain injury/

3. (stroke\$ or cva or poststroke or post-stroke or cerebrovasc\$ or cerebral vascular).tw.

4. ((cerebral or cerebellar or brain\$ or vertebrobasilar) adj5 (infarct\$ or isch?emi\$ or thrombo\$ or emboli\$ or apoplexy)).tw.

5. ((cerebral or brain or subarachnoid) adj5 (haemorrhage or hemorrhage or haematoma or hematoma or bleed\$)).tw.

6. hemiparesis/ or hemiplegia/ or paresis/

7. (hempar\$ or hemipleg\$ or paresis or paretic or brain injur\$).tw.

8. exp neurologic gait disorder/

9. 1 or 2 or 3 or 4 or 5 or 6 or 7 or 8

10. virtual reality/ or computer interface/ or exp computer/ or computer program/ or computer simulation/ or computer assisted therapy/ or computer graphics/ or *touch/

11. (virtual reality\$ or virtual-reality\$ or VR).tw.

12. (virtual adj3 (environment $\$$ or object $\$$ or world $\$$ or treatment $\$$ or system $\$$ or program $\$$ or rehabilitation $\$$ or therap $\$$ or driving or drive $\$$ or car or tunnel or vehicle)).tw.

13. (computer adj3 (simulat\$ or graphic\$ or game\$ or interact\$)).tw.

14. (computer adj1 assist adj1 (therap\$ or treat\$)).tw.

15. (computer adj1 generat\$ adj1 (environment\$ or object\$)).tw.

16. (video game\$ or video gaming or gaming console\$ or interactive game or interactive gaming or Nintendo Wii or gaming program\$).tw.

17. (haptics or haptic device\$).tw.

18. (simulat\$ adj3 (environment\$ or object\$ or event $\$ 1$ or driving or drive $\$$ or car or tunnel or vehicle)).tw. 
19. (user adj1 computer adj1 interface).tw.

20. or/10-19

21. Randomized Controlled Trial/

22. Randomization/

23. Controlled Study/

24. control group/

25. clinical trial/

26. Crossover Procedure/

27. Double Blind Procedure/

28. Single Blind Procedure/ or triple blind procedure/

29. placebo/

30. "types of study"/

31. (random\$ or RCT or RCTs).tw.

32. (controlled adj5 (trial\$ or stud\$)).tw.

33. (clinical\$ adj5 trial\$).tw.

34. ((control or treatment or experiment\$ or intervention) adj5 (group\$ or subject\$ or patient\$)).tw.

35. (quasi-random\$ or quasi random\$ or pseudo-random $\$$ or pseudo random\$).tw.

36. ((control or experiment\$ or conservative) adj5 (treatment or therapy or procedure or manage\$)).tw.

37. ((singl\$ or doubl\$ or tripl\$ or trebl\$) adj5 (blind\$ or mask\$)).tw.

38. (cross-over or cross over or crossover).tw.

39. placebo\$ or sham).tw.

40. trial.ti.

41. (assign\$ or allocat\$).tw.

42. or/21-41

43. 9 and 20 and 42

44. limit 43 to $D D=20131026-20170401$

\section{Appendix 4. AMED search strategy}

1. cerebrovascular disorders/ or cerebral hemorrhage/ or cerebral infarction/ or cerebral ischemia/ or cerebrovascular accident/ or stroke/ or brain injuries/

2. (stroke\$ or cva or poststroke or post-stroke or cerebrovasc\$ or cerebral vascular).tw.

3. ((cerebral or cerebellar or brain\$ or vertebrobasilar) adj5 (infarct\$ or isch?emi\$ or thrombo $\$$ or emboli\$ or apoplexy)).tw.

4. ((cerebral or brain or subarachnoid) adj5 (haemorrhage or hemorrhage or haematoma or hematoma or bleed\$)).tw.

5. hemiplegia/ or gait disorders/

6. (hempar\$ or hemipleg\$ or paresis or paretic or brain injur\$).tw.

7. 1 or 2 or 3 or 4 or 5 or 6 
8. virtual reality/or computer systems/or exp computers/ or internet/ or software/ or computer graphics/ or computer assisted instruction/ or computer simulation/ or therapy computer assisted/ or "play and playthings"/

9. (virtual reality\$ or virtual-reality\$ or VR).tw.

10. (virtual adj3 (environment\$ or object\$ or world\$ or treatment\$ or system\$ or program\$ or rehabilitation\$ or therap\$ or driving or drive \$ or car or tunnel or vehicle)).tw.

11. (computer adj3 (simulat\$ or graphic\$ or game\$ or interact\$)).tw.

12. (computer adj1 assist\$ adj1 (therap\$ or treat\$)).tw.

13. (computer adj1 generat\$ adj1 (environment\$ or object\$)).tw.

14. (video game\$ or video gaming or gaming console\$ or interactive game or interactive gaming or Nintendo Wii or gaming program\$).tw.

15. (haptics or haptic device\$).tw.

16. (simulat\$ adj3 (environment\$ or object\$ or event $\$ 1$ or driving or drive $\$$ or car or tunnel or vehicle)).tw.

17. (user adj1 computer adj1 interface).tw.

18. or/8-17

19. 7 and 18

20. limit 19 to UP=201310-201704

\section{Appendix 5. CINAHL search strategy}

S55 S54 and EM 201310-

S54 -S34 AND S53

S53 -S35 OR S36 OR S37 OR S38 OR S39 OR S40 OR S41 OR S42 OR S43 OR S46 OR S47 OR S50 OR S51 OR S52

S52 -TI trial OR ( TI (RCT or RCTs) OR AB (RCT or RCTs) )

S51 - TI ( counterbalance* or multiple baseline* or ABAB design ) or AB ( counterbalance* or multiple baseline* or ABAB design )

S50 -S48 and S49

S49 -TI trial ${ }^{*}$ or AB trial ${ }^{*}$

S48 - $\mathrm{TI}$ ( clin* or intervention* or compar* or experiment* or preventive or therapeutic ) or AB ( clin* or intervention* or compar ${ }^{\star}$ or experiment* or preventive or therapeutic)

S47 - $\mathrm{TI}$ ( crossover or cross-over or placebo* or control* or factorial or sham ) or AB ( crossover or cross-over or placebo* or control* or factorial or sham )

S46 -S44 and S45

S45 -TI ( blind* or mask ${ }^{\star}$ ) or AB ( blind* or mask ${ }^{\star}$ )

S44 -TI ( singl* or doubl* or tripl* or trebl ${ }^{\star}$ ) or AB ( singl ${ }^{\star}$ or doubl* or tripl ${ }^{\star}$ or trebl* )

S43 -TI random* or AB random*

S42 -(MH "Community Trials") or (MH "Experimental Studies") or (MH "One-Shot Case Study") or (MH "Pretest-Posttest Design+") or (MH "Solomon Four-Group Design") or (MH "Static Group Comparison") or (MH "Study Design")

S41 -(MH "Clinical Research") or (MH "Clinical Nursing Research")

S40 -(MH "Placebo Effect") or (MH "Placebos") or (MH "Meta Analysis")

S39 -(MH "Factorial Design") or (MH "Quasi-Experimental Studies") or (MH "Nonrandomized Trials")

S38 -(MH "Control (Research)") or (MH "Control Group") 
S37 -(MH "Crossover Design") or (MH "Clinical Trials+") or (MH "Comparative Studies")

S36 -(MH "Random Assignment") or (MH "Random Sample+")

S35 -PT randomized controlled trial or clinical trial

S34 -S15 AND S33

S33 -S16 OR S17 OR S18 OR S19 OR S20 OR S21 OR S22 OR S23 OR S24 OR S25 OR S26 OR S27 OR S28 OR S29 OR S30 OR S31 OR S32

S32 -TI (user N2 computer N2 interface) or AB (user N2 computer N2 interface)

S31 - TI (simulat* N3 (environment* or object* or event or events or driving or drive* or car or tunnel or vehicle)) or AB (simulat* N3

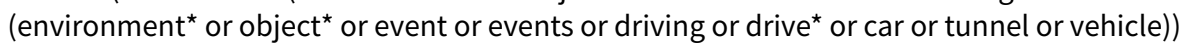

S30 -TI (haptics or haptic device*) or AB (haptics or haptic device*)

S29 -TI (video game* or video gaming or gaming console* or interactive game or interactive gaming or Nintendo Wii or gaming program ${ }^{\star}$ ) or $\mathrm{AB}$ (video game* or video gaming or gaming console* or interactive game or interactive gaming or Nintendo Wii or gaming program ${ }^{\star}$ )

S28 -TI (computer generat ${ }^{\star}$ N3 (environment* or object $\left.\left.{ }^{\star}\right)\right)$ or AB (computer generat* N3 (environment ${ }^{\star}$ or object $\left.^{\star}\right)$ )

S27 - TI (computer assist* N3 (therap* or treat $\left.{ }^{\star}\right)$ ) or AB (computer assist* N3 (therap* or treat*))

S26 -TI (computer N3 (simulat* or graphic ${ }^{\star}$ or game* or interact*)) or AB (computer N3 (simulat* or graphic* or game* or interact*))

S25-TI (virtual N3 (environment* or object* or world* or treatment* or system* or program* or rehabilitation* or therap* or driving or drive* or car or tunnel or vehicle)) or AB (virtual N3 (environment* or object $^{\star}$ or world ${ }^{\star}$ or treatment ${ }^{\star}$ or system ${ }^{\star}$ or program $^{\star}$ or rehabilitation $^{\star}$ or therap* or driving or drive* or car or tunnel or vehicle))

S24 -TI ( virtual reality* or virtual-reality* or VR ) OR AB ( virtual reality* or virtual-reality* or VR )

S23 -(MM "Touch")

S22 -(MH "Video Games")

S21 -(MH "Computer Graphics")

S20 -(MH "Microcomputers+")

S19 -(MH "Computer Systems") OR (MH "User-Computer Interface+") OR (MH "Software+")

S18 -(MH "Computer Assisted Instruction")

S17 -(MH "Therapy, Computer Assisted")

S16 -(MH "Computer Simulation") OR (MH "Virtual Reality") OR (MH "Computing Methodologies") OR (MH "Computers and Computerization")

\section{S15 -S1 OR S2 OR S3 OR S6 OR S9 OR S10 OR S11 OR S12 OR S13 OR S14}

S14 -TI brain injur* OR AB brain inju*

S13 -(MH "Brain Injuries")

S12 -(MH "Gait Disorders, Neurologic+")

S11 -TI ( hemipleg* or hemipar* or paresis or paretic ) or AB ( hemipleg* or hemipar* or paresis or paretic)

S10 -(MH "Hemiplegia")

S9-S7 and S8

S8 - TI ( haemorrhage* or hemorrhage* or haematoma* or hematoma* or bleed ${ }^{\star}$ ) or AB ( haemorrhage* or hemorrhage* or haematoma* or hematoma* or bleed ${ }^{*}$ )

S7 -TI ( brain* or cerebr* or cerebell* or intracerebral or intracranial or subarachnoid ) or AB ( brain ${ }^{\star}$ or cerebr ${ }^{\star}$ or cerebell* or intracerebral or intracranial or subarachnoid) 
S6 - S4 and S5

S5 -TI ( ischemi ${ }^{\star}$ or ischaemi ${ }^{\star}$ or infarct ${ }^{\star}$ or thrombo* or emboli* or occlus ${ }^{\star}$ ) or AB (ischemi ${ }^{\star}$ or ischaemi ${ }^{\star}$ or infarct* or thrombo* or emboli ${ }^{\star}$ or occlus $\left.{ }^{*}\right)$

S4 -TI ( brain* or cerebr ${ }^{\star}$ or cerebell* or intracran* or intracerebral ) or AB ( brain* or cerebr ${ }^{\star}$ or cerebell* or intracran* or intracerebral )

S3 - TI ( stroke or poststroke or post-stroke or cerebrovasc ${ }^{*}$ or brain vasc ${ }^{\star}$ or cerebral vasc or cva or apoplex or SAH ) or AB ( stroke or poststroke or post-stroke or cerebrovasc* or brain vasc* or cerebral vasc or cva or apoplex or SAH )

S2 -(MH "Stroke Patients") OR (MH "Stroke Units")

S1 -(MH "Cerebrovascular Disorders") OR (MH "Basal Ganglia Cerebrovascular Disease+") OR (MH "Carotid Artery Diseases+") OR (MH "Cerebral Ischemia+") OR (MH "Cerebral Vasospasm") OR (MH "Intracranial Arterial Diseases+") OR (MH "Intracranial Embolism and Thrombosis") OR (MH "Intracranial Hemorrhage+") OR (MH "Stroke") OR (MH "Vertebral Artery Dissections")

\section{Appendix 6. PsycINFO search strategy}

1. cerebrovascular disorders/ or cerebral hemorrhage/ or exp cerebral ischemia/ or cerebrovascular accidents/ or subarachnoid hemorrhage/ or brain damage/

2. (stroke\$ or cva or poststroke or post-stroke or cerebrovasc\$ or cerebral vascular).tw.

3. ((cerebral or cerebellar or brain\$ or vertebrobasilar) adj5 (infarct\$ or isch?emi\$ or thrombo or emboli\$ or apoplexy)).tw.

4. ((cerebral or brain or subarachnoid) adj5 (haemorrhage or hemorrhage or haematoma or hematoma or bleed\$)).tw.

5. hemiparesis/ or hemiplegia/

6. (hempar\$ or hemipleg\$ or paresis or paretic or brain injur\$).tw.

7. 1 or 2 or 3 or 4 or 5 or 6

8. virtual reality/ or role playing games/or exp computer assisted instruction/ or computer assisted therapy/or computer simulation/or computer games/ or simulation games/or computers/or microcomputers/or internet/ or computer applications/or computer software/

9. (virtual reality\$ or virtual-reality\$ or VR).tw.

10. (virtual adj3 (environment\$ or object\$ or world\$ or treatment\$ or system\$ or program $\$$ or rehabilitation\$ or therap\$ or driving or drive \$ or car or tunnel or vehicle)).tw.

11. (computer adj3 (simulat\$ or graphic\$ or game\$ or interact\$)).tw.

12. (computer adj1 assist\$ adj1 (therap\$ or treat\$)).tw.

13. (computer adj1 generat\$ adj1 (environment\$ or object\$)).tw.

14. (video game\$ or video gaming or gaming console\$ or interactive game or interactive gaming or Nintendo Wii or gaming program\$).tw.

15. (haptics or haptic device\$).tw.

16. (simulat\$ adj3 (environment\$ or object\$ or event\$1 or driving or drive $\$$ or car or tunnel or vehicle)).tw.

17. (user adj1 computer adj1 interface).tw.

18. or/8-17

19. 7 and 18

20. limit 19 to $y r=2013-C u r r e n t$

\section{Appendix 7. Cochrane 'Risk of bias' table}

The Cochrane tool for assessing risk of bias (Higgins 2011a) 
Describe the method used to generate the allocation sequence in sufficient detail to allow an assessment of whether it should produce comparable groups
Was the allocation sequence adequately generated?

$\square$ Yes $\square$ No $\square$ Unsure

\section{Allocation conceal- ment}

Describe the method used to conceal the allocation sequence in sufficient detail to determine whether intervention allocations could have been foreseen in advance of, or during, enrolment
Was allocation adequately concealed?

$\square$ Yes $\square$ No $\square$ Unsure

\section{Blinding of outcome assessors}

Assessments should be made for each main outcome (or class of outcomes)
Describe all measures used, if any, to blind personnel from knowledge of which intervention a participant received. Provide any information relating to whether the intended blinding was effective
Was knowledge of the allocated intervention adequately prevented during the study?

\section{Outcome assessors \\ $\square$ Yes $\square$ No $\square$ Unsure}

\section{Incomplete outcome data}

Assessments should be made for each main outcome (or class of outcomes).
Describe the completeness of outcome data for each main outcome, including attrition and exclusions from the analysis. State whether attrition and exclusions were reported, the numbers in each intervention group (compared with total randomised participants), reasons for attrition/exclusions where reported, and any re-inclusions in analyses performed by the review authors
Were incomplete outcome data adequately addressed?

$\square$ Yes $\square$ No $\square$ Unsure 
(Continued)
Selective outcome re- porting

Are reports of the study free of suggestion of selective outcome reporting?

$\square$ Yes $\square$ No $\square$ Unsure

WHAT'S NEW

\begin{tabular}{lll}
\hline Date & Event & Description \\
\hline 19 January 2018 & Amended & Two copy-editing errors corrected. \\
\hline
\end{tabular}

\section{H I S T OR Y}

Protocol first published: Issue 2, 2010

Review first published: Issue 9, 2011

\begin{tabular}{|c|c|c|}
\hline Date & Event & Description \\
\hline 31 July 2017 & $\begin{array}{l}\text { New citation required and conclusions } \\
\text { have changed }\end{array}$ & The conclusions of the review have changed. \\
\hline 31 July 2017 & New search has been performed & $\begin{array}{l}\text { We updated the searches to April } 2017 \text {. We have added } 35 \text { new } \\
\text { studies bringing the total number of included studies to } 72 \text {, in- } \\
\text { volving a total of } 2470 \text { participants. We have revised the review } \\
\text { throughout. We re-ran the searches in April } 2017 \text { and have added } \\
\text { new studies to the 'studies awaiting classification' list. }\end{array}$ \\
\hline 27 August 2014 & $\begin{array}{l}\text { New citation required but conclusions } \\
\text { have not changed }\end{array}$ & The conclusions of the review have not changed. \\
\hline 27 August 2014 & New search has been performed & $\begin{array}{l}\text { We updated the searches to November } 2013 \text {. We have added } 18 \\
\text { new studies, bringing the total number of included studies to } 37 \text {, } \\
\text { involving a total of } 1019 \text { participants. We have revised the review } \\
\text { throughout. }\end{array}$ \\
\hline
\end{tabular}

\section{CONTRIBUTIONS OF AUTHORS}

Kate Laver is the guarantor of the review. She was involved in conceiving, designing, and co-ordinating the review; designing the search strategies; undertaking the searches; screening the search results; organising retrieval of papers; screening retrieved papers against the inclusion criteria; appraising the quality of the papers; extracting data from the papers; writing to study authors for additional information; managing and entering data into Review Manager 5; analysing and interpreting the data; and writing the review.

Belinda Lange was involved in screening the search results; organising retrieval of papers; screening retrieved papers against the inclusion criteria; analysing and interpreting the data; and writing the review.

Stacey George was involved in conceiving and designing the review; extracting data; analysing and interpreting the data; and writing the review.

Judith Deutsch was involved in designing the review; screening retrieved papers against inclusion criteria; extracting data; appraising the quality of papers; analysing and interpreting the data; and writing the review. 
Gustavo Saposnik was involved in extracting data; appraising the quality of papers; analysing and interpreting the data; and writing the review.

Maria Crotty was involved in conceiving and designing the review; extracting data; appraising the quality of papers; analysing and interpreting the data; and writing the review.

\section{DECLARATIONS OF INTEREST}

Kate Laver: none known.

Belinda Lange: none known.

Stacey George: none known.

Judith Deutsch conducts research on virtual reality for stroke rehabilitation. This research is funded by various sources and presented at scientific and professional meetings. She is co-owner of a company that develops virtual reality for rehabilitation.

Gustavo Saposnik is the first author on two of the studies included in the review. He was not involved in assessment of these studies for inclusion or risk of bias and did not extract data for these studies. He is supported by the Distinguished Clinician-Scientist Award given by the Heart and Stroke Foundation of Canada following an open peer-reviewed competition.

Maria Crotty: none known.

\section{DIFFERENCES BETWEEN PROTOCOL AND REVIEW}

The protocol stated that we would handsearch conference proceedings and contact manufacturers of virtual reality equipment. We conducted these searches for the 2010 review. However, they were not successful in identifying additional studies for inclusion and therefore were not repeated in the updates. We also did not search INSPEC as stated in the protocol due to changes in access.

The protocol stated that we would assess trials for risk of bias related to blinding of participants and personnel. We assessed blinding of participants and personnel in the 2010 review. As expected, we deemed all the studies included in the 2010 review to be at high risk of bias. As blinding is not possible in most cases we decided to omit this domain of the 'Risk of bias' assessment tool in this update of the review.

The protocol listed three primary outcomes. This review identified upper limb function and activity as being the primary outcome and considered all other outcomes as secondary outcomes. We selected upper limb function and activity as the primary outcome as one of the most common applications of virtual reality in stroke rehabilitation is upper limb rehabilitation.

The protocol stated that we would look at imaging outcomes. We have removed this in this update as imaging is not considered an outcome that is of relevance to patients as it does not necessarily translate to changes in function.

\section{N DEX TERMS}

\section{Medical Subject Headings (MeSH)}

*Video Games; Activities of Daily Living; Gait; Postural Balance; Psychomotor Performance; Quality of Life; Randomized Controlled Trials as Topic; Stroke [psychology]; Stroke Rehabilitation [ ${ }^{*}$ methods]; Therapy, Computer-Assisted $\left[{ }^{*}\right.$ methods]; Upper Extremity; User-Computer Interface

\section{MeSH check words}

Humans 